\title{
BROKEN K PUEBLO
}

Prehistoric Social Organization in the American Southwest

\section{THE UNIVERSITY OF}

ARIZONA PRESS

TUCSON

1970 
ANTHROPOLOGICAL PAPERS OF

THE UNIVERSITY OF ARIZONA

NUMBER 18

\section{BROKEN K \\ PUEBLO}

Prehistoric Social Organization

In the American Southwest

JAMES N. HILL

ไ九才

THE UNIVERSITY OF ARIZONA PRESS

TUCSON, ARIZONA 1970 
Third printing 1978

Second printing 1973

First printing 1970

\section{THE UNIVERSITY OF ARIZONA PRESS}

Copyright (C) 1970

The Arizona Board of Regents

All Rights Reserved

Manufactured in the U.S.A.

L.C. No. $70-111383$

DocuTech version ISBN: $\quad 0-8165-1734-7$ 


\section{CONTENTS}

\begin{tabular}{|c|c|}
\hline LIST OF ILLUSTRATIONS & $i$ \\
\hline LIST OF TABLES & \\
\hline PREFACE & $\mathrm{v}$ \\
\hline ABSTRACT & \\
\hline 1. Introduction & \\
\hline 2. The Environmental Setting & \\
\hline Location & \\
\hline Physiography & \\
\hline Vegetation & \\
\hline Fauna & \\
\hline Climate & \\
\hline 3. The Site & \\
\hline Dating & \\
\hline Description & \\
\hline The Assemblage & \\
\hline 4. Theoretical Considerations & \\
\hline The Model & \\
\hline Sampling & \\
\hline Classification & \\
\hline Analysis & \\
\hline Fossil Pollen & \\
\hline Ethnographic Evidence & \\
\hline 5. Methodological Considerations & \\
\hline Sampling & \\
\hline Excavation & \\
\hline Classification & \\
\hline 6. Factor Analyses & \\
\hline Pottery-type Factors & \\
\hline Design-element Factors-Floors & \\
\hline Design-element Factors-Fills & \\
\hline 7. Intra-site Dating & \\
\hline Primary Evidence & \\
\hline Architecture and Stratigraphy & \\
\hline Trash in Rooms & \\
\hline Pollen & \\
\hline Secondary Evidence & \\
\hline Architecture & \\
\hline Animal Bone & \\
\hline Factor Analyses & \\
\hline Kiva Dating & \\
\hline
\end{tabular}

8. Room Types 37

Area Modes $\quad 37$

Features $\quad 38$

Artifacts $\quad 40$

Lithic Waste 42

Animal Bone 42

Seeds and Pollen 43

Ceramics 44

Summary and Comments $\quad 45$

9. Room Functions 48

Habitation Rooms 48

Food Preparation $\quad 48$

Eating 49

Water Storage and Use 50

Manufacture of Hunting Tools $\quad 50$

Other Functions 50

Storage Rooms 51

Storage of Food 51

Storage of Non-food Items $\quad 52$

Other Functions $\quad 52$

Ceremonial Rooms 53

Ceremonial Functions $\quad 53$

Other Functions 54

The Plaza and Outliers $\quad 54$

Changes of Function $\quad 55$

Summary $\quad 55$

10. Social Groups 57

Residence Unit Number I 59

Localization of the Unit 59

Subdivisions of the Unit 61

Aggregates of Females in Residence 61

Temporal Continuity 64

Subsidiary Evidence $\quad 64$

Residence Unit Number II 65

Localization of the Unit 65

Subdivisions of the Unit 67

Demonstration of Uxorilocal

Residence $\quad 68$

Subsidiary Evidence 68 
10. Social Groups continued

Matrilineal Groups

Demonstration of Integrated Groups 69 Demonstration of Corporate Groups 71 Demonstration of Matrilineal Groups

Comments and Comparisons

11. Population Size and Social Groups

Estimates Based on Ethnographic Data 75

Estimates Based on Cross-Cultural Data 76

Populations of the Residence Groups $\quad 77$

12. Burials

Infant Burial $\quad 78$

Adult Burial $\quad 78$

13. Environmental Shift 82

The Evidence $\quad 82$

Pollen 82

Tree-rings and Pollen 84

Physiography, Tree-rings, and Pollen 86

14. Responses to a Shifting Environment 87

Evidence From the Southwest 88

Evidence From Hay Hollow Valley $\quad 89$

Aggregation and Integration $\quad 89$

Subsistence Responses $\quad 90$

Discussion

95

15. Alternatives to a Shifting Environment 97
16. After Broken $\mathrm{K}$

Aggregation 99

Integration 99

Discussion $\quad 102$

17. Summary and Conclusions 104

Appendixes

1. Animal Bone Counts From

Broken K Pueblo

2. Plant Remains Found at Broken K, and Their Uses Among Modern Hopi and Zuni 113

3. Seeds From Broken K Pueblo $\quad 116$

4. Pollen Counts, in Numbers of Grains, From Floors and Features at Broken K Pueblo

5. Distributions of Pottery-type and Ceramic Design-element Factors Not Illustrated in Text

6. Distribution of Pottery Types (Sherd Counts) on Floors

7. Distribution of Ceramic Design Elements From Floors

8. Distribution of Ceramic Design Elements From Fills

\section{ILLUSTRATIONS}

Figure

1. Broken K Pueblo and other sites investigated by the Chicago Natural History Museum

2. Plan of Broken K Pueblo

4

3. Schematic plan of Broken K Pueblo 10

4. Photographs of Broken K Pueblo 11

5. Elements of design, numbers 1-90, from painted ceramics 26

6. Elements of design, numbers 91-179, from painted ceramics 27

7. Distribution of rooms having trash beneath floors 30

8. Distribution of rooms containing trash deposits above floors 31

9. Relative dating of rooms on the basis of pollen and stratigraphic evidence

10. Distribution of animal bone on floors 33

11. Distribution of room-types 38 
Figure

12. Typical habitation room 39

13. Typical storage room 40

14. A subterranean kiva and a room-type kiva 41

15. Locus of Residence Unit Number I and loci of its subdivisions 59

16. Factor distribution maps for Residence Unit Number I 60

17. Factor distribution maps for subdivisions of Residence Unit Number I 62

18. Subsidiary evidence for subdivisions of Residence Unit Number I 65

19. Locus of Residence Unit Number II and loci of its subdivisions 65

20. Factor distribution maps for Residence Unit Number II 66

21. Factor distribution maps for subdivisions of Residence Unit Number II 67

22. Subsidiary evidence for subdivisions of Residence Unit Number II 69

23. Distribution of factor $1 \quad 80$

24. Comparison of tree-ring indices and generalized arboreal pollen
chronology

\section{TABLES}

1. Plants Frequently Found in the Snowflake, Arizona, Area in the 1960s 5

2. Radiocarbon Dating on Samples From Broken K Pueblo 7

3. Radiocarbon Dating on Samples From Broken K Pueblo 8

4. Pottery Types From Broken K Pueblo 13

5. Animal Bone Recovered From Broken K Pueblo 14

6. Pottery-type Clusters Yielded From Factor Analysis 25

7. Seriation of Pottery-types 35

8. Room-types and Relative Dating 39

9. Distribution of Artifact-types on Floors 42

10. Pottery-types as Related to Room-types 45

11. Pollen-types Possibly Indicative of Ceremonial-Ritual Function 53

12. Major Residence Patterns and Distribution Correlates 63

13. Distribution of Stylistic Categories Used in Isolating Loci of Residence Units 70

14. Pottery-types Accompanying Adult Burial 79

15. Average Number of Artifacts Found per Habitation Room 94

16. Functional Characteristics of Room-types 106 



\section{PREFACE}

This report presents an analysis of a prehistoric Pueblo community in structural, functional, and evolutionary terms; it is a sequel to William A. Longacre's Archaeology as Anthropology: A Case Study (University of Arizona Press, 1970). The emphasis is on social organization (including the patterning of community activities) and on understanding changes in this organization in terms of adaptive responses to a shifting environment. A by-product of this analysis of social organization may be considered to be the development of a methodology.

This monograph is not to be considered as a site report, although many crucial raw data of importance to such a report are included. This work should be considered as a series of analytical projects based on data from Broken $\mathrm{K}$ Pueblo; it is an outgrowth of material that appeared in its preliminary form as a doctoral dissertation at the University of Chicago. Additional data may be found in the site report itself (Martin, Longacre, and Hill 1967) and in the microcard series of the Society for American Archaeology (Martin, Hill, and Longacre 1966).

The primary archaeological data used in this work were provided by field work carried out by the Chicago Natural History Museum (now Field Museum of Natural History) in east-central Arizona during the summers of 1962-1963. The project was directed by Dr. Paul S. Martin, Chief Curator of Anthropology. To Dr. Martin I owe a great debt, for his assistance and interest in all problems, large or small, and for his enthusiasm and acceptance of the insecurities of scientific experimentation.

The excavations of 1962 were supervised by Dr. John B. Rinaldo, Curator of Southwestern Archaeology. The 1963 season, of most concern in this presentation, was supervised by myself and John M. Fritz, a fellow graduate student at the University of Chicago. The field and laboratory work were supported by grants (g16006 and g22028) from the National Science Foundation to the Chicago Natural History Museum, and I wish to express my gratitude to the Foundation for its sustained interest and support.

My extensive use of the IBM 7094 computer at the University of Chicago was made possible by a grant (1524) from the Wenner-Gren Foundation for Anthropological Research to the Chicago Natural History Museum, for which I am very grateful.

I am also indebted to Dr. Lewis R. Binford, Department of Anthropology, University of New Mexico. Much of the theory and method incorporated herein originated with Dr. Binford, who has given direct assistance in the more sophisticated statistical problems presented here. Most importantly, however, he has contributed immeasurably to my understanding of how archaeology can contribute directly to the modern science of anthropology.

I also wish to thank Dr. William A. Longacre of the Department of Anthropology, University of Arizona, for many hours of invaluable discussion and criticism, and for years of fruitful acquaintance. Dr. Longacre was a leading participant in the Chicago Natural History Museum's Southwest Archaeological Expeditions from 1959 to 1963, and many of my data are derived from his work. He is also credited with performing the analysis of artifact materials from Broken $\mathrm{K}$ Pueblo. 
I offer my special thanks to John M. Fritz (Department of Anthropology, University of Chicago) for working with me in both the planning and execution of the field work at the site. We are jointly responsible for most of the best and worst aspects of the excavation itself. I cherish our many months of productive cooperation and mutual friendship.

The palynological research was carried out by Dr. Richard H. Hevly, then at the University of Arizona. Supported by National Science Foundation grants (g16006 and g22028) to the Chicago Natural History Museum, he analyzed over one hundred samples from the site alone-not to mention giving assistance during several previous seasons of work. He and James Schoenwetter are largely responsible for the pollen chronology on which many of my inferences are based. In addition, Dr. Hevly contributed to the analysis of pollen data in terms of intra-site dating and room function. Facilities and equipment for pollen analysis were generously provided by the Geochronology Laboratories, University of Arizona.

Several other people have contributed directly to the analytical work presented here. Dr. Hugh C. Cutler of the Missouri Botanical Gardens analyzed the seed remains. Sophie Andras of the Department of Zoology, Chicago Natural History Museum, identified the animal bone. Alan C. Hammaker, a student at Antioch College, performed a large part of the comparative analysis of room-size and artifact frequencies between Broken K Pueblo and Carter Ranch Site, an earlier site in the same valley. Mr. Stevens Seaberg, of the Department of Anthropology, Chicago Natural History Museum, classified the ceramic design elements that I have electronically analyzed; he prepared the plates of design elements.

I am also indebted to the staffs of the Field Museum of Natural History and of the Department of Anthropology, University of Chicago, from whom I received a great deal of assistance.

Without the assistance of several qualified statisticians, I would have been unable to carry out the factor analyses of ceramic design-elements and ceramic types which form an integral part of this study. In addition to Dr. Lewis R. Binford, the following University of Chicago people contributed much helpful statistical advice: Dr. Benjamin D. Wright, associate professor, Department of Education; Raymond E. Strecker, programmer, Computation Center; Clarence Bradford, programmer, Computation Center; and Eliot Simon, Department of Human Development. My special thanks go to Mrs. Eve Langston, Social Science Program Librarian, for her willingness to initiate me into the everyday secrets of computation center routine.

I am also indebted to Helen E. Hayes, Department of Anthropology, University of California at Los Angeles, for her assistance in preparing the appendices to this volume.

In addition, I am grateful for the cooperation and interest of all the people of eastern Arizona with whom I have had occasion to work. I am especially indebted to the James Carter family, on whose ranch the excavations were carried out, and whose interest in our work is greatly appreciated.

Many students, from the secondary through the graduate level, have contributed immeasurably to the ideas presented in this work. They are too numerous to mention individually, but their suggestions are now a part of my intellectual background.

Finally, I thank my wife, MaryAnn, for many months of critical reading and helpful suggestions.

J. N. H. 


\section{ABSTRACT}

Broken K Pueblo was the second of two sites near Snowflake, Arizona (east-central Arizona), investigated by the Field Museum of Natural History in 1961-63. This second study was intended to refine and test inferences about prehistoric social organization made in the first study (by Longacre), and to develop additional methods and techniques of data collection and analysis. The second site (about A.D. 1300) was slightly more recent than the first (Carter Ranch Site, about A.D. 1200) and was more than twice as large. The refinements in statistical analyses of data, along with the inclusion of a wider variety of data, resulted in a fuller description of the organizational features of prehistoric Pueblo society. Hypotheses accounting for observed changes in these organizational features were tested against the archaeological data, and additional hypotheses were generated. The study contributes to our understanding of the evolution of historic western Pueblo societies. 



\section{INTRODUCTION}

Archaeology has recently been defined as "a branch of the science of Anthropology ... concerned with the reconstruction of past human life and culture. Its primary data lie in material objects and their relationships; of equal importance may be ancillary data from other fields, including geology, biology, and history" (Champe 1961:137. Italics mine).

This would seem to be a reasonable general definition, and one with which few archaeologists would find serious fault. In practice, however, few systematic attempts have been made to elucidate prehistoric "life and culture." Instead, we have spent most of our energies in the development of taxonomies, and in the spatial and temporal relationships of culture traits. Little change has occurred in archaeological theory and method, and a feeling commonly persists that we cannot successfully make inferences about past behavior, beyond the description and comparison of artifacts themseives. In particular, little concern has been given the study of social systems and the processes involved in promoting variability and change in these systems. Although a number of important advancements have been made, most have been in the realms of chronology and taxonomy (Lister 1961:43; Johnson 1961; Taylor 1954:570).

We are still burdened with the idea that a description of a list of culture traits is synonymous with a description of culture, and that variability in cultures results from variation in specific historical circumstances (primarily diffusion). Reconstruction of prehistoric social systems, insofar as it has been done at all, has been largely the work of ethnologists; archaeologists have rarely been confident of their abilities to succeed along these lines (Johnson 1961:6). Our concern for the artifact, at the expense of describing and explaining past behavior, has led to the assertion that "over the past twenty-five years or so the stereotype of the American archaeologist has somehow come to be a pretty dull sort of clod, with most of his gray matter under his fingernails." (Wauchope 1956:V)

There is no need to belabor this point, of course, and certainly there is no need to cast blame. The point was forcefully made long ago by Walter Taylor (1948), and it has been driven home many times since then (Willey and Phillips 1958; Sears 1961; Binford 1962, 1964, 1965; and others). Many historical and ecological reasons could be brought to bear in explaining present-day archaeological theory, problem orientation, and methodology. Also, it is selfevident that much past research will serve as the foundation of future research. Now, however, we are beginning to develop the theoretical and methodological tools that will permit us to go beyond the description and comparison of trait lists and to begin the description and explanation of those aspects of prehistoric societies that are of interest to us as anthropologists.

Some notable substantive contributions, of course, have previously been made along these lines. Most of these works have been concerned with such things as settlement patterns, ceremonial organization, mortuary practices, social status, and specialization in tool manufacture. Several of these contributions are discussed by Sears (1961). The necessity of studying prehistoric societies as patterned wholes is discussed by Meggars (1956). With respect to Southwestern Archaeology, there have been a number of recent attempts to reconstruct certain aspects of the prehistoric social organization of the Pueblo Indians (Eggan 1950:123-33; Martin and Rinaldo 1950:556-69; Haury 1956; Wendorf 1956), all of which are based on a reconstruction by Steward (1937).

Three important examples have been influential in guiding my own approach. One of them, James Deetz' study $(1960,1965)$ of ceramic variability in an eighteenth century Arikara village (the Medicine Crow Site), makes use of both ethno-historic and archaeological information. Deetz proposed that as the Arikara moved up the Missouri River and farther out onto the Plains during the seventeenth and eighteenth centuries, a matrilocal resident pattern gradually shifted to one less rigidly matrilocal. He reasoned that if such a shift had indeed occurred, archaeological evidence should indicate it. Specifically, he hypothesized that since women had been the makers of pottery, one could expect that a breakdown in the rigidity of matrilocal residence would 
result in a breakdown in the rigidity of association among ceramic style elements. Using data from the three components of the Medicine Crow Site, he demonstrated that certain style elements did in fact become more randomly associated through time. This study represents a clear-cut attempt to test a hypothesis using archaeological data, and Deetz' results support the contention that the proposed shift in residence pattern had taken place.

Secondly, at about the time Deetz' study was being completed, Freeman and Brown (1964) successfully demonstrated that pottery types in the Southwest can be divided into functionally different groupings, depending on the kinds of pueblo rooms in which they are found. After establishing the existence of four different room-types at Carter Ranch Site (Longacre 1963, 1970), Freeman and Brown used a multiple regression analysis and demonstrated that different clusters of pottery-types tend to be found only in particular types of rooms. This clearly supported the idea that prehistoric remains are not distributed haphazardly but rather are found in locations that reflect the loci of specific tasks or activities.

The third example, and the one of most direct inspiration for the present study, is William A. Longacre's $(1963,1964 b, 1970)$ demonstration that matrilocal residence units existed in the American Southwest by at least A.D. 1100 .

Each of these studies, and others as well, indicate that we now have the capability of studying archaeological sites and settlement distributions in terms of gaining information about the institutional and behavioral aspects of prehistoric societies, rather than simply viewing these societies as components, phases, horizons, and traditions. We can begin to elucidate prehistoric cultural systems and can learn a great deal about how they operated as systemic wholes. We can also achieve an understanding of the factors contributing to variability and change in these systems. Given a laboratory that is worldwide in extent and many millenia in time, we can expect to learn much about processes of cultural evolution that are not easily observed by the ethnologist or social anthropologist.

This present report constitutes an analysis of a particular prehistoric community in the American Southwest in functional and evolutionary terms. The general theoretical orientation and methodological procedures presented here may be found useful in dealing with similar concerns in the future, and the presentation should at least provide some fodder for evaluating the usefulness of the approach. The primary purposes of this report are threefold:

1. To describe as much of the structure and social organization of a prehistoric community as was possible to discover.

2. To explain adaptive changes in this organization in the light of the evolution of the social organization of the Western Pueblos.

3. To contribute to the growing corpus of archaeological theory, method, and knowledge.

Further contributions may include the following:

1. A deeper understanding of the prehistory of the upper Little Colorado River drainage area.

2. A greater comprehension of the reasons for the abandonment of the area in the thirteenth century; and specifically, insight into the effects of environment on social organization.

3. A further demonstration of the usefulness of probability sampling and quantitative techniques of data manipulation.

4. A demonstration that many other classes of artifacts and non-artifact materials, in addition to sherds, are useful in delimiting temporal, functional, and social-group differences within a site.

5. A demonstration that pollen analysis is of value in intra-site dating, and in the identification of functionally specific rooms or areas within a site.

For additional information pertaining to the archaeological site (Broken K Pueblo) considered in this report, the reader is referred to Martin, Longacre, and Hill (1967); Martin, Hill, and Longacre (1966); Hill (1966, 1968); Longacre (1966); Hill and Hevly (1968). 


\section{THE ENVIRONMENTAL SETTING}

\section{Location}

Broken K Pueblo (L.S. 156) is located on the Colorado Plateau, near the Mogollon Rim, at an elevation of 5,800 feet. The site lies eleven miles east of Snowflake, Arizona, in the drainage area of the upper Little Colorado River (Fig. 1). Roughly, it is bounded by parallel $34^{\circ} 37^{\prime} \mathrm{N}$ on the north and $34^{\circ}$ $30^{\prime} \mathrm{N}$ on the south, and by meridian $109^{\circ} 50^{\prime} \mathrm{W}$ on the east and $110^{\circ} \mathrm{W}$ on the west $(\mathrm{T} 13 \mathrm{~N} ; \mathrm{R} 23 \mathrm{E}$; center of Sec. 8; G. and S.R.M.). It is approximately seven miles north of Carter Ranch Site (Longacre 1963, 1964b, 1970; Martin and others 1964), and both sites are located within 500 yards of Hay Hollow Wash.

\section{Physiography}

Physiographically, the Broken K Pueblo area is characterized by a series of broad valleys running in a south-north direction. These valleys contain either permanent streams or washes, and they form a part of the tributary system of the Little Colorado River. Although much of the area in east-central Arizona is dominated by cinder cones, lava flows, and basaltcapped mesas, the area in the vicinity of Snowflake and Broken $\mathrm{K}$ Pueblo is characterized by a sedimentary landscape. The fine-grained Chinle and Moenkopi sandstones outcrop as relatively low mesas, only a few of which are basalt-capped. One such mesa, called Point of the Mountain, is located about one mile east of the site. It is a long, narrow tongue of land that forms the eastern edge of the valley in which Hay Hollow Wash is located.

The relatively flat areas between the mesas are heavily dissected with washes or arroyos, and the surface of the ground is littered with fragments of sandstone and basalt. Some of the oldtimers in the area say that conditions have changed since the 1890s; they recall that the land was not so dry as it is now, and that the arroyos were not as deep. This same story, recurrent throughout the Southwest, is supported by geological evidence (Bryan 1925; Hack 1942; and others). A brief discussion of the geology of the Snowflake area can be found in Cooley and Hevly (1964). For a more complete description, see Akers (1962).

\section{Vegetation}

The vegetation of the Snowflake area has been classified as Pinyon Pine-Juniper Woodland (Nichol 1952) and as Grassland (Humphrey 1955). Actually, the area is in the transition zone between these two provinces. It is probably best to describe it as Savanna-Woodland, a term coined by Dansereau (1957). In any event, it consists of sparse, stunted juniper trees, several varieties of grass, and a number of small bushy plants. Some of the more conspicuous plants are listed in Table 1. Relatively complete discussions of the vegetation can be found in Hevly (1964:22-33).

\section{Fauna}

The fauna in the vicinity of Broken $\mathrm{K}$ in the 1960s appear to be roughly the same as between A.D. 1200 and 1300 , judging solely from the archaeologically recovered remains (Table 5 and Appendix 1). However, it has not been possible to determine whether there have been changes in the relative frequencies of the different animals through time.

The animals of primary interest to this report are the mammals. Only a few bones of birds or fishes (and no amphibians) were recovered from the site, and they are believed to have been relatively unimportant to the aboriginal inhabitants. Although such animals might be of value in studying environmental change, this would require a larger sample of bones than is presently available.

It is difficult to be sure which animals are most common in the area today, but even a casual observer cannot fail to notice the ubiquitous cottontail rabbit (Sylvilagus auduboni cedrophilus) and the somewhat less common jackrabbit (Lepus californicus texianus). There is also an extremely common form of squirrel, perhaps the rock squirrel (Citellus variegatus). The prairie dog (Cynomys gunnisoni) and the gopher (Thomomys bottae) can be seen now and then. Certainly less common, but nonetheless present, are the black-tailed deer (Odocoileus hemionus), the pronghorn antelope (Antilocapra americana), and the bighorn mountain sheep (Ovis Canadensis). This, of course, does not exhaust the list of present-day 


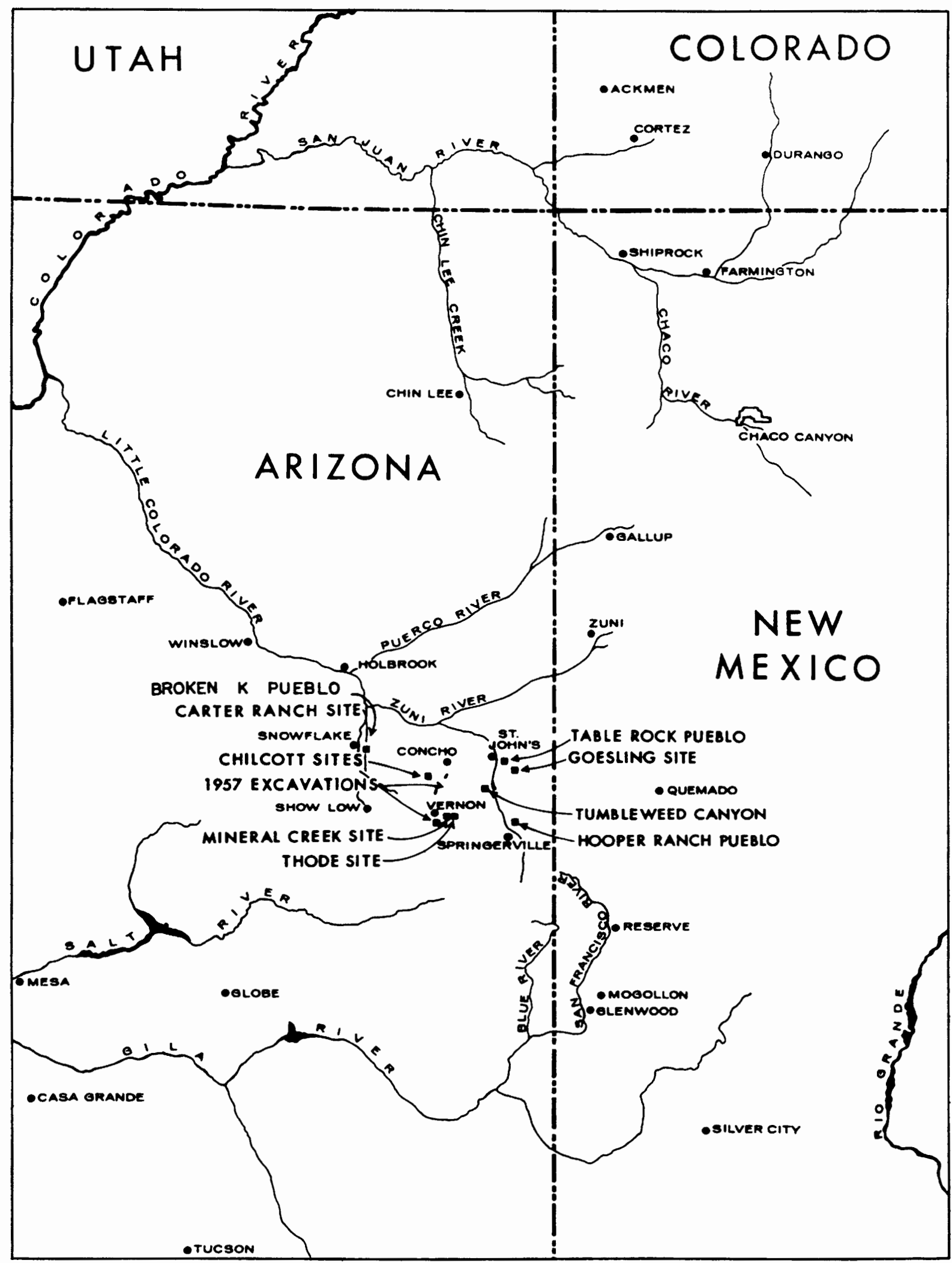

Figure 1. Broken K Pueblo and other sites investigated by the Chicago Natural History Museum. 
TABLE

Plants Frequently Found in the Snowflake, Arizona, Area in the 1960s*

\begin{tabular}{|c|c|c|}
\hline Soils in Which Located & Common Name & Scientific Name \\
\hline $\begin{array}{l}\text { Volcanic ash, cinder areas, or relatively deep soils } \\
\text { developed from them }\end{array}$ & $\begin{array}{l}\text { Wheat grass } \\
\text { Grama grass } \\
\text { Muhly grass } \\
\text { Threeawn grass } \\
\text { Galleta grass } \\
\text { Snakeweed } \\
\text { Pinque } \\
\text { Fleabane } \\
\text { Goldenweed } \\
\text { Paperflower }\end{array}$ & $\begin{array}{l}\text { Agrophyron smithii } \\
\text { Bouteloua spp. } \\
\text { Muhlenbergia spp. } \\
\text { Aristida spp. } \\
\text { Hilaria jamesii } \\
\text { Gutierrezia spp. } \\
\text { Hymenoxys spp. } \\
\text { Erigeron spp. } \\
\text { Haplopappus spp. } \\
\text { Psilostrophe spp. }\end{array}$ \\
\hline Alkaline, as near dry lakes & $\begin{array}{l}\text { Saltgrass } \\
\text { Alkali-sacaton } \\
\text { Greasewood } \\
\text { Shadscale } \\
\text { Chamiso }\end{array}$ & $\begin{array}{l}\text { Distichlis stricta } \\
\text { Sporobolus airoides } \\
\text { Sarcobatus vermiculatus } \\
\text { Atriplex confertifolia } \\
\text { Atriplex canescens }\end{array}$ \\
\hline Gravelly & $\begin{array}{l}\text { Sagebrush } \\
\text { Mormon tea } \\
\text { Saltbush }\end{array}$ & $\begin{array}{l}\text { Artemisia spp. } \\
\text { Ephedra spp. } \\
\text { Atriplex spp. }\end{array}$ \\
\hline Shallow soils or rock outcrops & $\begin{array}{l}\text { Apache plume } \\
\text { Cliffrose } \\
\text { Service berry } \\
\text { Black-bush } \\
\text { Mountain-mahogany } \\
\text { Fernbush } \\
\text { Barberry } \\
\text { Squawbush }\end{array}$ & $\begin{array}{l}\text { Fallugia paradoxa } \\
\text { Cowania mexicana } \\
\text { Amelanchier spp. } \\
\text { Coleogyne ramosissima } \\
\text { Cercocarpus spp. } \\
\text { Chamaebatiaria millefolium } \\
\text { Berberis fremontii } \\
\text { Rhus trilobata }\end{array}$ \\
\hline $\begin{array}{l}\text { Fine-textured, moist soils bordering springs, } \\
\text { seeps, creeks, and lakes (not present in } \\
\text { immediate vicinity of Broken K Pueblo) }\end{array}$ & $\begin{array}{l}\text { Willow } \\
\text { Seep-willow } \\
\text { (Also a number of gr }\end{array}$ & $\begin{array}{l}\text { Salix spp. } \\
\text { Baccharis spp. } \\
\text {, sedges, and rushes) }\end{array}$ \\
\hline Plants found at higher elevations than Broken $K$ & $\begin{array}{l}\text { Pinyon pine } \\
\text { Yellow pine } \\
\text { Spruce } \\
\text { Fir } \\
\text { Douglass fir }\end{array}$ & $\begin{array}{l}\text { Pinus edulis } \\
\text { Pinus ponderosa } \\
\text { Picea spp. } \\
\text { Abies spp. } \\
\text { Pseudotsuga menzeii }\end{array}$ \\
\hline
\end{tabular}

* Data from Hevly (1964). 
mammals in the area. For a more complete presenta. tion, see Cockrum (1960).

\section{Climate}

The climate in the Snowflake area today may be characterized as semiarid. The average maximum temperature is 69.5 degrees Fahrenheit, and the average minimum is 33.2 degrees Fahrenheit. The mean minimal temperatures for June, July, and August are 44.8, 54.5, and 53.7 degrees respectively (R. J. Martin 1933:17). Daily fluctuations in temperature are extreme, averaging about 15 to 25 degrees (Sellers 1960). Although the average length of growing season is 133 days, it has sometimes been as short as 103 days (R. J. Martin 1933:9).

Rainfall occurs during two principal seasons-July through September, and December through March. These rainy seasons are separated by pronounced dry seasons-October and November, and April through June. The average annual precipitation is 12.62 inches, exactly half of this falling during July, August, and September. The precipitation during the crucial agricultural months of June, July, and August averages $0.62,2.39$, and 2.57 inches respectively.

These figures fall short of telling the whole story, however. One of the most significant aspects of the precipitation pattern lies in the difference in character between winter and summer precipitation. Winter precipitation covers wide areas and is relatively gentle, so that the moisture soaks into the ground and helps raise the water table. Summer precipitation, on the other hand, usually takes the form of violent localized thunderstorms, and most of the water runs off the surface in the form of destructive flash floods. These floods cause extensive erosion in the floodplains of both major and minor drainages, and they do not contribute much to the effective ground moisture (Schoenwetter 1962: 193).

However, even the moisture contributed by winter precipitation is not very helpful to plant growth. Winter snows occur when most plants are not actively growing, when they cannot make good use of this moisture. In addition, the three dry months preceding the growing season permit the moisture reserve to evaporate just before it is needed for summer growth (Schoenwetter 1962: 193).

This situation places severe limits on the agricultural potential of the area. Less than two inches of rain falls in April, May, and June combined (Carter 1945:90), giving insufficient moisture for germination.

Another factor militating against dry farming in this area is the fact that summer nighttime temperatures are very low. When the average summer night temperature is less than 55 degrees, little corn can be grown (Finch and Baker 1917:29), and in Snowflake the average minimum summer temperature is 51 degrees (R. J. Martin 1933:17).

Thus it is not surprising that dry farming is not practiced in the area in the 1960s. Although it has been attempted by a number of people, it has not been successful. A few people do grow crops with irrigation, but the region is most efficiently utilized as range for cat tle. 


\section{THE SITE}

\section{Dating}

Broken $\mathrm{K}$ Pueblo is the largest and latest known site in the Hay Hollow Wash area. It belongs to the period generally known in the Southwest as Pueblo III, usually considered to span the time period from A.D. 1100 to 1300 (McGregor 1965). It falls within phases VI and VII in Longacre's scheme of unnamed phases (Longacre 1964a, 1970). (An excellent synthesis of prehistory in the upper Little Colorado River drainage is given in the same sources.)

The first attempt to determine an absolute date for Broken $\mathrm{K}$ was through a fairly elaborate method of pottery cross-dating. Several of the decorated types found at the site have been dated by association with tree-ring dates in various parts of the Southwest (Breternitz 1963; Southwestern Ceramic Seminars 1958-1964). Fourteen types were used, and each is marked with an asterisk in Table 4.

The assigned dates for these types ranged from A.D. 1050 to 1385 , with a mean of A.D. 1224 . However, because some of the sherds in Broken $\mathrm{K}$ Pueblo occurred in very small numbers, it was felt that an average early date and average late date for the sherds would be more accurate than individual dates. Accordingly, the types were considered in two groups-relatively early (A.D. 1050-1250) and relatively late (A.D. 1250-1385). The average date for each group was then determined, yielding a mean early date of A.D. 1175 and a mean late date of A.D. 1283. It seems reasonable to believe that these two dates define the general span of occupation of Broken $\mathrm{K}$ and that the error involved is probably minimal, considering the limitations of this dating method.

That these dates are reasonable is borne out by the fact that they correspond very well with most of the radiocarbon dates determined for the area. Six carbon samples were dated by Isotopes, Inc., as shown in Table 2. These dates, ranging from A.D. 1150 to 1270 , would suggest that the site was occupied for a span of roughly 120 years.

A single tree-ring specimen, dated by the Laboratory of Tree Ring Research, University of Arizona, clearly falls within this time-span. This sample was an uncharred portion of a roof-beam from Room 11, in the east wing of the pueblo; its date is A.D. 1260 .
TABLE 2

\begin{tabular}{|c|c|c|}
\hline Sample No. & Provenience & Date \\
\hline I-1590 & $\begin{array}{l}\text { Room 7, charcoal } \\
\text { from bottom of } \\
\text { firepit }\end{array}$ & A.D. $1240 \pm 115$ \\
\hline I-1591 & $\begin{array}{l}\text { Room 11, wood } \\
\text { from north-south } \\
\text { roof beam lying } \\
\text { just above floor }\end{array}$ & A.D. $1150 \pm 110$ \\
\hline I-1592 & $\begin{array}{l}\text { Room } 21 \text {, charcoal } \\
\text { from firepit }\end{array}$ & A.D. $1270 \pm 105$ \\
\hline I-1593 & $\begin{array}{l}\text { Room } 43 \text {, charcoal } \\
\text { from firepit }\end{array}$ & A.D. $1200 \pm 120$ \\
\hline I-1594 & $\begin{array}{l}\text { Room } 92, \text { charcoal } \\
\text { from firepit no. } 1 \text {, } \\
\text { in floor no. } 1 \\
\text { (upper or latest } \\
\text { floor) }\end{array}$ & A.D. $1235 \pm 115$ \\
\hline I-1595 & $\begin{array}{l}\text { Plaza-kiva (kiva in } \\
\text { N.W. corner of } \\
\text { plaza), remains of } \\
\text { a basket or matting } \\
\text { from niche under } \\
\text { bench }\end{array}$ & A.D. $1190 \pm 110$ \\
\hline
\end{tabular}
* Dating performed by Isotopes, Inc., Westwood, New
Jersey.

On the basis of the preceding evidence, it would seem reasonably clear that Broken $\mathrm{K}$ should be given a date range of about A.D. 1150 to 1280 . There is, however, a complication. Four carbon samples were sent to Groningen University in Holland, and none of the dates (Table 3) fell within the expected range. The range of these dates is about A.D. 810 to 1030, or at least 100 years earlier than any of the other evidence indicates. 
TABLE 3

\section{Radiocarbon Dating on Samples from Broken K Pueblo*}

\begin{tabular}{lll}
\hline Sample No. & \multicolumn{1}{c}{ Provenience } & \multicolumn{1}{c}{ Date } \\
\hline GrN-4360 & $\begin{array}{l}\text { Room 20, charcoal } \\
\text { from ashpit }\end{array}$ & A.D. $810 \pm 70$ \\
GrN-4361 & $\begin{array}{l}\text { Room 37, charcoal } \\
\text { from firepit (below } \\
\text { slabs) }\end{array}$ & A.D. $960 \pm 70$ \\
GrN-4347 & $\begin{array}{l}\text { Room 78, charcoal } \\
\text { from firepit (below } \\
\text { slab bottom, and } \\
\text { above deep hole } \\
\text { under firepit) }\end{array}$ \\
GrN-4351 & $\begin{array}{l}\text { 41-kiva (kiva under- } \\
\text { neath Room 41), } \\
\text { charcoal from } \\
\text { firepit }\end{array}$ \\
\hline
\end{tabular}

* Dating performed by Groningen University, Holland.

It is the author's opinion that these four dates should not be considered as indicative of the span of occupation of the site, for the following reasons:

1. They are much too early, if we accept the other eight dates (including tree-ring and pottery crossdating).

2. The dates were sent to a different laboratory than were the others, and all of them seem to be discrepant. It is too much to expect that all four of the samples sent to Groningen University should just happen to be much earlier than all the other dates. It is possible that some uniform error was introduced in to the samples prior to or during shipment.

3. There was nothing obviously peculiar or different about these four samples in terms of the archaeological contexts from which they were taken. (An examination of $\mathrm{C}-14$ dates from other sites in the area indicates no discrepancies of a similar magnitude to the present one, regardless of context.)

It is possible, of course, that these four samples sent to Groningen represent earlier cutting-dates than did the other samples; but if so, it is a remarkable coincidence that these were the only samples to which this explanation might reasonably apply. If the dates are accepted as valid, it becomes necessary to believe that the span of occupation of the site was about 460 years. All the other evidence suggests a span of about 120 to 130 years.

There is some independent evidence supporting a relatively short occupation. For example, although the architectural evidence shows at least two major periods of construction, there was remarkably little remodeling. In addition, the later parts of the pueblo were constructed with the same type of masonry as the earlier portions had been, and the stylistic attributes of room features are virtually homogeneous throughout the pueblo.

The paucity of midden material may also be indicative of short occupation. Very few rooms at Broken $\mathrm{K}$ contained dense trash deposits, and no general midden area was discovered. This situation is quite common in the Southwest (Bluhm $1957: 127,147)$, and it has sometimes been used as evidence for brief occupation (Mindeleff 1891:53-54,93).

Considering all of the evidence, then, it is probably correct to say that the site was occupied between A.D. 1150 and 1280 , although one might reasonably round-off the latter figure to A.D. 1300. Further consideration of the dating problem may be found in Martin, Longacre, and Hill (1967: 139-44).

Broken $\mathrm{K}$ will from time to time be compared with Carter Ranch Site, a slightly earlier village seven miles to the south (Longacre 1963, 1970); Martin, Rinaldo, Longacre et al. 1964). The temporal placement of Carter Ranch Site is considered to be approximately A.D. 1100-1225.

\section{Description}

Broken K Pueblo has been thoroughly described, with respect to both architecture and artifacts, in Martin, Longacre, and Hill (1967). However, a few of the more important facts will not be out of place here.

The ruin is a large, one-storied, rectangular, surface, masonry pueblo (Figs. $2 \& 4$ ). It contains Approximately 95 rooms, distributed in four large room-blocks, or wings, surrounding a roughly rectangular plaza. It has a wide entrance passage in the southeast corner, and a small one in the northeast corner. There are no doorways leading directly into rooms from outside the village. 




هi 


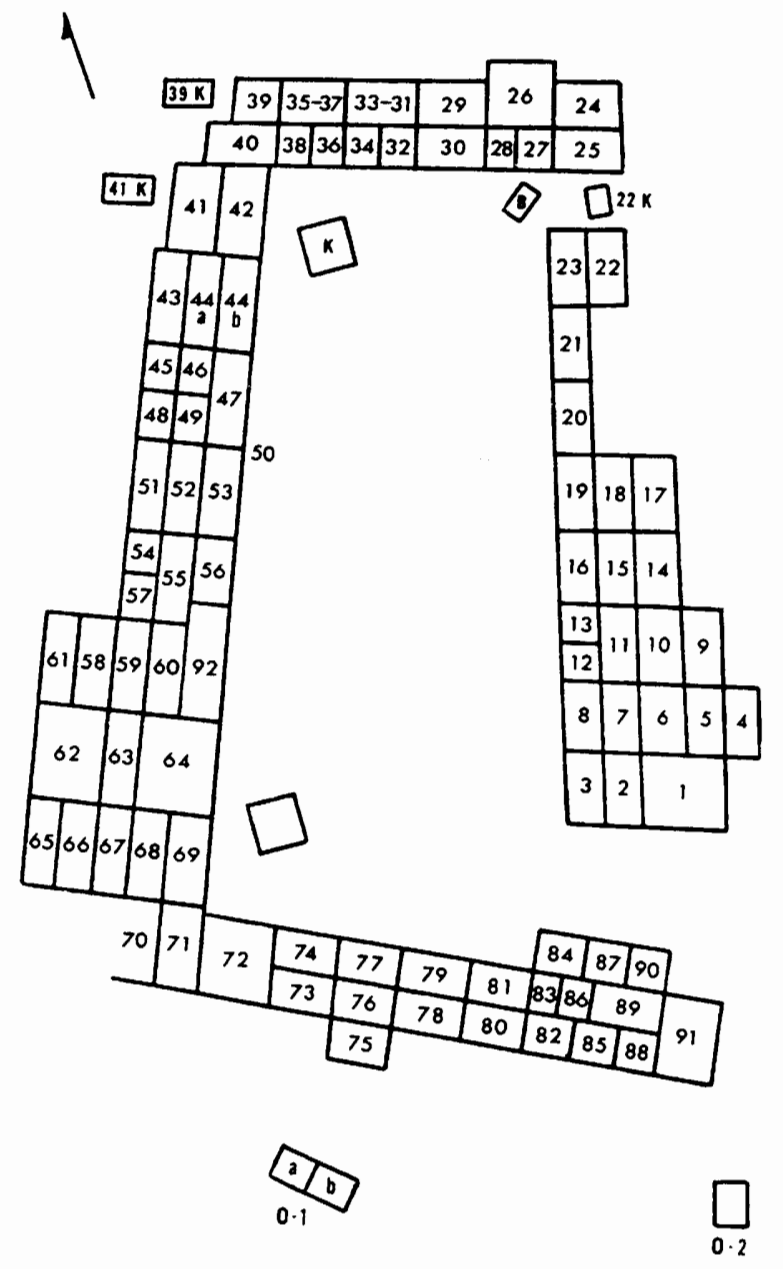

Figure 3. Schematic Plan of Broken K Pueblo (not to scale). This plan is used, for convenience, in the distributional analyses presented throughout the text. The numbers correspond to numbered rooms in Figure 2. $(\mathrm{K}=$ subterranean kiva; $\mathrm{O}=$ outlier; $\mathrm{B}=$ burial).

This type of village plan, common in the Southwest, has been characterized by Reed (1956:16) as having a plaza-type layout, facing systematically inward. It is in general similar to such pueblos as Kinishba (Cummings 1940), Foote Canyon (Rinaldo 1959), and Four Mile Ruin (Haury and Hargrave 1931). This classification would, in fact, include a great many of the larger and later Mogollon pueblos (Reed 1956:16). The shape of Broken K makes it look as if its development had been carefully planned.

Its orientation, or direction in which the entrance passages face, is approximately 25 degrees south of east. Such an orientation was extremely widespread on the plateau by at least A.D. 850 (Bluhm 1957:148; Rinaldo 1964a:53). Many, perhaps most, of the pueblos in the upper Little Colorado River area follow the same pattern. Carter Ranch Site, for example, is oriented 7 degrees 30 minutes south of east (Longacre 1970:20).

This east-southeasterly orientation is not limited to the major outlines of Broken K Pueblo and Carter Ranch Site; it is also true for many of the internal features, such as kivas, kiva vents, and benches. This characteristic is too widespread and too uniform to be accidental, but the reasons for it are not known. Although Longacre could discover no solar phenomena with which the orientation can be associated, it is possible that it may have had something to do with the location of a star or planet at a certain time of the year (1970:20-21). It has also been suggested that such an orientation was utilized to avoid facing the prevailing southwest winds(Mindeleff 1891:182-83); but if this were so, one wonders why the villages were not oriented toward the northeast instead of the southeast.

Fifty-four rooms were excavated at Broken $\mathrm{K}$ (while at Carter Ranch Site, 23 of approximately 39 rooms were excavated). Three distinct types of rooms were discovered-habitation rooms, storage rooms, and ceremonial rooms (kivas). Although these types are more fully discussed in Chapter 8 , it may be helpful to outline their characteristics here. The ordinary habitation room contained a vertical, slablined firepit and a slab-lined mealing bin, sometimes with a metate or mealing stone in place. These habitation rooms were usually larger than the storage rooms and contained greater frequencies of almost all types of artifacts. The storage rooms, on the other hand, were small and were characterized primarily by an absence of both slab-lined features and artifacts. Four ceremonial rooms were fully excavated, two of which were subterranean and two of which were surface rooms. One of the subterranean kivas was located beneath Room 41 and will henceforth be referred to as 41 -kiva. The other was in the northwest corner of the plaza, and will be referred to as Plaza-kiva. The room-type kivas, both of which were converted habitation rooms, are shown on the map as Rooms 6 and 29. They are referred to here as Room 6-kiva and Room 29-kiva (Fig. 2).

Although the structure in the southwest corner of the plaza was at first thought to be a kiva, it was 

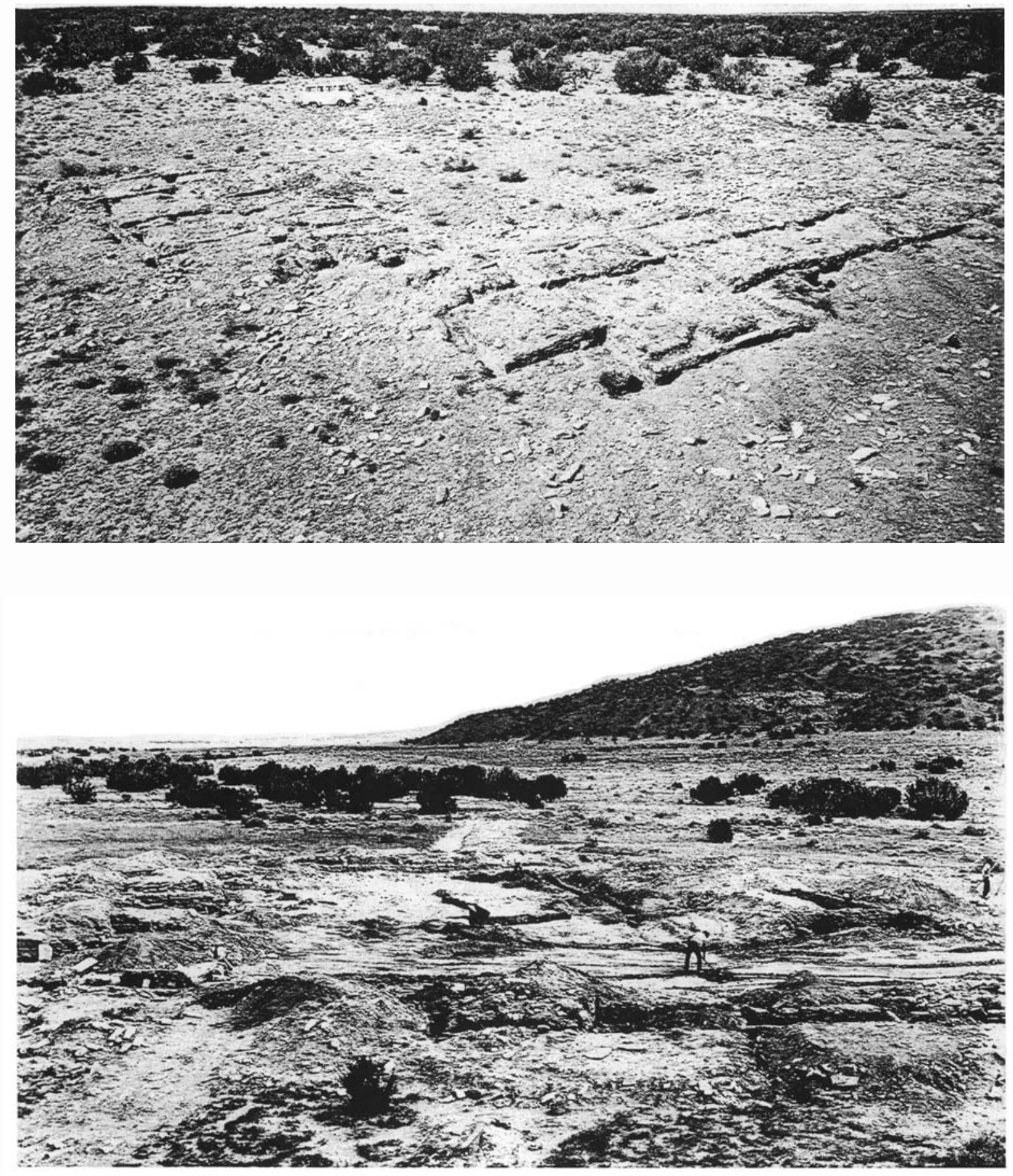

Figure 4. Top, view of entire Broken K Pueblo site, looking southwest. Shows wall-trenching prior to excavation. Vehicle is parked near Room 72. Bottom, view of site looking northeast. Shows condition of site as excavation nearly completed (trenching of the plaza). "Point of the Mountain" and Hay Hollow Wash are in background. Juniper-grassland vegetation is clearly visible. 
simply a large rectangular pit, full of trash, and without any of the characteristic features of ceremonial rooms. As it had been partially excavated into bedrock, it may have been intended for use as a kiva. For some reason, perhaps the hardness of the sandstone bedrock, it was never completed. The present-day Hopi usually construct their kivas in locations where excavations will be easy (Mindeleff 1891:61-63).

Two other subterranean kivas were uncoveredone under Room 22 and one under Room 39. It was not possible, however, to excavate them in the time allotted.

In addition to the subterranean kivas, several other subfloor structures are worthy of mention. An extremely large firepit, perhaps analogous to the Hopi pi-gummi pit, or roasting pit, was found below the north wall of Room 9. A similar one lay underneath the wall dividing Rooms 48 and 49 . Clearly, the pits were used by the inhabitants of the village before rooms were built over them. The shallow pit under Rooms 2 and 7 may be explained in the same manner, except that it was not a firepit. It contained a small circular firepit excavated into the center of its bedrock floor, but its use remains completely obscure.

Two burials were discovered. An adult male had been interred in a pit beneath the south wall of Room 27 , and an infant was found beneath the floor of Room 34. Both of these burials are fully discussed in Chapter 12 .

The only other subfloor structures that should be noted are 41-kiva and the pithouses underneath Rooms 33 and 48. Although these were not more than partially excavated, they were clearly associated with Forestdale Plain pottery, and probably date between A.D. 600 and 800 . There is no indication of continuity between these early houses and the main occupation of Broken K Pueblo.

The large plaza, which measures 30 x 20 meters, contained several features in addition to the Plazakiva and the pseudo-kiva in the southwest corner. The most obvious of these were the large roasting pits found along the edges of the plaza. Three of these were nearly a meter deep, and all were virtually filled with fire-cracked rock (mostly igneous). These large slab-lined pits were in no sense similar to the firepits found in the habitation rooms, either with respect to size or content.

In the southeast corner of the plaza, at least six postholes were discovered (Fig. 2), several of which contained the uncharred remains of vertical posts. Perhaps these represent the remains of a roofed outdoor work area.

In the center of the plaza, a small slab-lined "box" was discovered, which contained two worked sherds (textured). The box measured exactly 13 centimeters per side. A vertical sandstone slab had been placed about 15 centimeters to the west of it, and a large disk-like stream pebble lay between. The box was oriented north-south and east-west.

The final plaza feature to be discussed is the small segment of a masonry wall to the west of the small "box." It was only two courses in height (approximately $15 \mathrm{~cm}$.), and there was no evidence that it had ever been higher. It may represent an earlier structure which was later cannibalized for building stones.

Outside the walls of the pueblo proper, five outlying units were discovered and excavated. Outlier 1 consisted of two very small rooms, resting directly on bedrock, within the size range of storage rooms, and containing almost nothing in the way of artifact materials. Outlier 2, on the other hand, was larger and contained a vertical, slab-lined firepit. This suggests that it was a habitation room. Outlier 3 had been too badly disturbed by "amateurs" to permit the salvage of any information. Outliers 4 and 5 were small L-shaped masonry walls which appear never to have been over two or three feet high. No artifact materials were found in association with them.

There is no surface evidence in the vicinity of Broken $\mathrm{K}$ that would indicate the location of agricultural fields. They were probably quite close to the village, however. This inference is based on the fact that the agricultural plots of the modern Pueblos are located near their villages. The Hopi, for example, rarely cultivate fields more than five miles from home (Titiev 1944:183).

\section{The Assemblage}

A total of 2,931 artifacts were recovered from Broken K Pueblo, not including sherds. The artifacts have been analyzed by William A. Longacre (Martin, Hill, and Longacre 1966; Martin, Longacre, and Hill 1967: 56-125). In these reports, Longacre discusses his detailed classification of artifacts and also provides detailed distributional data within the site. My use of artifact data in this paper is completely dependent on his classification and distribution data. I have, however, performed many of the necessary statistical tests independently. 
The number of potsherds found at Broken $\mathrm{K}$ totaled 26,060. This is 8,000 fewer than were recovered at Carter Ranch Site (Longacre 1964c:125). Of this total number, 11,550 sherds represented textured wares, 12,807 were decorated, and 1,703 were plainware sherds. A tabulation of the various types represented is given in Table 4. The plainware sherds are omitted, primarily because they represent a much earlier occupation of the area than is considered in this paper. All sherd counts are given in Martin, Longacre, and Hill (1967: 136-138). PotteryTypes found on floors at the site are given in Appendix 6.

A total of 6,348 decorated sherds were found on the floors of rooms; 18,009 were found in the fills. On each floor were from 0 to 703 sherds, the average number per floor being about 60 . The average density of the sherds was approximately 6.0 per square meter.

However, these statistics present only a very generalized picture of sherd distributions. They do not, for example, take into consideration the fact that most storage rooms at the site contained few or no sherds, while habitation rooms generally contained more than 60 sherds each. This problem is taken up in Chapter 8.

Although no sherds were subjected to petrographic analysis, it seems probable that most of them had been locally made rather than imported. Such types as Pinto Polychrome, Tusayan Polychrome, Tusayan Black-on-white, and Kiet Siel Polychrome may be trade wares, but they represent very few sherds.

TABLE 4

\section{Pottery-types From Broken K Pueblo}

\begin{tabular}{|c|c|}
\hline \multicolumn{2}{|l|}{ Decorated Types } \\
\hline *Houck Polychrome. . . & 4 \\
\hline${ }^{* K i e t}$ Siel Polychrome $\ldots \ldots \ldots \ldots \ldots$ & 1 \\
\hline *Pinedale Black-on-red $\ldots \ldots \ldots \ldots \ldots \ldots$ & 1 \\
\hline *Pinedale Black-on-white $\ldots \ldots \ldots \ldots \ldots$ & 19 \\
\hline *Pinedale Polychrome $\ldots \ldots \ldots \ldots$. . . & 21 \\
\hline *Pinto Polychrome $\ldots \ldots \ldots \ldots \ldots$ & 65 \\
\hline *Querino Polychrome $\ldots$ & 28 \\
\hline *Showlow Black-on-red . . & 703 \\
\hline Snowflake Black-on-white & \\
\hline (Broken $\mathrm{K}$ variety) . & 196 \\
\hline Snowflake Black-on-white & \\
\hline (Carterville variety) & 1,682 \\
\hline Snowflake Black-on-white & \\
\hline (Hay Hollow variety) & 115 \\
\hline Snowflake Black-on-white & \\
\hline (Snowflake variety) & 2,648 \\
\hline *Snowflake Black-on-white & \\
\hline (Tularosa variety) ... & 646 \\
\hline *Springerville Polychrome. . & 28 \\
\hline *St. Johns Black-on-red & 878 \\
\hline *St. Johns Polychrome & 1,099 \\
\hline Tusayan Black-on-white & 1 \\
\hline *Tusayan Polychrome & 6 \\
\hline *Wingate Black-on-red & 14 \\
\hline Indeterminate Black-on-red & 719 \\
\hline Indeterminate Black-on-white $\ldots$ & 3,763 \\
\hline Indeterminate Polychrome $\ldots \ldots \ldots$ & 81 \\
\hline Indeterminate Red $\ldots \ldots \ldots \ldots \ldots$ & 52 \\
\hline Indeterminate White-on-red $\ldots \ldots \ldots \ldots$ & 37 \\
\hline
\end{tabular}

Total . . . . . . . . . . . . 12,807

\begin{tabular}{|c|c|}
\hline Textured Types & \\
\hline $\begin{array}{l}\text { Brown Indented Corrugated } \ldots \ldots \ldots \ldots \\
\text { Brown Indented Corrugated, } \\
\quad \text { smudged interior } \ldots \ldots \ldots \ldots \ldots \\
\text { Brown Plain Corrugated } \ldots \ldots \ldots \ldots \\
\text { Brown Plain Corrugated, smudged interior. }\end{array}$ & $\begin{array}{l}595 \\
600 \\
456\end{array}$ \\
\hline $\begin{array}{l}\text { Gray Indented Corrugated } \ldots \ldots \ldots \ldots \\
\text { Gray Patterned Corrugated } \ldots \ldots \ldots \ldots\end{array}$ & $\begin{array}{r}261 \\
10\end{array}$ \\
\hline Incised Corrugated & 4 \\
\hline $\begin{array}{l}\text { McDonald Indented Corrugated } \ldots \ldots \ldots \\
\text { McDonald Patterned Corrugated } \ldots \ldots \ldots \\
\text { McDonald Plain Corrugated } \ldots \ldots \ldots\end{array}$ & $\begin{array}{r}722 \\
38 \\
74\end{array}$ \\
\hline Orange Indented Corrugated & 12 \\
\hline $\begin{array}{l}\text { Patterned Corrugated } \ldots \ldots \ldots \ldots \ldots \\
\text { Patterned Corrugated, smudged interior } \ldots \\
\text { Punched Corrugated } \ldots \ldots \ldots \ldots \ldots \ldots\end{array}$ & $\begin{array}{r}283 \\
31 \\
8\end{array}$ \\
\hline $\begin{array}{l}\text { Red Indented Corrugated, } \\
\text { smudged interior .... } \\
\text { Indeterminate Textured }\end{array}$ & $\begin{array}{r}2 \\
353\end{array}$ \\
\hline Total & 11,550 \\
\hline
\end{tabular}

*Pottery-types dated by association with tree-ring dates.

NOTE: Detailed sherd counts, by provenience, are given by Martin, Hill, and Longacre (1966). 
However, Broken $\mathrm{K}$ sherds do exhibit strong stylistic similarities to the ceramics of other areas. Particularly in terms of design elements, one can see strong similarities to both the Mogollon and the Anasazi areas. This is not surprising, since the upper Little Colorado River region has for some time been known to possess stylistic similarities to both branches.

In addition to sherds and other artifacts, two other major classes of material-animal bones and plant remains-were recovered from Broken $\mathrm{K}$. The number of animal bones collected was 9,999; of these, 3,681 were found on floors, while 6,318 were in fills. A total of 179 bones had been burned. Considering all of the bones found on floors, most of them $(2,895)$ were found in habitation rooms. The storage rooms contained a total of only 671 , and 115 were found in the four excavated kivas.

However, of all the bones recovered, less than half could be identified zoologically; only 3,965 were large enough and complete enough for identification, and even these could not be identified below the generic level. Although more detailed work could have been done, the limitations of time and money did not permit it.

Still, the analysis revealed the presence of at least fifteen different kinds of animals (Table 5), six occurring in high enough numbers to indicate that they had been eaten in prehistoric times. Those falling in this category include the cottontail rabbit (Sylvilagus), jackrabbit (Lepus), deer (Odocoileus), mountain sheep (Ovis), prairie dog (Cynomys), and gopher (Thomomys). There were several unidentifiable bones of carnivorous animals, as well as several small birds, and one fish bone (Gila robusta); but these certainly do not represent dietary staples. Detailed counts by genera are given in Appendix 1 .

The plant remains recovered from Broken $\mathrm{K}$ fall into two general categories-seed and pollen. Thirtyfive genera or species were represented, and all of these have recorded uses among the present-day Hopi and Zuni Indians.

A total of 570 seeds were recovered, most of which were extracted from pollen samples. However, 90 of these seeds were found during the actual excavation of the site and were analyzed by Hugh $\mathrm{C}$. Cutler of the Missouri Botanical Gardens. Detailed counts by provenience are given in Appendix 3 .

A total of 115 pollen samples were taken, primarily from floors, mealing bins, and pits. Fifty-three of these ( 44 of which yielded pollen) were analyzed by Richard H. Hevly, Research Associate, Geochronology Laboratories, University of Arizona (Appendix 4). This analysis yielded many more plant genera than were indicated by the recovered seed, and the sample sizes were large enough to be used in several studies of major importance to this paper.

TABLE 5

Animal Bone Recovered From Broken K Pueblo

\begin{tabular}{llcrr}
\hline Common Name & $\begin{array}{c}\text { Scientific } \\
\text { Name }\end{array}$ & $\begin{array}{c}\text { No. Bones } \\
\text { on Floors }\end{array}$ & $\begin{array}{c}\text { No. Bones } \\
\text { in Fills }\end{array}$ & $\begin{array}{r}\text { Site } \\
\text { Totals }\end{array}$ \\
\hline Deer & Odocoileus & 152 & 281 & 433 \\
Mt. sheep & Ovis & 35 & 3 & 38 \\
Jackrabbit & Lepus & 366 & 660 & 1,026 \\
Cottontail & Sylvilagus & 1,801 & 508 & 2,309 \\
Prairie dog & Cynomys & 74 & 19 & 93 \\
Gopher & Thomomys & 54 & 12 & 66 \\
\multicolumn{1}{c}{ Total } & \multicolumn{2}{c}{ Bones Present in Small Numbers } \\
\hline \multicolumn{5}{c}{ Small bird } \\
\hline & Ground squirrel (Citellus) & Large bird & \\
& Porcupine (Erethizontidae) & Carnivore & \\
& Woodrat (Neotoma) & Fish (Gila robusta) & \\
& Mouse (Mus) & & \\
& Turkey (Meleagris) & & \\
\hline
\end{tabular}




\section{THEORETICAL CONSIDERATIONS}

\section{The Model}

The theoretical model used in this analysis is directly referable to Lewis R. Binford (1962, 1964, 1965 , 1968). Although the model has been considered by Linton and Eggan (Eggan 1952:37), and more recently by Rootenberg (1964:181), Binford is one of the first to make productive use of it archaeologically. This model is aimed at defining and explaining the structures of extinct cultural systems. Such an objective is believed necessary as a first step toward the scientific investigation of cultural process. As long as cultures are defined in terms of simple trait-lists, without regard to functional context, there is little possibility of dealing adequately with questions of process. "It is a system that is the seat of process" (Binford 1964:426).

The model simply states that human behavior is patterned or structured. To put it in its simplest form, people do certain things in certain places within their communities, and they leave behind them artifacts and other evidence of these activities. We, as archaeologists, can excavate the structured remains of these patterns. Heizer $(1960: 115)$ has stated this viewpoint clearly:

Where people were accustomed to collect and dump their trash and garbage, they may be assumed to have done this with some system or pattern. Any patterned practice thus evidenced offers a potential field of investigation into activity and behavior.

Mindeleff noticed such patterned behavior prior to 1891. He observed that Hopi and Zuni chimneys sometimes do not have chimney pots, and that "These [chimneys without pots] usually occur in clusters, simply because the builder of a room or group of rooms preferred that form of chimney." (Mindeleff 1891:179)

The problem with respect to Broken K Pueblo was to find as many clusters or patterns in the data as possible, and then attempt to interpret them as reflecting parts of a social system.

This basic theoretical orientation, and the interpretations that it will permit, can be stated succinctly in the form of a postulate:
I. Distributions are patterned or structured (nonrandom) and will be so within an archaeological site.

A. These patterns reflect the loci of patterned behavior that existed in prehistoric times.

B. The kind of behavior represented in these loci depends on the nature or "behavioral meaning" of the item or set of items, the distribution of which is being studied.

C. These "behavioral meanings" can be determined with the aid of specific ethnographic evidence or general world-wide comparative evidence. There is a wide variety of such "meanings" with which items (or stylistic elements) can be associated:

1. Some items or stylistic elements have functional meanings (that is, they are associated with certain economic, sociological, or religious activities).

2. Some of these functional classes of items may reflect the composition of social segments (for example, specific classes of items may be used by men, women, hunters, housekeepers, or priests).

3. Within any given class of items there may be stylistic differences associated with the various social segments (for example: men, women, hunters, housekeepers, priests, households, lineages, clans).

The second major tenet of the model is that changes in structural organization, or anything else for that matter, have causal explanations. Changes do not occur sui generis, even in those instances in which we cannot isolate a reasonable cause. One of the major differences between scientific explanation and simple description is that the former involves a search for causal relationships:

The meaning which explanation has within a scientific frame of reference is simply the demonstration of a constant articulation of variables within a system and the measurement of the concomitant variability among the variables within the system. Processual change in one variable can then be shown to relate in 
a predictable and quantifiable way to changes in other variables, the latter changing in turn relative to changes in the structure of the system as a whole. (Binford 1962:217)

It is assumed, then, that the observed structural changes within Broken $\mathrm{K}$ Pueblo, and among the sites in the same valley, represent adaptive changes in response to causal forces. In this particular instance, the evidence points strongly toward shifting conditions in the physical environment (Chapters 13 and 14).

The theoretical orientation involved here can be stated in the form of a second postulate, as follows:

II. Items and stylistic elements change in form and relative frequency through time, as their associated functions change in nature or relative frequency. Items and stylistic elements change through the action of selective pressures, as well as through a process of drift. Thus, temporal changes may be reflected in distribution patterns.

If the temporal variable can be controlled, the task of interpretation is somewhat simplifed. At any given point in time, it should be possible to interpret a particular distribution as reflecting one or both of the following:

1. The loci of a particular function or activity.

2. The loci of a social segment (or segments).

It is clear, of course, that a large number of more specific interpretations can be made, depending on the behavioral meaning of the class of items the distribution of which is being studied.

As an example, consider a hypothetical distribution of metates (mealing stones) at a site. Suppose that these metates were found only in a particular type of room (or area) and not in other rooms. On the basis of this evidence it could obviously be proposed that metates represent an activity that had been carried out in the specific room-type in which they were found to occur.

Now suppose that, with the aid of ethnographic evidence, it is determined that metates are generally used in the process of grinding grain into flour. This would permit the proposition that the distribution of metates represents the loci of grain-grinding activity at the site; it would thus be possible to say that grain-grinding was probably carried out in a particular type of room and not in others.

We might further suppose that there is ethnographic or comparative evidence indicating that metates are generally used by women rather than by men. We would then be able to infer, with respect to our archaeological example, that women were grinding grain in a particular type of room.

As a final supposition, consider the possibility that there are several different styles of metates represented at the site, and that each style-type is found to occur in a particular localized area of the site (for example, 15 contiguous rooms). With this evidence, and with some additional evidence of a similar nature, it would be possible to propose that each localized area represents the locus of a discrete social unit, or residential unit (Chapter 10).

This discussion is schematic, of course, and it is simplified by the lack of complications that might arise in a "real" situation. Nonetheless, it is representative of the kind of thinking used in interpreting the many distributions presented in this paper. For other theoretical discussions concerning the interpretation of spatial distributions, as well as examples of it, consult Duncan, Cuzzort, and Duncan (1961); Binford (1962, 1965, 1968); and Freeman and Brown (1964).

\section{Sampling}

The first problem faced was one of sampling the site. It was manifestly impossible to excavate the entire site, considering the limitations of available time and money. And yet, when one is attempting to learn something about the workings of an entire social system, he will want to recover the best sample possible. The possibility exists that one could excavate half of a site and recover information about half of a social system. Clearly, for the present concern, it is important to know at least a little about as many aspects of the complete system as possible. The goal is to obtain as representative a sample as possible of the site in question.

With this in mind, it would not be reasonable to excavate one large, contiguous portion of a site and leave the remainder untouched. This is sometimes done by those who treat their sites as "mines" for the extraction of specimens (Binford 1964:433), but it is inadequate unless one's interests lie in the preparation of trait lists or statements of chronology. Similarly, it would not be acceptable to recover only a few classes of artifacts, such as pottery and architecture alone (Rootenberg 1964:187).

A further point in this connection concerns comparability of samples within a site. If we ultimately wish to compare various subareas of a site 
with respect to frequencies of items, it is mandatory that each subarea be sampled in a comparable manner. It appears, then, that a representative sample is one that covers all areas of the site to an equivalent degree.

One way to obtain this kind of sample would be to use some form of systematic sampling. For example, one could excavate all of the odd-numbered rooms or squares at a site. This has its drawbacks, however, since it is possible that the even-numbered units might consistently contain important classes of information not found in the odd-numbered ones. Still, this method is much superior to the blockexcavation technique.

But the easiest way to obtain a relatively unbiased sample is to utilize some form of probability sampling (random sampling). Although this does not preclude sampling error, it clearly minimizes such error. J. G. D. Clark (1960:125) views the situation as follows:

... if we are to apply quantitative methods of analysis to settlement debris successfully, we must either totally excavate a site, which is only possible for certain rather primitive stages of culture as a rule, or we have to devise some system of sampling which approximates, as far as is possible, perfect random sampling ....

Such a method gives each of the units to be sampled an equal chance of being chosen, and it permits us to make statements of probability. Discussions of probability sampling are found in Deming (1950), Vescelius (1960), Duncan and others (1961), Binford (1964), Martin, Longacre, and Hill (1967), and Ragir (1967).

Assuming that a system of random sampling is decided on, the question then becomes one of deciding how large a sample is adequate. Vescelius (1960:462) notes that "a sample of 5 or 10 percent" of the units of a population is enough. This is an oversimplification, however. Rootenberg's survey of the statistical literature leads him to believe that there is no single optimum sample size, and that the size chosen should depend on the degree of heterogeneity within the population (1964:186). This would entail knowing a great deal about a site prior to excavation, and archaeologists are not usually in so fortunate a position. There are reasonably good solutions to this problem, however. The method used in sampling Broken $\mathrm{K}$ is presented in the following chapter.

Another point regarding sampling should be made. That is, whenever surface indications permit dividing a site into two or more different classes of units, these units should be sampled separately. Recognizable house depressions, for example, should not be lumped with the undifferentiated squares of a grid system. They are clearly different populations and should be treated separately. Such a method of stratified sampling can increase precision without increasing the total sample needed (Binford 1964:429).

Finally, it should be made clear that a random sample, whether simple or stratified, is not an end in itself. It can help the archaeologist obtain a good idea of the range of variation within and between sites, but it will not include all the information that may be of interest. It is merely an efficient way to begin. Once the archaeologist has excavated his initial sample of units, he may be able to use this information to stratify his site to a greater extent and thus refine his precision. In short, one of the most important functions of random sampling is in pointing out what else needs to be done. It is important that there be a continuous interplay between field work and analysis.

\section{Classification}

Assuming that a representative sample has been excavated, the next step is to classify all of the artifact and non-artifact materials. There is little point in examining the distributions of items within (or between) sites unless the items are reasonably well classified. By this it is simply meant that they should be divided into formal types that have some significance in terms of the specific archaeological problems being studied. It is assumed that real or inherent types are not the goals of classification, nor is it useful to attempt to discover what was in the minds of the makers. Since it is not feasible to isolate all of the potentially infinite number of attributes associated with a given set of items, it is most useful to classify materials in terms of similarities and differences among clusters of attributes that are directly relevant to the problem at hand.

While sets of items can be sorted into typegroupings on an intuitive basis, it is often useful to employ various statistical measures of association (Spaulding 1953, 1960; Sackett 1966). The methodologies involved in the classification of materials from Broken K Pueblo are given in Chapter 5.

$$
\text { Analysis }
$$

After all of the artifact and non-artifact materials have been classified, the next step is to examine their 
distributions and interpret them within the theoretical framework outlined at the beginning of this chapter.

First of all, the data need to be quantified. It is important to know how many of a given category of item are found in each of the spatial units at a site. After this is done, it is possible to compare units and thus determine where significant nonrandom (patterned) clusters occur. This kind of study can be done by simply plotting the frequencies of the various kinds of data on a map and then interpreting the distributions. However, when the archaeologist is dealing with large numbers of things, and with several variables, it is often more reliable and efficient to make use of a multivariate analysis technique (such as multiple regression or factor analysis).

In this way, it is possible to determine not only how each item (variable) distributes but also how each behaves with respect to the others. In other words, such an analysis can be of tremendous help in finding out what variables are associated or correlated. Ultimately, this can yield clusters of items which demonstrably behave together in an associational sense. The distributions of such clusters must then be interpreted, just as are the distributions of individual classes of items. The actual interpretations given are, of course, functions of the archaeologist, not of the computer. Once the distributions of artifacts and artifact clusters are clearly described, however, the job of interpretation becomes tremendously easier.

\section{Fossil Pollen}

Another theoretical problem that should be discussed concerns the interpretation of fossil pollen data. Archaeologists are rapidly becoming aware of the value of pollen analysis in archaeological research. Fossil pollen can yield information about past environments and about the diets of prehistoric peoples, and it is frequently used for these purposes. As far as I know it has never, until now, been used in determining room-types, room uses, and intra-site dating (Hill and Hevly 1968). Some archaeologists have, however, raised objections to some of the ways in which pollen data are interpreted in archaeological studies, and it is necessary that these objections be answered.

One of the objections is a very general one which questions the validity of making almost any kind of interpretation of pollen data, on the grounds that sample sizes are too small. When palynologists are counting the pollen grains in an individual soil sample, they conventionally stop counting when they have reached 200 grains. It has been suggested that 200 grains is not a large enough sample and that it may be biased. The answer to this objection has been given convincingly by a palynologist (Martin 1963:29-31). Martin has been able to show, by means of testing a number of samples of different sizes, that the difference between the 200-grain count and a 2,000-grain count does not exceed 4 percent.

The second objection is usually put in the form of a question: "How do you know whether the pollen found in an archaeological site was brought in by man or by some natural force such as wind?" It is important that we be able to distinguish these processes, if we are to adequately interpret pollen data with regard to either past environments or cultural behavior.

In some cases this question cannot be satisfactorily answered. However, a given pollen-type is usually considered as naturally introduced if its relative frequency is within the range of the modern pollen rain (modern surface samples). If it is much more frequent than in the modern rain, it is considered introduced by man (unless it is definitely a windblown pollen-type) (Richard H. Hevly, University of Arizona, personal communication).

In some cases the answer is quite clear. For example, in the Southwest, the pollen of Zea, Opuntia, Cleome, and Cucurbita (inter alia) are nearly always introduced by man. These pollen-types generally do not spread far by wind action, so they are usually not found at great distances from the locations in which the plants are (or were) actually growing. Their introduction into an archaeological site (in the Southwest) is probably dependent on human transport (Richard H. Hevly, University of Arizona, personal communication).

One of the best ways of learning how a pollen-type was introduced into a site is by examining the context in which it is found. That is, if a particular pollen-type is found only in a certain type of room, its distribution must usually be interpreted as a result of human agency. On the other hand, if it is evenly distributed all over the site, it may have been introduced by natural forces.

Another objection to the use of pollen data is, like the previous objection, concerned with the validity of using such data in making inferences about past 
environmental conditions. The argument is that areas of human occupation are areas of disturbed soil, and many wild plants (especially Chenopodiaceae and Amaranthaceae) proliferate in such a situation. Thus the inhabitants of a site could easily track pollen from these plants into the dwellings. The palynologist would then get a biased sample (so the argument runs) of the general vegetational conditions for that time period.

There are several possible answers to this objection. The most convincing, however, is that if such were the situation, we should expect all archaeological sites to contain large amounts of these types of weed pollen. But an examination of the pollen from sites of differing time periods reveals major changes in weed pollen frequencies through time. This would seem to reflect changes in the natural pollen rain in different periods. Furthermore, such shifts are paralleled by changes in the widths of tree-rings. This clearly suggests that changes in pollen frequencies through time can reflect changes in the physical environment (Hevly 1964:105-106).

Aside from answering the major objections to certain kinds of interpretations of pollen data, there is one point concerning its use at Broken $\mathrm{K}$ which should be mentioned. When pollen samples are taken from floors of rooms or houses, what do they signify in terms of the occupational history of the dwellings? It seems probable that such a pollen record reflects the last occupation of the unit. It probably does not reflect pollen deposition near the time of construction, because such pollen would tend to be destroyed by the crushing action of subsequent human occupation (Richard H. Hevly, personal communication).

\section{Ethnographic Evidence}

There is little doubt that ethnographic evidence can be of great value in archaeological interpretation-although the idea is still more often utilized by ethnologists than by archaeologists (Strong 1936:363; Eggan 1952:37; Service 1964:366).

The present paper depends heavily on ethnographic information. It is therefore desirable to say something about the validity of its use in this particular case. The argument rests on the assumption, and partial demonstration, that western Pueblo social organization and culture have changed slowly since A.D. 1200 or 1300 , and that there have been no changes drastic enough in that time to invalidate ethnographic inference.
Since the time the western Pueblos were first discovered by the Spanish, in 1540 , there has been remarkably little change in the fundamentals of their culture. Several early Spanish accounts of life among the Hopi ("Moqui") and Zuni make this very clear (Miller 1941). Most of the changes, at least until quite recently, have been relatively unimportant. In 1893, Donaldson made the following statements:

While the Moqui is stationary in many things he is progressive in adopting articles of comfort or utility.... It is true that there is not much more evidence of progress toward a real Anglo-Saxon civilization among the Moquis in 1890 than there was in 1540. (1893:43)

These Indians ... have ... changed in a less degree, while surrounded by Latin and Anglo-Saxon civilization, from old habits and customs than any people on the American continent, and perhaps in the world. For self-reliance and persistence in a beaten path they are unrivaled. (1893:2)

More recent observations are still in agreement with the preceding statement. Goldman (1937:313), in discussing Pueblo culture, stated:

At present the culture, in spite of "white" influences, is essentially the same as it was a number of centuries ago at the time of Coronado.

As late as 1964 , we have a similar statement by Dozier (1964:92):

The persistence of these traditional Pueblo social and cultural patterns indicates the continuity of Southwestern Pueblo cultures as unique segments of the American cultural scene for a long time to come.

More specific evidence concerning this relatively stable continuity can be found in the publications already cited, and in Bunzel (1929:83-84) and Hargrave (1935:22-24)-as well as many others.

It is clear, then, that the social organization of the western Pueblos has not changed fundamentally for at least 425 years. Broken K Pueblo was occupied approximately 665 years prior to the mid-1960s, or only about 240 years prior to Spanish contact. The argument here is that if Pueblo culture has changed little in the past 400 years, even in the face of white contact, it is reasonable to believe that it changed even less in the 240 year period before contact.

This argument is strengthened by abundant evidence to support the extension of this continuity backward in time at least as far as A.D. 1300. For example, an amazing continuity in architecture is 
evident between Broken $\mathrm{K}$ times and the earliest recorded Hopi and Zuni villages. Such early towns as Awatobi, Old Oraibi, Hawikuh, and Halona are generally similar to Broken $K$ in that they are rectangular plaza-type pueblos and are oriented generally eastward. Even the orientations of the kivas are similar (Mindeleff 1891:115-16). The many similarities, in fact, make it difficult to believe that significant social or cultural differences could have existed between the cultures (Mindeleff 1891:19, 49-50, 53, 59, 81, 98-100; Cushing, Fewkes, and Parsons 1922:254-56).

Even the artifacts recovered from Broken $\mathrm{K}$ are similar to those recorded in ethnohistoric times. Many of them are indistinguishable from those described by ethnographers for modern Hopi and Zuni (Woodbury 1954).

Further evidence of continuity and stability lies in the fact that the early Hopi villages on Jeddito Mesa exhibit strong ceramic similarities to the upper Little Colorado River area (including Broken K Pueblo), especially in Pueblo III times (Ellis 1951:150).
Similarities in polychrome wares are especially noticeable and clearly indicate spatial and temporal continuities of some kind (Brew 1937:129, 134; Jennings and others 1956:111). Watson Smith (1952:148-50) has been able to demonstrate that the kiva murals at Awatobi are also stylistically similar to the Little Colorado River polychromes.

Considering all of the evidence, then, it is probable that the use of ethnographic analogies in interpreting the remains of Broken $\mathrm{K}$ is legitimate. It is even more valid in those instances in which both the Hopi and Zuni information is in agreement.*

*These justifications of the use of ethnographic analogy are unnecessary if analogy is used in a manner consistent with good scientific methodology. An analogy may be drawn from any source, however distant in time and space, provided that it is used solely in generating hypotheses or propositions (context of discovery). Inferences drawn from such analogies, however, should be tested by means of data that are independent of the data used in establishing the analogy (context of validation). The reader is referred to Hempel (1966), Binford (1967) and Hill (1968). 


\section{METHODOLOGICAL CONSIDERATIONS}

\section{Sampling}

The first problem was to decide what portion of the Broken K Pueblo site to excavate, since there was no possibility of doing it all. Because we were concerned with learning as much as possible about the social organization and activity structure that had existed in the village prehistorically, it was decided that a random sample of rooms would give the best possible unbiased coverage. Carter Ranch Site had not been random sampled, and as a result several small, poorly preserved, but distinctive rooms were missed completely.

The first step was to uncover as many of the walls at Broken $\mathrm{K}$ as was necessary in order to make a rough ground plan of the site (Fig. 4). This was done in about three weeks time, and it is believed that no more than two or three rooms were missed. After this, all rooms were numbered systematically, from one to ninety-two. This did not include the outlying rooms or subterranean rooms.

At this point it should have been obvious that some rooms were very small and others were very large, and that they represented at least two nonrandomly different size classes. This was not observed, however, until later (Chapter 8). An opportunity to stratify the sample was thus missed. Unfortunately we did not know enough about sampling theory at that time to have been aware of this situation. Instead, a simple random sample was selected.

The size of this sample was more than adequate, however. It was decided that 50 percent of the rooms, or 46 rooms, should be excavated in the initial sample. Using tables of the cumulative binomial distribution (Aiken 1955), it was determined that this sample would give us a 90 percent chance (probability of 0.90 ) of discovering at least one of any item that might occur only five times (in five different rooms) at the site, and there was a 41 percent chance of finding at least three of these hypothetical items. It was also determined that there was a probability of 0.99 of discovering at least one of any items occurring in only ten rooms, and a probability of 0.61 of getting one of any item occurring only twice at the site.
Accordingly, a 50 percent sample was chosen from a table of random digits (Arkin and Colton 1961), and the selected rooms were excavated in the random order indicated by the table. This sample, however, was not considered an end in itself. It pointed up the fact that several other rooms needed to be excavated if we were to gain a more or less complete understanding of the total variability within the site. Thus, eight more rooms were dug, bringing the total number of excavated rooms to fifty-four (Fig. 2). This, of course, increased the chances of finding a given number of any particular class of item. In fact, a 54-room sample yielded a probability of 0.95 of finding at least one of any item occurring only five times at the site.

A by-product of random sampling is that, after the sample has been excavated and all the artifacts counted, it is a simple matter to predict approximately the total number of any given item at the site-even though all the rooms are not excavated. For example, at Broken $\mathbf{K}$ two surface room-type kivas were discovered in the 50 percent random sample (Room 6-kiva and Room 29-kiva). Since the unexcavated half of the site also constituted a random sample, we can expect that there are two more such kivas not yet found. This same kind of prediction can be made for any other category or item, and the accuracy of prediction increases when dealing with items that occur in relatively large numbers.

It is worthy of note here that if random sampling had not been employed, we probably would have missed several important rooms. We would, in fact, have missed three of the six kivas that were discovered-kivas located in areas either badly preserved or "potted" by amateurs. The employment of traditional methods of sampling, as was done at Carter Ranch Site, would almost certainly have meant selecting blocks of rooms in well-preserved portions of the pueblo.

In addition to the rooms within the pueblo proper, five outlying rooms, the plaza, and several areas surrounding the site were excavated. The plaza was scraped with a tractor blade in order to expose cultural features; and four trenches, approximately a 
meter deep, were dug in order to locate possible earlier living surfaces or features.

No true midden area was located outside the main portion of the pueblo. Two large trenches in likely areas, and a number of exploratory holes were dug. Although not enough time remained to get a representative sample of these areas, it is almost certain that no midden area exists there.

\section{Excavation}

Excavation of the rooms was carried out by natural levels. All trash or ash levels of the fill, as well as all materials on the floors, were put through a screen of hardware cloth of one-fourth inch mesh. Floor levels were also sifted. The floor level was defined as including everything resting on the floor or clearly associated with it. This method was employed in an effort to obtain materials definitely associated with the rooms, and to exclude those thrown into the rooms after abandonment. Such a procedure is mandatory if significant inferences concerning room function (uses) are to be made. In a few rooms, notably Rooms 1, 40, and 69, there may have been some mixture of floor and fill materials during excavation.

The rooms ranged in depth from about 20 to 110 $\mathrm{cm}$. The typical room was about $60 \mathrm{~cm}$. deep and usually contained three natural levels, including the floors. Level A, from the surface to $40 \mathrm{~cm}$. thick, contained windblown and water-washed brown humus and sand, fallen wall stones, and no trash. Level B, from 40 to $59 \mathrm{~cm}$., contained water-washed red sand or clay, sometimes trash, and roof beams occasionally. The floor level, 59 to $60 \mathrm{~cm}$., consisted of hard-packed red sand or gray plaster, about $2 \mathrm{~cm}$. thick. A few rooms had more than one floor, with later floors having been plastered over earlier ones; and in some rooms there was a trash or sterile layer intervening between floors.

All floors were troweled and swept, and features were carefully excavated and recorded. Artifacts recovered from features were "bagged" separately, although this separation was not found useful in this analysis. After a floor had been photographed and plans and notes completed, trenches were dug along the walls in an effort to locate any deeper floors or subfloor features.

Charcoal samples were taken from all rooms having any charcoal, and this included most habitation rooms at the site. Very little charcoal could be found in storage rooms, because these rooms rarely contained firepits and usually had not burned.

Pollen samples were taken from the floors of most of the excavated rooms, although eleven rooms (Rooms 19, 20, 28, 29, 30, 35-37, 39, 44a, 44b, 74 and Outlier No. 1) for a variety of reasons were not sampled. Fifty-three samples were analyzed for pollen; each sample consisted of about two-hundred grams of soil from an area measuring about forty centimeters in diameter and half a centimeter in depth. Although most of these samples were taken from floor surfaces (floor plaster), three were from the bottoms of floor-pits, two were from the basins of mealing bins, two were from the grinding surfaces of metates, one was from a sample of fecal material, and one was from the sediments underlying an infant burial in Room 34. Two samples taken from fill levels in Room 22 were also analyzed.

Not all samples yielded pollen, however. For this reason, nine of the sampled rooms (Rooms 25, 36, $41,43,54,64,65,69$ and 82 ) have no pollen record. Thus, of a total of forty-three sampled rooms, thirty-four yielded pollen (usually one sample per floor) (Appendix 4). This is considered a sufficiently large sample to use in the distribution studies of pollen-types that are presented in this paperespecially since the rooms that yielded pollen were rather evenly distributed throughout the site.

After all the materials had been classified and counted, some categories were discarded. It was felt that such items as pebbles, fire-cracked rock, and textured-ware sherds would not need to be looked at again, once they had been counted. Unfortunately, the textured-ware sherds could have been used in studying vessel form and function; but they can never be recovered. It is, of course, impossible to save everything that might one day be of use (Sears 1961: 227).

\section{Classification}

The general theory of classification utilized in this study has been given in the preceding chapter. Some of the recovered materials were treated statistically, but such methods were used only when extremely accurate classifications were considered vital. It is notable that in many cases the traditional typologies have proven to be quite useful. The methodology used in classifying the artifacts from Broken $\mathrm{K}$ is given by Longacre (Martin, Longacre, and Hill 1967: 56-125). 
Longacre's classification, however, was concerned only with artifacts proper-that is, the small, portable items such as tools and ornaments. Several other things required classification, such as rooms and features within rooms. The first step in classifying these things was to examine the items in an effort to find attributes that might be useful as typological criteria in terms of describing similarities and differences. In the case of rooms, for example, it was necessary to form some idea of which attributes contributed to differences among rooms. When it was discovered that some rooms possessed two or more attributes that the others did not have, and vice-versa, a chi-square test of association was applied to determine the validity of these associations. Many such tests were performed, and a number were successful in that the hypothesized associations were shown to be real (probability of 0.95 or greater).

Those materials not treated statistically were either fitted into an already existing classificatory system, or they were too complex to permit a thorough taxonomic analysis in the time available.
There was no need, for example, to devise methods for classifying animal bone or plant remains. In the case of ceramics, any new system of classification which could have been devised in a short time would probably not have been as useful as the one already in existence. For this reason, the ceramics were classified in the traditional Southwestern manner. Definitions and references for these types may be found in the Southwestern Ceramic Seminars (1958-1968), Breternitz (1963), and Longacre (1964c).

The ceramic design-elements used in this study, on the other hand, could not be classified on the basis of an extant typology. All of the decorated sherds had to be examined individually and then divided into element-classes. This was done largely on the basis of $f e e l$, and design categories were chosen with the view to the ultimate isolation of microstyle differences among rooms within the pueblo. It was no surprise to find that some of these element-types did not behave analytically in any systematic way. Mr. Stevens Seaberg, an artist at the Chicago Natural History Museum, is responsible for this classification. 


\section{FACTOR ANALYSES}

Most of the analytical techniques used in this paper will be apparent as particular topics are discussed. However, because the factor analyses of ceramic design-elements and ceramic types are not so easy to understand, and because they are referred to in nearly all of the succeeding chapters, it is important that they be discussed at this point.

Factor analysis is a multivariate statistical technique. That is, it is a tool useful in discovering relationships among more than two variables. One of its functions is to point out those variables (for example, sherd-types) which nearly always exhibit mutual covariation (that is, vary in the same way with respect to all other variables). It can then determine the groups, or clusters, of the variables that are most meaningful in explaining variability within a given body of data.

Consider a hypothetical archaeological site in which a large number of pottery-types are found. The first step in the analysis of these data is to discover the degree to which each one of the types is found to vary with respect to each of the other types (correlation). Each possible pair of types is given a correlation coefficient, ranging from -1.0 (perfect negative correlation) to +1.0 (perfect positive correlation). Thus we are given a numerical measure of how any particular type behaves with respect to any other.

The next step is to find out how many types can be linked together as related groups of types (that is, mutually covary with respect to all other types). For example, if types $\mathrm{A}, \mathrm{C}, \mathrm{F}$, and $\mathrm{Q}$ occur in a single group (cluster), this means that each behaves in the same way with respect to all other types used in the analysis. One can think of these types as being "correlated," which they are; but the most important thing is that they form a discrete unit that relates to all other types in a particular way. Each cluster of types relates to all of the types in the analysis in a way that is not duplicated by any other cluster. It is this process of finding these clusters that is properly called "factor analysis." The clusters themselves are called "factors."

The next step in the analysis is that of ensuring that these factors are discrete, or non-overlapping entities. This is done through a correlation analysis of the factors themselves, rather than the original pottery-types. If it can be shown that there is absolutely no correlation between the factors (coefficient of zero), then the reality or discreteness of the factors is demonstrated.

A factor analysis goes one step further, however, than generating factors. It also permits the user to determine the relative strength of each factor in each of the primary units of study (rooms of a pueblo in this case). Each unit is given a factor-score for each of the factors; and when the units are rooms in a pueblo, these rooms can readily be compared on the basis of the factors they contain. Some rooms will have high factor-scores (significantly positive) in certain factors, and low factor-scores (significantly negative) in others. This is simply a way of comparing the rooms with respect to the clusters of variables they contain. A straightforward discussion of factor analysis may be found in Binford and Binford (1966); but for a complete examination of the mathematics involved, see Fruchter (1954) and Harmon (1960).

It is noteworthy that in the present study raw factor-scores were not used. Instead, all of the positive factor-scores in each provenience unit were converted to percentages (per room). In other words, in any given provenience unit, each of the positive factors makes up a certain percentage of the factor composition of the unit. Thus, when factors are discussed in succeeding chapters, they will be referred to in terms of "percentages of factor composition."

This study incorporates the results of three separate factor analyses-one of pottery-types, and two of ceramic design-elements. These analyses were performed on the IBM 7094 computer at the University of Chicago; they were financed by a Wenner-Gren Foundation for Anthropological Research grant (no. 1524) to the Chicago Natural History Museum; the program used as MESA 83 (UCSL 301, 3/9/64).

\section{Pottery-type Factors}

The first factor analysis was concerned with pottery-types found on the floors of 42 rooms at Broken K Pueblo. A total of 16 pottery-types was used, including textured ware; the total number of sherds involved was 6,234. Only those pottery-types having a site-total of at least 25 sherds were used, and 
only those rooms having at least 10 sherds (of any type) were admitted. These restrictions were imposed in order to reduce the possibility of misleading correlations due to sampling error. Data concerning the frequencies of each type occurring on the floor of each room are given in Appendix 6. Complete sherd counts are in Martin, Hill, and Longacre (1966).

Before the program was executed, it was decided that it should be done twice-once using the frequencies of each pottery type on each floor, and once using the proportion that each type contributed to the total number of sherds on each floor. Since it was already known that the habitation rooms contained many more sherds than the storage rooms, it was felt that the use of proportions would tend to compensate for this variation in numbers. However, the results of both analyses were very similar, so at least in this case there is some doubt concerning the usefulness of transforming the data. The analysis using proportions was the one chosen for presentation in this study.

This analysis yielded factors, or nonrandom clusters of pottery types, as shown in Table 6.

Not all of these factors have the same meaning in terms of interpreting the structure or social organization of the site. Their distributions within the site can be related to activities, the loci of social groups, and temporal differences (any one or all of these). Their distributions will be considered individually, as they pertain to the solutions of particular problems throughout this study. Distribution maps for each factor will also be presented, so that the reader may have a clear understanding of where the factors were found within the site.

\section{Design-element Factors-Floors}

The second factor analysis was concerned with the ceramic design-elements found on floors at Broken $\mathrm{K}$. Of a total of 179 design elements isolated by $\mathrm{Mr}$. Seaberg, only 53 (791 sherds) were actually used in the analysis. This reduction in sample size was consid. ered necessary because many of the elements occurred in such small numbers (fewer than 10 sherds) that they would not have been statistically reliable. Similarly, only those rooms were used which contained more than four sherds; this meant that a total of 38 rooms was usable. A presentation of the design-elements and their frequencies by room is given in Appendix 7. Complete tabulations are in The Archives, Department of Anthropology, Field Museum of Natural History.
TABLE 6

Pottery-type Clusters Yielded

From Factor Analysis

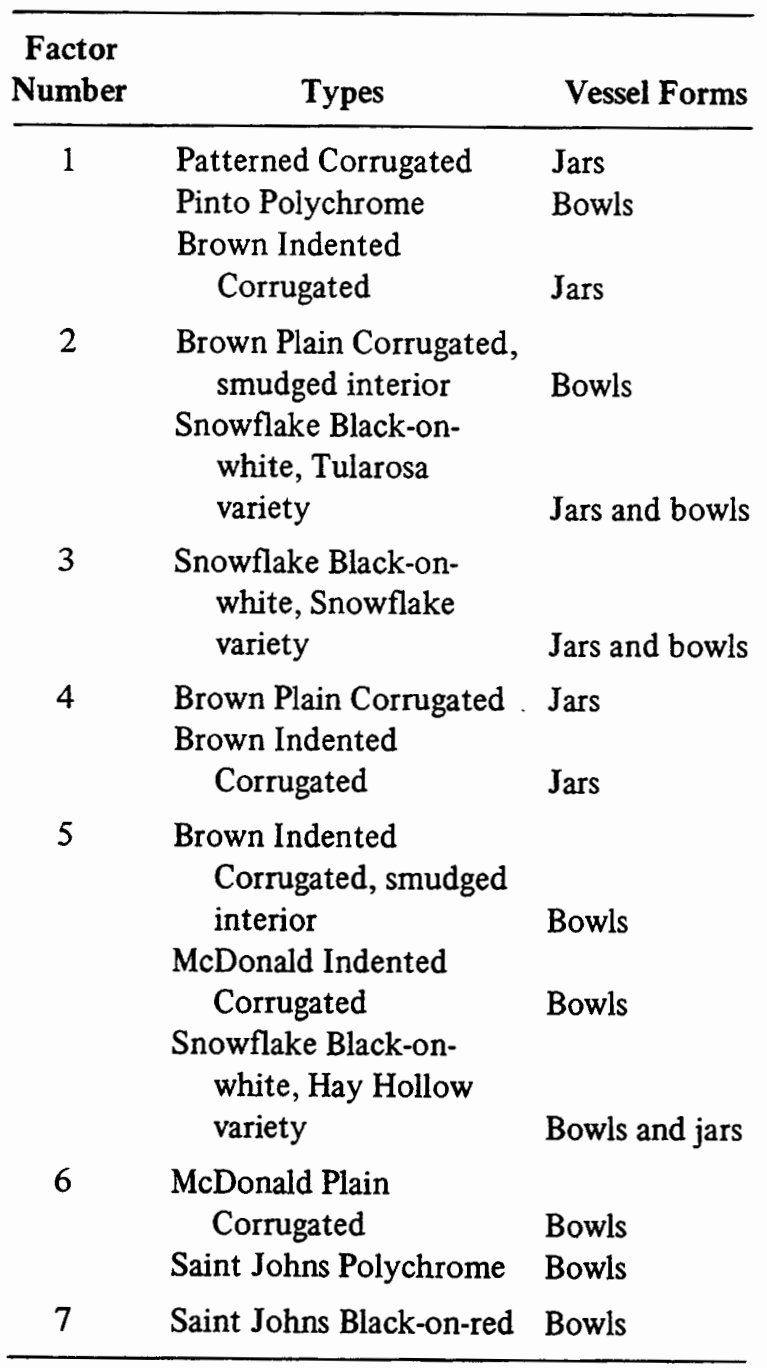

The sherds used in this study included black-onwhite, black-on-red, and polychrome types. Longacre's study of design-element distributions at Carter Ranch Site (Longacre 1964b; 1970:ch. 4 \& 5) used black-on-white wares only. But it was decided that the present study should make use of all painted wares, in an effort to determine whether or not it would make any difference in the results. In other words, if an element occurred on both red-ware and white-ware, would the factor analysis place the two types of ware in the same or different factors?

It was found that in most cases in which a design-element occurred on both types of ware, the 


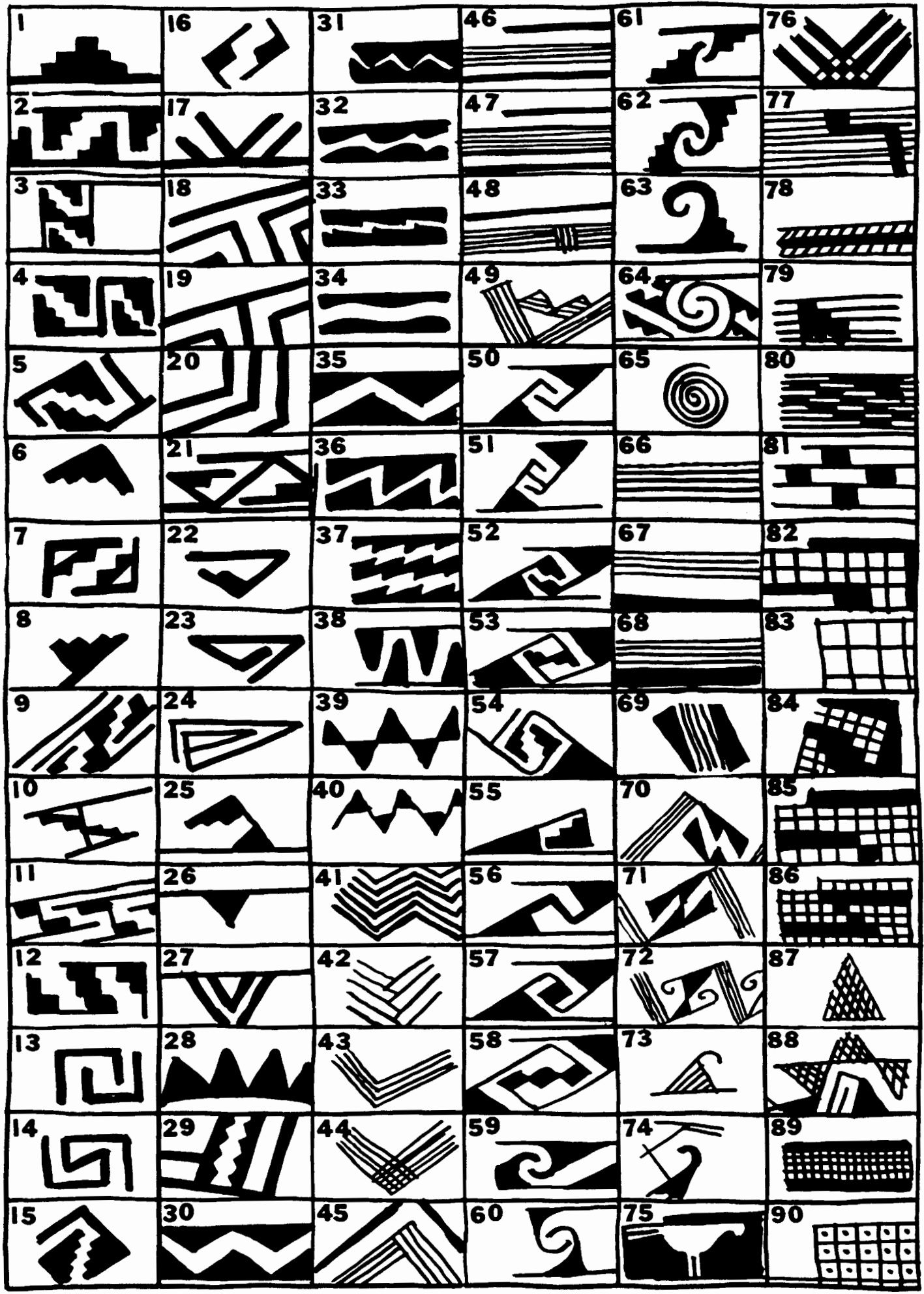

Figure 5. Elements of design, numbers 1-90, from the painted ceramics. 


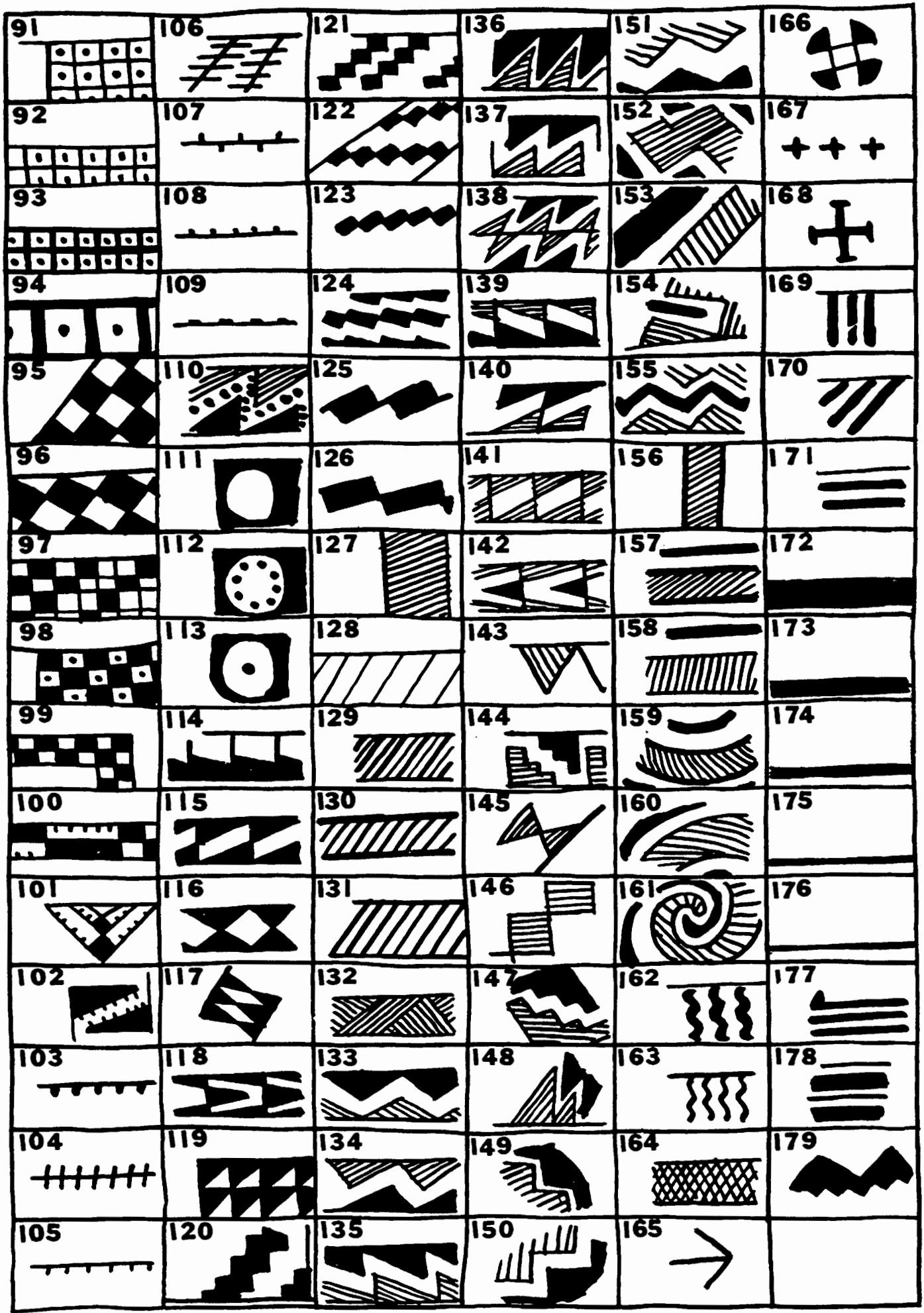

Figure 6. Elements of design, numbers 91-179, from the painted ceramics. 
factor analysis split the element into two different factors (by color). In fact, this occurred in four of five cases in which an element was found on both wares. This is a clear vindication of the decision to keep the wares separate during analysis. They are different entities, and they behaved differently in the analysis.

The following is a list of the factors that resulted from the analysis (red-wares boldface). The designelements included in these factors, as well as all of those elements originally isolated, are illustrated in Figures 5 and 6. (See also Appendixes $7 \& 8$.)

\begin{tabular}{|c|c|}
\hline Factor Number & Element Numbers \\
\hline 1 & $\begin{array}{l}6,45,46,50-51,65,82,130 \\
133,147,158,169,175\end{array}$ \\
\hline 2 & $45,134,135,146,155,158$ \\
\hline 3 & $\begin{array}{l}20,29,89,127,127,164 \\
174,175,176,177\end{array}$ \\
\hline 4 & $31,67,169$ \\
\hline 5 & $95-99,110,159,160$ \\
\hline 6 & $131,134,135,148,160$ \\
\hline 7 & $29,84,156$ \\
\hline 8 & $19,84,131$ \\
\hline 9 & $115,131,153$ \\
\hline 10 & 133,160 \\
\hline 11 & 39 \\
\hline 12 & $90-94$ \\
\hline 13 & 20 \\
\hline
\end{tabular}

As was the case with respect to the pottery type factors, these factors do not all have the same meaning. Some represent function (activities), and some represent social groups. Their distributions will be discussed individually, as they relate to the solutions of particular problems.

\section{Design-element Factors-Fills}

A third factor analysis was performed in exactly the same way as the first two, but it utilized only those design-elements which had been found in the fills of rooms. Longacre $(1964 \mathrm{~b} ; 1970: 40)$ found, on the basis of a very small sample, that the design-element clusters found in the fills of rooms at Carter Ranch Site were generally similar to those found on the floors. This did not seem entirely reasonable to me, since fill materials might be dumped into vacant rooms by people living in various parts of the pueblo, and this could lead to a more-or-less random distribution of elements in the fills. Also, material in the fills might reflect the pottery used on roofs, and this might differ from the pottery used inside the rooms. Therefore, it was decided that a comparison of the element clusters on the floors and in the fills at Broken $K$ would be useful.

The fill analysis utilized a total of 2,058 sherds, representing 92 design-elements. It was decided that an element, to be usable in the analysis, had to have at least 10 occurrences at the site. And in addition, no room was considered usable if its fill contained less than 10 sherds. A total of 42 rooms was used. The raw data input to the computer consisted of element frequencies. A tabulation of this data is found in Appendix 8. A complete tabulation of all design elements can be found in The Archives, Department of Anthropology, Field Museum of Natural History.

This analysis yielded the following factors:

$$
\begin{aligned}
& \text { Factor Number Element Number } \\
& 115,17,18,20,29,43,45,134 \text {, } \\
& 146,158,160,161,173 \\
& 26,89,127,130,172,173,174 \text {, } \\
& 175,176,177,178 \\
& 36,17,19,22,28,30,47,77-81 \text {, } \\
& 95,110,147,158,158,160,179 \\
& 47,9-11,45,46,49,71,77-81 \text {, } \\
& 127,135,136,147,160 \\
& 5 \quad 32,65,128,133,159,169 \\
& 6115,141,151,153,165 \\
& 7 \quad 10,156 \\
& 8 \quad 12,46,49,108 \\
& 941,139,159
\end{aligned}
$$

The distributions of these factors will be discussed as necessary throughout the succeeding pages. These, as well as the pottery type factors, are listed here so that the reader will be able to refer to them quickly and easily. No conclusions will be offered at this point. 


\section{INTRA-SITE DATING}

In order to study a social system, prehistoric or otherwise, it is necessary that the system be defined at a specific point or points in time. The reason it must be studied synchronically is that it may tend to change through time and gradually develop into a different system. While it is reasonable to compare systems that have existed at different points in time, it would not be very meaningful to consider them all as a single system. It is only after the separate systems have been defined that one can profitably consider comparative and evolutionary problems.

Broken K Pueblo was not constructed and inhabited at a specific point in time; it was occupied from about A.D. 1150 to 1280. This implies the possibility of systemic change. That such change almost certainly took place is shown by the fact that the site grew larger through time. In the early portion of its occupation, the Pueblo consisted of perhaps 10 or 20 rooms, but by the end of the occupation there were nearly 100 rooms. As the village itself changed, concomitant changes in social organization may be presumed. It was therefore decided that, for most purposes, the site should not be considered as representing a synchronic system but should at least be divided into an early system and a later system. Empirical evidence exists for such a division.

The evidence is of two kinds-primary and secondary. The primary evidence will be discussed first. It is more important and more convincing than the secondary evidence, because it employs data that can clearly be interpreted as having temporal significance. As a matter of fact, the primary evidence is enough, in itself, to establish a temporal division of the site.

The secondary evidence is of some significance, however, as it employs data that would not normally be interpreted as reflecting temporal change but which were found to follow the same pattern of distribution as indicated by the primary evidence. In other words, these secondary data were found to conform to an already established temporal division of the site, and they appear to reflect that division. Only in this sense are they indicators of time.

\section{Primary Evidence}

\section{Architecture and Stratigraphy}

The architectural evidence at first looked as if it would be inconclusive with respect to intra-site dating. An examination of through-walls, bonds, and abutments proved unsatisfactory, primarily because bonded walls or through-walls were virtually nonexistent. This meant that it was impossible either to isolate large blocks of rooms that had been constructed contemporaneously, or to determine relative dates for the four major wings of the pueblo. It looked almost as though the village had developed in increments of one room at a time.

More careful study of the abutments, however, yielded clear information concerning the architectural sequence within each wing; the developmental process appears to have been similar in each. First, three or four core rooms were built in the central portion of each wing. Then, as more rooms were added, each wing expanded in two directions. In the east wing, for example, the core rooms were Rooms 11,12 , and 13; from this nucleus, the wing expanded both northward and southward. In the north wing, Rooms 31-33, 32, and 34 were the core rooms, and the expansion proceeded in both easterly and westerly directions. The west wing began with Rooms 54 , 55 , and 57, and the south wing began with Rooms $73,74,80$, and 82 .

In order to determine the relative dates of all the rooms or groups of rooms within the pueblo, it was necessary to employ other kinds of evidence. The most convincing evidence was stratigraphic. Most of the rooms in the north half of the pueblo were built on top of a thin layer of midden; in the south half, the rooms were constructed on sterile soil (Fig. 7). This suggests that in the early stages of occupation people were living in the south half and dumping some of their trash in the open area to the north. Then, when it became necessary to add more rooms to the pueblo, the new rooms were built on top of this trash deposit. 


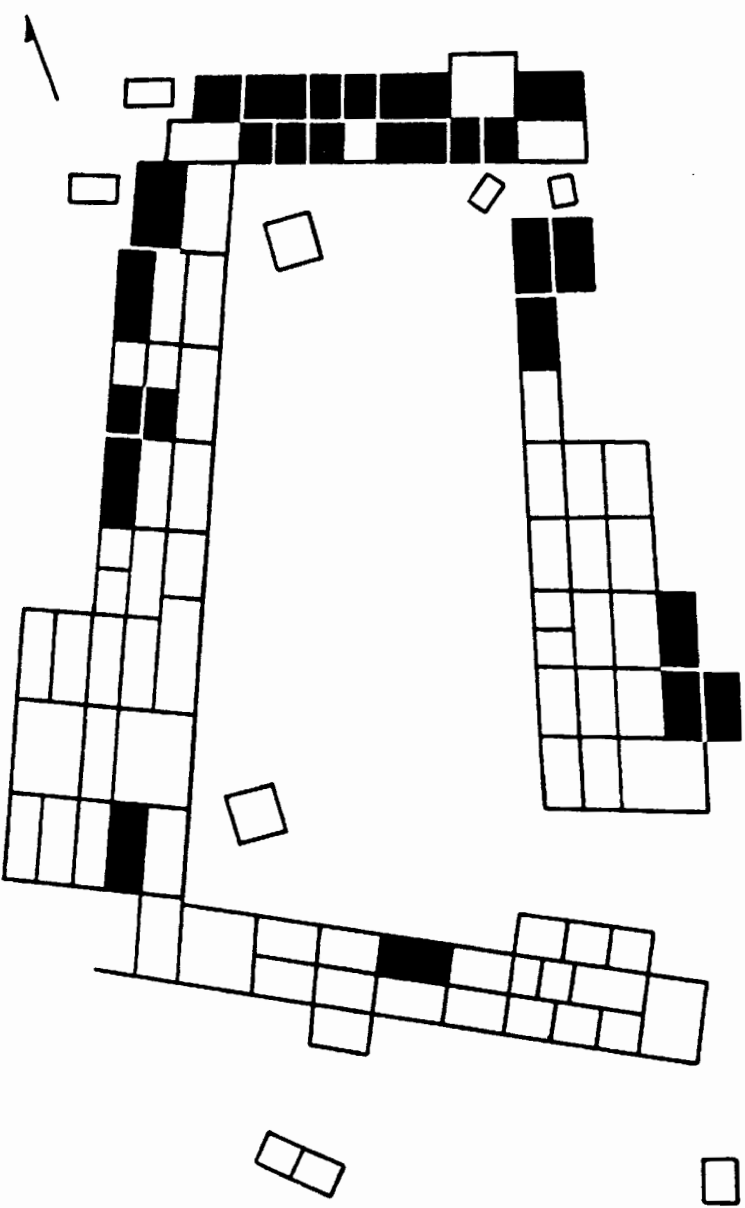

Figure 7. Distribution of rooms having trash beneath floors (dark areas).

Further stratigraphic evidence in support of this rough north-south division can be seen on the ground plan of the site (Fig. 2). It is notable that several of the rooms in the north half had been built on top of structural features that clearly predated these rooms and that must have been in use prior to the construction of the rooms. The three subterranean kivas (22-kiva, 39-kiva, and 41-kiva) were the largest of these subfloor structures, but there were several smaller features as well. A burial was found in a pit beneath the south wall of Room 27; a large roasting pit, similar to those in the plaza, was found beneath the wall dividing Rooms 48 and 49.

In the south half of the pueblo such structures are conspicuously absent. Although there was a roasting pit under Room 9 and a shallow pit beneath Rooms 2 and 7 , no other pre-room structures were found.
These data clearly suggest that the earliest inhabitants of the village lived in what is now the south half of the site and that they carried on some of their ceremonial and cooking activities in what was later to be the north half.

Although this dating scheme already seems conclusive, other bits of architectural information support it. The fact that much more remodeling is in evidence in the south half than in the north would seem to indicate that the southern rooms were lived in for a longer period of time. For example, in the south half, 13 excavated rooms contained at least two floors, and 9 rooms had only one floor. In the north half, on the other hand, only 10 rooms had two floors, and 18 rooms had one floor. A chi-square test (Cochran 1952:328-37; Siegel 1956:104-11) on these data revealed a 90 percent chance (probability 0.90 ) that this distribution of floors is not accidental-there are more rooms with two floors in the south than in the north.

\section{Trash in Rooms}

Further evidence concerning intra-site dating can be seen in the spatial distribution of midden material at the site. The accompanying distribution map (Fig. 8) shows clearly that most of the rooms containing trash deposits were found in the south half of the pueblo. In fact, 15 such rooms were discovered in the south while only 5 were found in the north half. This distribution was subjected to a chi-square test, and a 95 percent chance of a real difference was found between the amounts of trash in the north and the south halves.

It has been suggested (Mindeleff 1891:53-54) that the longer a site is occupied the more trash is accumulated. He states that when there is very little trash, it "strongly suggests that it [the site] was occupied for a very short time."

If it can be assumed that the amount of trash accumulation in any area of Broken $\mathrm{K}$ is a function of deposition over time, then it may be inferred that the south half of the site was occupied longest. And if the south half was occupied longest, it may also have been occupied first. The trash distribution evidence is not sufficient, in itself, to make such a demonstration, but when considered in the light of the architectural evidence previously offered, its value is greatly enhanced.

A further point should be made concerning this distribution. Nearly all the northern rooms containing 


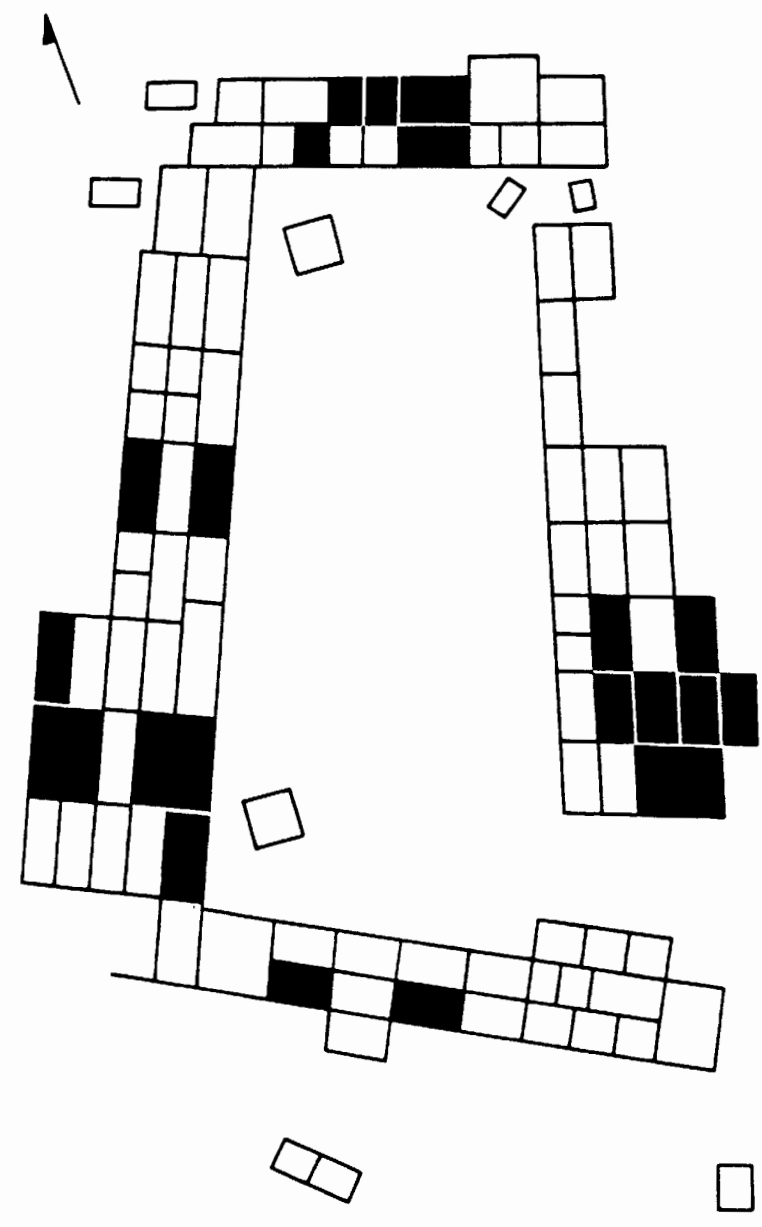

Figure 8. Distribution of rooms containing trash deposits above floors (dark areas).

trash were found in the central portion of the north wing, and no trash deposits were found in the northeast and northwest corner areas of the site. If it is generally true that rooms containing trash deposits are early rooms, then these data suggest that the core room area of the north wing was also early. Other evidence will be presented in support of this idea.

\section{Pollen}

After the relative dating of the two halves of the pueblo had already been demonstrated, by means of architectural and stratigraphic evidence, it was decided that palynological evidence should also be examined in this light. Apparently, this is the first time that such a study has been attempted, and the results were excellent beyond expectation. While it would not yet be proper to claim that pollen data can be used universally in this way, it is clear that the technique should be tested further (Hill and Hevly 1968).

The experiment at Broken $\mathrm{K}$ Pueblo was made possible by the fact that a fairly detailed pollen chronology for the area was already in existence (Schoenwetter 1962; Hevly 1964). This chronology will be discussed more completely in Chapter 13, but a particular aspect of it must be considered now.

During a period from about A.D. 900 to 1300 , a marked shift in environmental conditions took place. Palynologically, the shift was characterized by a change from a period in which arboreal pollen was relatively common (about A.D. 1000 to 1100 ) to a period in which non-arboreal pollen was relatively more abundant (about A.D. 1100 to 1300). The evidence indicates a gradual increase in the relative abundance of non-arboreal pollen throughout the period of Broken K occupation (Hevly 1964:74-110; Hill and Hevly 1968).

Ample evidence indicates that this shift reflects a shift in the environment to which the people of Broken $\mathrm{K}$ attempted to adapt (Chapters 13 \& 14). But the only important consideration at this point is the fact that changes in the relative frequencies of naturally deposited pollen-types were occurring throughout the occupation of the site. Therefore, it was thought possible that we would be able to use the changing ratio of arboreal pollen to non-arboreal pollen to date the rooms relative to one another. Presumably the earliest rooms would contain relatively large amounts of arboreal pollen (especially Pinus), and the latest rooms would show a decrease in arboreal pollen and an increase in non-arboreal pollen.

This hypothesis seems to have been well founded. Upon examining all of the pollen samples from the floors of rooms, it was found that most of the rooms considered early contained 20 to 40 percent Pinus pollen, while the late rooms had 0 to 20 percent (Hevly 1964:92; Hill and Hevly 1968).

The agreement between the palynological and stratigraphic evidence was so good, in fact, that Hevly was able to state in a letter that "We are in complete agreement as to the temporal sequence of room addition. Your core rooms were always in the category I termed 'early'.... and your late rooms... were always in my 'late' or intermediate categories." 
This conclusion was checked independently by the author, and aside from a few discrepancies between the pollen and stratigraphic determinations, the statement is correct. Of 18 excavated rooms that appeared architecturally and stratigraphically to be early, 15 were also considered early on the basis of pollen content. Of 15 late rooms, the pollen evidence was in agreement on 10 . These data were subjected to a chi-square test, and there is less than one chance in a hundred that the distribution of Pinus pollen is accidental (random).

In addition to this, it was possible to document Hevly's statement that the late rooms at Broken $\mathrm{K}$ not only contained less Pinus pollen but also contained more non-arboreal pollen (especially Compositae, Cheno-ams and Gramineae). This tested significant at the 0.05 level, which means that it may be considered non-accidental.

Thus, at this site at least, strong evidence suggests that pollen data can be of value in the relative dating of provenience units within a site.

Figure 9 shows the relative dating of excavated rooms within Broken $\mathrm{K}$, based on pollen and stratigraphic evidence combined. This map represents the best interpretation of intra-site dating that can presently be made. (See also Table 8, p.39.)

\section{Secondary Evidence}

As was mentioned earlier, several bits of secondary evidence pertain to the temporal division of the site. While this evidence has no inherent temporal significance, it does tend to conform to the pattern of distribution which, as has been pointed out, is interpreted in a temporal sense.

\section{Architecture}

One item of secondary evidence concerns the distribution of storage pits (in floors) at the site. The south half of the pueblo had 17 rooms that contained more than three storage pits each, while the north half had only 3 such rooms. If the south half had been occupied earliest and longest, one might expect a greater number of storage pits in this area (other things being equal). Many of the pits had been sealed over with plaster or subsequent floors, so there is good evidence that they were not all in use at the same time.

The distribution of ventilators also reflects temporal difference. Twelve ventilators (excluding kiva vents) were found at the site-all in the south half.

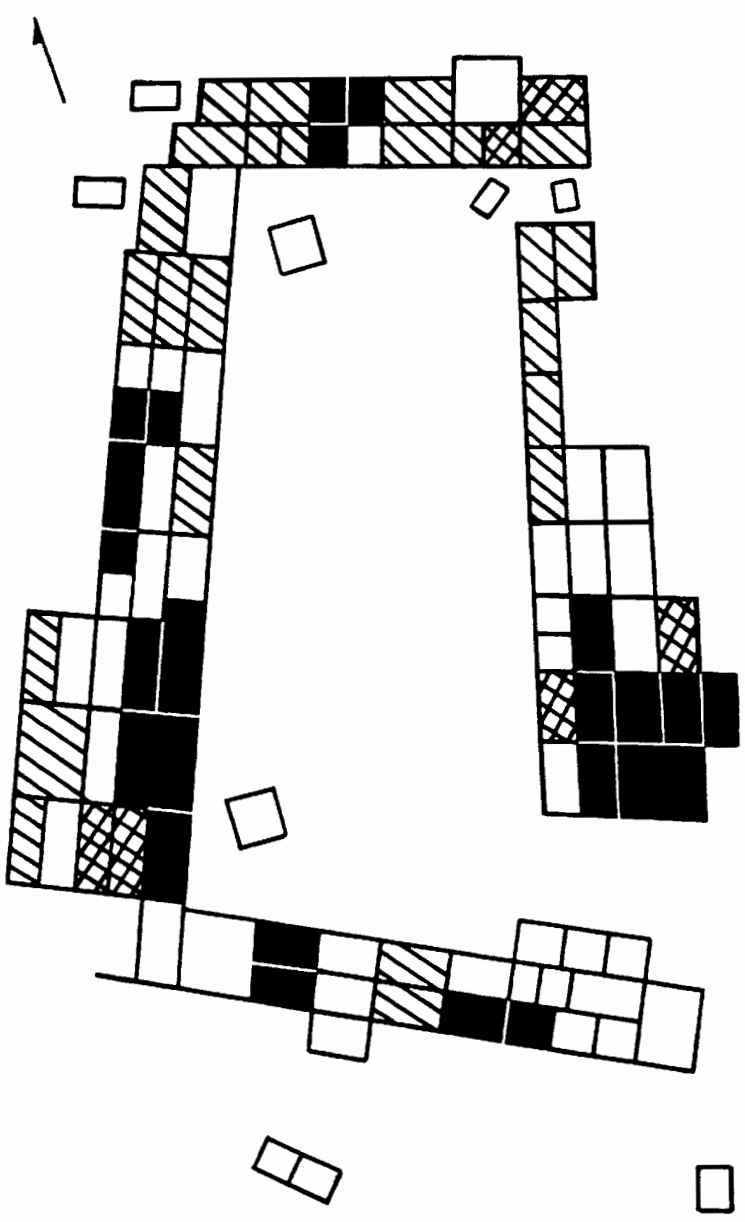

Figure 9. Relative dating of rooms on the basis of pollen and stratigraphic evidence. Heavily shaded areas represent early rooms; hatched areas represent late rooms; cross-hatched areas represent rooms which could not be dated; white areas represent unexcavated rooms. (See also Table 8.)

Why this should be so is unclear, but the distribution conforms to the demonstrated temporal division, and there is no adequate alternative to considering ventilators as attributes of early rooms.

\section{Animal Bone}

The distribution of animal bone at the site also reflects the established temporal division. Using all of the animal bones found on floors, it was discovered that the south half of the site contained by far the largest number. A graphic distribution of the numbers of bones per room showed that most of the excavated 


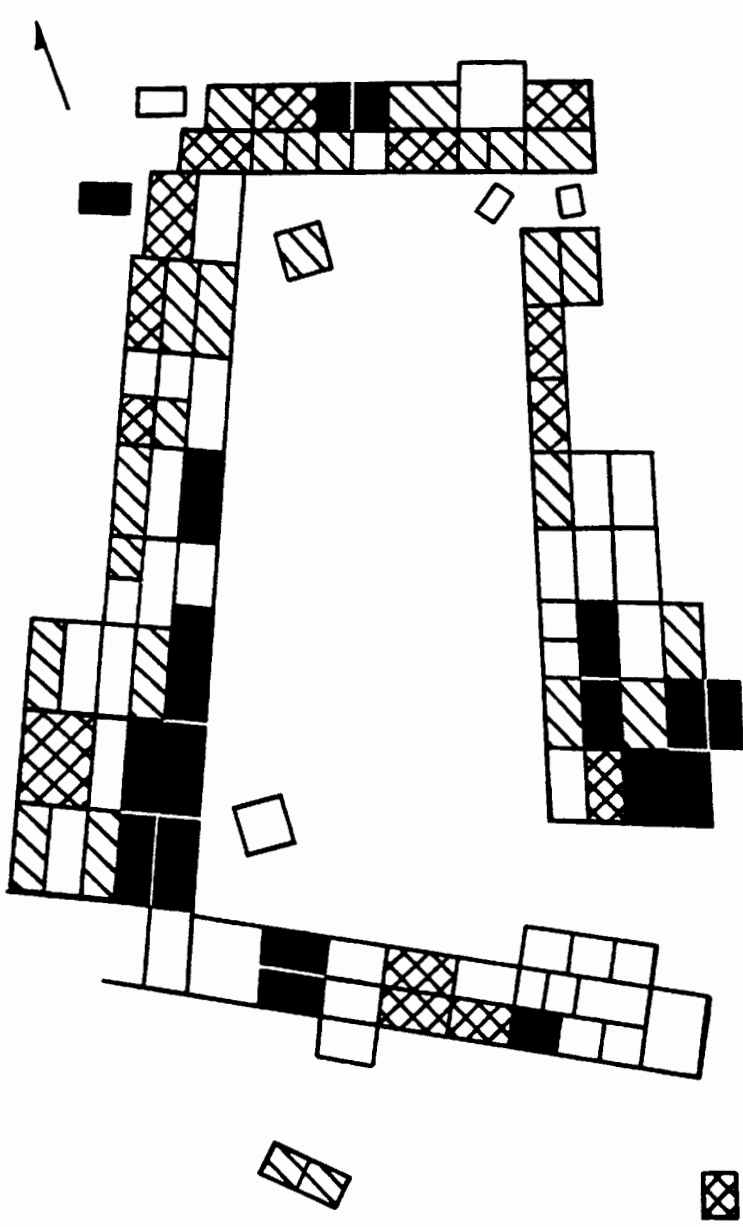

Figure 10. Distribution of animal bone on the floors of habitation rooms. Heavily shaded areas represent rooms containing more than 55 bones each; crosshatched areas represent rooms containing fewer than 55 bones each; hatched areas represent storage rooms; white areas represent unexcavated rooms.

rooms in the south half contained at least 55 bones each, while those in the north half had less than 55 each (Fig. 10). A chi-square test indicated a probability of 0.99 that this distribution is meaningful.

The bones found in the fills of each room were accorded the same treatment, with essentially identical results. Furthermore, after the bones had been identified zoologically, most of the individual genera represented followed the same kind of distributional pattern. This would seem to indicate that more game was being killed during the earliest part of the occupation than in later times. Or, it might be that the early portion was simply occupied longest, thus permitting the greatest accumulation of bone debris. In either case, the evidence suggests that the south half of the pueblo is different from the north half, and probably the oldest.

\section{Factor Analyses}

The factor analyses of pottery-types and pottery design-elements also present evidence related to intrasite dating. Although most of the factors do not follow a temporal pattern of distribution, a few do follow this pattern.

Factor 6 of the pottery type study is one of these. This factor includes McDonald Plain Corrugated (bowls) and St. Johns Polychrome (bowls). Its distribution with respect to storage rooms (small, generally featureless rooms) is interesting. It occurs commonly in these rooms in the north half of the site but rarely in the south half. In fact, five of six usable storage rooms in the north half were shown to have this factor, while only one of seven southern storage rooms had it. This suggests that factor 6 became more common through time, at least with respect to its use in storage rooms (Appendix 5, Fig. A2).

In the factor analysis of ceramic design-elements found on the floors of rooms, factor 1 clearly has temporal significance. Although its strongest occurrence was in the burial beneath Room 27, it occurred elsewhere only in the earliest areas of the site (Fig. 23, p. 80). Its primary occurrences were in the south halves of both the east and west wings, and these areas may be the oldest at the site.

Factor 9, of the same study, also has temporal implications. It occurred in significant amounts (greater than 10 percent per room) only in the south half of the pueblo and in the probably early central portion of the north wing (Fig. 21).

Factor 5 of the design study of the fills in rooms reflects a temporal distribution because it is found significantly (greater than 15 percent per room) in early areas only-the south halves of the east and west wings, and the subterranean kivas beneath Rooms 39 and 41 (Appendix 5, Fig. A8).

Factor 7 of the same study, on the other hand, is found almost exclusively in the late half of the pueblo. Eight rooms in the north half contain between 30 and 100 percent; in the south, no room contains over 30 percent (Appendix 5, Fig. A10).

The last factor that may be explained in terms of the temporal division of the site is factor 8 , also of 
the same study. It is found predominantly in the earliest areas of the site, especially in the vicinity of the core rooms in each wing (Appendix 5, Fig. A11).

\section{Kiva Dating}

A detailed relative dating of the kivas at Broken $\mathrm{K}$ is at present almost impossible, but the major outlines are reasonably clear. It is almost certain that the kivas underlying Rooms 22, 39, and 41 were the earliest ones (22-kiva, 39-kiva, and 41-kiva). It is only slightly less certain that the kiva in the northwest corner of the plaza (Plaza-kiva) is latest. Room 6-kiva and Room 29-kiva are probably intermediate in time, but there is no known way to date them relative to one another.

The evidence pointing to 22-kiva, 39-kiva, and 41-kiva as being the earliest is in part architectural and stratigraphic. Since they are located underneath rooms in the north half of the pueblo, they must be early enough to have been associated with the occupation of the south half. Furthermore, if they were not the earliest, it would have to be assumed that the earliest occupants had no kivas at all (on the basis of the excavated evidence). The reason for this is that the room-type kivas (6 and 29) were clearly not in existence during the earliest part of the occupation. Room 6-kiva was a remodeled habitation room, and Room 29-kiva was the last room constructed in the north wing. Prior to the construction of these two kivas, the inhabitants must have utilized 22-kiva, 39-kiva, 41-kiva, and perhaps others like them that have not been discovered.

There is the possibility, of course, that the Plaza-kiva was earliest. There are no architectural or stratigraphic data to argue against this, but the evidence to be presented shortly makes it unlikely.

This evidence is in part palynological. If other rooms in the pueblo can be assigned relative dates on the basis of pollen content, it should also be possible to do the same thing with kivas. The earliest kivas should have a high relative abundance of arboreal pollen, while the later ones should contain increased percentages of non-arboreal pollen. The percentages of both types of pollen on the floors of the excavated kivas are as follows: Plaza-kiva, 8 percent arboreal and 92 percent non-arboreal; Room 6-kiva, 34 and 66 percent respectively; and 41 -kiva, 50 and 50 percent respectively. This clearly suggests that 41 -kiva was earliest, Room 6-kiva later, and the Plaza-kiva latest.
In addition, there is some secondary evidence in support of this dating scheme. The distribution of animal bone, for example, is interesting in this light. It has already been shown that the earliest rooms contained, on the average, more than 55 bones per floor, while the later rooms contained considerably fewer. A count of the total number of bones on the floors of each of the excavated kivas yielded the following: Plaza-kiva, 5 bones; Room 6-kiva, 10; and 41-kiva, 98.

These figures leave no doubt that 41 -kiva is very different from the other two in terms of bone content. Ninety-eight bones is well within the range of the numbers of bones found on the floors of early rooms at Broken $K$, and this suggests that 41 -kiva is also early.

On this basis, the other two kivas should be considered late. One could push this even further and say that since Plaza-kiva has the smallest number of bones, it may be the latest. This might be true, but there is so little difference in numbers of bones in Room 6-kiva and Plaza-kiva that the inference would be tenuous at best.

Interestingly enough, the bones found in the fills of the kivas suggest a similar dating scheme. For this study, it was possible to increase the number of kivas considered. Although 22-kiva and 39-kiva had not been completely excavated, portions of the fill material had been saved, and they were more than adequate for the present purpose.

Counts of the numbers of bones in the fill of each kiva showed that 22-kiva, 39-kiva, and 41-kiva had many more bones than any of the others, and they were clearly within the range of early rooms. Room 6-kiva and Plaza-kiva, on the other hand, had very few bones and should probably be considered late.

Further secondary evidence concerning kiva dating is found in the factor analyses. Factor 6 (Appendix 5 , Fig. A2) of the pottery-type study, for example, tends to indicate that the Plaza-kiva is relatively late (as has been suggested). This factor makes up 8 percent of the pottery on the floor of this kiva, and no other kiva has any of it. Since this factor has already been found to have possible temporal significance with respect to other rooms in the pueblo, it is assumed that its distribution in kivas may be interpreted in the same way. In any event, the distribution of factor 6 clearly points up the fact that the Plaza-kiva is different from all the others. 
INTRA-SITE DATING

TABLE 7

Seriation of Pottery-types

\begin{tabular}{llll}
\hline \multicolumn{1}{c}{ 41-Kiva } & Room 6-Kiva & Room 29-Kiva & \multicolumn{1}{c}{ Plaza-Kiva } \\
\hline $\begin{array}{l}\text { Snowflake B/W } \\
\text { (Snowflake variety) }\end{array}$ & & & $\begin{array}{c}\text { Snowflake B/W } \\
\text { (Snowflake variety) }\end{array}$ \\
$\begin{array}{l}\text { St. Johns B/R } \\
\text { Brown Plain Corr. }\end{array}$ & St. Johns B/R & & \\
& Brown Plain Corr. & Brown Plain Corr. & Brown Plain Corr. \\
& Patterned Corr. & Patterned Corr. \\
& Pinto Polychrome & $\begin{array}{l}\text { Pinto Polychrome } \\
\end{array}$ \\
& & $\begin{array}{c}\text { Snowflake B/W } \\
\text { (Tularosa variety) }\end{array}$ \\
& & St. Johns Polychrome \\
& & Brown Plain Corr., \\
& & smudged interior \\
& & McDonald Plain Corr. \\
\hline
\end{tabular}

Although factor 6 is the only pottery-type factor that tends to follow a temporal distribution, it is possible that the kivas can be dated relatively by comparing their contents with respect to all seven pottery-type factors. In order to do this, all of the positive factors in each kiva were listed in terms of their pottery-type content, and the kivas were compared on the basis of the pottery types they contained. This amounted to a seriation of these types, the results of which are given in Table 7 . The table clearly shows that 41-kiva and the Plaza-kiva are very different with respect to their dominant pottery types. On the basis of all the previous evidence, this seriation should indicate that 41-kiva is the earliest and Plaza-kiva the latest.

This is not the only possible interpretation of the seriation, however. It is obvious that 41-kiva and Room 6-kiva are similar with respect to pottery types, and the same can be said for Room 29-kiva and Plaza-kiva. It may be that two pairs of kivas are represented, and that the kivas within each pair were related functionally or in terms of social group affinity. These interpretations cannot be tested on the basis of presently available evidence, but even if they have some validity, there would be no conflict with the general scheme of kiva-dating proposed here.
The only other factor-analysis evidence useful in kiva dating is found in factor 5 of the design-element study (fills). This factor makes up between 48 and 83 percent of the fill content in 41-kiva and 39-kiva; the only other significant occurrences of it were in the early halves of the east and west wings (Appendix 5, Fig. A8). This seems to indicate that the subterranean kivas underlying rooms in the north half of the pueblo were indeed associated with the early rooms in the south.

It is noteworthy that 41-kiva, 39-kiva, and 22-kiva all appear to have been early. From the small amount of information available, it is known that they are architecturally similar to one another and that they are quite different from any of the other kivas. Such similarity might argue for their contemporaneity. It thus seems probable that an early date for 41-kiva implies an early date for 22-kiva and 39-kiva as well; this is supported by the fact that these are the only kivas located stratigraphically beneath rooms.

In conclusion, most of the evidence presented here leaves little doubt that 41-kiva (and presumably the other subfloor kivas) were the earliest and that the Plaza-kiva was the latest. The dating of the room-type kivas (6 and 29) is not clear, but probably they were intermediate in time. 
A final point regarding kiva dating should be made. That is, there is strong evidence that no kivas were being used just prior to the abandonment of the site. All the kivas that were discovered contained trash materials in their fill levels, indicating that they were all being used as dumps to some extent. If any of the kivas at the site are free of trash, it seems reasonable that at least one of them would have been discovered in the extensive random sample. It therefore appears likely that the latest inhabitants of the site were either not performing ceremonies, or they were using ordinary habitation rooms for the "kiva" portions of the ceremonies. 


\section{ROOM TYPES}

Archaeologists have long recognized that there are differences in the types of rooms found in prehistoric pueblo sites. Ordinarily, a large room containing a firepit and mealing bin is called a living room or habitation room, while a small room without a firepit is called a storage room. A ceremonial room is often recognized as being a subterranean structure with a roof entrance, a firepit, a ventilator, some wall niches, and a bench or platform along one or more of the walls.

This kind of classification is probably adequate with respect to ceremonial rooms, since these rooms contain so many peculiar attributes that their recognition is often obvious; unfortunately, however, it is not always adequate for defining habitation and storage rooms. The differences between these roomtypes are not always obvious, and a casual classification of them on the basis of one or two attributes may not be reliable.

Furthermore, many authors of archaeological reports do not make explicit statements regarding the attributes they have chosen to use in determining room-types. This makes it extremely difficult for a reader to understand what really constitutes a habitation or storage room. In fact, one wonders how sure the author himself is that his types have any meaning. Such classifications are based on feel rather than on any systematic comparison, and their imprecision makes them almost unusable if one wishes to make inferences concerning the functions of rooms.

The present chapter is dedicated to a systematic, and largely statistical, definition of room-types at Broken K Pueblo.* There will be no discussion of kiva features, simply because they were so obvious (Smith 1952:154-65; Martin, Longacre, and Hill 1967) but the contents of the kivas will be considered, because they are of some importance in the succeeding chapter.

The attributes used in this discussion of roomtypes are as follows:

Size (floor area)

Firepits (presence or absence)

*For a methodologically different presentation of the analysis of room-types and room-function see Hill (1968).
Mealing bins (presence or absence)

Ventilators (presence or absence)

Artifact types (frequency differentials)

Lithic waste (frequency differentials)

Animal bone (frequency differentials)

Seeds (frequency differentials)

Pollen types (frequency differentials)

Sherds (frequency differentials)

Pottery-type factors (strength differentials)

Ceramic design-element factors (strength differentials)

The differential distributions of these attributes permitted an accurate determination of room-types at the site.

The first step in this analysis was the establishment of room-types based on associations among the first four attributes listed above. Following this, the other attributes were used to verify the types. Although the problem of room function is avoided here, a foundation is laid here for its discussion in Chapter 9.

\section{Area Modes}

During the excavation of the site, it was noticed that some rooms were much larger than others. It looked as if the rooms could be divided into two different categories, on the basis of size alone. As more and more rooms were excavated, it became apparent that the larger rooms often possessed certain features that were rarely found in the small ones. This evidence suggested the possibility of at least two major types of rooms at the site-in addition to the kivas.

The question was: Were these differences real, or largely figments of the excavator's judgment? It was decided that the best solution to this problem would be a statistical one. In this way it would not only be possible to determine the existence or nonexistence of formal differences, but also it would be possible to make definite statements concerning the discreteness of the types and the attributes that were significant in defining them.

The first step was to determine whether or not the observed differences in size were really nonrandom. In other words, were there two statistically discrete size-modes? In order to do this, the floor-area of each excavated room was determined (in square meters), and the rooms were graphed on an interval scale of 
size. It was immediately apparent that the distribution was in fact not random and that there was an obvious bi-modal distribution. Approximately half the rooms were in the small size-mode, or less than 6.5 square meters in floor-area. They ranged in size from 2.5 square meters to 6.5 square meters; the average was 5.0 square meters. The large rooms, including the kivas, ranged in size from 6.5 to 33.5 square meters, with an average of 9.7 square meters.

The next step was to perform the same kind of analysis using all of the rooms at the site, whether excavated or not. The results were the same as when only the excavated rooms were used-except that the dividing point between the two modes became 7.0 square meters instead of 6.5 square meters. This analysis clearly suggests that room-types, at least on the basis of size, can be determined even before the rooms are excavated.

There was some indication, however, that this distribution of size should actually be considered tri-modal. Seven of the rooms (Rooms 1, 10, 26, 47, 64,72 , and 91) were noticeably larger than most of the rooms in the "large" mode, ranging from 16.0 to 33.5 square meters in floor-area. Although these rooms were larger, there was no sure evidence that they represent another type. Two of them (Rooms 1 and 64) were excavated in the initial sample, and no evidence was found in support of the hypothesis that they were in any way different from the majority of large rooms. Still, to be sure, two more such rooms (72 and 91) were excavated solely for the purpose of obtaining a larger sample.* The result was negative. If these rooms were recognized as different by the inhabitants of the village, there is apparently no way to know it now. Today their only distinguishing attribute is size. The possibility still exists, however, that they represent a separate room-type analogous to the modern Hopi clan houses (Eggan 1950:62, 89-90, 178).

\section{Features}

An examination of the excavated rooms revealed that most of the large rooms contained firepits while

\footnotetext{
*These two rooms were excavated during the summer of 1964, after the main efforts at Broken $K$ had been terminated. They were done under the pressure of limited time; the deposits were not screened, nor were adequate notes taken. Thus, these rooms have not been included as part of the sample used in other analyses, and they have not been considered as "excavated" rooms (Fig. 2).
}

the small ones generally did not. In fact, of a total of 29 firepits, only 6 occurred in the small-sized rooms. This observed association was tested by chi-square, giving a probability of 0.99 that the association is valid. A similar test, this time associating slab-lined firepits with the large rooms, showed that there were 999 chances in 1,000 that the association was real. Only 1 of 23 slab-lined firepits occurred in small rooms.

The next step was to associate unsealed mealing bins with the large room category. Thirteen of 15 bins occurred in large rooms, and the association was significant at the 0.05 level (probability of 0.95 ).
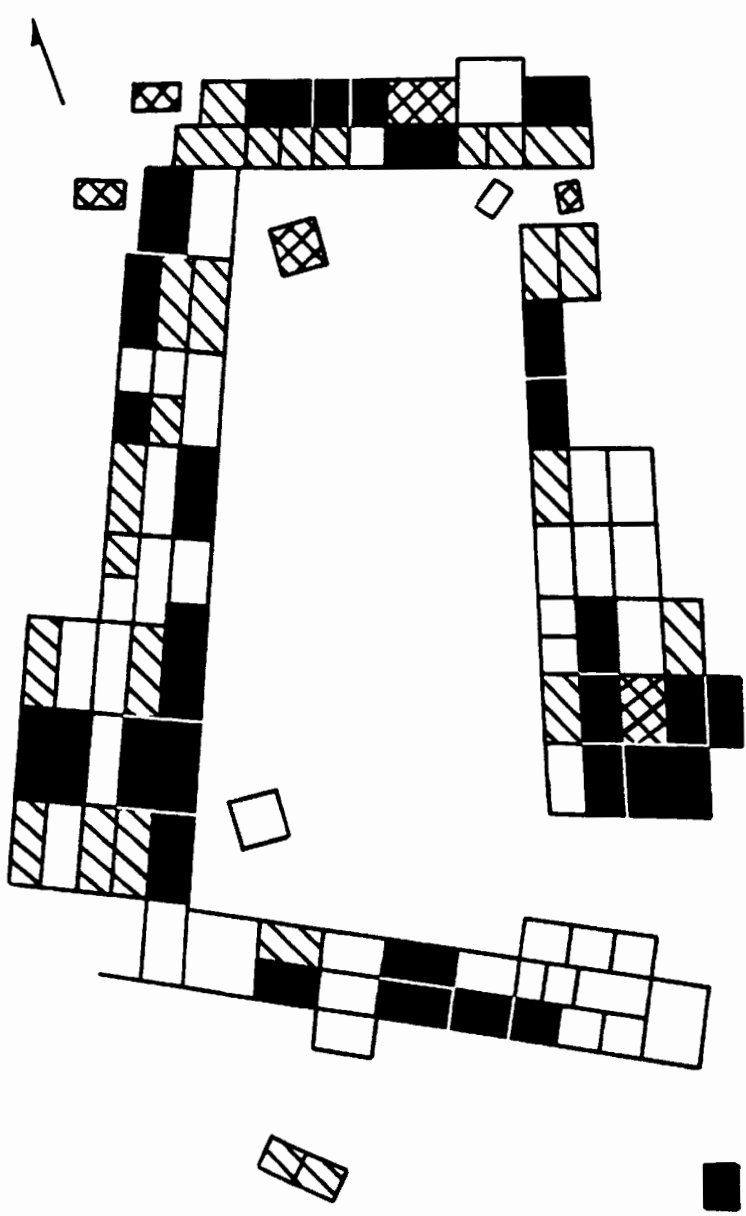

Figure 11. Distribution of room-types. Heavily shaded areas represent habitation rooms; hatched areas represent storage rooms; cross-hatched areas represent ceremonial rooms (kivas); white areas represent unexcavated rooms. 
Several other tests of association were then performed. It was discovered that 10 of 11 ventilators at the site were associated with the large rooms $(0.02$ level). Furthermore, the ventilators, firepits, and mealing bins were associated with one another with a probable validity of at least 0.95 .

This evidence suggested that, in addition to the kivas, there were two major room-types at Broken $\mathrm{K}$. Although it is possible that the seven extremely large rooms in the large room category represent another type, this division will not be made in the succeeding analyses.

Figure 11 shows the distribution of the roomtypes at the site. The large rooms containing firepits, mealing bins, and ventilators are henceforth referred to as habitation rooms; the small rooms, primarily characterized by having no features at all, are termed storage rooms. The ceremonial rooms are very distinctive in terms of their features, and they are, of course, called kivas. Of all the rooms excavated, 26 were habitation rooms, 24 were storage rooms, and 4 were kivas (although 2 additional kivas were partially excavated) (Table 8). Photographs of the room-types are presented in Figures 12,13 and 14. For a
TABLE 8

Room-types and Relative Dating

\begin{tabular}{llll}
\hline & \multicolumn{1}{c}{ Habitation } & \multicolumn{1}{c}{ Storage } & Kiva \\
\hline Early & $1,2,4-5,7,11$, & $34,49,51,54$, & 6,41 \\
& $31-33,48,64$, & 60,74 & \\
& $69,73,80,82$, & & \\
& 92 & & \\
Late & $20,21,30,35-37$ & $19,22,23,25$ & 29 \\
& $40,41,43,53$, & $28,36,39,44 a$, & Plaza \\
& $62,78,79$, & $44 b, 61,65$, & \\
& Outlier 2 & Outlier 1 (a,b) & \\
Indef. & 24 & $8,9,27,67,68$ & \\
\hline
\end{tabular}

complete discussion of the attributes of the kivas, see Martin, Longacre, and Hill (1967).

The reader should not be left with the impression that all rooms fell neatly into one category or another. Although this was true for most rooms, in six cases classification was extremely difficult (Rooms 9, 27, 40, 48, 60, and 74). These rooms

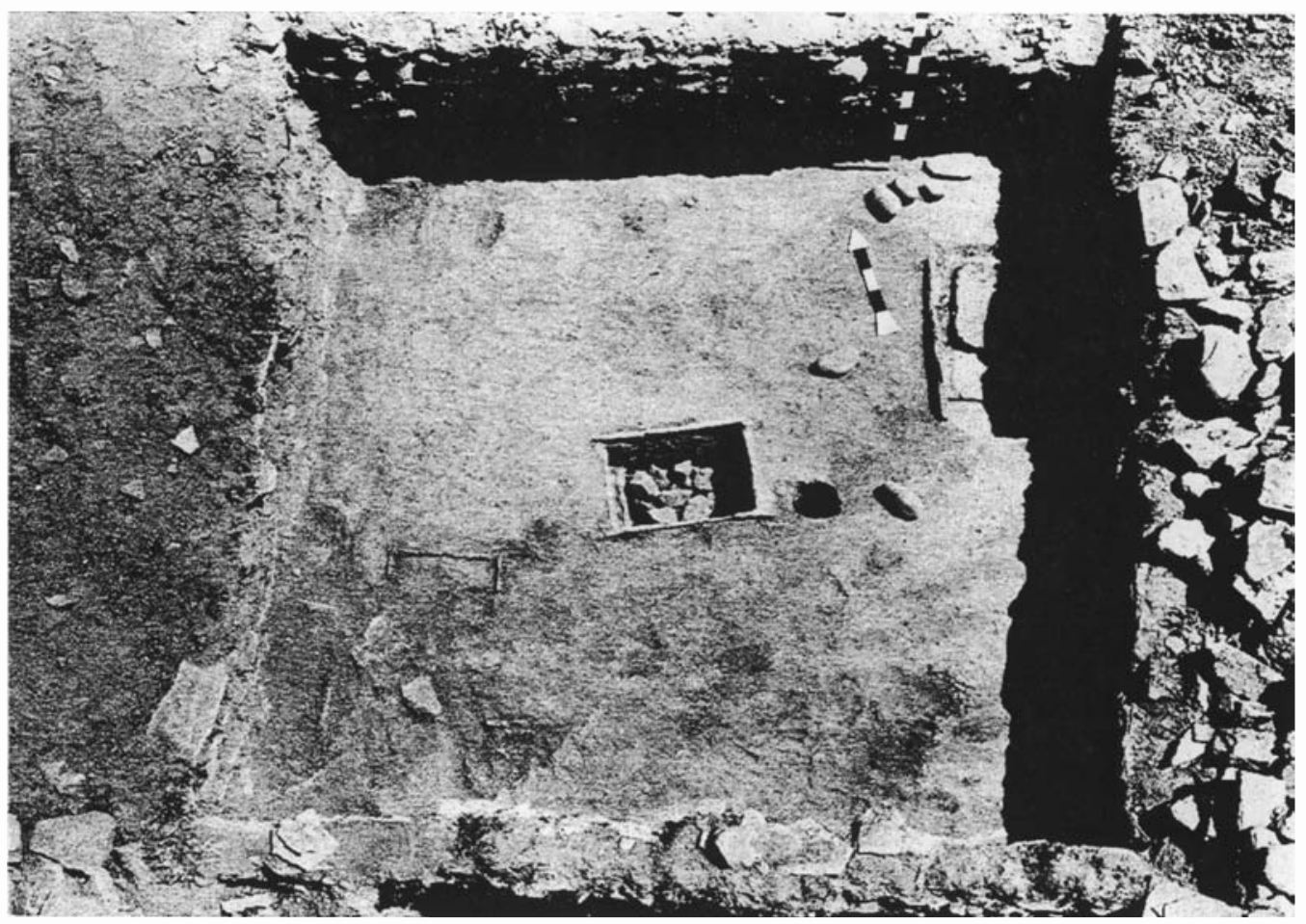

Figure 12. Typical habitation room. Note meter stick and directional arrow; arrow points to magnetic north. 
exhibited some of the attributes of both habitation and storage rooms, and they may actually represent functional overlap. For purposes of analysis, they were placed in the category to which they seemed most similar. All except Rooms 40 and 48 are considered to be storage rooms.

\section{Artifacts}

A number of significant attributes of these roomtypes have not yet been considered. These attributes are important, both in terms of verifying the validity of the room-types and in analyzing the functions of the different types (Chapter 9).

Consider the distribution of artifacts found on floors at the site, for example. Almost all of them were found in habitation rooms or kivas. Regardless of whether one examines the distribution of general artifact-density or the distributions of individual artifact-types, the result is the same.

An examination of Table 9 will make this quite clear. (The table lists all artifacts having a frequency greater than four specimens on floors.) The first thing to notice is that 11 of the 22 artifact-types are highly dominant in habitation rooms, to the virtual exclu- sion of other kinds of rooms. This suggests that the inhabitants of the village had used (or stored) about 50 percent of their nonperishable material items in the habitation rooms.

Secondly, no types of artifacts were highly dominant in storage rooms, and only one (antlerflakers) was dominant in kivas. However, eight types were fairly frequent in both habitation rooms and kivas, and two types were largely peculiar to habitation and storage rooms. Only one type (utilized flakes) was strongly associated with all three roomtypes.

These data thus suggest that the "tool kits" used in each type of room were as follows:

Habitation rooms: all types, except antler-flakers.

Storage rooms: utilized flakes, blades, and graverburins.

Kivas: projectile points, antler-flakers, utilized flakes, cores, choppers, scrapers, hammerstones, worked slabs, and ornamental items.

Several fairly obvious functional and sociological conclusions can be drawn from all of this; these are considered in Chapter 9.

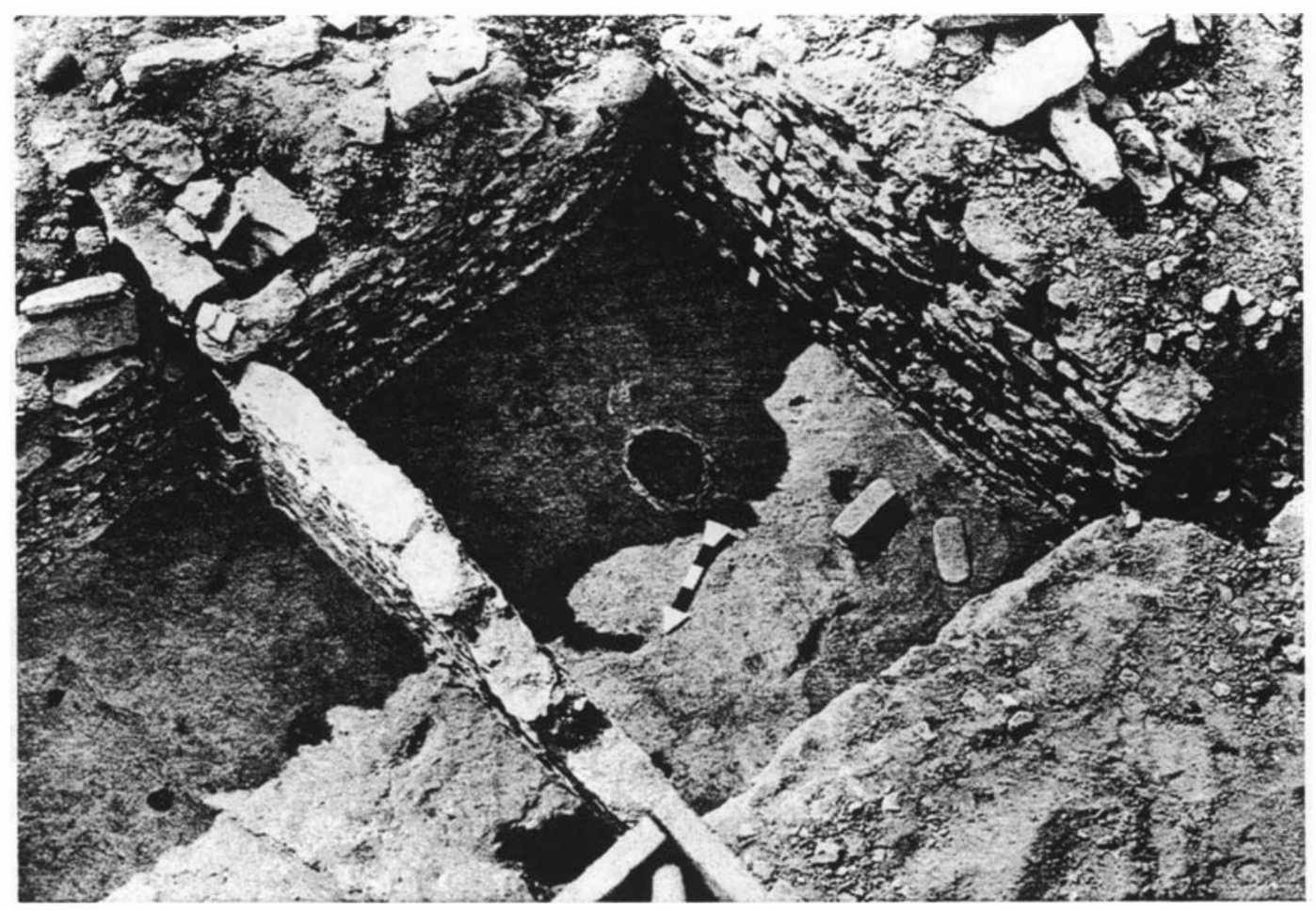

Figure 13. Typical storage room. Note meter stick and directional arrow; arrow points to magnetic north. 

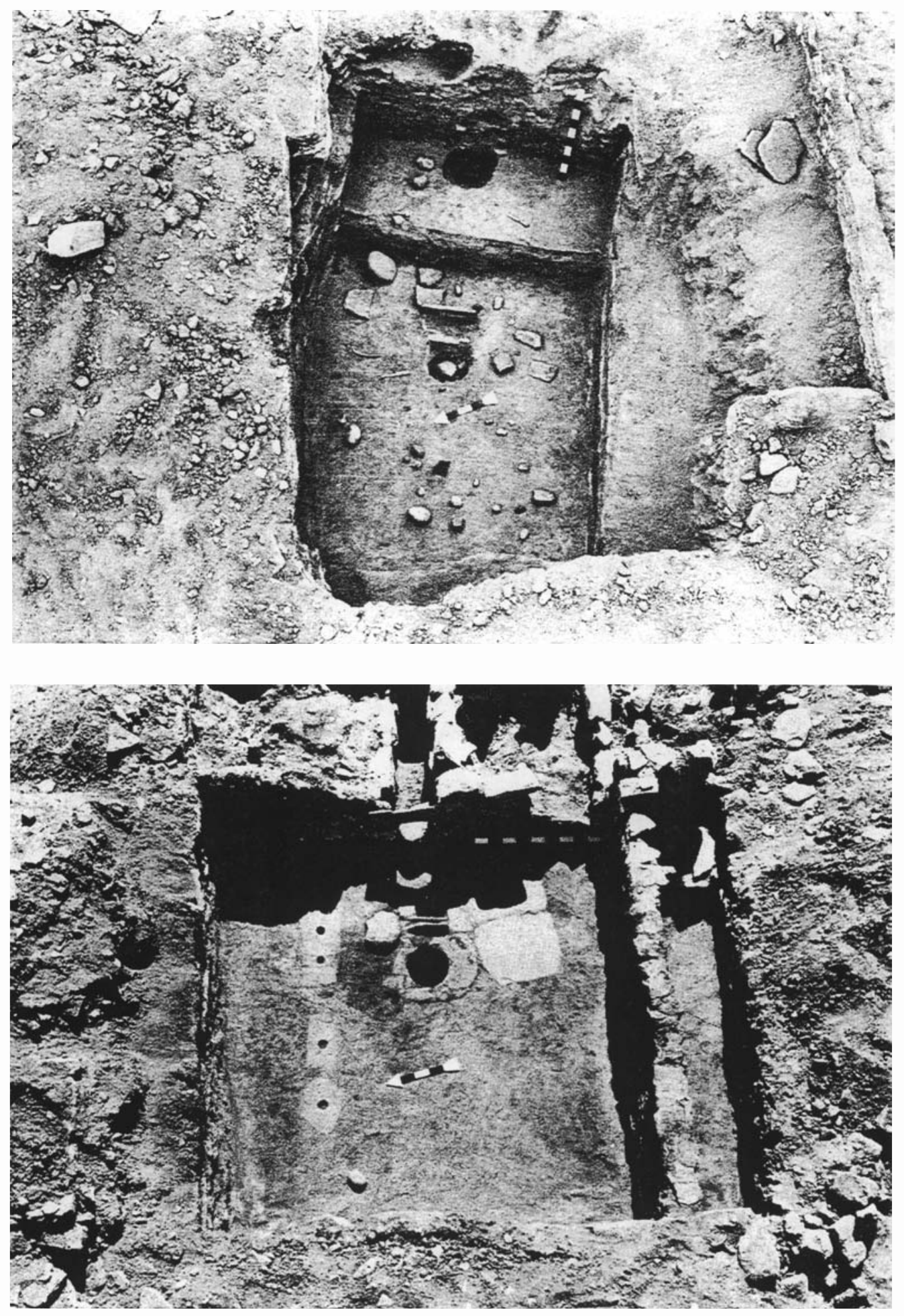

Figure 14. Top, a subterranean kiva; bottom, a room-type kiva (ceremonial room). Note meter sticks and directional arrows; arrows point to magnetic north. 
TABLE 9

Distribution of Artifact-type on Floors

\begin{tabular}{lcccrcrc}
\hline \multicolumn{1}{c}{ Artifact-type } & $\begin{array}{c}\text { Mean No. per } \\
\text { Habit. Room }\end{array}$ & $\begin{array}{c}\text { Mean No. per } \\
\text { Storage Room }\end{array}$ & $\begin{array}{c}\text { Mean No. per } \\
\text { Kiva }\end{array}$ & Total & $\begin{array}{c}\text { Dominant } \\
\text { Room-types }\end{array}$ \\
\hline Projectile points & 0.92 & 0.08 & 0.50 & 27 & $\mathrm{H}$ & $\mathrm{K}$ \\
Arrowshaft tools & .88 & .11 & .00 & 25 & $\mathrm{H}$ & \\
Antler flakers & .08 & .08 & .25 & 5 & & $\mathrm{~K}$ \\
Saws & .28 & .04 & .00 & 8 & $\mathrm{H}$ & \\
Graver-burins & .20 & .20 & .00 & 10 & $\mathrm{H}$ & $\mathrm{S}$ \\
Flake knives & 1.70 & .23 & .00 & 48 & $\mathrm{H}$ & \\
Bifacial knives & .20 & .07 & .00 & 7 & $\mathrm{H}$ & \\
Utilized flakes & 2.40 & 1.00 & 2.00 & 96 & $\mathrm{H}$ & $\mathrm{S}$ & $\mathrm{K}$ \\
Blades & .16 & .16 & .00 & 8 & $\mathrm{H}$ & $\mathrm{S}$ & \\
Cores & .92 & .23 & $1.50^{*}$ & 35 & $\mathrm{H}$ & $\mathrm{K}$ \\
Scrapers & 3.00 & .84 & $3.00^{*}$ & 108 & $\mathrm{H}$ & $\mathrm{K}$ \\
Choppers & 2.60 & .44 & $4.70^{*}$ & 96 & $\mathrm{H}$ & $\mathrm{K}$ \\
Axes & .32 & .00 & .00 & 8 & $\mathrm{H}$ & \\
Mauls & .28 & .11 & .00 & 10 & $\mathrm{H}$ & \\
Hammerstones & 3.70 & .69 & $2.00^{*}$ & 118 & $\mathrm{H}$ & $\mathrm{K}$ \\
Metates & 1.10 & .15 & .25 & 32 & $\mathrm{H}$ & \\
Manos & 6.60 & 1.00 & .25 & 192 & $\mathrm{H}$ & \\
Worked slabs & .88 & .15 & .75 & 29 & $\mathrm{H}$ & $\mathrm{K}$ \\
Worked sherds & 1.50 & .15 & .25 & 42 & $\mathrm{H}$ & \\
Bone awls & 1.60 & .27 & .25 & 48 & $\mathrm{H}$ & \\
Bone rings and & & & & & & & \\
$\quad$ ring material & 1.00 & .11 & .25 & 30 & $\mathrm{H}$ & \\
“Ornamental" items & .96 & .19 & .50 & 31 & $\mathrm{H}$ & $\mathrm{K}$ \\
\hline "Represts & & & & & & \\
\hline
\end{tabular}

*Represents 41-kiva primarily (early kiva).

NOTE: Detailed distributions of artifacts, by room and level, are given in Martin, Hill, and Longacre (1966).

\section{Lithic Waste}

During the excavation of Broken $\mathrm{K}$, the sifters caught 5,868 unutilized chert chips. These were lithic waste products of the manufacture of chert tools, and some were extremely small. They represented all stages or steps of manufacture, from blanks to finished products, and each chip was classified in accordance with the stage of manufacture it represented. It was hoped that a study of the spatial distribution of each of the types of chips would yield information concerning the specific areas of the site in which particular stages of manufacture had been carried out (Martin, Longacre, and Hill 1967: 122-125).

The results showed that most of these chips were in habitation rooms. Longacre found that 17 of 23 habitation rooms analyzed had an average of 127 chips per floor; the over-all average for habitation rooms was 98 chips per floor. The storage rooms averaged 30 per floor, but 17 of 25 of these rooms had only about 10 chips per floor. The kivas generally had 8 to 14 chips per floor, but $41-$ kiva had 98 of them.

This evidence suggests that lithic waste was primarily associated with habitation rooms rather than storage rooms or kivas, and the distribution of this material tends to further substantiate the classification of rooms.

\section{Animal Bone}

A further demonstration of the classification of rooms is found in the distribution of animal bone. A 
total of 3,681 bones (both identified and unidentified) were found on the floors of rooms. Of these, 2,895 were in habitation rooms, 671 were in storage rooms, and 115 were in kivas. The habitation rooms averaged 120 bones each, the storage rooms nearly 26 each, and the kivas about 29 each.

In comparing habitation rooms with the other room-types, however, it was decided that a correction should be made to compensate for the fact that the average floor-area was greater in habitation rooms than in storage rooms, and one would thus expect habitation rooms to contain more bones. Therefore, instead of using gross frequencies of bones, it was necessary to determine the numbers of bones per square meter of floor-area in each room (density).

The results were still highly significant. Almost all the habitation rooms contained more than two bones per square meter (usually much more), and the storage rooms and kivas generally had less than two bones per square meter. A chi-square test showed that this differential distribution was significant at the 0.001 level; in other words, there is only one chance in a thousand that it is accidental. There is thus almost no doubt that habitation rooms and animal bones were associated.

Similar tests were performed to find out whether any specific species or genera of animal bone were distributed in some other way-that is: Were there particular kinds of animals that were important only in storage rooms or kivas? The result was negative. All of the animals followed the same distribution pattern as did the combined bone counts (Appendix 1).

It is interesting to note, however, that the bone found in the fills of rooms did not follow this pattern. It seems to have been distributed in a random manner with respect to room-types, and it was of no use in developing a classification of rooms or in determining the functions of rooms. This is a clear demonstration of the fact that the floors of rooms must be kept separate from the fills, if we are to learn much about room-types and functions. Fill material may often reflect random distribution simply because it can be largely a result of indiscrim. inate trash dumping.

\section{Seeds and Pollen}

The next step in the analysis of room-types was an examination of the distributions of seeds and fossil pollen. The distribution of seeds was interesting in that over twice as many seeds (including charred corn) were found in habitation rooms as in storage rooms. Of a total of 352 seeds (not including the seeds in a fecal sample from Room 31-33) there were 233 in habitation rooms, 109 in storage rooms, and 10 in kivas. The average numbers of seeds for these rooms were $9.3,4.2$, and 2.5 , respectively. Furthermore, of the 20 rooms in which seeds were found, 14 were habitation rooms, 5 were storage rooms, and 1 was a kiva (Room 6-kiva). There is little doubt that seeds were primarily associated with habitation rooms rather than with storage rooms or kivas. This distribution is significant at the 0.01 level (probability of 0.99 ), and it may thus be considered nonaccidental.

With respect to pollen, however, a reversal of this distribution is evident. Economic pollen, at least, was much more common on the floors of storage rooms than on the floors of habitation rooms or kivas (Hevly 1964:91; Hill and Hevly 1968). Economic pollen includes Zea (corn), Cucurbita (squash), Cleome (beeweed), Opuntia (prickly pear), Oenothera (evening primrose), Sphaeralcea (mallow), Typha (cattail), Polygonum (buckwheat), and Cyperaceae (sedge). These are called economic simply because they were so common at Broken $\mathrm{K}$ that they were probably introduced by man (Hevly 1964:96).

Most of the storage room samples contained more than 43 grains of economic pollen each, while the habitation rooms generally had between 0 and 42 grains. A Fisher Exact Test (Fisher 1938:100-104; Siegel 1956: 96-104) revealed that this distribution is highly nonrandom. There is less than one chance in a thousand that it is in error. A separate test was performed using the frequencies of Zea and Cucurbita alone, with exactly the same results. Storage rooms clearly had most of the pollen of these two types.

One pollen-type, the Cheno-ams (Chenopods and Amaranths), clearly was most common in habitation rooms. The pollen samples from habitation rooms generally contained from 30 to 80 grains of this type, while the storage rooms usually had 10 to 29 grains. A Fisher Exact Test was used to show that this was valid ( 0.001 level).

The pollen content of the kivas was in many ways similar to that of the habitation rooms. Both of these room-types contained little economic pollen but had high concentrations of Cheno-am pollen. A minor difference between habitation rooms and kivas was that the latter contained relatively high concentrations of Ephedra (Mormon tea) and Eriogonum (buckwheat) (Hill and Hevly 1968). 


\section{Ceramics}

Further evidence supporting the room-type division made in this paper is found in the differential distributions of pottery-density, pottery-types, and ceramic design-elements.

First of all, there were simply many more sherds in habitation rooms and kivas than in storage rooms. After the frequency of sherds in each of the rooms had been converted to a density-figure, it was discovered that the habitation rooms and kivas generally contained more than three sherds per square meter, and the storage rooms usually had less than this. A chi-square test demonstrated that this was valid, with less than one chance in a hundred that no such association exists.

The same result was obtained whether the frequencies or densities of sherds were compared. When frequencies were used, it was found that the habitation rooms and kivas usually had more than 60 sherds, while storage rooms had significantly fewer.

The factor analysis of pottery-types also sheds some light on the subject of room-types. Factor 1 (Patterned Corrugated, Pinto Polychrome, and Brown Indented Corrugated) is clearly associated with habitation rooms. Of the total of 24 habitation rooms used in the analysis, 15 were positive in factor 1; of the 13 storage rooms used, 12 were negative in this factor. A chi-square test showed less than one chance in a thousand that this difference is insignificant (Fig. 16 , Map A).

Similarly, factors 2,3 , and 5 were shown to occur primarily in habitation rooms. The pottery-types involved in these factors, as well as in factor 1 , are listed as follows:

\begin{tabular}{|c|c|}
\hline Type & Vessel Form \\
\hline Patterned Corrugated & jars \\
\hline Pinto Polychrome & bowls \\
\hline Brown Indented Corrugated & jars \\
\hline $\begin{array}{l}\text { Brown Plain Corrugated, } \\
\text { smudged interior }\end{array}$ & bowls \\
\hline $\begin{array}{l}\text { Snowflake Black-on-White, } \\
\text { Tularosa variety }\end{array}$ & jars, bowls \\
\hline $\begin{array}{l}\text { Snowflake Black-on-White, } \\
\text { Snowflake variety }\end{array}$ & jars, bowls \\
\hline $\begin{array}{l}\text { Brown Indented Corrugated, } \\
\text { smudged interior }\end{array}$ & bowls \\
\hline McDonald Indented Corrugated & bowls \\
\hline $\begin{array}{l}\text { Snowflake Black-on-White, } \\
\text { Hay Hollow variety }\end{array}$ & bowls, jars \\
\hline
\end{tabular}

The factor most strongly associated with storage rooms was factor 6 (McDonald Plain Corrugatedbowls; St. Johns Polychrome-bowls). Of 13 storage rooms, 6 possessed this factor, but only 3 of 24 habitation rooms definitely had it. A Fisher Exact Test showed that this factor was primarily associated with storage rooms, with a probability of 0.95 (Appendix 5, Fig. A2).

The dominant factors in the kivas were as follows (in order of importance): Room 6-kiva, factors 7 and 4; Room 29-kiva, factors 1 and 4; 41-kiva, factors 4, 3 , and 7; and Plaza-kiva, factors 1 and 3. Thus, of a total of seven factors, four were commonly found in kivas (factors 1, 3, 4, and 7). Although none of them were found in all kivas, they do appear to represent the pottery types which the inhabitants of the site had most frequently used in kivas.

In comparing this group of factors with those in the other room-types, it will be noted that factors 1 and 3 were also common in habitation rooms. This similarity between kivas and habitation rooms ends here, however. Factors 2 and 5, which were very important in habitation rooms, were not present at all in the kivas. It is also notable that the "storage room factor" (factor 6) was absent in the kivas. Presumably, factors 2,5 , and 6 were not important ceremonially.

This comparison of room-types with regard to factor content becomes more clear when the dominant factors in each room-type are converted to their constituent pottery-types. Table 10 contains a list of all the pottery-types, together with the room-types in which each was commonly found.

It is clear that the pottery-type factors do not distribute in a random manner throughout the site. Particular room-types were found to contain generally distinctive constellations of pottery-types. This information will be useful in considering the functions of these room-types.

The design-element factor analysis (floors) will also be of some use in this respect, but the evidence is very meager. Most of the 13 factors were distributed in a random manner with respect to room-types. Factors 2, 5, and 13 were the only ones of much importance in this light, and all three of them were dominant in habitation rooms.

Factor 2 (Fig. 16, Map D) occurred in 13 rooms at the site, 10 of which were habitation rooms. Factor 5 (Fig. 17, Map I) was found in 12 rooms to some extent, 9 of which were habitation rooms. Factor 13 
TABLE 10

Pottery-types as Related to Room-types

\begin{tabular}{|c|c|c|}
\hline Pottery-type & Vessel-form* & Room-type \\
\hline Brown Plain Corrugated, smudged interior & B & Habitation \\
\hline Snowflake Black-on-white, Tularosa variety & $\mathrm{J}, \mathrm{B}$ & Habitation \\
\hline Brown Indented Corrugated, smudged interior & B & Habitation \\
\hline McDonald Indented Corrugated & B & Habitation \\
\hline Snowflake Black-on-white, Hay Hollow variety & $\mathrm{B}, \mathrm{J}$ & Habitation \\
\hline Patterned Corrugated & $\mathrm{J}$ & Habitation, Kiva \\
\hline Pinto Polychrome & B & Habitation, Kiva \\
\hline Brown Indented Corrugated & $\mathrm{J}$ & Habitation, Kiva \\
\hline Snowflake-Black-on-white, Snowflake variety & $\mathrm{J}, \mathrm{B}$ & Habitation, Kiva \\
\hline Brown Plain Corrugated & $\mathrm{J}$ & Kiva \\
\hline St. Johns Black-on-red & B & Kiva \\
\hline McDonald Plain Corrugated & B & Storage \\
\hline St. Johns Polychrome & B & Storage \\
\hline
\end{tabular}

*Abbreviations refer to bowls and jars - in order of frequency of occurrence.

(Fig. 17, Map F) was significant in 8 rooms, all of which were of the habitation variety.

All three of these factors primarily are indicators of the loci of social groups (Chapter 10). Thus, they are attributes of room-types within certain localized areas of the site rather than having pan-village significance.

Although no design-element factors were peculiar to kivas, it is also true that not all of the factors were of equal importance in kivas. The significant factors found in each of the three kivas used in this analysis (in order of importance) were: Room 6-kiva, factor 3; 41-kiva, factors 7, 3, and 6; Plaza-kiva, factors 5 and 6 . It is reasonable to infer that the design-elements constituting factors $3,5,6$, and 7 were decorative aspects of ceramic vessels used in ceremonial activities, and that they might even have had some ceremonial significance of their own. Since these elements were found in other rooms throughout the site, however, they presumably had other significance as well.

\section{Summary and Comments}

The evidence presented in this chapter demonstrates the existence of three basic types of rooms at Broken K Pueblo-presumed to be habitation, storage, and ceremonial rooms. Although six of the rooms were difficult to classify, the basic classification is considered remarkably good. It will be useful at this point to summarize the principal characteristics of each type.

The habitation rooms were the largest at the site, ranging from about 6.5 to 33.5 square meters in floor-area. Generally, each contained a vertical, slablined firepit and a slab-lined mealing bin; a number of them had ventilators. They contained most of the pottery at the site, although the kivas also contained relatively high densities of pottery. In addition, they contained most of the artifacts, lithic waste, animal bone, and seeds. Considering all of the categories recovered from the site, it is evident that most of them were primarily associated with the habitation rooms rather than with the storage rooms or kivas.

The storage rooms were characterized as being the smallest rooms at the site, ranging in size from 2.5 to 6.5 square meters in floor-area. They generally lacked any of the floor features found in habitation rooms, and they contained only small quantities of most of the other materials discussed. In other words, one of the most important attributes of storage rooms was the fact that they contained very little of almost everything. They did, however, contain much more 
economic pollen than did the other two room-types; this fact will be of some significance in the next chapter.

The ceremonial rooms, or kivas, did not present a classificatory problem. Their function would have been obvious to most Southwestern archaeologists and ethnologists. In terms of floor-area, they fell within the range of habitation rooms, but their distinctive features would not permit them to be confused with this room-type. The artifacts found on the floors of kivas were not very different from those found in the habitation rooms, except that fewer artifact-types were represented. These types included projectile points, antler-flakers, utilized flakes, cores, choppers, scrapers, hammerstones, worked slabs, and "ornamental" items.

The kivas were also similar to the habitation rooms in having relatively high densities of sherds, large amounts of Cheno-am pollen, and very small amounts of economic pollen. They were similar to the storage rooms in that they contained few animal bones or seeds.

Each of the room-types contained its own constellation of dominant pottery-types. The design-element factors, however, distributed in an almost random fashion. Three design-element factors were peculiar to habitation rooms, but they were not common to all of the habitation rooms at the site.

The three room-types recognized at Broken $\mathrm{K}$ are not peculiar to that site, or even to eastern Arizona. Archaeologists have recognized them in many areas of the Southwest (Bluhm 1957:126, 138-47). They first appear in the archaeological record at about A.D. 800 (Bluhm 1957:148), and all three types are still used by most of the Puebloan peoples of today.

This continuity becomes obvious when one compares the rooms at Broken $\mathrm{K}$ with their equivalent types among the Hopi Indians of recent years. Each Hopi "family" has at least one habitation room and one storage room (Beaglehole 1937:5). The habitation room generally contains a fireplace, two or three mealing bins, and two or three water jars, or ollas (Mindeleff 1891:109-10). The storage rooms are usually smaller than the habitation rooms (Mindeleff 1891:144; Forde 1931:393) and presumably have no significant features other than their stored contents.

Hopi kivas are also similar in appearance to those at Broken $\mathrm{K}$. They are rectangular subterranean structures, generally possessing a roof-entrance, a firepit, a ventilator, some wall-niches, and a bench or platform at one end (Mindeleff 1891; Donaldson
1893:55; Parsons 1936:719-22). Although these kivas are somewhat larger than those at Broken $\mathrm{K}$, there is little doubt that they represent the same kinds of structures and presumably the same kinds of uses.

Most Hopi ceremonies are carried out, at least in part, in these subterranean kivas. A few rites, however, are conducted in the main houses of the clans in charge of the ceremonies (Titiev 1944:103). Each clan in a village has such a "clanhouse." It is regarded as the "home" of that clan in the village; it is here that the headwoman of the clan usually lives, and the clan meetings are held. The ritual paraphernalia used in clan controlled ceremonies is also kept here (Parsons 1936:XXXII; Eggan 1950:62).

There is some evidence for the existence of clanhouses at Broken $\mathrm{K}$, although the evidence is inconclusive. It is possible that the so-called roomtype kivas (Room 6-kiva and Room 29-kiva) served this function. They were certainly surface rooms, and they possessed many of the features common to kivas. It is also possible, however, that the extremely large habitation rooms previously mentioned were clanhouses. If clanhouses did exist at Broken K, they were almost certainly represented by one of these two kinds of rooms.

In any event, it seems reasonably clear that the three basic room-types discovered at Broken $\mathrm{K}$ are also the basic room-types among the modern Hopi. An examination of the Zuni data yields similar comparative results, but the similarities are not so clear-cut. While the three basic room-types evidently exist at Zuni, there seems to have been enough functional overlap to cloud any exact identification. Nevertheless, each room seems to have a primary function or group of functions, and there is some basis for dividing the rooms into types.

The largest room in a Zuni household is usually an all-purpose habitation room, containing a fireplace and three or more mealing bins (Stevenson 1904:292-93). The storage rooms are somewhat smaller, as was the case at Broken $\mathrm{K}$; but unlike the Broken $\mathrm{K}$ storage rooms, they often contain fireplaces and large slab-lined storage bins (Stevenson 1904: 292-93, 352). The fireplaces, however, are not the same type as in the habitation rooms, and this is interesting because the few firepits found in storage rooms at Broken $\mathrm{K}$ were also quite unlike the ones in living rooms.

Subterranean kivas are no longer used at Zuni (Kroeber 1917:197), but folk tales indicate that they were once used for all ceremonies (Bunzel 
1932a:878). Today, kiva activities are carried out in ordinary large surface-rooms. There is little structural evidence to distinguish these rooms as different from other large rooms beyond the fact that each has a special fireplace and a trap-door entrance (Mindeleff 1891: 112). These rooms may be analogous to the Hopi clanhouses, but it is clear that they also function as kivas.
Enough has been said to indicate that both the Hopi and Zuni make use of the three basic roomtypes-habitation, storage, and ceremonial. A few relatively minor structural differences exist between these room-types and their presumed equivalents at Broken $\mathrm{K}$, but this is to be expected. There are so many formal similarities that it is probably safe to assume some similarities in function. 


\section{ROOM FUNCTIONS}

Using the distributions of features, artifacts, and non-artifact materials presented in the preceding chapter, it should be possible to make some statements about the functions (uses) of the three basic room-types.

The success of such an analysis will, of course, depend heavily on our ability to assign functional meaning to the various artifacts and other materials involved-and this is not always possible. Even when it cannot be done, however, some functional information can be obtained from an examination of the differential distributions of the items. Binford (1965:206) has stated this idea as follows: "Even in cases where specific functions cannot be determined for the recognized types, the spatial configuration of their occurrence tells something of the spatial structure of differentiated activities within or between sites."

In short, if a particular category of artifact is found consistently in the same kind of location (for example room-type), it is reasonable to infer that that type of artifact represents an activity or function carried out in such locations, even though the exact nature of the activity represented is not known.

This will simply be assumed in this study, and there will be few attempts to make guesses concerning the possible functions of items for which no functional evidence is available. Some guesses will be made, however, since the functions of a few artifacts seem reasonably deducible. On the other hand, in a number of cases it will be possible to use ethnographic evidence of the functions of types, and this is clearly most reliable.

The organization of this chapter is in terms of room-type. Each room-type is discussed separately, and each of the functions involved is considered in turn. A brief summary of the results is given at the end of each of the major sections.

In addition to discussion of the functions of the room-types per se, there is a discussion of the functions of the plaza and a brief consideration of the functions of the outliers (the five units located outside the pueblo proper).

\section{Habitation Rooms}

As previously pointed out, the habitation rooms contained by far the largest numbers of almost everything found on the floors of rooms at the site. In fact, if the four excavated kivas are ignored, one gets the impression that the inhabitants of Broken $\mathrm{K}$ carried on most of their activities in the habitation rooms. They were living rooms par excellence.

\section{Food-Preparation}

Food-preparation was almost certainly a function of the habitation rooms. One of the most important indications of this is the fact that most of the mealing bins, metates, and manos were in these rooms. Many habitation rooms contained two or three mealing bins side by side; one room (92) had four of them. Whenever a room had two or more bins containing metates, the metates were found to vary in the coarseness of their grinding surfaces; this would seem to indicate that at least two stages were involved in the food-grinding process.

Perhaps the most important reason for believing that the mealing-bin-metate-mano combination was used in food-preparation comes from the ethnographic evidence. Pueblo Indian women throughout the Southwest use these tools in grinding corn and other plant materials into flour for use in the diet (Mindeleff 1891:211-12). And furthermore, just as at Broken $\mathrm{K}$, the metates vary in degree of roughness, depending on the stages of grinding for which they are used (Mindeleff 1891:212).

Another indication that these artifacts represent food-preparation at Broken $\mathrm{K}$ lies in the fact that a number of edible seeds were recovered from the basins, or bottoms, of the mealing bins (Appendix 3). of 12 different types of seeds found in these locations, 7 are eaten by the modern Hopi or Zuni Indians. These include the following plants (Stevenson 1909; Whiting 1939): Amaranthus (pigweed), Chenopodium (goosefoot family), Cucurbitaceae (squash), Cycloloma (goosefoot family), Opuntia (prickly pear), Juniperus (juniper), and Zea (corn). Of the other five types of seeds recovered from mealing bins, two are used medicinally and ceremonially by the Hopi and Zuni, and three apparently are not used.

Pollen samples collected from mealing bins yielded pollen from 16 different kinds of plants, at least 9 of which are eaten by the Hopi and Zuni. Those which are eaten are listed as follows (Stevenson 1909; Whiting 1939): Cheno-ams (Chenopods and 
Amaranths), Cleome (beeweed), Compositae (lowspine and high-spine, incl. Artemisia), Cucurbitaceae (squash), Gramineae (grasses), Juniperus (juniper), Opuntia (prickly pear), Pinus (pinyon pine, P. edulis), and $Z e a$ (corn). At least three of these plants were not represented by seeds in the mealing bins. Why they should be represented by pollen alone is not clear, since it is usually the seeds of plants that are ground today. It may be, of course, that the flowers were ground for various nondietary purposes. In any event, most of the pollen recovered from the mealing bins at Broken $K$ represents plants that are eaten by the western Pueblos today, and this is offered as evidence that the prehistoric inhabitants of the site utilized mealing bins in the preparation of food.

It is noteworthy, in this connection, that all of the above listed plants were present in the fecal sample from Room 31-33, so the evidence is even stronger that they were being prepared for dietary use.

Vegetal foods were not the only foods prepared in habitation rooms, however. Judging from the great preponderance of animal bone found in these rooms, a great deal of butchering may have gone on. Seventy-seven percent of the animal bone found on floors at the site came from the habitation rooms, while only 18.3 percent came from storage rooms and only 3.1 percent from kivas (and 1.6 percent from the plaza). Although this evidence does not constitute proof that butchering was being carried out in the habitation rooms, it suggests that at least certain stages of the butchering process were being carried out in these rooms. It is possible, of course, that these data simply show that animals were being cooked or eaten, rather than being butchered in these rooms. There is no evidence, however, that butchering was done anywhere else in the site, or near it.

Furthermore, it is probably no accident that the tools logically associated with butchering are found predominantly in habitation rooms. Of all of the artifacts listed in Table 9, three would seem to be useful for butchering-saws (Rinaldo 1964b:87), flake knives, and choppers. All three were clearly dominant in habitation rooms.

Another function of great importance in the habitation rooms was cooking. One reason for believing this is that most of the firepits were found in these rooms. Although eight large firepits or roasting pits were located in the plaza, there probably were not enough to provide cooking fires for the entire population of the site. Furthermore, there were no burned bones, charred corncobs, or other evidence that these pits had been used in the routine task of cooking-although some cooking must have been done in them.

The habitation rooms, on the other hand, contained many burned bones and charred corncobs. There were 179 fragments of burned bone, most of which were found in habitation rooms (chi-square 0.001 level). Of 37 charred corncobs, 28 were in these rooms (chi-square 0.001 level).

Further evidence that cooking was done in habitation rooms lies in the fact that most of the textured (utility) pottery was found in these rooms (or in kivas) rather than in storage rooms. This pottery is unpainted, and in that sense it is similar to the undecorated cooking pots that have in the past been used by the Hopi (Parsons 1936:1190) and presumably by the Zuni (Donaldson 1893:127). Although no systematic record was kept concerning the distribution of sherds exhibiting evidence of exterior burning (and thus cooking), it was clear that most such sherds did occur in the habitation rooms.

The ethnographic evidence concerning the loci of cooking activities is not as clear as it might be. Apparently the Hopi situation is much like that at Broken $\mathrm{K}$, with the cooking being done on fireplaces in the living rooms. Some cooking, however, is done in other rooms (Eggan, personal communication). Among the Zuni, cooking may be done in more than one room in any given household, and sometimes there is a special room for it (Cushing 1920:295-96).

\section{Eating}

Although the evidence is meager, it would seem that the inhabitants of Broken $\mathrm{K}$ also did much of their eating in habitation rooms. This is suggested by the already established fact that most of the animal bone and charred corn was recovered from these rooms. There is little evidence of anything that might be called dietary remains in the other room-types.

In addition to this evidence, most of the ceramic vessel forms that would have been useful in serving food were found in habitation rooms. Presumably, food would be served in bowls, and the dominant pottery-type factors in habitation rooms consisted largely of bowls. This is not surprising, considering the ethnographic evidence. The Hopi and Zuni, at least until fairly recently, are known to have used bowls in both the preparation and serving of food (Donaldson 1893:127-28; Cushing 1920:296, 313; Brainard 1935:267; Beaglehole 1937:57-65; Roberts 1956:15). 
Even more interesting, however, is the fact that most of the bowls with smudged interiors occurred in habitation rooms at Broken $\mathrm{K}$. In fact, of a total of four types of bowls having smudged interiors, three were found primarily in habitation rooms (Brown Plain Corrugated, smudged interior; Brown Indented Corrugated, smudged interior; McDonald Indented Corrugated). Such vessels are almost always used for serving food among historic Pueblo groups (Alfonso Ortiz, San Juan Pueblo, personal communication).

\section{Water Storage and Use}

In addition to using ceramic vessels in the preparation and serving of food, the inhabitants of Broken $\mathrm{K}$ probably also used them for carrying and storing water. The nearest source of water was probably not less than 300 yards from the village, so that some kind of transportation and storage vessel would have been necessary. It may also be presumed that such vessels would possess relatively small orifices, so that the water would not easily spill. This would eliminate bowls, of course, and it would also prouably elim. inate jars with relatively large orifices.

An examination of the different kinds of large, "olla"-type jars at Broken $\mathrm{K}$ revealed that most of those fitting this description were found in habitation rooms. This was clearly shown in the factor analysis of pottery-types. Snowflake Black-on-white (Tularosa variety), Snowflake Black-on-white (Hay Hollow variety), and Snowflake Black-on-white (Snowflake variety) are the only types entering into the factors which possess narrow-necked jars, and they belong in factors that were clearly associated with the habitation rooms. (Although Snowflake Black-on-white, Carterville variety, did not enter into any of the factors, it was also most common in habitation rooms.) It is true that Snowflake Black-on-white (Snowflake variety) jars were also found in kivas, but this may simply mean that water was stored and used in these rooms too.

Turning to the ethnographic data, it is clear that the Hopi and Zuni used large jars in the transportation and storage of water (Brainard 1935:72; Parsons 1936:614); but there is apparently no evidence concerning the types of rooms in which they were used. It is noteworthy, however, that these vessels were decorated (Parsons 1936:1190; Beaglehole 1937:57, 72), and the ones found at Broken $K$ were also decorated. The undecorated (textured) jars at the site tend to have relatively large orifices and were probably not used to contain water.

In conclusion, it would appear that water storage, and presumably use, were functions associated primarily with the habitation rooms at the sitealthough the kivas may have had this function too. One would certainly expect the habitation rooms to have this function, since water would be important in the preparation of food, as well as for drinking.

\section{Manufacture of Hunting Tools}

Another important function carried on primarily in the habitation rooms was the manufacture of hunting equipment. Like so many of the artifacts recovered from Broken $\mathrm{K}$, the ones which seem to be related to hunting activities were far more common in habitation rooms than anywhere else, except perhaps the kivas (especially 41-kiva).

Of all of the artifact materials recovered, the ones most logically related to hunting are the hammerstones, cores, lithic waste, antler-flakers, arrowshaft tools, and projectile points. Their primary importance in habitation rooms has already been demonstrated (Table 9).

This evidence suggests that all of the stages involved in the making of hunting tools, from the preparation of cores to the finished products, were carried out in these rooms as well as in the kivas; it also suggests that both the manufacturing tools and the finished products were kept in these rooms when not in use. Unfortunately, no ethnographic data were found that would permit comparison of this information with the present-day Hopi or Zuni.

\section{Other Functions}

Several other functions were carried on in the habitation rooms, of course; and while it is not possible to isolate them all, a few can be partially documented.

One of these is the manufacture of pottery. The evidence for this is that most of the "worked sherds" were found in habitation rooms (Table 9). In fact, of a total of 42 worked sherds found on floors at the site, only 4 were in storage rooms and none in kivas. The plaza contained 4 of them, but they were not found on any identifiable floor.

Haury has suggested that worked sherds may have been used for smoothing pottery before it was fired, just as the recent Pueblo women use scrapers of 
gourd-rind (Rinaldo 1964b:105). If this is correct, then the women of Broken $\mathrm{K}$ may have been carrying on at least one stage in the pottery-making process in their habitation rooms.

Another function that may have been performed in these rooms is the manufacture of ground and pecked stone implements such as metates and manos. The only evidence for this is that most of the hammerstones were found in habitation rooms (Table 9). It has already been suggested that hammerstones may have been used in the manufacture of hunting tools, but there is ethnographic evidence for their use in roughening the grinding surfaces of manos and metates (Rinaldo 1964b:73).

Another activity that may have been carried on in the habitation rooms is the manufacture of ornamental items. Most of these items, including bone-rings, occurred in the habitation rooms (Table 9). It was also discovered that the bone-ring material, or the bone material from which the rings were being cut, was most common in these rooms.

There were various other artifacts which might have been useful in this analysis, except for the fact that their functional meanings seemed even more obscure than those already discussed. Almost all of them, however, were found predominantly in habitation rooms, thus implying some kind of relationship with those rooms.

The only other function of the habitation rooms that can presently be discussed is that of sleeping. Although the evidence is indirect, it seems reasonably certain that people slept in them. Because these rooms and the kivas were the only rooms containing firepits, it is probably a good guess that they were utilized for sleeping, during the cold winter months at least. The present-day Pueblo Indians clearly use their living rooms for this purpose (Stevenson 1904:292-93; Judd 1954: 40), although they sometimes sleep in storage rooms too (Roberts 1956: 11, $45-46,80-81$ ). It is not always true, however, that the rooms are heated (Eggan, personal communication).

\section{Storage Rooms}

When Southwestern archaeologists talk about storage rooms, they do not always mean that they have found concrete evidence that items were actually stored in such rooms. In some cases, of course, this evidence is available, in the form of piles of corncobs or other materials. In other cases it must simply be assumed that small, featureless rooms were storage rooms-because it is difficult to imagine their being used in any other way.

Although this problem is often recognized, there has been no generally satisfactory solution of it. A colleague recently pointed up the problem when he said, referring to some storage rooms he had excavated, "there was nothing in their features or contents to suggest this use [storage] as they contained no more corn than the "dwelling rooms" "(Rinaldo 1964a:33).

This is not as hopeless a problem as it might appear. It has been possible to demonstrate, at Broken $\mathrm{K}$ at least, that such rooms actually did serve as storage facilities. The demonstration is largely palynological.

\section{Storage of Food}

Although the storage rooms generally contained no features and few artifacts, they did contain tremendous amounts of pollen. Most of this pollen was economic, in the sense that it occurred in such great quantity that it must have been introduced by man. The habitation rooms and kivas, on the other hand, had much smaller quantities of economic pollen.

The most interesting aspect of this, however, is the fact that Zea and Cucurbita pollen were much more common in the storage rooms than in the habitation rooms or kivas. These pollen-types definitely represent domesticated corn and squash. Their great density in storage rooms clearly suggests that these crops were stored in these rooms.

It is difficult to imagine any alternative interpretation, because there is no evidence indicating that these crops were processed, cooked, or eaten in these rooms. Furthermore, the rooms were small and often did not have doorways; they must have been dark and generally inconvenient for any activity other than storage.

There is some additional logical evidence too. One would expect that when corn and squash were brought in from the fields for storage, a certain amount of pollen might have been carried in with them-either in the form of the flowers themselves, or by merely clinging to the produce. Then, as the crops were being stacked in the storerooms, some of the pollen would fall onto the floor. Finally, as the crops began to dry out, any flowers that had been introduced might also fall to the floor, depositing 
large amounts of pollen. By the time the crops were needed as food, much of the pollen would presumably have been deposited on the storage-room floors, and very little would find its way into the habitation rooms.

Obviously, this argument is hypothetical, but it is certainly a possible explanation of the pollen distribution (Richard H. Hevly, University of Arizona, personal communication). In any event, the fact that the storage rooms contained most of the economic pollen is, in itself, sufficient evidence for believing that they were used for storage.

But why were there not more seeds found in storage rooms? Over twice as many seeds were found in habitation rooms as in storage rooms. Again, the answer is merely a logical one. Seeds are generally small and difficult to handle individually. Presumably they would be stored in containers, such as jars or bowls. Being thus enclosed, few would have spilled onto the floors of storage rooms; but when they were brought out for use, they would have been handled frequently and sometimes spilled. As they were ground into flour, some would probably fall to the floor near the mealing bin, and some would collect in the basin of the bin. In short, seeds would tend to be handled more frequently in living rooms than in storage rooms, and this would presumably increase the chances of spillage.

The ethnographic evidence concerning the storage of food is fairly clear. Among the Hopi and Zuni, the primary function of storage rooms is the storage of food crops (Mindeleff 1891:14344; Cushing $1920: 167,171-73,179)$. The most important crops stored are corn, squash, beans, fruit, and cotton (Beaglehole 1937:43-44).

Among the Hopi, corn is usually dried, and the cobs are stored in stacks on the floor. Beans are stored in sacks (formerly pots) and sometimes in small holes dug into the floors of the storerooms. Squash is cut into strips, dried, and hung from the rafters. Seed corn, for the next season's planting, is also hung from the rafters, while reserve squash seeds are kept in clay jars or boxes (Forde 1931:393-94; Beaglehole 1937:43-45). The Hopi also store jerked meat in their storage rooms (Titiev 1944:194).

A similar situation is found among the Zuni, except that they store some grains, especially wheat, in large slab-lined bins or large jars (Stevenson 1904:352). The similarities between Hopi and Zuni with respect to the storage of food are remarkable, and it seems likely that the inhabitants of Broken $K$ Pueblo followed a similar pattern.

It is interesting to note, however, that while the Hopi and Zuni frequently store food in large jars (Cushing 1920:208; Bunzel 1929:41), the Broken K people seem to have used mostly bowls. As shown in the preceding chapter, the only pottery-types dominant in storage rooms were McDonald Plain Corrugated and St. Johns Polychrome, both of which consist of bowl forms only (Hill 1968).

\section{Storage of Non-food Items}

There is little evidence that the storage rooms at Broken $\mathrm{K}$ Pueblo were used to store anything but food. To be sure, a number of different kinds of artifacts were represented in these rooms (Table 9), but it is unlikely that many of them were being stored. Perhaps most important is the fact that of 29 different types of pollen found at the site, nearly all were found to some degree in the storage rooms (Hill and Hevly 1968). Judging from the ethnobotanical evidence (Stevenson 1909; Whiting 1939), many of these pollen-types do not represent plants that were eaten by the inhabitants of the site; it is thus not likely that they were being stored as food crops.

In any event, it is almost certain that many items that were stored in the Broken $\mathrm{K}$ storage rooms have not been preserved for archaeological identification. This is suggested by the fact that the Zuni (and presumably the Hopi) store their ceremonial paraphernalia in such rooms (Stevenson 1904:352). In fact, Stevenson was able to say that "A Zuni storage room ... contains a promiscuous mass of material ranging from objects of the most sacred character to those of little or no value" (1904:352).

\section{Other Functions}

If it were not for the palynological evidence concerning the functions of storage rooms at the site, it would not be possible to discuss their functions at any length.

The three types of artifacts found in these rooms (Table 9) are of no value in determining room function, since their own functional meanings are not known. Furthermore, two of the types (graver-burins and blades) occurred in such small numbers that their appearance in storage rooms could be ascribed to accident. The third type (utilized flakes) was more common, averaging about 1.0 per storage room; but this is less than half the number found in habitation 
rooms. Thus, regardless of the uses to which utilized flakes were put, they probably do not represent functions which were in any way peculiar to storage rooms.

This evidence does suggest, however, that other functions besides storage were occasionally carried out in these rooms. This is clearly the case among the modern western Pueblos. At Zuni, for example, a storeroom may also serve as a workroom, bedroom, or kitchen (Roberts 1956:11, 45-46, 80-81). Thus, it is obvious that rooms can be multifunctional.

\section{Ceremonial Rooms}

Ceremonial rooms, among the Hopi and Zuni, serve other functions than simply religious ones. Their use is reserved primarily for males, and they serve as male clubhouses and craft-centers (Mindeleff 1891: 130). The men do their weaving in these rooms, for example, and they discuss important matters of public concern (Mindeleff 1891:130). Considering the architectural similarities between these kivas and the ones at Broken $\mathrm{K}$, it is reasonable to believe that there were functional similarities as well.

\section{Ceremonial Function}

That the kivas at Broken $\mathrm{K}$ served a ceremonial function seems clear and need not be argued in detail. Aside from the many general architectural similarities to Hopi and Zuni ceremonial rooms, two specific similarities are indicative of ceremonial activity. In the first place, most of the Broken $\mathrm{K}$ kivas had wall niches. The Hopi use such niches to contain "idols" or fetishes (Donaldson 1893: 55). Secondly, each kiva at Broken $\mathrm{K}$ had a bench at the east end of it; the Hopi kivas have a somewhat similar raised area, on which spectators watch the ceremonies (Titiev, personal communication).

In addition, palynological information suggests a ceremonial function for the Broken $\mathrm{K}$ kivas. The pollen content of the kivas was in many ways similar to that of the habitation rooms (Hill and Hevly 1968). As previously noted, however, a major difference was in the fact that the kivas had greater concentrations of Ephedra and Eriogonum pollen. More pollen of these two types was found in the kivas than in the other rooms at the site (Appendix 4). Both of these plants have historically had ceremonial and medicinal uses among the Hopi and Zuni Indians (Stevenson 1909; Whiting 1939). Their presence in the kivas lends support to the idea that these rooms were indeed ceremonial rooms.

In addition, several other pollen-types in these rooms might indicate a ceremonial or ritual function. These are listed in Table 11. (See also Appendices 2 and 4; Stevenson 1909; Whiting 1939.) It is important to stress the point that these pollen-types were not found primarily in kivas. Several-especially Chenopodium and related plants (Chenopodiaceae)occurred significantly in the habitation rooms.

It is interesting to note that the Broken $\mathrm{K}$ kivas contained little pollen from domestic plants. There is ample evidence that the present-day Hopi use large amounts of domestic pollen, especially corn pollen, in their kivas (Parsons 1936: 595,608). Often, in fact, entire corn plants, bean plants, and squash plants are

TABLE 11

Pollen-types Possibly Indicative of Ceremonial-Ritual Function

\begin{tabular}{|c|c|}
\hline Pollen-type & Ceremonial Use \\
\hline $\begin{array}{l}\text { Artemisia (sagebrush or } \\
\quad \text { wormwood) }\end{array}$ & $\begin{array}{l}\text { Prayer sticks (Hopi); used } \\
\text { in dance, "The Coming of } \\
\text { the Corn Maidens" (Zuni) }\end{array}$ \\
\hline $\begin{array}{l}\text { Chenopodium (goosefoot } \\
\text { family) }\end{array}$ & $\begin{array}{l}\text { Main kiva fuel, "grease- } \\
\text { wood" (Hopi); Prayer } \\
\text { sticks, for abundance of } \\
\text { cottontail (Zuni) }\end{array}$ \\
\hline Cleome (beeweed) & $\begin{array}{l}\text { Prayer sticks (Hopi and } \\
\text { Zuni) }\end{array}$ \\
\hline $\begin{array}{l}\text { Compositae, Low-spine } \\
\text { (ragweed and } \\
\text { cocklebur types) }\end{array}$ & $\begin{array}{l}\text { Ground for certain } \\
\text { ceremonies (Zuni) }\end{array}$ \\
\hline Polygonum (buckwheat) & $\begin{array}{l}\text { Root ground and used in } \\
\text { physical purification, and } \\
\text { as an emetic (Zuni) }\end{array}$ \\
\hline Sphaeralcea (mallow) & $\begin{array}{l}\text { Used in a "tea" drunk } \\
\text { each evening during a } \\
\text { ceremony of the Sword } \\
\text { Swallower's Fraternity } \\
\text { (Zuni) }\end{array}$ \\
\hline Typha (cattail) & $\begin{array}{l}\text { Ceremonially important } \\
\text { as a plant associated with } \\
\text { water (Hopi) }\end{array}$ \\
\hline
\end{tabular}


brought into the kivas, and these crops are even germinated in kivas (Forde 1931:398; Parsons 1936: 188, 287, 623, 690; Titiev 1944:166). Why these domestic plants were not represented to any great degree in the kivas at Broken $\mathrm{K}$ is not known, but it is clear that many wild plants were represented. It may be that the inhabitants of the site were simply not depending on domesticates as much as on wild products for their food. For this reason, perhaps, domesticates were not as often represented ceremonially. This idea is given some credence in Chapter 14 .

Further evidence that may suggest ceremonial functions for the kivas lies in the distinctive constellation of pottery-types they contained. The mere fact that this constellation is largely different from those in the other room-types indicates that at least something was functionally different in the kivas, whether the pottery was ceremonial or not.

There is, however, some indication that the constellation is one that was largely peculiar to kivas or ceremonial contexts at other sites besides Broken $\mathrm{K}$. Longacre found that at Carter Ranch Site a constellation of five pottery-types was peculiar to such contexts; he was able to make the following statement (1970:36-37):

Thus, we can suggest that these ceramic types were used together in ceremonial activities. We can go one step further and suggest that when these types are found in a nonrandom high frequency on the floor of a cultural unit, that particular unit should be classed as a ceremonial one.

Although the Carter Ranch Site ceremonial types differ somewhat from the equivalent constellation presented here, there are striking similarities. The Broken $\mathrm{K}$ Site includes St. Johns Black-on-red; Patterned Corrugated; Brown Plain Corrugated; Brown Indented Corrugated; Snowflake Black-onwhite, Snowflake variety; and Pinto Polychrome. The Carter Ranch Site includes St. Johns Black-on-red; Patterned Corrugated; Brown Plain Corrugated; Brown Indented Corrugated, smudged interior; and Brown Plain Corrugated, smudged interior. The first three types were characteristic of the kivas at both sites; the fourth type is also the same, except that it had a smudged interior and a different shape at Carter Ranch Site. The others are different between the two sites. The only major difference, however, is that the two smudged-interior types at Carter Ranch Site were not characteristic of Broken $\mathrm{K}$ kivas. In their places we have a black-on-white and a polychrome type.

It is suggested that the first three, and possibly the fourth type, may be ceremonial types in this area of the Southwest. Their differential distribution (in kivas) points up the fact that the kivas were functionally different from the other types of rooms. If the constellation truly represents ceremonial function, it should be found in the kivas (and perhaps cemeteries) of other pueblo sites in the area. Such a finding would not be at all surprising, since it is known that the present-day western Pueblos have functionally specific vessel-types for use in ritual activities (Titiev 1944:16).

\section{Other Functions}

In addition to ceremonial uses, other functions probably were served by the kivas at Broken $\mathrm{K}$, just as today (the 1960s). Since the primary users of kivas among the Pueblos today are men (Mindeleff 1891: 134), we may expect to find evidence that kiva activities were predominantly male activities in prehistoric times. Such is, in fact, the case.

First of all, there were loom-holes in two of the Broken K kivas (Room 6-kiva and Room 29-kiva). This indicates that weaving was sometimes carried out in kivas. Since weaving is today done in kivas, and by men (Mindeleff 1891:129; Parsons 1936:33, 134, $188,202)$, it may be that the same situation existed at Broken K.

Secondly, it is probable that the manufacture of hunting equipment was done in the kivas, as well as in the habitation rooms. This is indicated by the fact that many of the artifacts-hammerstones, cores, antler-flakers, and projectile points-found on the floors of the kivas can be linked to this activity. Furthermore, lithic waste was extremely dense in one of the kivas (41-kiva), and this represents the unutilized products of chert-tool manufacture. Since it is known that Hopi and Zuni men carry on similar crafts in their kivas (Mindeleff 1891:130), the present interpretation is not unreasonable.

No other functions of the Broken $\mathrm{K}$ kivas can be demonstrated. It is well known, however, that Hopi kivas are often used for eating (but not cooking), sleeping, and lounging (Mindeleff 1891:130; Parsons 1936:605, 607). These activities may also have taken place in the Broken K kivas ( $c f$ Hill 1968).

\section{The Plaza and Outliers}

The most obvious function of the plaza, that of cooking, is indicated by the presence of eight large roasting pits. These pits may be analogous to the 
large, subterranean pits used by the Hopi and Zuni to cook either green corn or pi-gummi (baked mush)except that among the modern western Pueblos such pits are located near the agricultural fields (Mindeleff 1891:163-64; Cushing 1920:205-208; Beaglehole 19.37:44).

Support is given this interpretation by the fact that these pits contained great quantities of fireburned volcanic rock and very little charcoal or ash. It may be that the rocks were heated in separate fires outside the firepits and subsequently placed in the pits with the food to be cooked. Hopi pi-gummi is baked in a similar way, but apparently without heated rocks. In that case, the pit is heated by a fire within it; then the fire is removed, the food is put in, and the pit is covered for cooking (Mindeleff 1891:163-64). It is, of course, not possible to be sure that the roasting pits at Broken $\mathrm{K}$ represent anything similar to this.

There were no artifacts peculiar to the plaza, and the density of artifacts was much lower than in either the habitation rooms or kivas. The most common items in the plaza were scrapers, utilized flakes, and lithic waste materials. This probably indicates that a certain amount of chert-tool manufacturing was being carried on here, as well as some scraping activitywhatever this means specifically.

The pottery-type factors dominant in the plaza are interesting in a functional sense, because they contain types that were significant in both habitation rooms and kivas-but not storage rooms. The pottery-types contained in these factors (factors 3, 4, and 7) are Snowflake Black-on-white, Snowflake variety (jars, bowls); Brown Indented Corrugated (jars); Brown Plain Corrugated (jars); and St. Johns Black-on-red (bowls). The first two types were found to be most common both in habitation rooms and in kivas; the second two types were most important in kivas. It is possible that some of the functions normally carried out in the habitation rooms and kivas were also carried out in the plaza. This would not be surprising, since the present-day Pueblo Indians use their plazas both as work-areas and as ceremonial dancing areas (Stubbs 1950:8).

That the plaza at Broken $\mathrm{K}$ served a ceremonial function is suggested by the small, slab-lined box located in the center of it, and by the large, flat pebble adjacent to it. Mindeleff found a similar feature in the plazas of several of the Hopi villages, and he mentions Shipaulovi, Mashongnovi, and Hano specifically. He states that these features consisted of "a small box-like stone inclosure, covered with a large slab, which is used as a sort of shrine or depository for the sacred plume sticks and other ceremonial offerings" (1891:71-72). This description fits the Broken $\mathrm{K}$ feature exactly.

Apparently this feature is very common in Hopi plazas, and it may symbolize the sacred "sipapu," or "place of emergence" (Parsons 1936:362, 438, 1076). Spruce boughs, as well as prayer sticks, are placed in or near them during rituals (Parsons 1936:641). Among the Rio Grande pueblos, this feature is called "earth navel" (sacred center of the world), and seeds are sometimes planted in it during rituals (Alfonso Ortiz, San Juan Pueblo, personal communication).

Little can be said about the functions of the five outlying units surrounding Broken $\mathrm{K}$ (Fig. 2). Outlier 1 consists of two small rooms within the size-range of storage rooms. Since they contained almost nothing, they are presumed to have been used for storage (no pollen sample taken). Outlier 2 was in the size-range of the habitation rooms and had a slab-lined firepit; it is presumed to have been a habitation room. The other three units do not seem to have been rooms at all. Two were L-shaped and had apparently been low masonry walls. It is possible that they were fences or windbreaks associated with small garden-plots or corrals. Such structures are used by both the Hopi and Zuni (Mindeleff 1891:146-47, 216).

\section{Changes of Function}

Three rooms at Broken $\mathrm{K}$ exhibited definite evidence that their functions had been altered. Room 6-kiva was first a habitation room and was later made into a kiva. Room 27 was originally a habitation room but later became a storage room. Room 31-33 was originally a habitation room, but its last use was apparently as a privy-judging from the large quantity of fecal material discovered.

\section{Summary}

The evidence presented in this chapter constitutes an attempt to isolate the primary functions of the three basic room-types demonstrated in Chapter 8 . It has been shown that the habitation rooms contained most of the artifacts found at the site, and that they were living rooms in a very real sense. Specifically, evidence has been presented to demonstrate that the following functions were almost definitely carried out 
in these rooms: preparation of food, eating, water storage and use, and manufacture of hunting tools. In addition, several other functions were discussed, but the evidence to substantiate them was not conclusive. These functions were manufacture of pottery, manufacture of ground and pecked implements, manufacture of ornamental items, and sleeping.

Most of these functions were found to occur in Hopi and Zuni habitation rooms, and this lends support to their existence at Broken $\mathrm{K}$. There is every reason to believe that these rooms functioned much as the historic Zuni living rooms have done. Stevenson (1904:292-93) states that, "The largest [room] is the general living room, where the entire household works, eats and sleeps, and where guests are entertained."

The storage rooms at Broken $\mathrm{K}$ were characterized as containing little of anything except pollen. Their pollen content was used to demonstrate, beyond any reasonable doubt, that both food and non-food items were actually stored in these rooms. It was also suggested that certain non-storage functions were occasionally carried out in them.

The ceremonial rooms, or kivas, were shown to have had ceremonial uses (inter alia). The kivas at Broken $\mathrm{K}$ share certain stylistic features with Hopi and Zuni ceremonial rooms. In addition, they contained at least two pollen-types that have ceremonial significance in the two ethnographic control groups. They also contained a rather specific constellation of pottery-types not found elsewhere in the pueblo. Most of the types in the constellation were the same as those occurring in ceremonial contexts at Carter Ranch Site (Longacre 1970:Table 4). Presumably, these types represent activities that were commonly carried out in kivas, but the exact nature of the activities is unknown.

The kivas served as locations for weaving and the manufacture of hunting equipment-both of which are male activities among the Hopi and Zuni.

The plaza contained eight large roasting pits, which presumably were used in a specialized form of cooking. The dominant pottery-types in the plaza consisted of a combination of the dominant types in both habitation rooms and kivas. Although no artifacts were peculiar to this area, the fairly large numbers of scrapers, utilized flakes, and lithic waste presumably represent scraping and tool manufacturing activities.

The small "box" in the center of the plaza may have been analogous to similar features found in the plazas of several of the Hopi villages, which were found to have ceremonial functions.

The brief discussion of the outlier units surrounding Broken $\mathrm{K}$ was inconclusive; one of them presumably represents two small storage rooms, while the second was probably a habitation room. The other three units may have been "fences" surrounding small garden plots.

Three rooms within the pueblo are considered to have undergone functional change with the passage of time.

It should be made clear that the functions discussed in this chapter are primary functions only, since it seems probable that few of them were completely restricted to a single room-type (or area). There was probably a great deal of functional overlap between the room-types, and each room-type was clearly multifunctional. This is exactly the situation among the western Pueblos today. 


\section{SOCIAL GROUPS}

Longacre $(1964 b ; 1970)$ has tentatively demonstrated the existence in prehistoric times of two, and possibly three, matrilocal (or uxorilocal) residence groups at Carter Ranch Site (Martin and others, 1964). His demonstration was based on a nonrandom distribution of ceramic design-elements at the site. He was able to show that the north and south halves of the site were different in terms of constellations of design-elements.

Two important reasons existed for interpreting this differential distribution as reflecting the loci of social groups. In the first place, no other interpretation seemed to fit the facts. It seemed unlikely that the distribution could reflect temporal differences within the site, because there was little independent evidence to support such an interpretation. It was also unlikely that a functional interpretation was applicable, because the distribution did not represent a sorting based on room-types or functionally specific areas.

The second reason for believing that the distribution represented social groups (uxorilocal residence units) was that it conformed to the previously formulated hypothesis that different localized matrilineal groups ought to exhibit subtle differences with respect to the design-elements on their pottery. Among the modern western Pueblo peoples, the art of pottery-making is transmitted from mother to daughter through time, and within the localized matrilineal framework (Bunzel 1929:51-54). Knowing this, Longacre formulated the hypothesis that there should be more similarities in design-elements through time within the matrilocal group than there would be between such groups at any given point in time (1963:59-62; 1970; see also Cronin 1962). Presumably, mothers would teach their daughters certain subtle peculiarities of design and technique that would not be shared by women who learned how to make pottery within a different matrilineal setting. Longacre stated his hypothesis as follows (1963:61).

If we assume ... that pottery making was a female occupation [prehistorically] as it is today...then we may be able to delimit ... ceramic tradition within the village level. This would be the lineage style of decoration. The localized matrilineage would form the pottery making unit. This tradition would therefore be kin-based. The art of pottery manufacture and decoration would be learned and passed down within the lineage frame. Preference for designstyle, shapes, and possibly for temper might show statistically within this social grouping.

Longacre's test of this hypothesis, using designelement data from Carter Ranch Site, was extremely interesting and stimulating. His presentation of nonrandom distributions of elements and element clusters clearly demonstrated that the two halves of that site were different; it is possible that they represent the loci of two distinct uxorilocal residence units.

In his original analysis (1963), Longacre claimed to have demonstrated the existence of localized matrilineages. This interpretation has been altered however (Longacre 1970:50-51), since there was not enough evidence to demonstrate that the units were actually lineages. A localized lineage, as it is commonly understood, has the following major attributes (Aberle 1961: 655-727; Schneider 1961: 2-4; Gough 1961: 57, 451-55; Service 1962: 31-2, 123-5):

1. It is a group of people who live together in one place (that is, localized).

2. The group must live together in the same place for at least two generations (or at least two generations must be represented).

3. The members of the group are consanguineally related kinsmen (excludes affinals), in terms of unilineal descent (either patrilineal or matrilineal).

4. The members of the group generally cooperate economically (share production and distribution).

5. The members of the group inherit membership in the group and may also inherit status and/or property (especially land and other non-movable property).

If it had been possible to demonstrate that all (or most of these attributes had existed with respect to each of the two spatial units isolated at Carter Ranch Site, Longacre would have had a strong case for localized matrilineages. As it was, he demonstrated the following with reasonable certainty:

1. The two halves of Carter Ranch Site possessed significantly different clusters of ceramic designelements. 
2. The two halves of the pueblo represented the loci of two discrete aggregates of women who were sharing design-elements among themselves.

3. The two halves of the pueblo represented the loci of two uxorilocal (or matrilocal) residence units.

The last two inferences were based on two lines of evidence. First of all, it is known that among the modern Pueblos the women are the pottery-makers. Secondly, there seemed to be no localized clusters of stylistic elements (of any nature) at the site that might have been dependent on male manufacture.

The present analysis was aimed at demonstrating the existence of uxorilocal residence units at Broken $\mathrm{K}$ Pueblo, and a certain amount of success has been achieved. In addition, it has been possible to isolate a small amount of evidence that suggests that the units were matrilineal as well (at least in terms of inheritance of property).

Since Broken $\mathrm{K}$ was almost three times as large as Carter Ranch Site, it was felt that it probably contained a somewhat larger number of residential units (of an equivalent nature). Although it is not possible to be sure that the localized residential units at Broken $\mathrm{K}$ were actually equivalent to those units that existed at Carter Ranch Site, it is possible to make a rough comparison of the numbers of such units at each site.

There were 39 rooms at Carter Ranch Site, and Longacre found two distinct residence units with approximately 20 rooms per unit. If equivalent units existed at Broken $\mathrm{K}$, and if the size of these units remained roughly constant through time in the Carter Ranch Valley, one would expect to find evidence of five such units at Broken $\mathrm{K}$ (given 95 rooms)-and this is exactly what was discovered.

These five residential units appear, however, to have been subdivisions of two much larger units at Broken $\mathrm{K}$. There is no evidence for more than one such large unit at Carter Ranch Site. It may be that the present study has isolated two different levels of residential unit (possibly analogous to clan and lineage).

In addition to establishing the existence of uxorilocal residence units at the site, this chapter will show that the study of ceramic design-element distributions is not the only way in which the demonstration of such units can be achieved. There is strong evidence, at Broken $\mathrm{K}$ at least, that such units can be delineated through examining the distributions of pottery-types, firepit-types, storage pits, "chopper"-types, and animal bone.
The basic problem may be stated in the form of a proposition: Given the fact that uxorilocal residence is the dominant residence pattern among the western Pueblos, it is proposed that this was the case at Broken $\mathrm{K}$ also.

In order to support this proposition, the following points should be demonstrated:

1. There should be nonrandom distributions of items (or stylistic elements within classes of items) which delineate localized areas of the pueblo as being different from one another.

2. It should be found that these items or stylistic elements can be associated with female activities primarily, and not male activities. (This would suggest that there were different aggregates of females performing tasks.)

(Items or elements representing male activities should not aggregate to a significant degree in large, specific areas of the pueblo, since in an uxorilocal system, there should be no localized related group of men.)

3. It should be found that these female-associated items or stylistic elements were used (or usable) in the day-to-day maintenance of a residential unit. (This would suggest that the items or stylistic elements were actually pertinent to isolating residence units, and not something else.)

4. It should be found that there is a temporal continuity for these items or elements within each of the areas of the pueblo which represent different aggregates of female activity. (This would suggest that the residence units were permanent, or stable.)

If all of these things can be demonstrated, it would seem highly likely that uxorilocal residence was the dominant residence pattern at Broken $\mathrm{K}$.

The organization of this chapter is in terms of the loci of residential units rather than in terms of the separate analytical projects that were used in isolating these units. All of the evidence pertaining to the delineation of the locus of a particular unit will be brought to bear on the discussion of that unit.

Much of the evidence presented here has been drawn from the same factor analyses of ceramic design-elements and pottery-types that have been consulted from time to time in the preceding pages. Most of the methodological considerations involved were discussed in Chapter 6 and need not be repeated here.

It is noteworthy that a few of the factors presented in this chapter have yielded information 
related to intra-site dating (Chapter 7) or room-types and functions (Chapters 8 and 9). This does not mean that there has been any confusion with respect to the distributional meanings of these factors. It simply illustrates the fact that not all factors have importance in any single sense.

A few factors cannot presently be interpreted at all. Presumably they have some meaning, since they are discrete entities; however there is no correlation between them and any of the others (correlation coefficient 0 ). The distributions of these factors, as well as others that have been referred to but not illustrated, are given in Appendix 5.

\section{Residence Unit Number I}

\section{Localization of the Unit}

As has been pointed out (Point 1), a necessary step in the establishment of an uxorilocal residence unit is the demonstration of localization. This was relatively easy to accomplish with the Broken $\mathrm{K}$ material.

Before discussing the distributions of stylistic elements which delineate the locus of Residence Unit $I$, it will be helpful to show what is meant by Unit I. Figure 15 illustrates the general spatial locus of the unit, as well as the subdivisions (Subunits IA, IB, and IC) within the unit. These subdivisions will henceforth be referred to by their alpha-numerical designators.

Two groups of rooms at the site were not adequately excavated, and it is difficult to determine the residence units with which they were associated. The rooms to the east of Unit IB (in the south wing) cannot be discussed at all in this light; therefore they are not shaded on any of the distribution maps. The rooms immediately south of Unit IC (central portion of the east wing) did yield a small amount of evidence and appear to have been affiliated with Residence Unit II.

The nonrandom distributions of stylistic elements that are of primary importance in establishing the location of Unit I are given in Figure 16. The reader will notice that almost all five of these distributions are similar in general pattern and that the pattern is the same as shown in Figure 15. This clearly indicates that the areas designated as IA, IB, and IC had a number of things in common that were generally not shared by the other areas.

Map A (Fig. 16) shows the room-floors having significant amounts of factor 1 of the pottery-type study (greater than 30 percent of the factor-

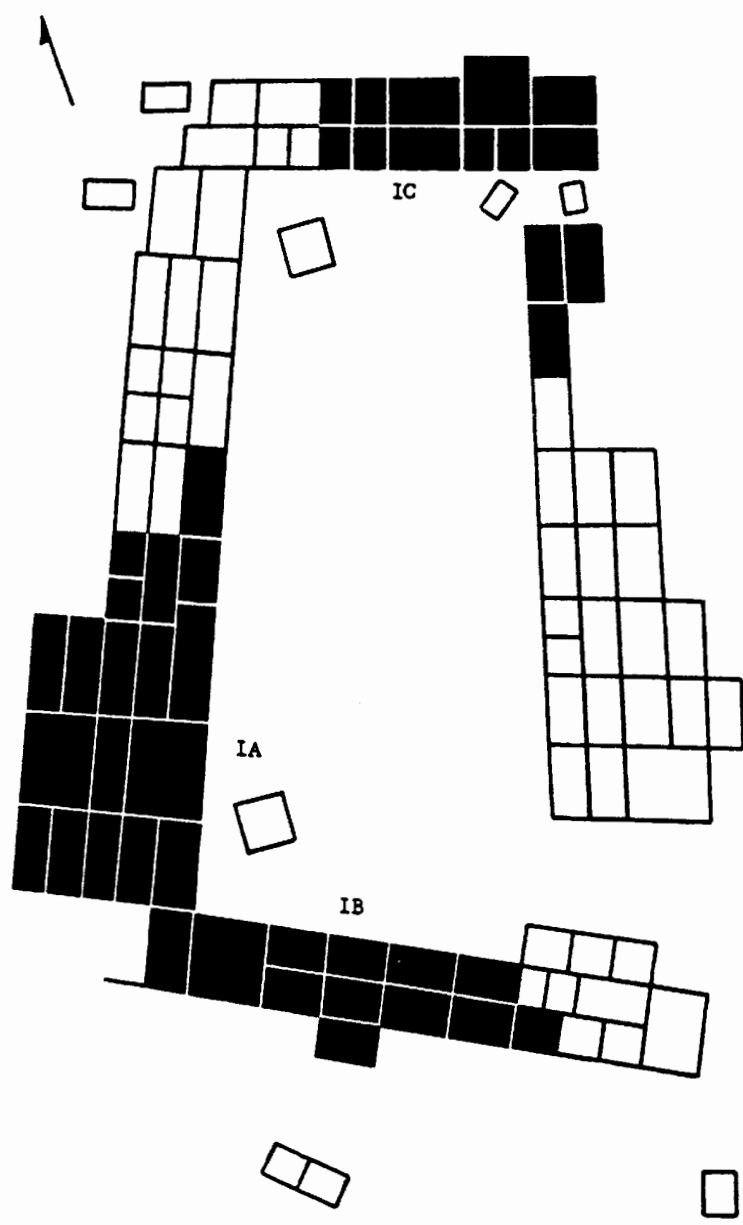

Figure 15. Locus of Residence Unit No. I (dark area). The unit is divided into sub-units IA, IB, and IC.

composition of each room). Apparently the people who lived in Areas IA, IB, and IC were the only ones who made and used large quantities of the potterytypes involved in this factor.

Map B (Fig. 16) shows the room-floors having significant amounts of factor 2 of the same study (greater than 30 percent of the factor-composition of each room). These rooms are clearly located in the same general areas of the pueblo as were those with significant amounts of factor 1 .

Map C (Fig. 16) shows the distribution of factor 12 of the ceramic design-element study (floors). Again, its occurrence is significant (greater than 29 percent of the factor-composition of each room) in Areas IA, IB, and IC-with one exception. A single room in the east wing was found to contain a significant amount of this factor also. As indicated on 



$\infty$

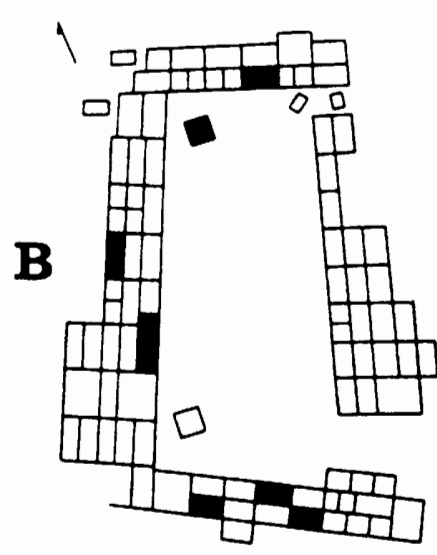

$\varnothing$

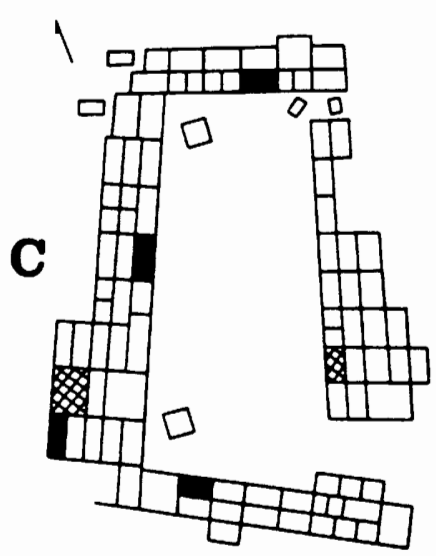

$\infty$

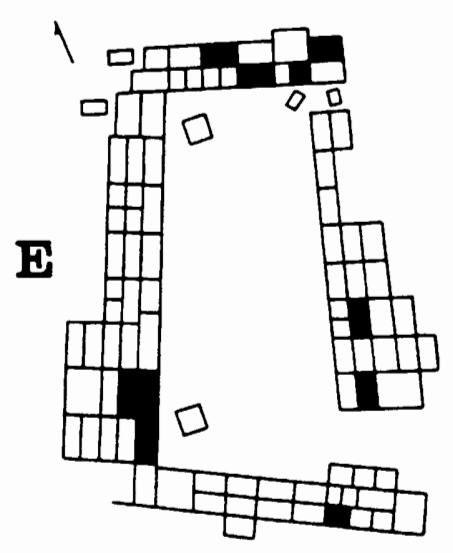

$\varnothing$

Figure 16. Factor distributions used in establishing locus of Residence Unit Number I. A, factor 1, potterytypes, on floors: white areas indicate 0 to 27 percent of factor-composition; dark areas, 34 to 100 percent. B, factor 2, pottery-types, on floors: white areas indicate 0 to 27 percent of factor-composition; dark areas, 35 to 100 percent. C, factor 12, ceramic designs, on floors: white areas indicate 0 to 18 percent of factorcomposition; cross-hatched, 30 to 32 percent; dark, 38 to 52 percent. D, factor 2 , ceramic designs, on floors: white areas indicate 0 percent of factor-composition; cross-hatched, 1 to 30 percent; dark, 55 to 80 percent. E, firepits, type IV: dark areas indicate presence of type IV firepits.

the map, however, it was not as significant as in the other areas.

Map D (Fig. 16) shows the distribution of factor 2 of the same study. Although this factor occurred to a significant degree only in Area IC (55 to 80 percent of the factor composition of each room), it was present to some extent in all three of the subdivisions of Area 1. Again, however, one room in the east wing had a small amount of this factor.
Map E (Fig. 16) shows the distribution of a particular stylistic variation of firepit. During the excavation of the site, tremendous variability was noticed among the slab-lined firepits in the habitation rooms, particularly with respect to the details of construction of the bottom portions of the pits. Investigation, then, of the possibility of several well-defined stylistic classes of firepits, based on bottom-construction, gave quite exciting results. Five 
different types were identified, which proved to be useful in isolating localized residence units.

Type IV firepit (distribution illustrated in map E, Figure 16) was characterized by having a flat, earth-lined bottom. Although it appears to have been the only type used in Area IC, its distribution also includes Areas IA and IB to some extent. This is not as clear-cut a distribution as the others, however, since two rooms in the east wing also had this type of firepit.

Considering all of the distributions illustrated in Figure 16, there can be little doubt that Areas IA, IB, and IC should be considered related in some sense; when taken together, these areas form the locus of Unit I. No distributions were found that systematically cross-cut this pattern; this suggests that no subdivisions of Unit I were closely associated with any other areas of the site. For this reason, it is proper to say that the locus of Unit I, whatever it represents in terms of residence units, has been identified.

\section{Subdivisions of the Unit}

Although Unit I must be considered as a discrete spatial unit, there is ample evidence to justify its designated subdivisions. The nonrandom distributions of stylistic elements of primary importance in establishing the discreteness of these subdivisions are given in Figure 17, maps $F$ through $\mathrm{K}$.

Map $F$ shows the distribution of room-floors having significant amounts of factor 13 of the design-element study of floors ( 1 to 10 percent of the factor-composition of each room). This factor was clearly localized in Areas IA and IB, but not in Area IC. This suggests two things. First of all, Area IC was apparently different from the other two areas in Unit I; secondly, Areas IA and IB were apparently more closely related (in some sense) to one another than either was to Area IC. In other words, this evidence suggests that Area IC should be considered as partially separate from the larger group.

Map G (Fig. 17) illustrates exactly the same thing. It shows the distribution of rooms having Type I firepits. These firepits were characterized by the fact that they possessed a simple U-shaped, earthlined bottom. There can be little doubt that Areas IA and IB were related in terms of firepit styles and that Area IC was separate in this sense.
Map H (Fig. 17) is somewhat different from the first two and indicates a relationship between Areas IA and IC. This map shows the distribution of room-fills having significant amounts of factor 9 of the design-element study of fills (greater than 30 percent of the factor-composition of each room). This evidence suggests that Area IB was in some sense separate from the other two areas.

Map I (Fig. 17) shows the distribution of rooms having significant amounts of factor 5 of the designelement study of floors (greater than 20 percent of the factor-composition of each room). It appears to isolate area IA as being somewhat different from Areas IB and IC. Since one room in the northern portion of the east wing contained a significant amount of this factor, however, it may be that the distribution actually shows a relationship between IA and IC.

Map J (Fig. 17) shows the distribution of rooms having significant amounts (greater than 57 percent of the factor-composition of each room) of factor 4 of the design-element study of fills. Only two rooms were significantly high in this factor, and they were located in Area IA. This, of course, would suggest that Area IA was separate from the other two. It may indicate, however, that these two rooms should be considered as a subdivision of Area IA.

Map K (Fig. 17) shows the distribution of rooms having significant amounts of factor 6 of the designelement study of floors (greater than 22 percent of the factor-composition of each room). It clearly suggests that area IB may be regarded as a separate entity.

A consideration of all of the evidence presented in Figures 16 and 17 leads to the inescapable conclusion that although Unit I may be regarded as a discrete entity, it may also be regarded as three distinct subentities. There can be little doubt that the distributions of ceramic design-elements, potterytypes, and firepit-types show distinct localizations in these three areas. It can thus be concluded that the first step in isolating an uxorilocal residence unit has been completed.

\section{Aggregates of Females in Residence}

The second step in the establishment of uxorilocal residence units is the demonstration that the above localizations of items represent the localizations of female activities. In other words, it should be found 

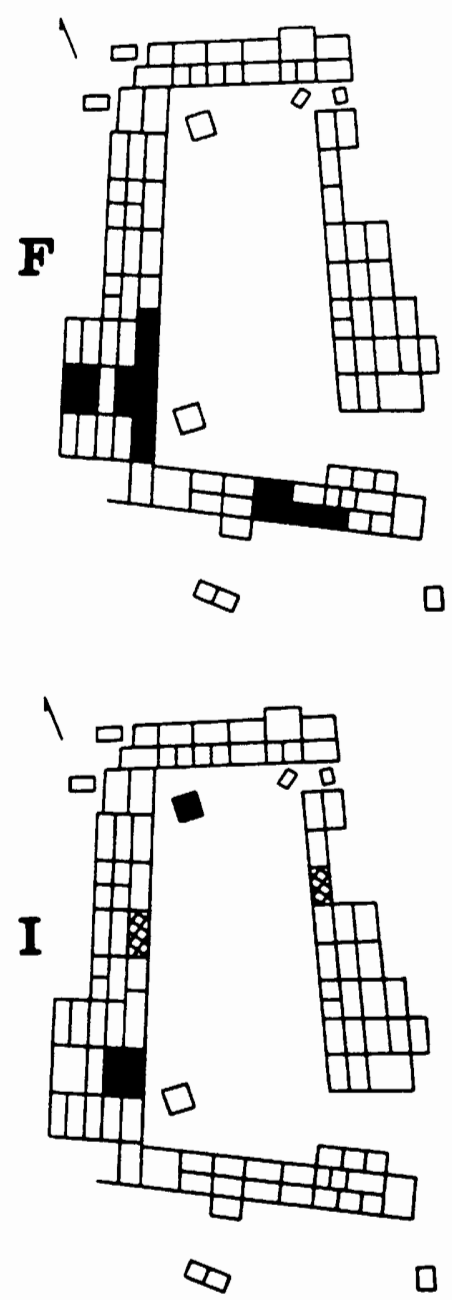
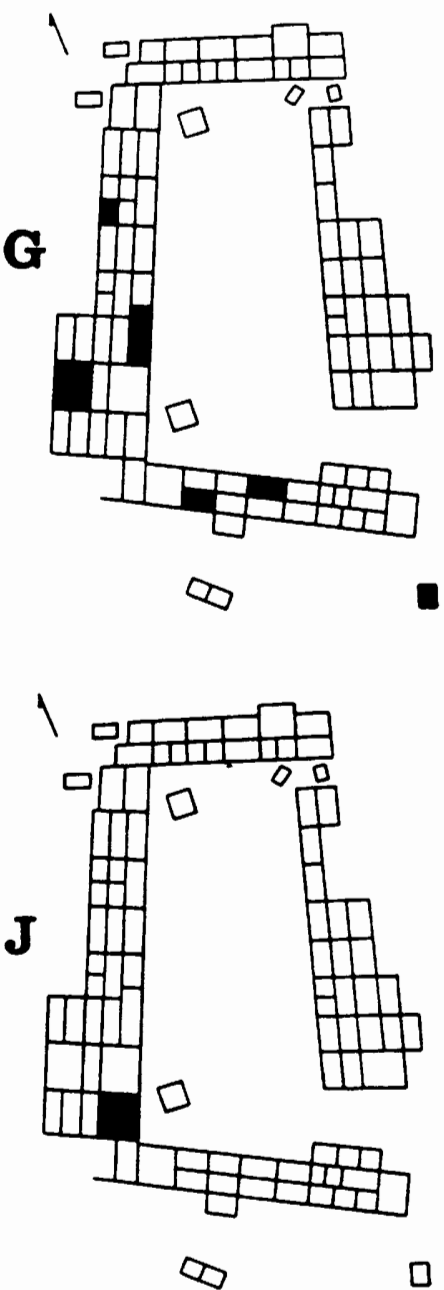
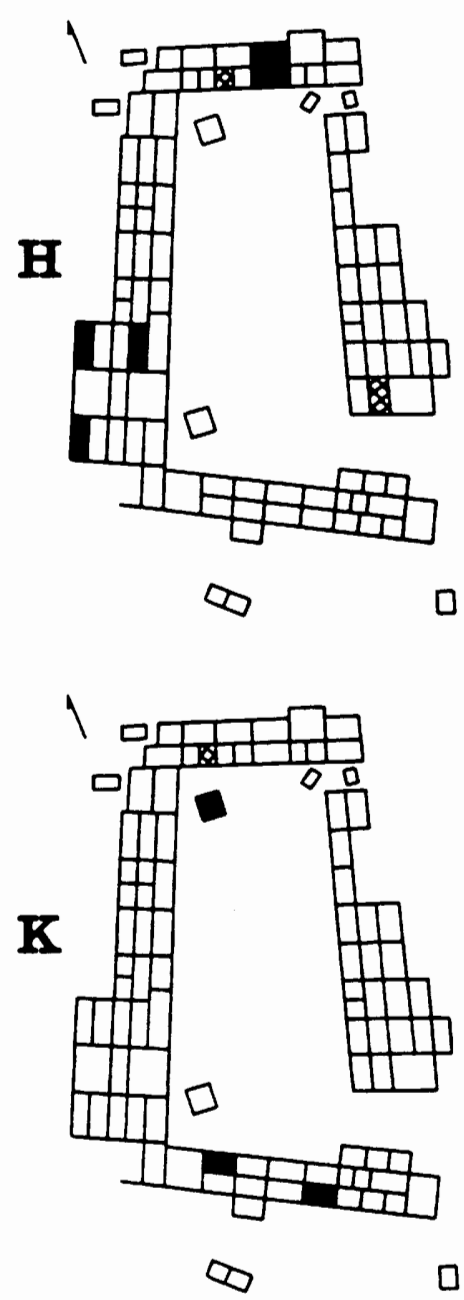

Figure 17. Factor distributions used in establishing loci of subdivisions of Residence Unit No. I. F, factor 13, ceramic designs, on floors: white areas indicate 0 to 10 percent of factor-composition; dark areas, 11 to 62 percent. G, firepits, type I: dark areas indicate presence of type I firepits. $H$, factor 9 , ceramic designs, in fills: white areas indicate 0 to 30 percent of factor-composition; cross-hatched, 31 to 60 percent; dark, 61 to 100 percent. I, factor 5, ceramic designs, on floors: white areas indicate 0 to 20 percent of factor-composition; cross-hatched, 30 to 40 percent; dark, 41 to 70 percent. J, factor 4 , ceramic designs, in fills: white areas indicate 0 to 18 percent of factor-composition; dark areas, 49 to 66 percent. $\mathrm{K}$, factor 6 , ceramic designs, on floors: white areas indicate 0 to 22 percent of factor-composition; cross-hatched, 40 percent; dark, 49 to 60 percent.

that ceramic design-elements, pottery-types, and firepit-types were associated with female rather than male activities (Point 2).

There would seem to be little doubt that ceramic design-elements and pottery-types were associated with female activities primarily, since this is the case ethnographically. Longacre $(1963,1970)$ has gathered ample evidence to show that pottery is made by women among the recent Hopi and Zuni, and the women are also responsible for the execution of the design-elements on the pottery (see also Bunzel 1929). Some of the pottery is used by the men, of course, but it is used primarily in women's activities.

The same is probably true with respect to firepits. Although Hopi and Zuni women may not actually construct their firepits, it may well be that they have 
some control over their planning and construction. This is a reasonable idea, since firepits are used primarily for cooking, and cooking is a function of women. This would probably be correct on a worldwide basis too.

Establishment of the fact that design-elements, pottery-types, and firepit-types should be associated with female activities is not enough, however. It should also be the case that there are no items or stylistic elements related to male activities that cluster to a significant degree in large specific areas of the pueblo (Point 2). Unfortunately, this was not adequately demonstrated. While a number of presumably male-associated items were examined in terms of spatial distribution, and while none exhibited localized clustering, it is also clear that not enough attention was paid to the distributions of subtle style differences among these items. This portion of the demonstration must remain a concern for the future (Hill, in press).
Table 12 lists the major types of possible residence patterns, their definitions, and the kinds of distributions one would expect to find for both femaleassociated and male-associated stylistic elements. Although the distributions are called either random or nonrandom, it is not intended that they should be considered perfectly random or nonrandom. It seems likely, however, that they would approximate such distributions.

An examination of Table 12 reveals that the only residence patterns that would have significant nonrandom distributions of female-associated stylistic elements would be either uxorilocal or duolocal. Duolocal residence, however, should exhibit nonrandom distributions of both male- and femaleassociated elements, and this was probably not the case at Broken $\mathrm{K}$.

It is clear, then, that the nonrandom distributions of ceramic design-elements, pottery-types, and firepittypes at Broken $\mathrm{K}$ reflect localized female activities,

TABLE 12

Major Residence Patterns and Distribution Correlates

\begin{tabular}{|c|c|c|c|}
\hline $\begin{array}{l}\text { Residence } \\
\text { Patterns }\end{array}$ & Definition & $\begin{array}{l}\text { Distribution } \\
\text { of Female } \\
\text { Stylistic Items }\end{array}$ & $\begin{array}{l}\text { Distribution } \\
\quad \text { of Male } \\
\text { Stylistic Items }\end{array}$ \\
\hline Uxorilocal & $\begin{array}{l}\text { Husband and wife live in vicinity of } \\
\text { wife's maternal relatives }\end{array}$ & Nonrandom & Random \\
\hline Matrilocal & $\begin{array}{l}\text { Husband and wife live in vicinity of } \\
\text { wife's mother }\end{array}$ & Nonrandom & Random \\
\hline $\begin{array}{l}\text { Matrilocal, with } \\
\text { resident male head }\end{array}$ & $\begin{array}{l}\text { Same, but a mother's brother and his } \\
\text { family reside within the group }\end{array}$ & Nonrandom & Random \\
\hline Virilocal & $\begin{array}{l}\text { Husband and wife live in vicinity of } \\
\text { husband's relatives - patrilineal or } \\
\text { matrilineal }\end{array}$ & Random & Nonrandom \\
\hline Patrilocal & $\begin{array}{l}\text { Husband and wife live in vicinity of } \\
\text { husband's father }\end{array}$ & Random & Nonrandom \\
\hline Avunculocal & $\begin{array}{l}\text { Husband and wife live in vicinity of } \\
\text { husband's maternal uncle }\end{array}$ & Random & Nonrandom \\
\hline Neolocal & $\begin{array}{l}\text { Husband and wife live separate from } \\
\text { either mate's relatives }\end{array}$ & Random & Random \\
\hline Bilocal & $\begin{array}{l}\text { Husband and wife live either in vicinity } \\
\text { of husband's or wife's relatives }\end{array}$ & Random & Random \\
\hline Duolocal & $\begin{array}{l}\text { Husband and wife live separately, each } \\
\text { with own relatives }\end{array}$ & Nonrandom & Nonrandom \\
\hline
\end{tabular}


and it may be inferred that they represent discrete, localized aggregates of women-probably uxorilocal units. It must further be shown that this set of stylistic elements was used (or was usable) in the day-to-day maintenance of a residence unit (Point 3). This hardly needs discussion, since it will certainly be agreed that pottery and firepits are generally used in activities related to food preparation and serving-and part of maintaining a residence unit is the feeding of its people. It thus seems probable that we are defining the loci of actual residence units rather than the loci of some other activity (such as ritual, gambling, or weaving).

\section{Temporal Continuity}

The final thing needed in this attempt to isolate an uxorilocal residence unit is a demonstration that the unit had time-depth (Point 4). Presumably a true localized residence unit should exist in time as well as in space. If it can be shown that the abovedemonstrated aggregates of females lived in specific areas of the pueblo (IA, IB, and IC) for at least two generations, then it is reasonable to believe that true uxorilocal residence existed in the village.

This demonstration of time-depth is not difficult. We know, first of all, that the site was occupied for roughly 130 years. Although the northern half of the site (the latest half) could not have been in existence this long, it seems reasonably clear that the southern half was inhabited throughout most of the time span. The more extensive remodeling and addition of rooms in the south than in the north would seem to indicate a relatively long period of occupation.

Even if each half of the puebio was only occupied for half of the total time span, it is clear that each was occupied for at least 65 years. If a single generation is considered to have had a time span of about 20 years, then each half of the site would have housed at least three generations of people. It would seem, then, that each of the subdivisions of Unit I contained at least three generations of aggregated women; if the entire unit is considered, there must have been about six generations. Either way, there was certainly enough time for the establishment and maintenance of uxorilocal residence units.

If the residence units had been impermanent or transitory (that is, women frequently changing residence location), we should probably have found more-or-less random distributions of design-elements, pottery-types, and firepit-types. This, of course, was not the case; and this is a further reason for believing that the residence units were relatively stable through time.

Considering all of the preceding evidence, it seems quite likely that Unit I (Fig. 15) constituted a large uxorilocal residence unit, with three subdivisions.

\section{Subsidiary Evidence}

In addition to the evidence already presented, three other distributions of items appear to reflect the same pattern of distribution that has been found to delineate the locus of Residence Unit No. I. These distributions were not discussed with the others because it was not possible to identify the items involved as representing definite female activity. They almost certainly do represent female activity, however, because their patterns of distribution conform exactly to those already considered (and they are probably not related to male activities).

The first of these distributions involves the numbers of storage pits found in the floors of rooms. Each of the rooms at Broken $\mathrm{K}$ contained anywhere from 0 to 15 such pits. Although most of the rooms had 0 to 5 pits, nine rooms had between 7 and 15 of them. All of the rooms that had between 7 and 15 such pits were found within the locus of Unit I (Fig. 18, Map L). It may be inferred, on the basis of this evidence, that the residents of Unit I used more storage pits than did the other people at the site, and that the women were in control of their construction and use. It is impossible, of course, to be sure that these pits were actually used for storage, but if they were, there would be a good case for believing that the women were largely responsible for storage activities. There is some evidence, at Zuni at least, that women actually do control such activities (Gold$\operatorname{man} 1937: 323$ ).

The second distribution to be considered concerns "choppers" found on floors. Several classes of choppers were found at Broken $\mathrm{K}$, but one particular class (made on large flakes) was found to distribute in a highly nonrandom manner (Fig. 18, Map M). They were found predominantly in areas IA and IB, and they present further evidence that these two areas were closely associated. In addition, it may be inferred that the women of this group had something to do with choppers. It seems likely that the women were doing the chopping and that they preferred choppers made on flakes or that they were performing some activity the other people in the village were 

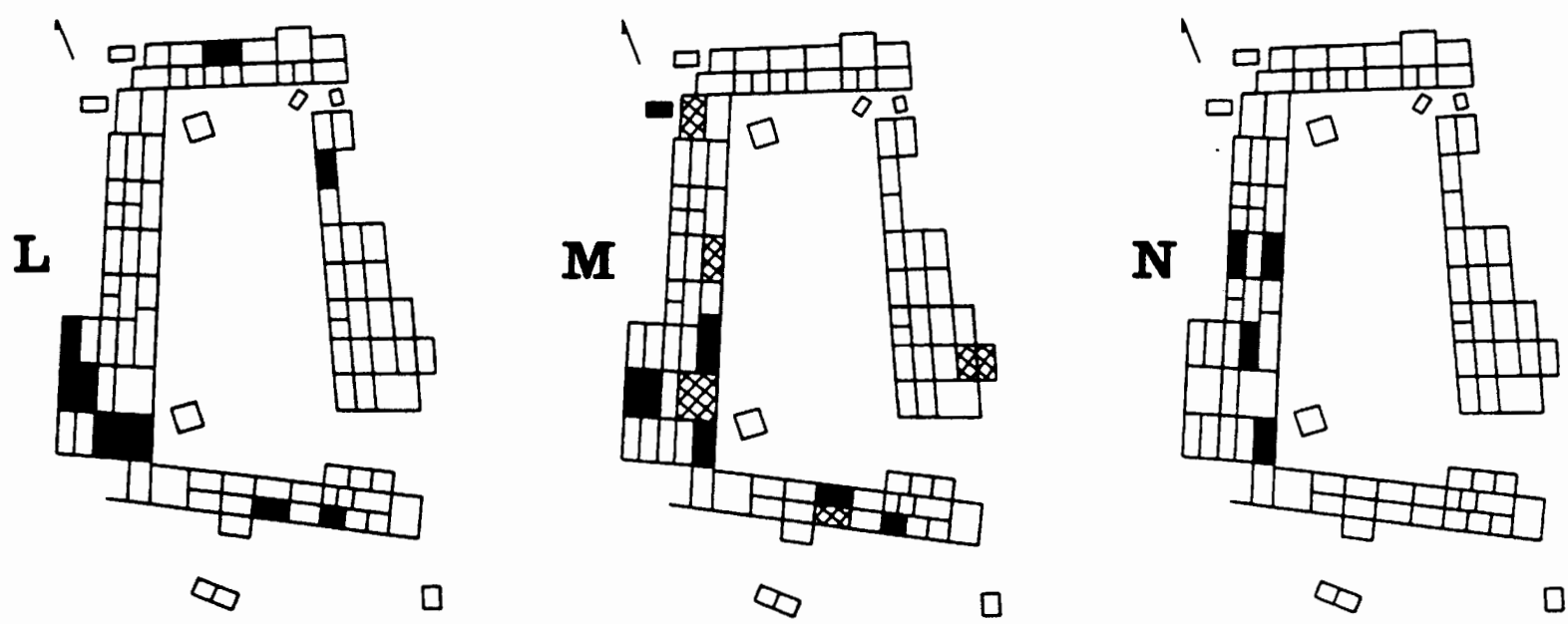

Figure 18. Subsidiary evidence for loci of subdivisions of Residence Unit No. I. L, storage pits per floor: dark areas indicate rooms having 7 to 15 storage pits. $M$, choppers made on flakes: cross-hatched indicate rooms having one chopper; dark areas, rooms having 2 to 4 choppers. N, prairie-dog bones: dark areas indicate rooms having 5 to 29 bones.

not performing. If choppers were used in butchering (Chapter 9), it seems likely that women were involved in the butchering process.

The third subsidiary distribution is that of prairiedog bone found on floors at the site. Most rooms contained no prairie-dog bone at all, and a few rooms had from 1 to 3 such bones. Most of the bones occurred in rooms located in Unit IA (Fig. 18, Map N). Four rooms in this unit had between 5 and 29 prairie-dog bones each. This supports the idea that Unit IA may be considered as a discrete subdivision of Unit I; it also suggests that the women of this group either preferred prairie dog for some reason, or they had men-folk who were-adept at hunting this animal.

\section{Residence Unit Number II}

\section{Localization of the Unit}

Given the demonstration of Residence Unit I and the evidence and arguments used in achieving it, it should be possible to isolate another such unit without quite so much verbiage. The general locus of the second major residence unit, and its subdivisions, is given in Figure 19. It includes most of the rooms at the site that were not affiliated with Unit I.

The nonrandom distributions of stylistic elements that are of primary importance in establishing the location of this unit are given in Figure 20. It will be noticed that all five of these distributions are similar in general pattern.

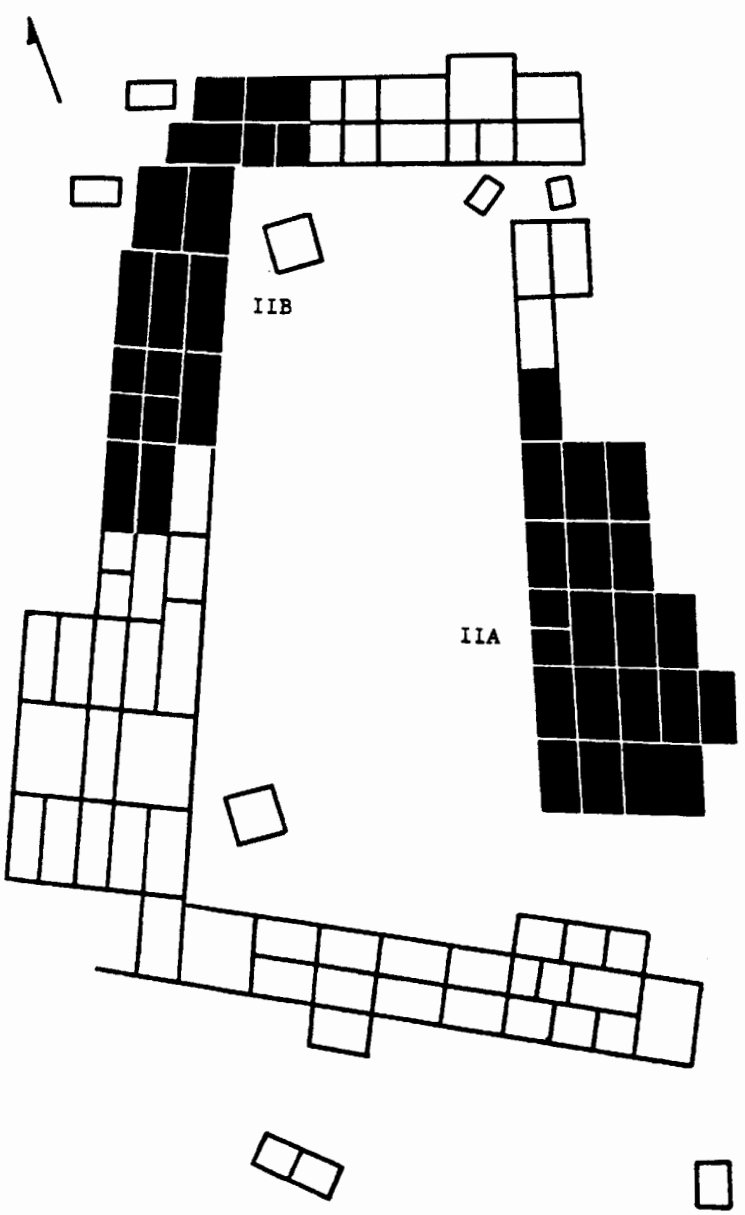

Figure 19. Locus of Residence Unit No. II (dark area). The unit is divided into subunits IIA and IIB. 

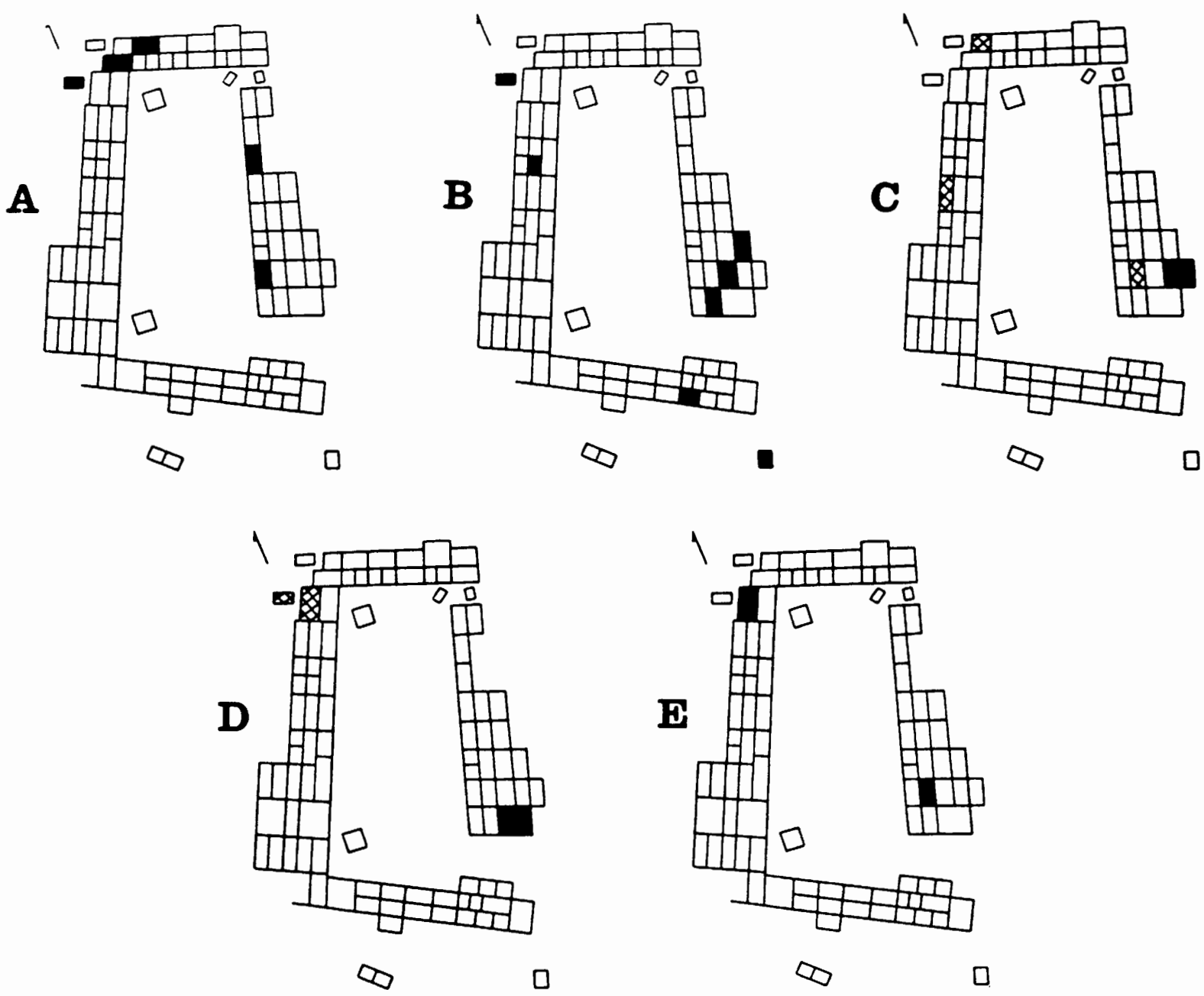

Figure 20. Factor distributions used in establishing locus of Residence Unit Number II. A, factor 3, potterytypes, on floors: white areas indicate 0 to 25 percent of factor-composition; dark areas, 26 to 100 percent. $B$, factor 4, pottery-types, on floors: white areas indicate 0 to 35 percent of factor-composition; dark areas, 40 to 94 percent. C, factor 1 , ceramic designs, in fills: white areas indicate 0 to 13 percent of factorcomposition; cross-hatched, 31 percent; dark, 79 percent. $D$, factor 2, ceramic designs, in fills: white areas indicate 0 to 24 percent of factor-composition; cross-hatched, 25 to 26 percent; dark, 75 percent. E, firepits, type III: dark areas indicate type III firepits.

Map A (Fig. 20) shows the distribution of floors having significant amounts of factor 3 of the potterytype study of floors (greater than 25 percent of the factor-composition of each floor). This would seem to indicate that Units IIA and IIB were related in some sense.

Map B (Fig. 20) illustrates the distribution of factor 4 of the same study (greater than 39 percent of the factor-composition of each floor). Although this factor was dominant in the southern portion of the east wing (Unit IIA), it was also found in a room in
Unit IIB. The fact that it occurred in one of the rooms in Unit IB (Room 82) is difficult to explain, but this seems relatively unimportant since it represents one of only two cases in which Units IB and IIA appear to overlap.

Map C (Fig. 20) shows the distribution of rooms having significant amounts of factor 1 of the designelement study of fills (greater than 13 percent of the factor-composition of each room). It represents a further demonstration that Units IIA and IIB were related. 

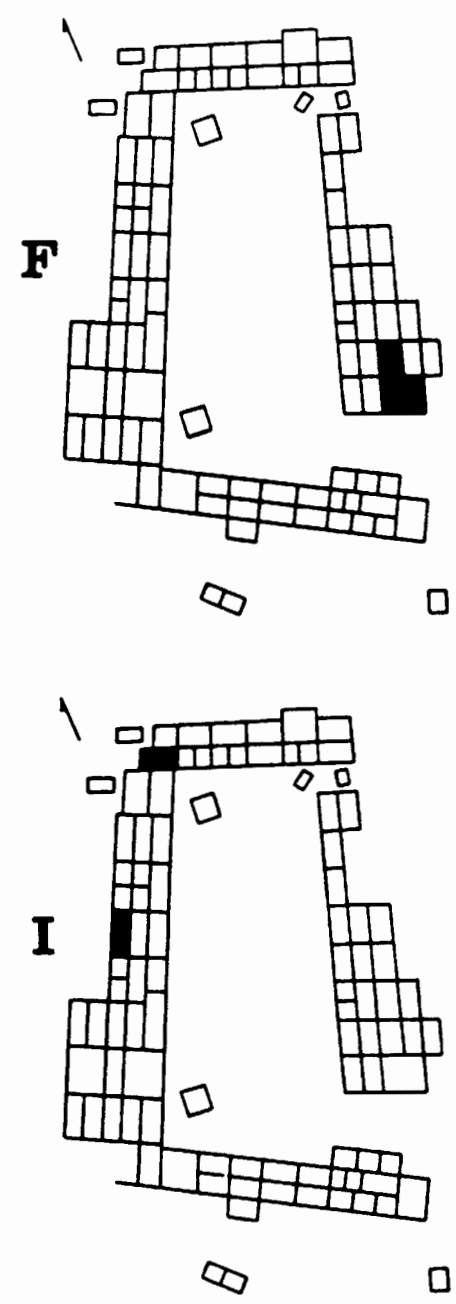
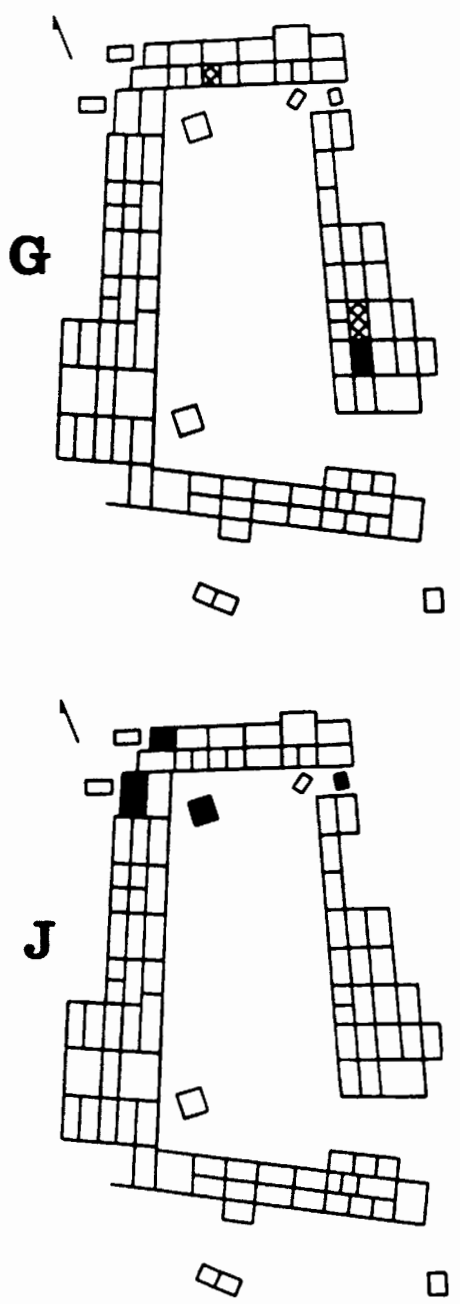
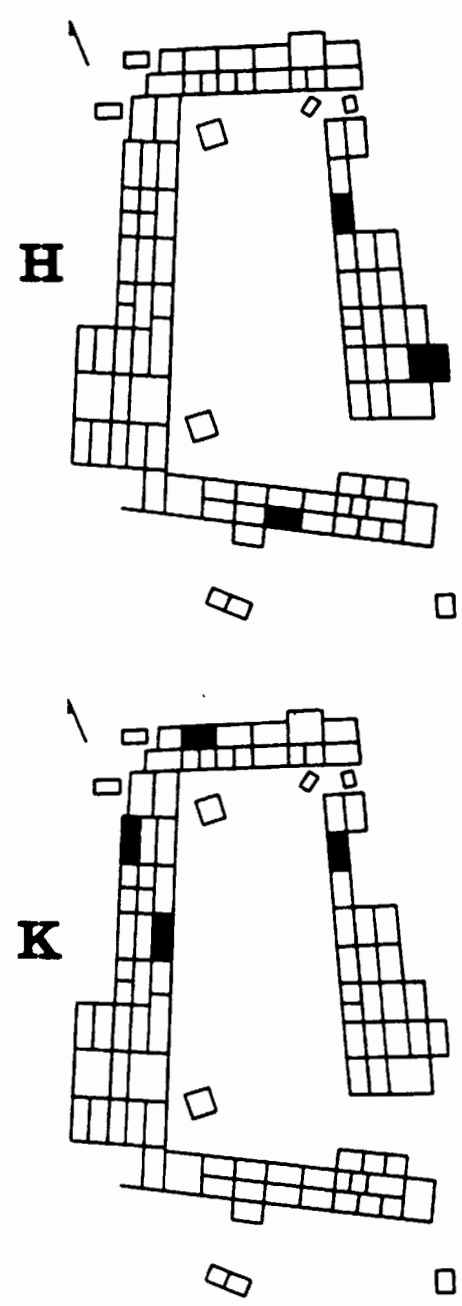

Figure 21. Factor distributions used in establishing loci of the subdivisions of Residence Unit Number II. F, factor 3, ceramic designs, on floors: white areas show 0 to 39 percent of factor-composition; dark areas, 59 to 99 percent. G, factor 9 , ceramic designs, on floors: white areas show 0 to 23 percent of factor-composition; cross-hatched, 33 to 34 percent; dark, 75 percent. H, firepits, type V: dark areas show locations. I, factor 4 , ceramic designs, on floors: white areas show 0 to 17 percent of factor-composition; dark areas, 41 to 69 percent. $\mathrm{J}$, factor 3, ceramic designs, in fills: white areas show 0 to 12 percent of factor-composition; dark areas, 39 to 70 percent. $K$, firepits, type II: dark areas show locations.

Map D illustrates the distribution of factor 2 of the same study (greater than 24 percent of the factor-composition of each room); it also suggests the IIA-IIB relationship.

Map E shows the distribution of rooms having Type III firepits. This type of firepit is characterized by a flat, slab-lined bottom. The distribution of this stylistic variant is even further evidence that Units IIA and IIB may be considered as a single unit.

Considering all of these distributions together, it is evident that Unit II was a discrete entity. No distributions were found that systematically cross-cut this pattern (thus suggesting that Units I and II were closely related to one another).

\section{Subdivisions of the Unit}

Although Unit II must be considered as a discrete spatial unit, there is evidence to justify its designated subdivisions. The nonrandom distributions of stylistic elements that are of primary importance in establishing the discreteness of these subdivisions are given in Figure 21, maps F through K. 
Map F (Fig. 21) shows the distribution of roomfloors having significant amounts of factor 4 of the design-element study of floors (greater than 40 percent of the factor-composition of each room). This factor was clearly localized in Unit IIA and not in Unit IIB. This suggests that Unit IIA may be considered as a separate unit.

Map G (Fig. 21) shows the distribution of rooms having significant amounts of factor 9 of the same study (greater than 35 percent of the factorcomposition of each room). It is notable that only one room, located in Unit IIA, had a really significant amount of this factor.

Map H (Fig. 21) does not illustrate quite so neat a distribution as shown in maps $F$ and $G$, but it tends to show a localization in Unit IIA. This map shows the distribution of rooms having Type $\mathrm{V}$ firepits. These firepits were characterized by the fact that they possessed a rectangular, slab-lined hole or sump in the bottom of the pit. Why it is that one of these firepits should be found in the south wing (Unit IB) is not known.

Maps I to K (Fig. 21) illustrate a very different pattern of distribution than that shown in maps $F$ to $\mathrm{H}$. They suggest that Unit IIB may be considered as at least partially separate from Unit IIA.

Map I shows the distribution of room-floors having significant amounts of factor 4 of the design-element study of floors (greater than 40 percent of the factor-composition of each room). Only two rooms, located in the area of Unit IIB had significant amounts of this factor.

Map J shows a somewhat similar distribution. It illustrates the distribution of rooms having significant amounts of factor 3 of the design-element study of fills (greater than 38 percent of the factorcomposition of each room). It constitutes a further demonstration that Unit IIB may be considered as a separate entity.

Map K illustrates the distribution of rooms having Type II firepits. These firepits were characterized as having a U-shaped, earth-lined bottom, but with a small, unlined hole or depression in the center of the bottom surface. Such firepits occurred primarily in Unit IIB.

Consideration of all of the above distributions (Maps A to K) leads to the conclusion that although Unit II may be regarded as a discrete entity, it may also be regarded as two distinct subentities.

\section{Demonstration of Uxorilocal Residence}

Since the localization of Unit II has been established, it must now be shown that it and its subdivisions represent uxorilocal residence units. In order to do this, it is necessary to show that the stylistic items used in isolating the units can be associated with female activities and that these activities were related to the day-to-day maintenance of a residence unit. Furthermore, it must be shown that these activities had a temporal span of at least two generations.

Since these things have already been demonstrated with respect to Residence Unit $I$, there is no need to recapitulate the evidence. The two situations are identical. It has already been shown that ceramic design-elements, pottery-types, and firepit-types were probably associated with female activities and that these activities were related to maintaining residence units. The evidence concerning time-depth is also exactly the same. It is thus reasonable to conclude that Unit II constituted an uxorilocal residence unit, with two subdivisions.

\section{Subsidiary Evidence}

In addition to the evidence already presented, three other distributions appear to reflect the same pattern of distribution that has been found to delineate the locus of Unit II. Although they cannot be related directly to female activity, the fact that they follow the same distribution pattern as the female-associated items is sufficient to suggest that aggregates of females were in some way responsible for them (Fig. 22).

Map L (Fig. 22) shows the distribution of gopher bones at the site. The only rooms having significant quantities of these bones ( 8 to 24 bones per floor) were located in Unit IIA. This clearly suggests that, in some things at least, Unit IIA was different from Unit IIB.

Map M (Fig. 22) shows approximately the same thing. The only rooms having significant quantities of mountain sheep bone (Ovis) were in Unit IIA ( 7 to 16 bones per floor).

Map N (Fig. 22) shows the distribution of rooms that did not have any storage pits in their floors. The largest concentration of such rooms was clearly in Unit IIB, which seems to indicate that this unit may be considered as a separate subdivision of Unit II. 

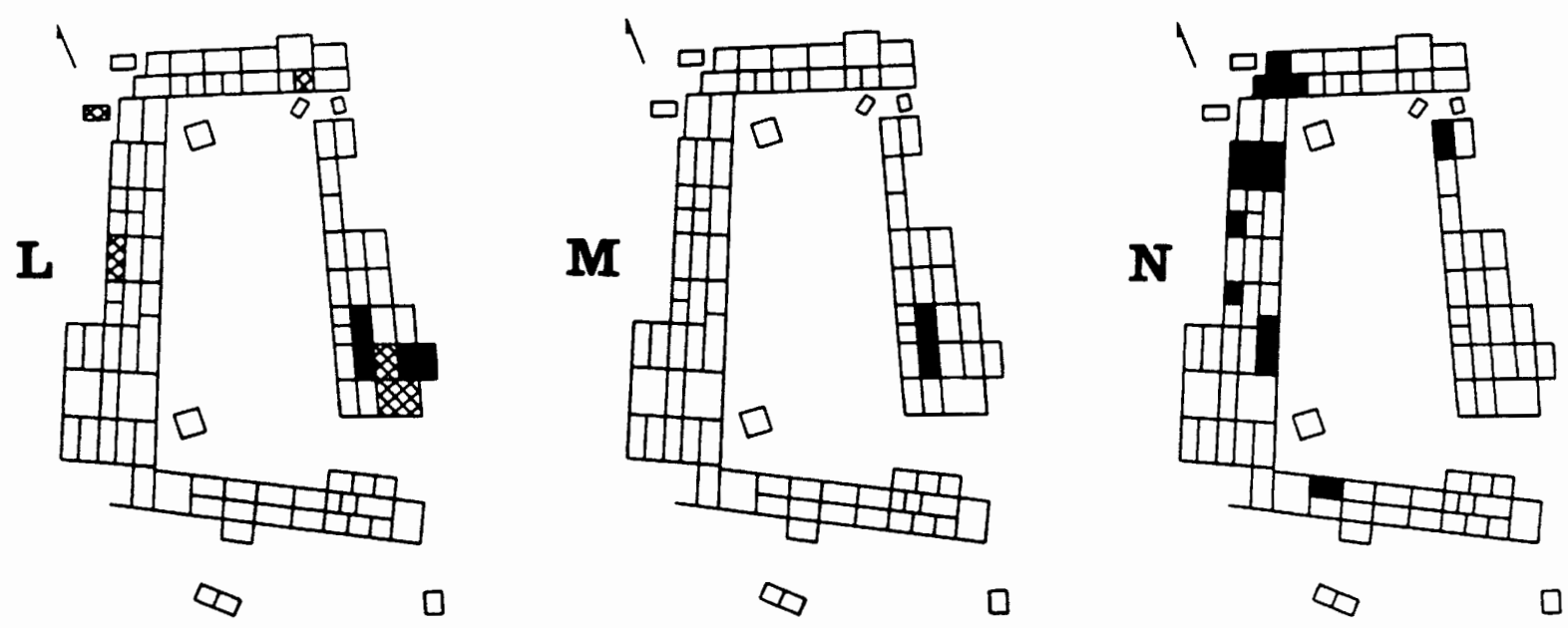

Figure 22. Subsidiary evidence for loci of the subdivisions of Residence Unit Number II. L, gopher bones: cross-hatched areas indicate rooms having 1 to 3 bones; dark areas, rooms having 8 to 24 bones. M, mountain sheep bones: dark areas indicate rooms having 7 to 16 bones. $N$, zero storage pits per floor, as indicated by dark areas.

It is interesting that, except for the fact that chopper-styles do not aid in delineating Unit II, the other two subsidiary items used are the same as those that were used as subsidiary evidence in connection with Unit I (that is, animal bone and storage pits). This evidence further reinforces the idea that animal bone and storage pits were in some way associated with aggregates of females rather than with males.

\section{Matrilineal Groups}

Although it seems quite likely that uxorilocal residence units existed at Broken $\mathrm{K}$ in prehistoric times, it is quite another thing to suggest that they were matrilineal groups (Gough 1961:551-52). So far, no evidence has been presented to show that the residence units were even groups, much less matrilineal groups. In order to be sure that matrilineal groups actually existed, it would be necessary to demonstrate that all of the attributes of such groups (as defined by social anthropologists) can be isolated at the site. Clearly this cannot be done. (See list of the major attributes of localized lineages given near the beginning of this chapter.)

Nonetheless, some bits of evidence suggest that matrilineal groups actually did exist at Broken $\mathrm{K}$. In any event, a case can be made in support of the idea that they were corporate groups with matrilineal inheritance.
In order to support this proposition, the following points will be tentatively demonstrated:

1. The uxorilocal residence units defined above consisted not simply of aggregates of women who shared certain stylistic peculiarities, but they were also integrated groups of women.

2. These integrated groups of women were "corporate," in the sense that they cooperated in certain activities, and in the inheritance of nonmovable property.

If it can be shown that the uxorilocal residence units at Broken $\mathrm{K}$ were probably corporate groups, within which nonmovable property was inherited, then it will be reasonable to believe that a system of matrilineal inheritance was in existence in the Southwest by at least A.D. 1200. Furthermore, given the existence of matrilineal inheritance, it is somewhat probable that matrilineal descent was also involved (Murdock 1949:37-38). The isolation of an actual descent system, however, can perhaps never be demonstrated with archaeological evidence.

\section{Demonstration of Integrated Groups}

The first step in showing that the two major residence units at Broken $\mathrm{K}$ consisted of integrated groups of people is to show that there was less social distance within each of the units than between them. An examination of the distribution maps illustrated 
in Figures 15 to 22 shows that this was probably the case. If similarities in ceramic design-elements, pottery-types, and firepit-types can be used as measures of social distance, then it is clear that there was a great deal of social distance between the two major residence units. In fact, of all of the stylistic attributes used here to isolate residence units, none were clearly shared by both units. Within each unit, however, there was a tremendous amount of stylistic sharing.

Within Unit I, for example, stylistic elements were shared to a great degree by all three subunits (IA, IB, and IC). Although Units IA and IB appear to have been more closely related in terms of stylistic sharing than either was to Unit IC, it is clear that all three of these subunits were more similar to one another than any of them were to either of the subdivisions of Unit II.

In examining Unit II, the same kind of relationships are evident. Much more internal homogeneity existed within Unit II than between either of its subunits and Unit I. It is interesting, however, that more distance appears to have existed between the subunits of Unit II than between those of Unit I.

All of these relationships that appear to be measures of social distance can be seen at a glance in Table 13. This table contains a list of all of the various stylistic categories used in isolating the loci of

TABLE 13

Distribution of Stylistic Categories Used in Isolating the Loci of Resident Units

\begin{tabular}{llllll}
\hline \multicolumn{1}{c}{ Stylistic Category } & \multicolumn{5}{c}{ Residence Units } \\
\cline { 2 - 6 } & IA & IB & IC & IIA & IIB \\
\hline Firepits, type IV & $\mathrm{X}$ & $\mathrm{X}$ & $\mathrm{X}$ & $\mathrm{X}$ & - \\
Factor 2, pottery-types, floors & $\mathrm{X}$ & $\mathrm{X}$ & $\mathrm{X}$ & - & - \\
Factor 1, pottery-types, floors & $\mathrm{X}$ & $\mathrm{X}$ & $\mathrm{X}$ & - & - \\
Factor 12, ceramic design, floors & $\mathrm{X}$ & $\mathrm{X}$ & $\mathrm{X}$ & - & - \\
Factor 2, ceramic design, floors & $\mathrm{X}$ & $\mathrm{X}$ & $\mathrm{X}$ & - & - \\
Storage pits, 7 to 15 present & $\mathrm{X}$ & $\mathrm{X}$ & $\mathrm{X}$ & - & - \\
Factor 13, ceramic design, floors & $\mathrm{X}$ & $\mathrm{X}$ & - & - & - \\
Firepits, type I & $\mathrm{X}$ & $\mathrm{X}$ & - & - & - \\
Flake choppers, floors & $\mathrm{X}$ & $\mathrm{X}$ & - & - & - \\
Factor 5, ceramic design, floors & $\mathrm{X}$ & - & - & - & - \\
Factor 4, ceramic design, fills & $\mathrm{X}$ & - & - & - & - \\
Prairie-dog bone, floors & $\mathrm{X}$ & - & - & - & - \\
Factor 9, ceramic design, fills & $\mathrm{X}$ & - & $\mathrm{X}$ & - & - \\
Factor 6, ceramic design, floors & - & $\mathrm{X}$ & - & - & - \\
Factor 3, pottery-types, floors & - & - & - & $\mathrm{X}$ & $\mathrm{X}$ \\
Factor 4, pottery-types, floors & - & - & - & $\mathrm{X}$ & $\mathrm{X}$ \\
Factor 1, ceramic design, fills & - & - & - & $\mathrm{X}$ & $\mathrm{X}$ \\
Factor 2, ceramic design, fills & - & - & - & $\mathrm{X}$ & $\mathrm{X}$ \\
Firepits, type III & - & - & - & $\mathrm{X}$ & $\mathrm{X}$ \\
Factor 3, ceramic design, floors & - & - & - & $\mathrm{X}$ & - \\
Factor 9, ceramic design, floors & - & - & - & $\mathrm{X}$ & - \\
Mountain-sheep bone, floors & - & - & - & $\mathrm{X}$ & - \\
Gopher bone, floors & - & - & - & $\mathrm{X}$ & - \\
Firepits, type V & - & $\mathrm{X}$ & - & $\mathrm{X}$ & - \\
Factor 4, ceramic design, floors & - & - & - & - & $\mathrm{X}$ \\
Factor 3, ceramic design, fills & - & - & - & - & $\mathrm{X}$ \\
Firepits, type II & - & - & - & - & $\mathrm{X}$ \\
Storage pits, none present & - & - & - & - & $\mathrm{X}$ \\
\hline
\end{tabular}


residence units, and it shows the areas within the pueblo in which each was dominant (marked with an $\mathrm{X})$. The first thing to notice is that there was little stylistic overlap between Units I and II. Within each major unit, however, there was a tremendous amount of overlap (sharing). If stylistic sharing is a reflection of other kinds of sharing and cooperation, then it can be concluded that the major lines of cooperation (and thus integration) were within each of the major residence units rather than between them.

A more direct way to demonstrate that the two major residence units were internally integrated, however, is to show that their subunits were closely articulated through common membership or control of an integrative institution-represented by kivas in this case.

Using the distribution maps of ceramic designelement and pottery-type factors already presented, it is possible to make some inferences concerning which residence units owned or used which kivas. The reader may already have noticed that some of the factors that characterized residence units were also found to a significant degree on the floors of one or another of the kivas. It seems likely that if the floor of a kiva contained a significant amount of a factor that was dominant in the location of a particular residence unit, then the kiva was used or controlled by that unit.

The earliest excavated kiva at the site (41-kiva) is the only kiva that appears to have been used or controlled by all of the inhabitants of the site. Of the three factors dominant in this kiva, two (Fig. 20, Maps A and B) were most significant in Units IIA and IIB, while the third (Fig. 16, Map D) was most significant in Units IA, IB, and IC. Since this was an early kiva, however, it may be that units IA, IB, and IIA (in the earliest half of the site) were the only units participating in its activities. Nonetheless, both major residence units seem to have been associated with it, and this suggests that the entire village was integrated by the ritual carried on in this kiva-at least during the early stages of occupation.

The factors in the later three kivas indicate a possible breakdown in this pan-village integration. Room 29-kiva, for example, shows an association with Units IA, IB, and IC only (Fig. 16, Map A). The suggestion here is that this kiva was controlled or used by the people of Unit I only, and it probably served as an integrative mechanism binding Units IA, IB, and IC together.

The plaza-kiva was also associated with Unit I. In this case, three different factors showed that the kiva was associated with Units IA, IB, and IC (Fig. 16, Maps $A$ and $B$ ), and two factors showed it associated with Units IA and IB, respectively. It seems likely that the ritual carried on in the plaza-kiva served as an integrative mechanism for all of Unit I and that Unit II did not participate in it.

Unit II apparently had a kiva of its own-Room 6-kiva. Two factors occurred to a significant degree in this kiva (Fig. 20, Map B; Fig. 21, Map F), and both were of particular importance in Unit IIA. Although one was significant in Unit IIB, it was somewhat weak in that unit, and it is possible that Unit IIB was not sharing in the control or use of this kiva. This is not surprising, however, since Unit IIB was probably one of the latest residential units at the site; it may have been in existence after all of the kivas had been abandoned (Chapter 7).

Still, there is ample evidence to propose that, except during the earliest stages of occupation of the site, each of the two major residence units had its own kiva (or kivas). And in the case of Unit I, at least, all of the subunits of the major unit appear to have been associated with the kiva activities.

Since both of the major units appear to have been integrated in terms of participation in common ritual and the sharing of stylistic features, it is now permissible to refer to them as residence groups. The term group carries with it the implication that the members were integrated in some way.

\section{Demonstration of Corporate Groups}

Some evidence has already been presented that suggests that the two major uxorilocal residence groups had corporate characteristics (for a definition of corporate, see Service 1962:123-25). First of all, within each of the groups there was a sharing of stylistic features. This suggests the possibility that the people within each group were cooperating with one another in certain economic concerns in which pottery, storage pits, and choppers played a part; and, secondly, that the subgroups within at least one of the major groups (Unit I) were cooperating in certain ritual concerns.

As further evidence of corporateness, it may be possible to show that nonmovable property was being inherited within each of the groups. It does not seem possible to know how land was inherited; but rooms constitute nonmovable property, and a small amount of evidence suggests that rooms were inherited within the groups. 
It has already been shown that each of the residence groups lived in certain localized areas of the pueblo for at least three generations. There is no evidence that women changed residence locations frequently. The fact that the same groups of rooms were occupied for three generations, and by the same uxorilocal residence groups, suggests that rooms were inherited through time within the groups.

Kivas may have been inherited within the group too (and possibly membership in the kivas). As has been shown, each major residence group probably had its own kiva; if this kiva was controlled by the group for more than two or three generations, it was probably inherited. It seems likely that each kiva was in use for at least two generations, since the village was occupied for about 130 years, and there seem to have been three different kinds of kivas used during this time $(130 / 3=43$ years $)$.

Considering the evidence presented here, there is some indication that we are dealing with true corporate groups and that these groups were uxorilocal residence groups. This is precisely the pattern among the modern western Pueblos (Eggan 1950:299).

\section{Demonstration of Matrilineal Groups}

Turning now to a consideration of the major attributes of lineages, it is clear that four of five of these attributes have been demonstrated, at least in part, with respect to Broken $\mathrm{K}$ Pueblo. The following have been so demonstrated: (1) localization of the group, (2) time-depth (at least two generations), (3) cooperation within the group (ritual and possibly economic cooperation), and (4) inheritance of nonmovable property within the group.

It cannot actually be shown that the members of each major uxorilocal residence group at Broken $\mathrm{K}$ were consanguineally related kinsmen in terms of matrilineal descent (Point 3), but the fact that the other four attributes of lineages have been at least partially demonstrated is sufficient to suspect that matrilineages existed at the site.

Perhaps the most important reason for thinking this is that the uxorilocal residence groups at Broken $\mathrm{K}$ possessed certain corporate characteristics. Corporateness is usually, though not always, associated with lineality (Murdock 1949:37-38; Service 1962:123-25). On this basis, it is possible that we are dealing with matrilineal descent groups. Murdock's cross-cultural data support this inference, as follows (1949:38);
1. Twenty societies had matrilocal residence; 13 of these had matrilineal inheritance. On the basis of this sample, there is a probability of 0.65 that a matrilocal (or uxorilocal) society will have matrilineal inheritance.

2. Twenty-seven societies had matrilineal inheritance; 23 of these, had matrilineal descent. On the basis of this sample, there is a probability of 0.85 that a society with matrilineal inheritance will also have matrilineal descent.

Both of these findings support those presented in this paper, but the second one is by far the more interesting. If, as has been partially demonstrated, matrilineal inheritance existed at Broken $\mathrm{K}$, then the probability is quite high (roughly 0.85 ) that matrilineal descent existed also.

Considering these figures in conjunction with the fact that matrilineal descent groups are the rule among the modern western Pueblos (Eggan 1950:291-92), we may reasonably suggest that matrilineal descent existed at Broken $\mathrm{K}$.

It is even possible that matrilineal clans and lineages, as they are known today among the western Pueblos, existed at the site. The two major residence groups may have been clans, and their subdivisions may have been lineages. This idea is supported by the fact that the major groups seem to have owned or controlled the kivas, while the subdivisions generally did not have kivas. Among the Hopi and Zuni, kivas (or ceremonial rooms) are owned by particular clans, and each clan provides the officers and most of the ceremonial paraphernalia for the rituals carried out in the kiva (Titiev 1944:104; Eggan 1950:89-90, 220-21). If kivas were controlled by clans at Broken $\mathrm{K}$, then it seems likely that the two major residence groups at the site should be identified as clans (or possibly even moieties). There is no adequate way, however, to demonstrate this.

\section{Comments and Comparisons}

Evidence has been presented that makes it reasonably certain that uxorilocal residence groups existed at Broken $\mathrm{K}$, and the groups may have been matrilineal. The groups were defined on two different levels-large groups and subdivisions of these groups. The two large groups may have been analogous to clans, while the subdivisions may have been analogous to lineages.

In the process of isolating these groups, a few cases were seen in which a particular stylistic item used in defining the locus of a group was found to occur (to a 
minor degree) in an area considered to have been occupied by a different group. It was particularly noticeable that a few of the stylistic items used in defining Group I were also found to occur in a single room in the east wing (Group IIA). This happened so infrequently, however, that it does not suggest the possibility of any significant mixing of Groups I and II. Since the stylistic elements involved were all associated with female activities, there is a possibility that at least one woman from Group I had taken up residence within the locus of Group IIA. If so, we have discovered an exception to the general pattern of residence. The question is, how could this have come about?

One possible explanation comes immediately to mind, although it may not be the only possibilitythat is, matrilocal residence with resident male head (Table 12). Certainly this model would fit the facts. In this situation, the general residence pattern would be matrilocal (or uxorilocal), but each localized group would have a resident mother's brother acting as headman. This man might bring (or import) his wife and children from another group. In other words, it may be that one of the men from Group IIA at Broken $\mathrm{K}$ married a woman from Group I and, instead of living uxorilocally, he brought his wife to live with him in his natal lineage. The presence of a woman from Group I in the area occupied by Group II could lead to the presence in that group of certain female-associated stylistic elements normally peculiar to Group I.

It would be extremely difficult to demonstrate that this actually happened at Broken K; nonetheless, it is a possibility that would account for certain "abnormalities" in the distribution of certain stylistic elements. It is difficult to believe, however, that in a village as small as Broken $\mathrm{K}$ a man would find it necessary to maintain his residence among his own matrilineal kinsmen. Even as a headman, he could probably have maintained control of his lineage if he had lived in some other part of the village. Nonetheless, the kind of residence postulated here has been found to occur from time to time among the Zuni (Kroeber 1917:105), and it might have happened at Broken K.

Regardless of this possible exception to the residence mode, it is evident that most men were living uxorilocally.

If the two levels of residence units defined at Broken $\mathrm{K}$ can be likened to clans and lineages, for the sake of argument, there is an interesting parallel to the modern western Pueblos-particularly the Hopi. It is often the case that Hopi clans are composed of more than one lineage (Eggan 1950:299-300). The lineages are subunits of the clan; and this kind of organization may be very similar to the situation that existed at Broken $\mathrm{K}$, where each major residence unit had at least two subunits.

Comparison of this two-level kind of organization with what Longacre found at Carter Ranch Site is interesting (Longacre 1964b,1970). He seems to have isolated two localized residence units at that site. Whatever they were, each occupied a cluster of about 20 rooms. This is approximately the number of rooms occupied by each of the subgroups at Broken $K$. If equivalent kinds of social units tended to occupy equivalent numbers of rooms, it would seem that Longacre's two units were equivalent to the smallest units defined at Broken K; and Carter Ranch Site as a whole was equivalent to one of the major units at Broken $\mathrm{K}$.

This would suggest that there were changes in the social organization of villages through time in the Carter Ranch Valley, as these villages increased in size (based on a sample of two villages). Carter Ranch Site may have consisted of a single exogamous clan, with two lineages; while Broken $\mathrm{K}$ consisted of two exogamous clans, with two or three lineages each. And it can be further supposed that while Carter Ranch Site was exogamous as a unit, Broken $\mathrm{K}$ was endogamous.

Although these things cannot actually be demonstrated, the evidence that has been presented certainly points in the right direction. In short, there may have been a tendency about A.D. 1200 (in east-central Arizona) for an increase in the number of clans per village, as village size increased. Specifically, there may have been a shift at this time from single-clan villages to multiple-clan villages.

At the same time, there may have been a shift toward more lineages per clan. At Carter Ranch Site there seems to have been two lineages (perhaps constituting a clan), while at Broken $\mathrm{K}$, one of the clans had three lineages. If this is true, we should presumably find that in the smaller pueblo sites antecedent to Carter Ranch Site there was only one lineage per clan (lineage equals village).

Should this be the case, we will have some good evidence in support of a proposition made by Steward (1937) and reiterated in somewhat modified form by Eggan (1950). Eggan states this proposition as follows (1950:300): 
It is probable that an equivalence of clan and lineage is the earlier pattern.... But with the growth of populations and the widespread migrations of the thirteenth and fourteenth-and later-centuries, the development of multi-lineage clans was almost inevitable in the western Pueblos. Multiple-lineage clans are more stable and organize a larger population, other things being equal, than do single lineages.

Eggan's dating of this shift may be somewhat late, since the present evidence suggests that it began by at least A.D. 1100; but the essential aspects of his proposition would seem to be supported.

Even if the residence units at Carter Ranch Site and at Broken $\mathrm{K}$ did not correspond to clans and lineages, the fact that the units appear to have been organized on two different levels of social grouping is an indication that the basic principles of organization seem to have been similar to those in existence among the modern Hopi.

Furthermore, it now seems reasonably certain that it is possible to identify social units in prehistoric sites (at least at some of them) and that these units can be compared in time and space. Instead of using such names as clan and lineage, we can give arbitrary names to the units. In the present case, for example, we could call the largest units A-groups, and their subdivisions B-groups, and then proceed to discuss their characteristics and interrelationships. As more and more sites are subjected to this kind of study, it should become possible to make classifications and comparisons of social organizations. Once we have defined spatial and temporal variability in social organization, we should be in a position to explain this variability in terms of associated ecological variability and change.

Apparently, this can be done in the absence of ethnographic evidence. Although such evidence is more than merely helpful, it should be possible to compare social organizations relative to one another without it. In the event that adequate ethnographic evidence is not available (and even when it is available), it should be possible to compare sites with respect to their equivalent kinds of social groupings, just as has been done here with regard to Carter Ranch Site and Broken K. The actual names that might be assigned to different levels of social grouping would be relatively unimportant, as long as their general characteristics were clearly understood. It would still be possible to define the groups and measure and explain their changes in time and space. When this can be done, we shall have a much improved basis for explaining cultural variability and change. 


\section{POPULATION SIZE AND SOCIAL GROUPS}

The purpose of this chapter is to devise an acceptable approximation of the numbers of people who once lived at Broken K Pueblo and, from this, to determine the number of people who lived within each of the previously determined loci of residence groups. It may even be possible to establish certain rough equations between the residence groups at Broken $\mathrm{K}$ and those among the western Pueblos, based on similarities in numbers of people.

Given the kinds of evidence available, it would seem that the size of the population can be estimated in at least two ways. Perhaps the most accurate method is to determine the average numbers of people per room (and/or household) in the two ethnographic control groups (Hopi and Zuni) and then apply this information to Broken $\mathrm{K}$. The other method is to use independent cross-cultural comparative information on the average numbers of people per square unit of floor area, and apply this to the site.

Both of these methods of estimation should yield population sizes somewhat in excess of the actual number of people who inhabited Broken $\mathrm{K}$ at any one time. The reason for this is that it is very doubtful that all of the rooms were occupied simultaneously. We know, from ethnographic evidence, that the Pueblo Indians frequently abandon rooms within an occupied village and build new ones in other locations in the village (Donaldson 1893:47). There is even some evidence concerning the percentages of rooms that we can expect to find abandoned in a living Pueblo village. This evidence is as follows (figures derived from data in Kroeber 1917:110-16 and Stubbs 1950:91-93, 95-97, 113-15, 117-19): Zuni, 19 percent of rooms abandoned; Walpi, 25 percent; Shongopovi, 10 percent; and Oraibi, 33 percent. Although these figures may be somewhat in error, and the sample of villages is small, the percentages are not highly variant from one another. The mean of these figures, about 22 percent, will be applied to Broken $\mathrm{K}$.

One other point should be brought up at this time. The population figure determined in this study will be assumed to represent a time during the occupation of the site when it was a healthy and prosperous village. If we could determine the size of the population near the time of abandonment (about A.D. 1280), we might find that most of the rooms were abandoned and that very few people were in residence.

\section{Estimates Based on Ethnographic Data}

There is fairly clear ethnographic evidence with respect to the numbers of people per occupied room among the modern Pueblos. Stubbs (1950) presents evidence showing that there are, on the average, about three people per room. A careful examination of his data on four of the Hopi villages led to the following averages: Walpi, 3.3 persons per room; Shongopovi, 4.6; Oraibi, 2.4; and Hano (Tewa), 2.1. The average number of people per room here is 3.1 . Titiev (personal communication) believes that an average of somewhere between 2.5 and 3.0 people per room is reasonably correct.

Roberts $(1956: 9,43,78)$ provides data on three individual Zuni households; his figures give an average of almost 2.0 per room. This, of course, is a much smaller sample than we have used with respect to the Hopi, and for this reason the accuracy of the figure may be questioned. A figure of 2.8 people per room will be used in the present study.

It should then be possible to multiply 2.8 times the number of rooms at Broken $\mathrm{K}$ (minus 22 percent) and obtain a rough estimate of the population. First, however, it must be determined that modern Pueblo rooms are roughly the same size as those at the site (about 8.3 sq. m. of floor area, on the average). Zuni rooms are often much larger than this. A typical Zuni room apparently measures 20 feet or more per side (roughly 27 sq. m.) (Stubbs 1950:91-93; Roberts $1956: 12,45,81)$. Hopi rooms, on the other hand, are similar in size to those at Broken K (roughly 9.0 sq. m.) (Mindeleff 1891:108-109; Donaldson 1893:53).

Since our determination of the number of people per room (2.8) was based on Hopi data, and since Hopi rooms are roughly the same size as those at Broken $\mathrm{K}$, it seems that we are justified in believing that there were about 2.8 people per room at the site, other things being equal. Since there were 89 rooms at the site (excluding kivas), the population may be 
estimated at 249 people. If 22 percent of the rooms had been abandoned, however, the population estimate should be reduced to 193 . With 700 square meters of floor-area at the site (minus 22 percent), each person must have been allotted about 2.8 square meters-a very small space in which to live!

Another way to use ethnographic evidence in this problem is to take independent data on the average numbers of people per household among the Hopi and multiply this by the number of households at Broken K. First, of course, it will be necessary to estimate the number of households at the site.

Chang (1958:302) has suggested that throughout the world the most obvious index of a household is its hearth or fireplace. The Hopi are apparently no exception (P. Beaglehole 1935:42). It should be possible, then, to count the number of firepits in habitation rooms at Broken $\mathrm{K}$ (minus 22 percent) and thus determine the number of households. This procedure indicates that there were roughly 25 households.

But it would also seem to be legitimate to simply count the number of habitation rooms themselves. There is evidence that among the modern Hopi each household has a single room that is the nucleus of a group of two or more rooms, and it is regarded as the essential unit in the household (Mindeleff 1891:102; Titiev 1944:197). At Broken $\mathrm{K}$ the only rooms which would appear to have been analogous are the habitation rooms; since there were 26 of them, it is reasonable to suggest that there were also 26 households.

This, of course, assumes that the households did not have more than one habitation room. There is some evidence that among the Hopi most households occupy a group of two rooms-one habitation room and one storage room (Mindeleff 1891:65). At Broken $\mathrm{K}$ there were almost exactly the same number of habitation rooms as there were storage rooms ( 26 and 24 , respectively); this suggests that each household had approximately one of each. On this basis, we would still conclude that there were approximately 26 households at the site (during the entire occupation). Subtracting 22 percent of these households as a correction for abandoned rooms, it is concluded that about 20 households existed during a single time period.

The next step is to determine the approximate number of people living in these households. On this point the ethnographic evidence is fairly clear.
Steward (1937:95), using data provided by Parsons (1929: 9-10) and Kroeber (1917:123), concluded that in a sample of 14 pueblos, the average number of people per household was 5.0. Donaldson (1893:47) provided data for the Hopi that suggest an average of 5.7 per household, and Beaglehole (1937:37) suggested a mean of 7 or 8 . Titiev (1944:52) conducted a census at Old Oraibi in 1933-34 and provided data suggesting a mean of 5.9 for that village. P. Beaglehole $(1935: 41)$ stated that for two Hopi villages (Shipaulovi and Mishongnovi) the mean was about 6.5 people per household.

Averaging all of the above figures, it is concluded that 6.1 (or 6) people per household is the most reasonable figure to use with regard to Broken $\mathrm{K}$. If there were 20 households at the site, and if each housed 6 people, there should have been a population of about 120 people (that is, 4.55 sq.m. per person).

This would seem to be somewhat more reasonable, in terms of the amount of space allotted each person, than was the estimate based on numbers of people per room ( 2.8 sq. $\mathrm{m}$. per person). It is somewhat difficult to imagine a person living in an area of only 2.8 square meters. This would be hardly enough room in which to lie down, let alone carry on an active life, store material goods, and so on. If the people were only sleeping in the rooms, and not carrying on other activities, it is possible that they could be allotted so small a space-but the modern Pueblos carry on many activities in their rooms, and presumably this was the case at Broken $\mathrm{K}$. It seems likely, therefore, that a population of about 120 people is more probable than a population of 193 .

\section{Estimates Based on Cross-Cultural Data}

Naroll (1962:587-89) studied data from a sample of 18 different societies to find out whether or not there was a consistent relationship between the total area of dwelling floors and the total population. His study showed "a loglog regression which suggested that the population of a prehistoric settlement can be very roughly estimated as of the order of one-tenth the floor area in square meters" (that is, 10 sq. m. per person).

Without questioning Naroll's methods, and realizing that his sample of societies was small, it was decided to apply his results to Broken $\mathrm{K}$. Based on a floor area of 700 square meters at the site, his figure yields a population estimate of 70 people. Then, applying the 22 percent correction for abandoned 
rooms (abandoned floor area), the estimate would be 55 people. This is clearly a much lower estimate than the two that were based on direct ethnographic data, and its validity is seriously questioned. It seems likely that Naroll's small sample was biased (that is, was not representative of societies living under such crowded conditions as do the Pueblos).

Another study, similar to that made by Naroll, was published by Cook and Heizer (1965). Using data from 27 tribes or localities in California, they present evidence which suggests that there should be one person for every 33 square feet (about 3 sq. m.) of floor area. Applying this to Broken $\mathrm{K}$, we would have a population estimate of about 233 people. Then, subtracting 22 percent to correct for abandoned rooms, we are left with an estimated population of 182. This seems to be in line with the two estimates made on the basis of ethnographic data.

Judging from the apparent discrepancy between this study and that made by Naroll, it probably is not safe to rely on either of them in estimating the population of Broken $\mathrm{K}$. It is not surprising that their results differ, since neither study employed a very large sample of the world's societies. The possibility of sampling error must certainly be considered, and it also seems likely that there is no relationship between floor area and population that is constant on a world-wide basis. It must not be implied that the works of Naroll, Cook, and Heizer have no value; but it would not be judicious to apply their specific results blindly to the present problem.

\section{Populations of the Residence Groups}

Since it has been possible, through the use of ethnographic data, to make a rough estimate of population-size for Broken $\mathrm{K}$ as a whole, it will be a simple matter to apply the result to estimating the populations of the previously determined residence groups.

If the population of the site was in fact about 120 people, we can divide this total by the number of rooms at the site (minus 22 percent) and determine the approximate number of people per room. We can then multiply this figure by the number of rooms in each residence unit (minus 22 percent) and obtain a rough estimate of the population of each unit.

The total number of nonceremonial rooms at the site, minus 22 percent, equals 69 rooms. Considering a population of 120 people, there would have been about 1.7 people per room. Residence Unit I had a total of about 48 rooms (minus 22 percent) and would thus presumably have housed close to 65 people. Residence Unit II had about 41 rooms (minus 22 percent) and may have housed about 55 people. The five subgroups (IA, IB, IC, IIA, and IIB) averaged 18 rooms each (minus 22 percent) and perhaps housed roughly 24 people apiece.

A comparison of the estimated populations of the residence units at Broken $\mathrm{K}$ with estimates of the sizes of certain Hopi and Zuni social groups is interesting. Although there is much variability in the sizes of particular kinds of social groups in both societies, the average sizes of some have been estimated. Eggan $(1950: 201 ; 1964: 178)$ gives the following figures:

$\begin{array}{ccc}\text { Social Group } & \text { Hopi } & \text { Zuni } \\ \text { Phratry } & 100 & \ldots \\ \text { Clan } & 35 & 100 \\ \text { Subclan } & . & 35 \text { (probably) }\end{array}$

The average size of Zuni subclans is not given in numerical form by Eggan, but he suggests that it may be approximately the same size as the Hopi clan, and it has been represented as such above.

If these three kinds of social groupings have remained roughly constant in size since A.D. 1300, we may suspect that the smallest units at Broken $\mathrm{K}$ (population of 24) were analogous to the Hopi clan and the Zuni subclan, while the largest units (population about 55) were analogous to the Hopi phratry and the Zuni clan (although the similarities in size are not very close).

Many problems are involved in this kind of estimation. One complication involves the fact that we know that Hopi and Zuni clans have been greatly reduced in size in recent years (Eggan 1950:201, 300). If in earlier times the clans were twice the size they are now, then the largest units at Broken $\mathrm{K}$ might have been analogous to Hopi clans rather than to Hopi phratries-and there would have been no group analogous in size to a Zuni clan. There is clearly not enough evidence to permit any accurate statements concerning the equivalence of social groupings between Broken $\mathrm{K}$ and the modern western Pueblos. This attempt to establish such equivalence has been included simply because it seems likely that it represents a problem which may become of increasing concern to southwestern archaeologists. 


\section{BURIALS}

As noted in Chapter 3, only two burials were recovered from Broken $\mathrm{K}$-an infant under Room 34 and an adult male under Room 27. It is unfortunate, of course, that no other burials were discovered. A large number of them, such as were found at Carter Ranch Site (Martin and others 1964; Longacre 1964b,1970:41) would have been extremely useful in analyzing the social organization of the people of Broken $\mathrm{K}$.

Longacre was able to show quite convincingly that the burials in the midden at Carter Ranch Site could be divided into three statistically different segments. One segment was clearly associated with the residence unit in the north half of the pueblo; another segment was associated with the residence unit in the south half; a third segment, located between the first two, contained a mixture of people from both units. Since this last group of burials was composed almost entirely of males, and since there were many more grave-goods with them than with any of the other burials, Longacre was able to infer that they represented relatively high-status individuals (1970: 43).

The fact that this kind of analysis cannot be done for Broken $\mathrm{K}$ is not surprising. It is often the case that few or no burials are found at pueblo sites. This is especially true for the Mogollon area (Bluhm 1957:127, 147) and for Pueblo III sites in other areas of the Southwest (Judd 1954:341). Even some of the largest sites, such as Pueblo Bonito and Awatobi, contained very few burials (Judd 1954:325; Brew 1940:47).

In the light of ethnographic evidence, one might not expect to recover many burials in prehistoric pueblos. The present-day Pueblo Indians are afraid of death (Kennard 1937:491-96; Judd 1954:330), and many of them do not bury their dead in the immediate vicinity of their villages (Parsons 1925:77, 1932:248-50). Of course a number of recent Pueblos bury their dead in church cemeteries within the boundaries of their villages, but this is clearly a post-contact phenomenon.

In any event, considering the probable population of Broken K (Chapter 11), it is obvious that not all of the burials have been found. It is also clear that the main burial ground did not lie within the site or within 50 yards of the site in any direction. If it had been anywhere within this area, the sampling procedure employed would almost certainly have permitted its discovery.

\section{Infant Burial}

One of the two burials recovered was that of an infant, the sex of which could not be determined. The infant had been interred in a small hole dug through the floor of Room 34, a small storage room in the north wing. The skeleton lay at a depth of about 30 centimeters below the floor in the northeast corner of the room. It was lying on its side, semiflexed, with the head oriented toward the northwest. No evidence remained to suggest that the body had been wrapped in anything, and there were no grave-goods at all. The only thing peculiar about the burial was that it contained extremely large quantities of Sphaeralcea pollen.

The fact that so much of this pollen-type was recovered from the burial is interesting, especially as the plant was found to be an important ceremonial or ritual plant among the present-day Zuni. It would seem likely that its association with the infant burial was ceremonial in nature. This might be interpreted as an indication that graveside ritual was involved in the interment.

The fact that the infant was buried under the floor of a room is not surprising, since this kind of infant-burial is an ancient Pueblo custom still practiced in several villages (Bunzel 1932b:482-83; Parsons 1939:71). Before a child reaches a certain age, he may not be buried in an adult cemetery (Beaglehole and Beaglehole 1935:13).

\section{Adult Burial}

The other burial recovered was that of an adult male who had probably reached an age of 18 to 30 years. He was interred in a pit underneath the south wall of Room 27 in the north wing, but this occurred before the room was constructed. At the time he was buried, the entire northern half of the site (late half) may not have been in existence, and it may be inferred that he was buried in the open area to the north of the earliest portions of the pueblo. This 
would probably be equivalent to a burial in the plaza, since this open area apparently served as a plaza for awhile.

The pit in which he was placed was almost a meter deep, two meters long, and 80 centimeters wide. It had been dug into extremely hard clay soil, and the bottom 25 centimeters of it had been cut into the sandstone bedrock. The excavation of such a pit would be no easy task, given the kinds of digging equipment the Indians probably had.

The burial was a semiflexed, primary interment; the body was lying on its back, just as were most of the burials at Carter Ranch Site (Rinaldo 1964c:60). It was oriented in a southwesterly direction, unlike the burials at Carter Ranch Site, and the arms were folded across the abdomen. The body had been wrapped in a twilled yucca mat and a fur blanket.

The grave-goods accompanying the burial consisted of a six-strand stone-bead bracelet on the left wrist (with red, black, and white beads), a stone-bead necklace around the neck, and sixteen pottery vessels. (One of these vessels contained corn and squash seeds; another contained some squash seeds and a bone ring.) The pottery-types, vessel-forms, and frequencies of each are listed in Table 14. It is notable that three of these types are painted wares and four are textured wares. Although it is not possible to know what, if any, meaning this symmetry had to the inhabitants of the village, it is possible that it had some importance. With only one adult burial, however, there is no way to compare it with other burials in order to look for regularities in mortuary practices.

The same difficulty applies to the nearly symmetrical distribution of vessel-forms. There were nine bowls and seven jars-or an almost equal number of each. This also might have had some significance.

It is interesting that 10 of these 16 vessels belonged to four of the pottery-types found to be of importance in kivas at the site-St. Johns Black-onred; Snowflake Black-on-white, Snowflake variety; Brown Indented Corrugated; and Patterned Corrugated. Four of the remaining vessels belonged to two of the pottery-types found to have been of ceremonial significance at Carter Ranch Site-McDonald Plain Corrugated and McDonald Indented Corrugated. This means that 14 of the 16 vessels in this burial belong to pottery types considered to have had ceremonial or mortuary importance within the same valley. The other two vessels (Snowflake Black-on-
TABLE 14

Pottery-types Accompanying Adult Burial

\begin{tabular}{llc}
\hline \multicolumn{1}{c}{ Pottery-Type } & Form $^{*}$ & Number \\
\hline $\begin{array}{l}\text { St. Johns Black-on-red } \\
\text { Snowflake Black-on-white, }\end{array}$ & $\mathrm{B}$ & 3 \\
$\quad$ Hay Hollow variety & $\mathrm{B}(\mathrm{J})$ & 2 \\
$\begin{array}{l}\text { Snowflake Black-on-white, } \\
\quad \text { Snowflake variety }\end{array}$ & $\mathrm{J}(\mathrm{B})$ & 3 \\
McDonald Plain Corrugated & $\mathrm{B}$ & 1 \\
McDonald Indented Corrugated & $\mathrm{B}$ & 3 \\
Brown Indented Corrugated & $\mathrm{J}$ & 3 \\
Patterned Corrugated & $\mathrm{J}$ & 1 \\
\hline
\end{tabular}

*Letters indicate bowls or jars.

white, Hay Hollow variety) were found to be of importance in habitation rooms only.

The presence of the two McDonald types of pottery in the burial is interesting, because at Carter Ranch Site these types were normally found with males (Rinaldo 1964c:61). The Broken K burial was male, and this evidence constitutes at least a weak corroboration of the idea that these smudged-interior bowls were in some way associated with males.

Perhaps the most interesting thing about the burial is the fact that the man was probably a high-status individual. There are several reasons for thinking this. First of all, he was given special treatment by being buried in the plaza-a place where most people were not interred. Secondly, the pit into which he had been placed had been excavated into hard earth and even bedrock, and it is difficult to imagine such effort being accorded an ordinary man. (Most burials are found deposited in trash in prehistoric Pueblo sites.) Thirdly, he was wearing both a bracelet and a necklace, things found primarily in high-status burials at Carter Ranch Site (Longacre 1964b, 1970:43).

In the fourth place, over twice as many pottery vessels were associated with this burial as with any of the burials at Carter Ranch Site. Most of the burials at that site contained three or four pots, and the one burial with seven vessels was considered to have had "unusually elaborate grave furniture" (Rinaldo 1964c:61-62). Even at such a large and important site as Pueblo Bonito, most of the burials contained many fewer vessels. One of the most ornate burials at that site had only 14 vessels (Judd 1954:325-37). 
There is one final but very interesting bit of evidence that the Broken $\mathrm{K}$ burial was of high status. An examination of the distribution of factor 1 of the ceramic design-element study of floor sherds (Fig. 23) revealed that this factor was of primary importance in the burial, and it was not found to a significant degree anywhere else in the site. The composition of the burial pottery was 96 percent factor 1 , while no room in the pueblo contained over 16 percent factor 1 . Only one room (Room 51 ) had 16 percent. None of the others had more than 6 percent. This evidence suggests that the designelements used on this pottery were somewhat different from those used on ordinary pottery, and the vessels may have been made specifically for the burial. Presumably the design-elements were consciously selected.

It is thus apparent, considering all of the evidence, that this man had been accorded special treatment, and there can be little doubt concerning the importance of the man (or his position) to the people of Broken $\mathrm{K}$.

It can also be inferred that this man was a member of one of the earliest groups to occupy the site. This is indicated not only by his stratigraphic position (prior to at least some rooms in the northern portion of the site) but also by the fact that factor 1 elsewhere in the site was found primarily in early rooms. Of nine rooms in which it occurred to a minor extent, only one (Room 65) can possibly be considered to have been relatively late (Fig. 2).

The social group to which this man belonged is difficult to determine. Since the highest concentration of factor 1 outside the burial was in Room 51, however, it is possible that he was a member of Group I.

Mortuary practices among the present-day western Pueblos exhibit many similarities to those which apparently existed at Broken $\mathrm{K}$ and other prehistoric pueblos. When a person dies, various rituals are performed and the body is buried as quickly as possible (Parsons 1936:824-28; Judd 1954:330). The body is wrapped in a blanket (Donaldson 1893:61) and placed in a grave that is often about an arm-length deep (Parsons 1936:827). Sometimes, at least among the Hopi, the deceased is "buried" in a rock outcrop (Donaldson 1893:61), but interment in the ground appears to be most common.

Offerings of food and water are sometimes (perhaps usually) placed in the grave with the body,

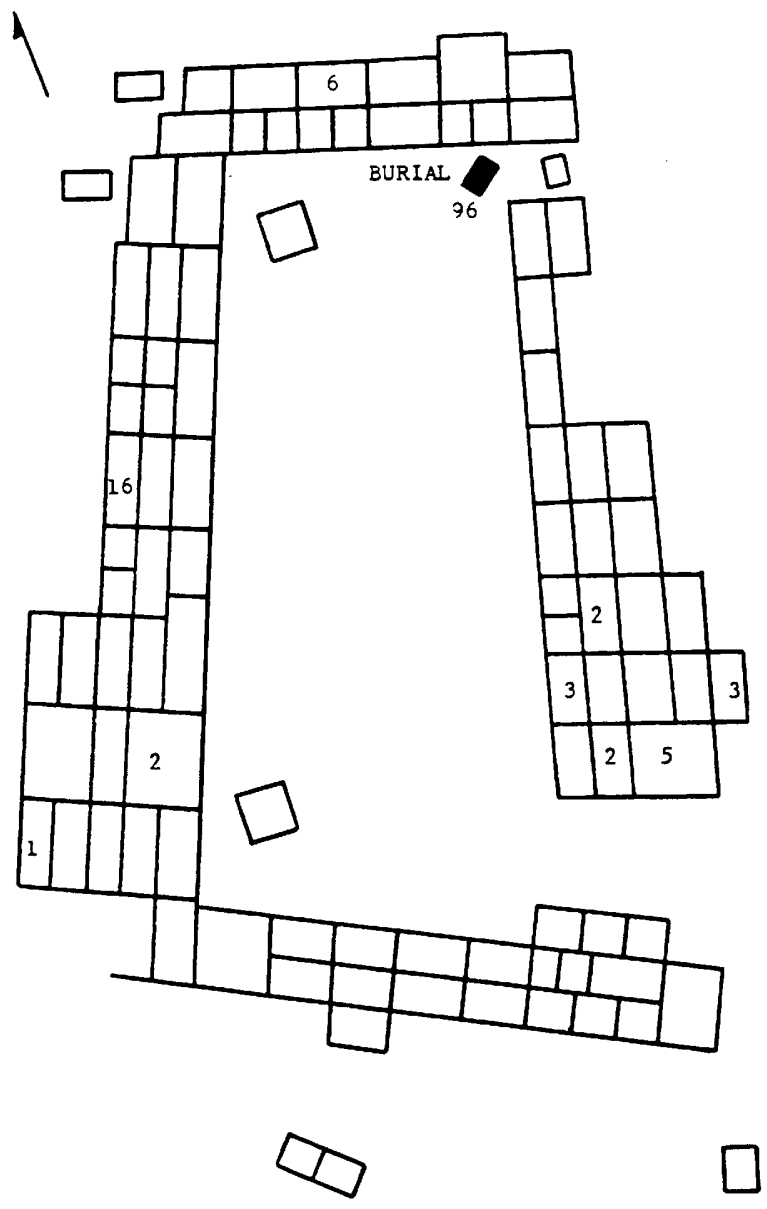

Figure 23. Distribution of factor 1, ceramic designs, on floors. Numbers are percentages of the factorcompositions of the areas in which they are found.

but sometimes such offerings are taken to the grave after burial (Donaldson 1893:61; Bunzel 1932b:540; Parsons 1936:828). At Awatobi, an early Hopi town, there is definite evidence that the people buried their dead with pottery (Fewkes 1893:375), and presumably these pots contained food and water, just as today.

It is important to point out, however, that the pottery itself is not considered to be important-it is the contents that are important (Alfonso Ortiz, San Juan Pueblo, personal communication). Nonetheless, the pottery used in burials is probably somewhat different from the ordinary household wares. The reason for thinking this is that at Zuni, at least, there are two general kinds of pottery-sacred and secularand certain kinds of designs are restricted to one or 
another of these types (Bunzel 1929:23-24). It is reasonable that pottery with sacred designs would be placed in burials more frequently than would pottery with secular designs, and this is apparently what happened at Broken $\mathrm{K}$.

There is also ethnographic evidence that persons who have achieved high status are accorded special treatment in burial. Southwestern archaeologists have usually ignored the possibility of isolating status differences among burials because it is a well-known fact that recent Pueblos do not have highly stratified societies. Nonetheless, achieved status differences are common in Pueblo groups (Brainard 1935:58-61; Li An-che 1937:68-69; Titiev 1944:59-68), and this is reflected in mortuary customs.

Among the Zuni, for example, deceased priests and other officials are accorded much more elaborate treatment than are ordinary men. They are given special garments and special ornaments, and they are permitted to lie in state for an hour or two so that the people can view them (Stevenson 1904:305-306, 316-17). It seems likely that similar treatment may have been accorded the man at Broken $\mathrm{K}$.

In addition to the fact that achieved status is reflected in mortuary treatment, it is also likely that the sexes were accorded different treatment. It has already been pointed out that at Carter Ranch Site, at least, men and women had slightly different types of pottery in their graves. This is reasonable in the light of ethnographic evidence.

Among the Hopi, deceased women are dressed in their marriage robes and deceased men are given society markings. Both sexes are given new names (Eggan, personal communication). At Zuni, the men are buried in separate locations from the women, and each body is clothed in the characteristic garments of his group (for example, society) (Bunzel 1932b:482-83). The fact that differential treatment of the sexes can be found in prehistoric burials is thus not surprising. 


\section{ENVIRONMENTAL SHIFT}

Although the climate of Arizona, and the Southwest in general, seems to have remained almost stable for the past 10,000 years (Martin 1963:61), there is evidence which suggests that small environmental shifts have taken place from time to time (Schoenwetter 1962; Martin 1963; Hevly 1964; Schoenwetter and Eddy 1964; Martin and Byers 1965). These shifts have apparently been important enough to stimulate adaptive responses by the human and nonhuman occupants of the area (Chapter 14).

One of these shifts apparently occurred sometime between A.D. 900 and 1300; this is most noticeable in the palynological record between A.D. 1100 and 1300. This, of course, was the time of the Great Drought, which is so frequently mentioned in the Southwestern archaeological literature. It also coincides roughly in time with the abandonments of large areas of the Southwest by Pueblo peoples. It has been suggested, time and time again, that the drought was a causal factor promoting these abandonments. Hargrave (1932:4) went so far as to say that, "There seems to be little doubt that drouths were fundamentally responsible for the great changes which took place during the time when so many pueblos were abandoned."

The usual form of this argument is that the postulated drought resulted in extreme dessication and a large-scale destruction of plant life. This, in turn, permitted a tremendous increase in the rate of soil erosion and a concomitant lowering of the water table. As a result, there was a significant decrease in the amount of arable land, and a reduction in the amount of land that could be supplied with water for farming. Under these conditions, many pueblos were abandoned (Douglass 1929; Hack 1942; Bryan 1954; Wendorf 1956).

This interpretation has recently been questioned, however. The term "drought" implies an extreme reduction in precipitation and a general drying-up of an area. It has been suggested (Schoenwetter 1962; Martin 1963; and others) that there may not have been a drought at all, and that the well-documented period of erosion may have been caused by a change in the periodicity of rainfall rather than an actual decrease in rainfall. This viewpoint is stated in summary fashion as follows (Martin 1963:68):
The classic Bryan-Antevs climatic model, deeply enmeshed in the literature of Southwestern prehistory and Pleistocene geology, relates prehistoric erosion to drought. I believe the same field evidence, with the addition of both fossil pollen and the biogeographic record, supports a model in which postglacial erosion is attributed to periods of intense summer rainfall. Alluviation of the headwater flood plains occurred during periods of relatively light summer rainfall. I find no reliable pollen evidence that postglacial droughts, if they occurred, were sufficient to shift biotic zones above their present level. [Italics mine]

If Martin is correct, there is no longer any need to invoke drought as a causal factor explaining the widespread erosion of the latter part of the twelfth century, the thirteenth century, and the early part of the fourteenth century in the Southwest.

There is not yet enough evidence to be sure that a drought did not occur, but it is becoming more and more evident that the problem is not as simple as it was at first thought to be. Regardless of the causal factors involved, however, it seems reasonably clear (on the basis of present evidence) that an environmental shift of some kind actually did occur at this time. Whether or not such a shift was the only factor that may have promoted the above-noted population disturbances is not yet clear (Chapter 15).

The concern of this chapter is to outline some of the major evidence which tends to document the occurrence of this shift. This is a necessary prelude to the following chapter, which is concerned with a discussion of some of the adaptations or responses to the shift that seem to have occurred in Hay Hollow Valley and at Broken K Pueblo itself.

\section{The Evidence}

Pollen

Recent palynological studies in the Southwest have led to the development of a general pollenchronology which has proved to be of great value for our understanding of prehistoric environments and environmental change. There are actually several separate chronologies from different areas, and most of them indicate that there was an environmental shift sometime between A.D. 1000 and 1350. The 
dates that have been given, in four of these chronologies, are as follows (the last two estimates are variant interpretations of eastern Arizona data):

Southern Arizona, A.D. 1200-1300 (Martin 1963)

Tesuque New Mexico region, A.D. 1100-1400 (Leopold, Leopold and Wendorf 1963)

Navajo Reservoir District, N.M., A.D. 800-1100 (Schoenwetter, in Schoenwetter and Eddy 1964) Upper Little Colorado River Drainage, Arizona, A.D. 1000-1350 (Schoenwetter 1962)

Upper Little Colorado River Drainage, Arizona, A.D. 1100-1300 (Hevly 1964)

Apparently the shift occurred somewhat earlier in the Navajo Reservoir District than elsewhere. Schoenwetter finds this somewhat difficult to explain, but he attempts to justify it in terms of ecological differences between his area and the others. There is also the possibility that the shift did not occur simultaneously throughout the Southwest (Schoenwetter, in Schoenwetter and Eddy 1964:103). Since Schoenwetter's pollen chronology was truncated just prior to A.D. 1100 , and there was no further record until A.D. 1550, there is no sure way to compare the data he does have with the other three chronologies. On this basis, it seems best to ignore the Navajo Reservoir District chronology for the time being. If this is done, the average beginning date for the environmental shift appears to be about A.D. 1100; it seems to have ended shortly after A.D. 1300.

The shift has been characterized palynologically as a change from a period in which arboreal pollen (especially Pinus) was relatively abundant to a period in which nonarboreal pollen (especially Chenopodiaceae and Amaranthaceae, or Cheno-ams) were relatively more abundant. Prior to A.D. 1100 (about A.D. 1000-1 100) arboreal pollen was quite common; between A.D. 1100 and 1300 it decreased, and nonarboreal pollen was relatively abundant (Schoenwetter 1962:188-89; Hevly 1964:101-109; Hill and Hevly 1968). This does not mean that there was a period in which actually more arboreal than nonarboreal pollen existed, since the latter was dominant throughout the period involved. It simply means that there were changes in the percentages of the types relative to one another (Hevly 1964:34-42, 106).

At the same time, changes occurred in the composition of arboreal pollen. One of these was a change in the ratio of pine to juniper. Prior to A.D. 1100 the record shows a high ratio of pine to juniper pollen, but between A.D. 1100 and 1300 a proportional increase in juniper took place, paralleling the relative abundance of nonarboreal pollen (Hevly 1964:101).

Another change in composition involved a change in the sizes of Pinus pollen grains. Large-sized grains (probably referable to Pinus ponderosa) dominate the arboreal spectrum prior to A.D. 1100 , while smaller grains (probably Pinus edulis-pinyon) were dominant between A.D. 1100 and 1300 when soil conditions were presumably less moist. As is the case with respect to the arboreal-nonarboreal shift, the change in size of pine grains has been found to occur in several areas of the Southwest (Schoenwetter 1962; Hevly 1964:101; Martin and Byers 1965).

Because these changes are found to have occurred over so wide an area, and because they have been observed in datable geological strata as well as in archaeological sites (Hevly 1964:100-104), there can be little doubt that the palynologists have found something pertinent. The problem now is largely one of refining our interpretations of this shift.

Apparently the shift reflects an actual change in the composition of the vegetation. It is now known, through studies of both modern and prehistoric vegetation communities in the Southwest, that in forested areas (or near forests) the proportion of arboreal to nonarboreal pollen is relatively high while on the grasslands and deserts there is a much larger proportion of nonarboreal pollen (for example, Chenopods and Amaranths) (Schoenwetter 1962:188; Martin 1963:69). Aside from the palynological differences between the forested and nonforested areas, however, there are other important differences, as follows (Schoenwetter 1962: 188-89; Martin 1963:15, 52, 69):

\section{Forested Areas}

Light summer rains-stability or alluviation Low moisture evaporation-cool and moist High water-table

Low soil-salt content

\section{Non-forested Areas}

Heavy, torrential summer rains-heavy erosion and disturbed soil conditions

High moisture evaporation-warm and dry

Low water-table

High soil-salt content

Although these differences must be expressed in relative terms, they are nonetheless real. 
Since these differences have been established, and since they are found to be associated with palynological differences, it seems reasonable that we can use pollen data in establishing changes in environmental conditions through time. Periods in which there is a relatively high proportion of arboreal pollen (especially Pinus) were probably characterized by a forest or near-forest environment, with the above associated conditions; periods having relatively high proportions of nonarboreal pollen were probably characterized by nonforest or floodplain environments, with their associated conditions (Schoenwetter 1962; Martin 1963:52-60).

This is the reasoning that has permitted the palynologists to infer the occurrence of an environmental shift about A.D. 1100 (or perhaps slightly earlier).

But what could have caused this shift? The problem is not simple, and is far from resolved. Schoenwetter and Eddy believe that there are three possible causes (1964:101-102): (1) a shift in temperature, (2) a shift in total precipitation (annual), (3) a shift in the periodicity of precipitation (that is, change in rainfall pattern, rather than amount of rainfall). Apparently, any or all of these things could promote such a shift, but the last possibility is clearly being favored. Schoenwetter and Eddy state that "The change has been interpreted as due to a fluctuation in periodicity of rainfall, but ... this is far from a resolved matter" (1964:103).

All of the palynologists cited seem to agree with this idea. Presumably there was a period (roughly A.D. 1000-1100) in which the annual precipitation was fairly evenly distributed throughout the year, with relatively light summer rainfall. About A.D. 1100 , however, this pattern shifted to one characterized by heavy, torrential summer thundershowers (without any major change in total annual precipitation). This shift created conditions in which there was heavy run-off and soil erosion, and this situation led to disturbed soil conditions which were more favorable to the growth of Chenopods and Amaran ths than to the growth of pine trees and other arboreal types. It is also believed that there was a general decrease in the amount of annual effective moisture and a concomitant recession of the tree-line about 500 feet upward (Hevly 1964:100-10). For more complete discussions of this interpretation, see Schoenwetter (1962), Martin (1963), Hevly (1964), Martin and Byers (1965), and Hill and Hevly (1968).

\section{Tree-rings and Pollen}

The excellent tree-ring chronology in the Southwest also has a bearing on this discussion of environmental shift. It has been known for a number of years that the growth rings of pine trees (pinyon and ponderosa) decreased in width during the thirteenth century (about A.D. 1215-1300) (Martin $1963: 61,66)$. It was at first thought that this was an indication of a drought during this time period and that this drought was related to a failure of agriculture and the widespread abandonments in the Southwest. More recently it has been believed that treerings are affected by winter precipitation primarily, so that they probably could not be used as indicators of summer precipitation conditions-and it is the summer precipitation that is of primary importance where agriculture is concerned. Thus, it was no longer considered correct to associate narrow tree-rings with dry summers, agricultural adversity and abandonments (Gladwin 1947:1-36; Martin 1963:66). Very recently, however, it seems to have been found that some tree rings are in fact affected by summer precipitation (especially Pinus ponderosa). If so, this might well have affected agriculture in prehistoric times (Bryant Bannister, University of Arizona, paper presented at S.A.A. meetings, Urbana, Illinois, May 8 , 1965).

Regardless of the complications, this period of narrow tree-rings coincides quite well in time with the vegetational shift indicated in the pollen chronologies (Figure 24). This is such a coincidence, in fact, that it is difficult to believe that the two things were not in some way related. Martin (1963:66) claims that they were related.

There is some even stronger evidence in support of this idea, however. In addition to the fact that the pollen and tree-ring chronologies both suggest an environmental shift about A.D. 1100 , they indicate that a similar shift may have occurred about A.D. 700. In fact, the two chronologies are closely paralle] from about A.D. 400 to the 1960s. Figure 24 reveals that during periods characterized by narrow tree-rings there was also a low proportion of arboreal to nonarboreal pollen; during periods of wide tree-rings there was a high proportion of arboreal pollen. This parallelism is remarkable and strongly suggests that the tree-ring data and arboreal and nonarboreal pollen data can be associated with common causal factors (Hevly 1964:106-107; Hill and Hevly, 1968). 


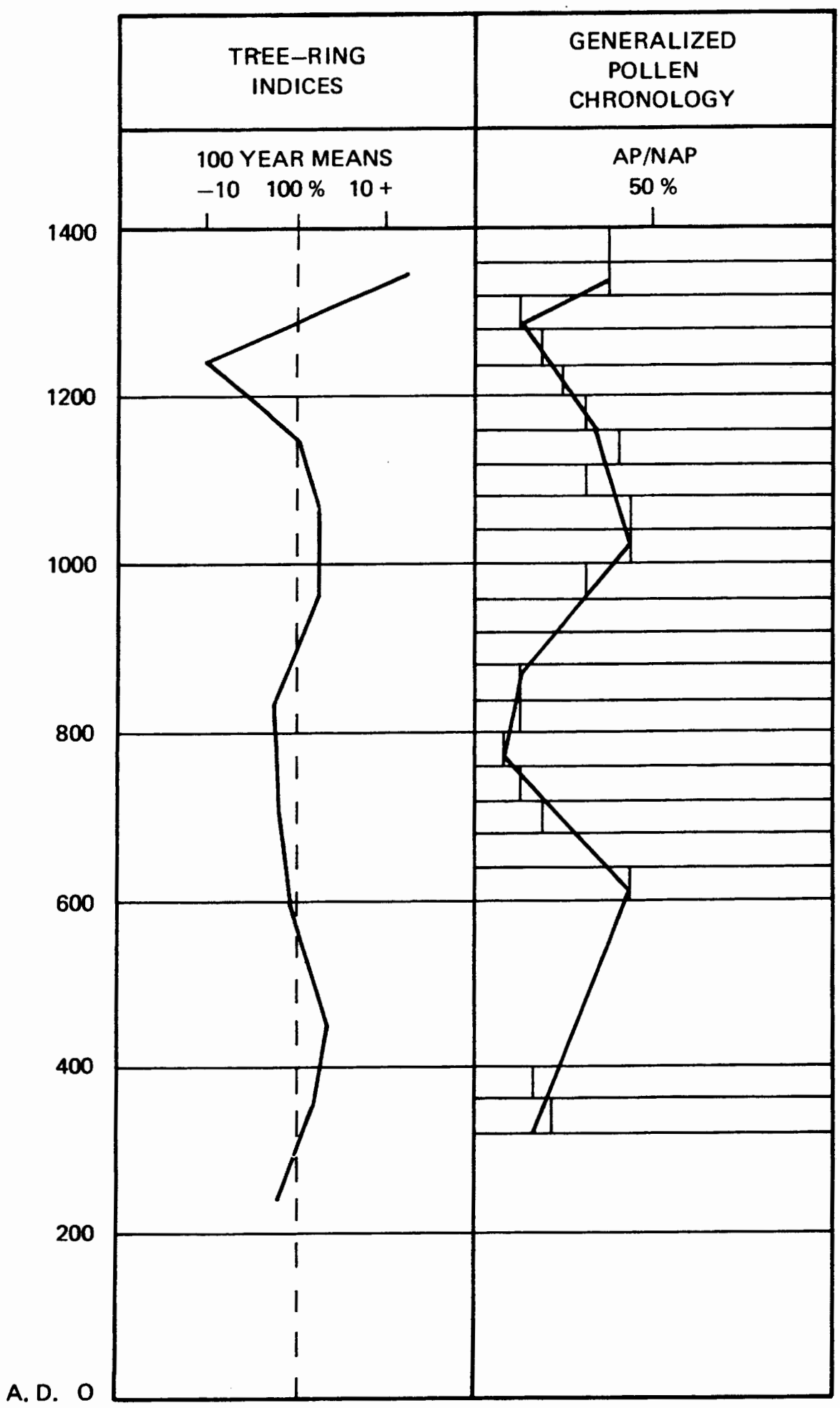

Figure 24. Comparison of tree-ring indices and generalized arboreal pollen chronology for southern portion of the Colorado plateau. This chart serves simply as illustrative material. A more detailed chart (and discussion) is given in Hill and Hevly (1968). 
One of these factors may have been annual effective moisture, as already suggested. Presumably, as the rainfall pattern changed from a situation characterized by evenly distributed annual precipitation to one characterized by torrential summer thundershowers, there was an increase in the rate of run-off and soil erosion. This led to a lowering of the water table and a situation in which there was no longer adequate moisture retained in the soil for the growth of many kinds of plants (Schoenwetter 1962; Hevly 1964:94-110).

\section{Physiography, Tree-rings, and Pollen}

The widespread erosion and arroyo-cutting in the Southwest during the twelfth, thirteenth, and fourteenth centuries is so well documented that it hardly needs discussion here (Douglass 1929; Hack 1942; Bryan 1954; Wendorf 1956; Schoenwetter and Eddy 1964).

The interesting thing in the light of the present problem is that it occurred at the same time as did the changes in the relative frequencies of pollen types and the changes in the widths of tree-rings. This temporal coincidence is so close, in fact, that it would appear that all three of these things were related (Schoenwetter and Eddy 1964:108-18).

That changes of some kind were occurring in the environment at this time can scarcely be denied, and it seems likely that the population movements and abandonments were related to these changes. Although there will be no attempt in this chapter to demonstrate a causal relationship, the possibility that such a relationship existed is evident (Chapter 14).

The upper Little Colorado River drainage, in which Broken $\mathrm{K}$ is located, was apparently no exception to the general pattern of environmental shift. Although there is little physiographic or treering evidence in this area, the pollen chronology is becoming increasingly refined, and it seems to fit well with the other chronologies. For thorough discussions of this specific chronology, see Schoenwetter 1962, Hevly 1964, and Hill and Hevly 1968. 


\section{RESPONSES TO A SHIFTING ENVIRONMENT}

It is a well-known fact that much of the Southwest is marginal for agriculture and for people who practice agriculture. This is true today-the 1960s-and it was apparently true in the past as well. Kroeber (1953:189-90), speaking of the Southwest, said:

The whole region is so arid that permanently dependable farming is generally only just within the threshold of possibility. Even a slight local or periodic variation in the summer rainfall, insufficient to change materially the native plant cover, might therefore suffice to push the barely held frontier of the farming culture forward or backward two or three hundred miles. Because of poising on the edge of feasibility, Pueblo farming and therefore culture were far more dependent on a single factor of climate than on fundamental physiographic configuration or general climatic type as reflected in natural vegetation. [Italics mine]

This statement clearly shows Kroeber's belief that even a very slight environmental shift might have had severe effects on prehistoric Puebloan peoples-and Kroeber is not alone in this belief. A number of studies of prehistoric (and modern) environment and agriculture in the Southwest seem to agree with this (Forde 1931; Beaglehole 1937; Hack 1942; Carter 1945, and others).

The modern Hopi are very closely tied to the environment. Whenever there are two or more successive years of drought, the Hopi are in dire straits (Titiev 1944:199). Agriculture, for them, is on the borderline between being possible and impossible (Forde 1931). They farm almost all of the arable land available (Hack 1942:18), and they have to use a tremendous amount of ingenuity in locating their fields so that crops will receive adequate moisture but will neither wash out during rainstorms nor get buried in silt (Forde 1931:362).

Hopi farming is predominantly of the floodwater type. Prior to the present epicycle of erosion (about A.D. 1900-present), many of their fields were located on the floodplains of seasonally active streams. As the land has become more heavily eroded, this type of farming has become more and more difficult. As the arroyos deepen and the water table gets lower, less and less land is reached by the floodwaters; thus floodwater farming is becoming increasingly less important (Forde 1931:363; Hack 1942:29-31). This apparently is making agriculture even less reliable than in the past.

The environmental shift may have had similar effects on prehistoric agriculture in the Southwest. Schoenwetter (1962:202) states this idea as follows:

The advent of ... a heavy summer rainfall pattern similar to that of the present, must have made dry farming an almost impossible practice. Significantly, most sites are located near permanent drainage ways or permanent springs.

The use of irrigation in the valleys near permanent drainages might have been a cultural advancement, but it could not have lasted long under the environmental conditions postulated... Sooner or later dissection of the flood plain by high energy summer storms would have caused the water table to fall to the point where irrigation could not be practiced. Since dry farming could not be practiced either, the area would have had to be abandoned if the culture remained committed to cultigens.

Whether or not the environmental shift was promoted by a change in rainfall-pattern, it is fairly generally accepted that the epicycle of erosion could have had serious effects on agriculture and other aspects of human life (Hack 1942:70-78; Wendorf 1956:21).

If this is correct, it should be possible to find some archaeological evidence reflecting human adaptations or responses to the shift. The widespread abandonments, previously mentioned, would seem to constitute such evidence, but there should have been many other observable responses as well-and apparently there were.

This chapter is devoted to isolating some of these responses and to relating them (when possible) to the environmental shift. The fact that both the shift and the responses occurred at the same time (about A.D. 1100-1300) suggests a possible causal relationship, and there is circumstantial evidence in support of this. If it can be shown that the responses were likely to have been promoted by shifts in the physical environment, we will have a more sharply refined understanding of the reasons underlying sociocultural change in the Southwest during this time period. This understanding may also be useful in studying the 
evolution of western Pueblo social organization and in studying sociocultural change in general.

\section{Evidence From the Southwest}

One possible response to a shifting environment was a marked change in the size of the population in the Southwest, which was in full force by about A.D. 1250. Several studies of population trends in different parts of the Southwest generally agree on an increase in population between about A.D. 500 and A.D. 1250 but a marked decrease thereafter. The date when the decrease began varies slightly, depending on the region studied; but considering the Southwest as a whole, it seems to have begun between A.D. 1000 and 1450. The date most frequently given is A.D. 1250, however (Brew 1940:4546; Hack 1942:78-80; Watson 1945:21; Bluhm 1957:120-21, 132-34; Longacre 1970:16-17).

A second possible response to a shifting environment was the general aggregation of population beginning between about A.D. 1050 and 1300. Prior to that time innumerable small pueblo villages were located in many areas of the Southwest; but after that the people seem to have come together into increasingly fewer, but larger pueblos (Fewkes 1893, 1900; Kroeber 1928:385; Hargrave 1935:24; Steward 1937:97; Haury 1956:5-7; Wendorf 1956:24-25; Bluhm 1957:91; Ellis 1964a:34, 38).

The interesting thing about this.process of aggregation is that the movement was generally toward large, permanent streams (Hack 1942:70-78; Eggan 1950:129; Bluhm 1957:121; Longacre 1970:16-17). This suggests that the people were moving in response to a need for water and perhaps arable land. Since these sites were generally no more defensible than the earlier ones, it seems reasonable that defense was not a primary motive for aggregation. It is more likely that aggregation was related to a shift in the physical environment.

Another possible response to a shifting environment was the apparent tendency for increasing the scope of social integration after A.D. 1050 or 1100 (somewhat earlier in Chaco Canyon). The development of the use of Great Kivas is one indication of this. These extremely large kivas were often located between villages rather than within them, thus suggesting ritual cooperation between villages. Prior to this time there is no evidence that ritual cooperation transcended the boundaries of individual villages (Wendorf 1956:19-24). It seems likely that the development of inter-village ritual ties is a reflection of the fact that there were also inter-village economic ties-the ritual simply serving as an integrative mechanism. It could be, of course, that the fundamental ties were for defense, or perhaps some other reason; but this is considered somewhat unlikely, given the nondefensive locations of most of the villages.

Steward (1937:96-99) suggests another index of an increasing scope of integration during this time period. He has noticed that prior to roughly A.D. 1100 or 1200 the ratio of numbers of kivas (small kivas) to numbers of rooms was usually about one to six. After that time (especially in Pueblo III and later) the ratio becomes much smaller-that is, fewer kivas per number of rooms. Steward's ratios, by period, are approximately as follows:

$\begin{array}{ll}\text { Pueblo I } & 1: 6 \\ \text { Pueblo II } & 1: 6 \\ \text { Pueblo III (early) } & 1: 10 \\ \text { Pueblo III (late) } & 1: 18 \\ \text { Pueblo IV } & 1: 60 \\ \text { Pueblo V } & 1: 100\end{array}$

These are averages, of course, and there is a tremendous amount of variation in sites of any given period. Nonetheless, they seem to reflect a real trend toward fewer kivas per unit of population. From this, Steward infers a trend of increasing widening of the scope of social integration, and this interpretation has been accepted by others (Eggan 1950:198-200; Wendorf 1956:19-20; Longacre 1970:16-17).

If this trend in kiva-room ratio does represent broadening integrative patterns, it is still not possible to demonstrate that it was promoted by an environmental shift. All that can be suggested is that because the trend began about A.D. 1100 and because the environmental shift began about that time, there might have been a relationship. It is the author's opinion that this is likely.

Given the evidence thus far presented, it looks as though the environmental shift may have been responsible for at least three major developments in the Southwest between about A.D. 1100 and 1350: (1) a decrease in population, (2) an increase in aggregation, and (3) an increase in the scope of integration (probably economic, social, and religious integration). None of these, except perhaps the aggregation, can definitely be related to an environmental shift. However, an examination of developments in the Hay Hollow Valley, and Broken K 
Pueblo in particular, strongly suggests that such a relationship should be postulated.

\section{Evidence From Hay Hollow Valley}

\section{Aggregation and Integration}

Before discussing the specific evidence which suggests a causal relationship between a shifting environment and social changes in the Hay Hollow Valley, it will be profitable to compare the general trends of development in this valley with those discussed for the Southwest as a whole.

First of all, the population trend is parallel. Longacre (1970: Ch. 2) has conducted a surface survey of the Hay Hollow Valley, as well as other areas in the upper Little Colorado River drainage region, and he has found that there was a steady increase in the numbers and sizes of sites through time-until about A.D. 1300. Following this, there was a rapid decrease. He infers from this that the population of the area must have followed a similar curve. At the same time, he has pointed out the fact that the sites became larger and fewer between about 1050 and 1400 , and that they tended to be located along major drainageways (1970:9-14). This is precisely parallel to developments in other areas of the Southwest and seems to represent the increasing aggregation of populations.

Since Broken K Pueblo was the latest site occupied in the Hay Hollow Valley, one might expect it to represent a later stage in the general trend of population aggregation than do the other sites. This seems, superficially at least, to be the case. Broken $\mathrm{K}$ is almost three times as large as any other site, including the relatively large Carter Ranch Site (with about 39 rooms).

A comparison of the numbers of equivalent social groups at Carter Ranch Site and Broken $\mathrm{K}$ would also seem to support the idea of increased aggregation. It will be recalled (Chapter 10) that at Broken $K$ there seem to have been five social units, each equivalent in size to the two (or possibly three) units discovered at Carter Ranch Site. If these units represent discrete social groups that came together from previously separate villages, then it would appear that Broken $\mathrm{K}$ constituted the largest aggregation of these groups.

There is an important problem here, and the solution is by no means obvious. It could be that Broken $\mathrm{K}$ reached its maximum size through a process of internal population growth. In other words, it might have expanded in size without any additions coming in from the outside. This was, in fact, suggested in Chapter 10. Under this model, the site might have been occupied initially by two (or three) separate social groups, such as were discovered at Carter Ranch Site. Then, as these groups increased in size, each of them split into at least two subgroups (possibly lineages). The data presented in Chapter 10 would certainly not contradict this model.

Nonetheless, there is at least one reason for suspecting that this model is incorrect. If we postulate an environmental shift that was making agriculture difficult, it does not seem likely that the population of Broken $\mathrm{K}$ would have been expanding. Evidence will be presented shortly which suggests that subsistence was becoming increasingly difficult through time, and this would not be a favorable situation for population expansion. If anything, the population should either have remained stable or declined. For this reason, we might suggest that Broken K Pueblo was probably formed by means of aggregation and that it represents the most advanced stage of aggregation in the Hay Hollow Valley.

Along with this process of aggregation, there appears to have been an increase in the scope of integration. This is indicated by the fact that Great Kivas make their appearance sometime around A.D. 1050. Longacre interprets these kivas as reflecting a ritual integrative mechanism superimposed on a fundamental integration of economic concerns (1970:13, 17). Presumably something happened at this time which made economic and ritual cooperation necessary, and Longacre subscribes to the idea of a change in rainfall pattern $(1970: 13,17)$.

At Broken $\mathrm{K}$ Pueblo itself there is excellent evidence which seems to be indicative of an increased scope of integration through time. Again, it is necessary to compare the site with Carter Ranch Site. Longacre found no concrete evidence to suggest that the two social units at that site were tied together by institutional integrative ties. Apparently, each unit maintained its own kiva and existed as a somewhat separate entity (Longacre 1970:46). This was clearly not the case at Broken $\mathrm{K}$. The kivas apparently were being shared to some degree, at least within each major residence group (Chapter 10). This is a clear documentation of the idea that intra-village integration was becoming more important through time.

Another indication of this is the fact that the residence units at Broken $K$ were not so highly localized as at Carter Ranch Site. At that site, there were two primary residence units, represented by the 
north and south halves of the site. The only evidence of a breakdown in strict localization was a small group of rooms that seems to have been related to the southern residence unit, although attached to the northern unit. This may represent an offshoot of the southern unit that was no longer localized with its parent unit.

At Broken $\mathrm{K}$, however, this situation was somewhat more advanced. Regardless of whether the village was formed by means of population expansion or aggregation from the outside, the residence units at the site were definitely not strictly localized (in the usual meaning of the word). It will be recalled that Units IA and IB were located adjacent to one another in the southwestern portion of the site-but Unit IC, even though it seems to have been related to these units, was located in the northeastern corner of the site. A similar situation was found with respect to Unit II. Units IIA and IIB were located diagonally across from one another, in separate areas of the pueblo. This clearly suggests that strict localization was breaking down, and it would seem to indicate that the village was becoming an integrated whole.

There is further evidence of the increased scope of integration. A comparison of architectural features between Carter Ranch Site and Broken K reveals that there was much more homogeneity at the latter. Even such features as firepits and mealing bins were quite similar to one another at Broken $\mathrm{K}$, while at Carter Ranch Site there was a tremendous amount of variation. This suggests that the people at Broken $\mathrm{K}$ were sharing ideas concerning methods of construction to a much greater degree than were the people at Carter Ranch Site. They may even have been cooperating in some of the construction work. This is a rather subjective comparison, but there would seem to be little doubt that it could be put in quantitative terms.

Another bit of evidence is the fact that apparently no kivas were being used at Broken $K$ during the last stages of occupation. This suggests the possibility that most of the ritual was being carried on in the plaza and that it was open to pan-village participation. If so, this would be strong evidence for a high degree of integration in the village. Unfortunately there are alternate interpretations. It may be that at the time the kivas were abandoned, few people were left in the village and there was a complete breakdown of ritual activity. Or, it may be that some ritual was still being carried on in the ordinary habitation rooms.
One final item of evidence should be noted. As has already been suggested the adult male burial beneath Room 27 was probably a high-status individual. As far as is presently known, he was the only adult accorded the privilege of interment within the village proper. This suggests that he may have been recognized as an important man to the entire village. It is possible that either the man or his social position represented a centralized authority of some kind, and that this is a reflection of at least one major intra-village integrative institution.

\section{Subsistence Responses}

Up to this point, the entire argument has been somewhat hypothetical. Although it is reasonable to believe that the trends of aggregation and integration between A.D. 1100 and 1300 were promoted by an environmental shift, little evidence has been presented to support a causal relationship. Although it does not seem possible to relate aggregation and integration directly with an environmental shift, it can be shown that the people of Broken $\mathrm{K}$ were responding in other ways to this shift. Once this is established, we will have a much stronger basis on which to suppose that aggregation and integration also constituted adaptive responses.

There is evidence at Broken $\mathrm{K}$, for example, that agriculture was becoming difficult and that it was replaced to a large extent by the collection of wild vegetal foods. An examination of the distribution of corn $(Z e a)$ pollen at the site showed that most of it occurred in the early rooms. The early rooms contained between 6 and 85 Zea grains, while the late rooms generally contained between 0 and 5 grains. Using a chi-square test, this proved to be significant at the 0.05 level.

The distribution of corncobs followed a similar pattern. Of the 53 corncobs found at the site, 46 were in early rooms. There would thus seem to be little doubt that, as time went on, corn was entering into the diet to a decreasing extent.

The distribution of Cucurbita (squash) seeds is also interesting. Of a total of 72 such seeds, 49 were found on the floors of early rooms.

At the same time, there was a tremendous apparent increase through time in the consumption of wild plants. The distributions of Compositae, Cheno-ams, and Gramineae were particularly instructive. Fourteen of 16 of the early rooms contained between 40 and 119 grains of these pollen-types in their floor 
samples, while 7 of 13 late rooms had between 120 and 150 grains in their samples. This tested significant at the 0.05 level, and it clearly suggests that these plants were being collected (and probably consumed) more frequently through time.

Distributions of the pollen of all wild plants recovered from the site were subjected to the same kind of analysis, and only one plant (Cycloloma) seems to have been slightly more common in the early rooms. The others were more common in late rooms.

One of the most interesting discoveries was the fact that domesticates may never have been significant in the diet at Broken $\mathrm{K}$. Of 157 seeds recovered from 11 mealing bins, only one was Zea. Only two of these mealing bins had Cucurbita seeds, and these were in early rooms. On the other hand, 6 of 11 bins contained Cycloloma seeds. Furthermore, of the 157 seeds recovered, only 50 represented domesticates. On the basis of this evidence it would seem that the people of Broken $\mathrm{K}$ were actually relying more heavily on wild plants than on domesticates.

One further bit of evidence along these lines is interesting. The kivas (and room-kivas) at the site contained little corn pollen compared to other rooms. (Chapter 8 and Appendix 4). It is a well-known fact that among the modern Hopi, corn plants and corn itself are used extensively in kiva ceremonies (Forde 1931: 398; Parsons 1936:188, 595, 608). Why did we not find more evidence of corn in the kivas at Broken $\mathrm{K}$ ? Instead of finding large amounts of corn pollen, we found tremendous quantities of Cheno-am pollen. If the inhabitants of the site were using food-plants (and pollen) in their ceremonies, it would appear that they were concerned with using wild plants more frequently than domesticates. This may be a further indication that the people were depending primarily on collected foods.

This apparent change in the subsistence pattern is not surprising, given the model of environmental shift and a concomitant deterioration of agricultural conditions. In fact, it tends to support the validity of the proposition. It is also in line with ethnographic evidence. Among the Hopi, wild food-plants are immediately resorted to whenever agriculture is undependable (Beaglehole 1937:70-71; Whiting 1939:20-21; Watson 1945:25). Apparently this is what happened at Broken K.

In conjunction with this shift in the subsistence pattern, there seems to have been a change through time in the requirements for storage space. The percentage of total floor space devoted to storage rooms was determined for Carter Ranch Site, the early half of Broken $\mathrm{K}$, and the late half of Broken $\mathrm{K}$. This permitted the examination of changes in storage space through three different time periods. The percentages are as follows: Carter Ranch Site (about A.D. 1100-1225)-21-25 percent, early Broken $K$ (about A.D. 1150-1220)-25 percent, and late Broken K (about A.D. 1220-1283)-41 percent.

It seems rather obvious that the later occupants of Broken $\mathrm{K}$ had more storage space than did the occupants of Carter Ranch Site or early Broken K. It is notable, however, that this increase in storage space was not primarily a result of the use of larger storage rooms. Instead, there was an increase in the number of storage rooms in late Broken K. Early Broken K had a ratio of $8: 13$ storage to habitation rooms, while late Broken K had a ratio of 17:13.

Apparently the latest inhabitants of Broken $\mathrm{K}$ were storing more food than were the people at early Broken K or Carter Ranch Site. But why should this be so? It seems likely that if domestic crops were becoming undependable, the people would have needed to store more seeds of these crops to use in planting succeeding crops. In other words, they would have needed to store enough seed for two or three (or more) plantings, as insurance against crop failure-and this might require more storage rooms.

This, of course, is what the historic Hopi and Zuni have done (Stevenson 1904:353; Brainard 1935:262, 264; O'Kane 1953:18). In recent years, however, the Hopi have been less subject to famine because of modern means of transportation and participation in a cash economy; as a result, they no longer store food for long periods of time (Whiting 1939:11).

Further evidence that the people of Broken $\mathrm{K}$ were being subjected to the exigencies of a shifting environment is found in the animal bone data. The distribution of animal bone at the site has already been discussed to some extent in Chapter 7. It was shown there that most of the bone was found in the early rooms at the site and that relatively few bones were found in the late rooms (chi-square 0.01 level). This was found to hold for both floor and fill levels.

Perhaps the most interesting thing about this distribution is that relatively large numbers of deer, mountain sheep, and jackrabbit bones were found in the early half of the site, while very few were found in the late half. The only animal represented to a 
significant degree in the late half was the cottontail rabbit-and even this animal was more frequent in the early part of the site.

This apparent switch from hunting a variety of relatively large animals to a virtually complete reliance on cottontail was also observed in the stratigraphic evidence, but the reasoning here is somewhat involved. We know, from ethnographic evidence, that the modern Pueblos sweep their floors daily (Donaldson 1893:57, 100; Cushing 1920:545; Parsons 1936:496，526，667，719; Beaglehole 1937:61; Roberts 1956:15, 18). If the people of Broken $\mathrm{K}$ also cleaned their floors, it seems likely that the bones (and other materials) found on them represent the last day of occupation on the floors-or perhaps the last few days. If, when the floors were swept, the accumulated debris was consistently thrown into a nearby vacant room, as may well have been the case, then we might expect that fill materials in such rooms would consist of debris accumulated over a relatively long period (in contrast to debris on floors). This would mean that the bulk of the materials found in the fills should be earlier, in general, than those found on the floors. To put this another way, the fills would receive cultural material throughout the occupation of the site, but the floors would be continually swept and would thus tend to have the latest materials in general.

It was discovered at Broken $\mathrm{K}$ that fill levels contained approximately twice as many bones of the larger animals (deer, mountain sheep, and jackrabbit) as did the floors; the floors had over three times as many bones of cottontail rabbit as did the fills (chi-square 0.05 level). If the floors were generally younger than the fills, as suggested, then the evidence indicates a change through time from dependence on relatively large animals to dependence on cottontail. This is exactly what was found in comparing the early and late halves of the site. Both lines of evidence suggest that hunting was becoming more and more difficult through time, and this should probably be considered as a reflection of the environmental shift.

If the reasoning used above is anywhere near correct, then we would seem to be discussing a case somewhat similar to reverse stratigraphy; and it may carry with it certain implications for the interpretation of stratigraphic sequences in Pueblo sites in general. In any event, it does not seem reasonable to assume that materials on floors are always older than those in the fills-as is frequently done.
Another approach to elucidating responses to a shifting environment involved examining changes in the frequencies of various classes of artifacts through time in the valley, using Carter Ranch Site, early Broken $\mathrm{K}$, and late Broken $\mathrm{K}$ as temporal vantage points. The hypothesis was that if an environmental shift had stimulated significant responses by the people in the valley, this should be reflected in changes in cultural activities, which in turn would be reflected in changes in the frequencies of various kinds of artifacts.

The fact that Carter Ranch Site was used in the analysis meant that certain methodological problems had to be considered. One of these was the fact that the two sites had not been sampled in exactly the same way, and there was a possibility that the samples were not strictly comparable. Although 59 percent of the 39 rooms at Carter Ranch Site were excavated, the sample was subjectively selected. At Broken $\mathrm{K}$, on the other hand, a random sampling technique was employed. Nonetheless, rooms were excavated in most of the major room-blocks at Carter Ranch Site, so that the sample was probably generally representative of the site as a whole; it is probably legitimate to compare it with the excavated sample at Broken $\mathrm{K}$.

Another problem was that no sifting of cultural levels was performed at Carter Ranch Site. Sifting permits greater comparability between excavation units (for example, rooms or sites), and its employment would have permitted greater certainty for the results of the present study. Still, all levels at Carter Ranch Site were carefully searched by hand and trowel, and the samples are probably reasonably comparable.

In order to make comparisons of tool-frequencies, a standard unit of measurement had to be devised. Absolute numbers of artifacts could not be used because the sites are of different size. It was decided that averages would be most useful.

The first average considered was the mean frequency of each artifact-type per room. This idea had to be rejected because the high proportion of storage rooms in late Broken $\mathrm{K}$ would create a skew by unduly lowering the averages for that portion of the site (since habitation rooms contained many more artifacts than did storage rooms).

It was thus decided that it would be best to determine specific artifact-averages by dividing the total frequency of an artifact-type from all rooms in a 
site (or portion of a site) by the number of habitation rooms in that site. This eliminated the skew and had the additional advantage of yielding an artifactaverage per population unit-assuming that a habitation room represents a generally constant unit of population.

Because it was decided to use all artifacts found in a site, or portion thereof, regardless of whether they came from floors or fills, another possible source of bias became apparent. It could be argued that the occupants of late Broken $\mathrm{K}$ carried their trash to the southern, or early, part of the site when disposing of it. Such differential dumping might tremendously increase the frequencies of artifacts in the south half of the site.

To determine whether or not such dumping had occurred, the early and late parts of Broken $\mathrm{K}$ were examined separately to find the relative contributions of the floors and fills to the number of artifacts for each part of the pueblo. In the early half, 50.5 percent of the artifacts came from floors and 49.5 percent came from fills. In the late half, the floors contributed 54.8 percent of the artifacts and the fills contributed 45.2 percent. If the late occupants had been dumping their trash in some of the early rooms, the contribution of the early fills could be expected to be much greater than 49 percent. The conclusion was that little differential dumping was practiced, and it is safe to consider both the floors and fills together.

The most difficult possible source of error to be aware of was the effect of different lengths of occupation among the three areas under consideration. Will a longer occupation of one area cause higher artifact-averages than would be found in an area occupied for a shorter length of time? The answer is probably yes, and a correction eventually had to be made for this.

A number of different artifact-types were analyzed, and some of them were then lumped into two general categories-hunting-related artifacts and grinding-related artifacts. Only those artifacts were included whose uses are reasonably well known.

The method of determining the averages per habitation room will be illustrated with the huntingrelated artifact group. The averages found for all hunting-related implements were 5.20 for Carter Ranch Site, 5.53 for early Broken $\mathrm{K}$, and 2.87 for late Broken K. At each site (or area) there were, respectively, 78, 83, and 23 hunting-related artifacts. The averages were determined by respectively dividing the above totals by 15 (number of habitation rooms at Carter Ranch), 16 (number of habitation rooms at early Broken $\mathrm{K}$ ), and 9 (number of habitation rooms at late Broken $\mathrm{K}){ }^{*}$

The tool types used in the hunting-related group were arrowshaft tools, projectile points, and antlerflakers. The averages per habitation room for each tool-type and for the three types grouped are shown in Table 15. Antler-flakers show a continuous drop in average occurrence, while grouped hunting tools, arrowshaft tools, and projectile points show a slightly higher average at early Broken $\mathrm{K}$ than at Carter Ranch Site. But from early Broken $\mathrm{K}$ to late Broken $\mathrm{K}$ there is a drop to an average below that of Carter Ranch Site.

Assuming roughly equivalent lengths of occupation, for the sake of argument, certain inferences can be made. First of all, it is doubtful that the slight differences between the averages at Carter Ranch Site and those at early Broken $\mathrm{K}$ are very significant, and it may be suggested that these averages represent a fairly similar pattern of hunting. The marked drop in average between early Broken $\mathrm{K}$ and late Broken $\mathrm{K}$, however, is notable. As was the case with respect to the decrease in animal bone at the site through time, this suggests that the people were suffering from increased hunting difficulties. It is possible that much of the game in the area died out or moved southward toward the White Mountains as vegetation zones shifted in that direction.

The next group of artifacts to be considered was that which was related to a grinding industry. These included manos, metates, mortars, pestles, and stone bowls. The averages for each type are shown in Table 15. As can be seen, mortars, pestles, and stone bowls increased from 0.80 per habitation room at Carter Ranch Site to more than twice as many at early Broken $\mathrm{K}$, and then to an average at late Broken $\mathrm{K}$ slightly less than one-third the Carter Ranch rate. The other categories all have higher averages at early Broken $\mathrm{K}$ than at Carter Ranch Site, while the averages at late Broken $\mathrm{K}$ drop somewhat.

These figures seem to suggest (again assuming equivalent lengths of occupation) that grinding activity increased during early Broken $\mathrm{K}$ times but then decreased in late Broken $\mathrm{K}$ times. It may be that the initial adaptation of the village was relatively

*Detailed artifact counts, by provenience, may be found in Martin, Hill and Longacre (1966). 
successful in terms of agricultural productivity, and that there was a need for an increased number of grinding tools in order to process the crops. It is also possible that this need was stimulated by an increased productivity in the collection of wild crops-or by an increase in the variety of the plants collected. In any event, the drop in the rates of grinding-related artifacts during late Broken $\mathrm{K}$ times suggests a drop in productivity, and it is likely that the environmental shift had something to do with it.

The next group of artifacts studied was that which is considered to have had ceremonial or ornamental functions (animal effigies, pendants, pipes, shell bracelets, and so forth). These were grouped and the averages were determined as given in Table 15 . The average for early Broken $\mathrm{K}$ shows a slight increase over that for Carter Ranch, but the average for late Broken $\mathrm{K}$ is approximately half of that for Carter Ranch Site.

These figures show the same increase from Carter Ranch Site to early Broken $\mathrm{K}$ as did the grindingrelated tools. The average of ornamental-ceremonial items for late Broken $\mathrm{K}$, however, drops to a level below that at Carter Ranch. The initial upward increase may perhaps be explained in the same fashion as the increased grinding activity at early Broken $\mathrm{K}$-that is, a successful initial adaptation. The drop in average during late Broken $\mathrm{K}$ might be an indication that life was becoming more and more difficult, and people were no longer spending a great deal of time in the manufacture and use of ornamental or ceremonial items.

The reader will recall that the averages at early Broken $\mathrm{K}$ for hunting-related artifacts, grindingrelated artifacts, and ornamental-ceremonial items were higher than the averages for these categories at Carter Ranch. At late Broken $\mathrm{K}$ each of the averages declined, but the hunting-related artifacts declined to an average even lower than at Carter Ranch Site. These trends raise a question - whether the numbers of all tool-types would behave in the same general way, perhaps because of non-equivalence in length of occupation of the three areas in question. It might be that early Broken $\mathrm{K}$ had higher averages simply because it was occupied longest. Such regularity, however, was not found to be the case. An examination of the averages for most of the other artifacts at Carter Ranch Site and Broken $\mathrm{K}$ revealed that some of them increased steadily through time, some decreased steadily, and some remained virtually stable. Axes, for example, exhibited a steady increase in average occurrence, while saws showed a steady decrease.

This does not serve to demonstrate equivalent lengths of occupation, and the above figures and interpretations can be questioned. In order to obviate

TABLE 15

Average Number of Artifacts Found per Habitation Room

\begin{tabular}{llcr}
\hline \multicolumn{1}{c}{ Type } & \multicolumn{1}{c}{$\begin{array}{c}\text { Carter } \\
\text { Ranch }\end{array}$} & $\begin{array}{c}\text { Early } \\
\text { Broken K }\end{array}$ & $\begin{array}{c}\text { Late } \\
\text { Broken K }\end{array}$ \\
\hline $\begin{array}{l}\text { Hunting tools } \\
\text { Arrowshaft tools }\end{array}$ & 1.60 & 2.47 & 1.00 \\
$\quad$ Projectile points & 2.20 & 2.40 & 1.87 \\
$\quad$ Antler-flakers & 1.40 & 0.67 & 0.00 \\
$\quad$ Total & $5.20(23 \%)$ & $5.53(17 \%)$ & $2.87(13 \%)$ \\
$\quad$ & 12.73 & 20.13 & 15.13 \\
Grinding-related artifacts & 1.00 & 2.67 & 1.13 \\
$\quad$ Manos & 0.80 & 1.93 & 0.25 \\
$\quad$ Metates & $14.53(65 \%)$ & $24.73(74 \%)$ & $17.50(80 \%)$ \\
$\quad$ Mortars, pestles, and stone bowls & & & $1.38(6 \%)$ \\
$\quad$ Total & $2.73(12 \%)$ & $3.13(9 \%)$ & $21.75(99 \%)$ \\
Ornamental and ceremonial items & $22.46(100 \%)$ & $33.39(100 \%)$ & \\
$\quad$ Total & & & \\
Group Total & & & \\
\hline
\end{tabular}


this problem, it was decided to convert the averages for the three grouped categories of artifacts to percentages. It was thus possible to determine the approximate percentage-composition of each category at Carter Ranch Site, early Broken K, and late Broken K (Table 15).

The figures in Table 15 suggest that huntingrelated artifacts and ornamental-ceremonial items decreased steadily in relative proportion through time, while grinding-related artifacts increased steadily through time. It is thus clear that the preceding interpretations need not be greatly changed. Presumably hunting became more and more difficult while grinding activities became more important-perhaps because there was an increase in the amount and variety of wild food-plants to be ground. Ornamentalceremonial items declined in relative proportion, which may reflect a diversion of energy to subsistence concerns.

Artifacts other than those used in this analysis could have been used if their cultural or adaptive meanings could have been determined. It seemed meaningless, however, to present figures for artifacts, the changes of frequency for which could not be adequately interpreted. Nonetheless, those trends that have been discussed can reasonably be considered as reflecting responses to a shifting environment-particularly in the realm of subsistence concerns.

\section{Discussion}

It has been suggested that, given a shift in the physical environment, it should be possible to isolate some of the human responses or adaptations to the shift. Several responses to something have been fairly clearly demonstrated. The most important of these may be listed, as follows: (l) decreasing population, (2) increasing aggregation, (3) increasing scope of integration, (4) decreasing agricultural productivity (Broken K), (5) increasing reliance on wild food plants (Broken $\mathrm{K}),(6)$ increasing requirements for storage space (Broken $\mathrm{K}$ ), and (7) increasing difficulties in hunting (Broken $\mathrm{K}$ ). There is a fairly convincing argument which suggests that these responses were causally related to an environmental shift.

First of all, there is strong evidence that the people of Broken $\mathrm{K}$ were having agricultural and hunting difficulties-especially near the end of the occupation. If this is correct, it seems likely that other villages in the Southwest may have been facing similar difficulties at this time period. Surely such difficulties were not peculiar to a single site. This idea is supported by the fact that there were so many abandonments at this time.

Secondly, as sites were abandoned, the people began to aggregate along major waterways or in areas having permanent water supplies of another nature (for example, springs). This clearly suggests a need for water, permanent soil moisture, or something of the sort. It is difficult to conceive of any other suitable explanation.

Further support for the idea that moisture was lacking lies in the fact that virtually all of the examples of ditch irrigation in the Southwest fall within the tenth to thirteenth centuries (Woodbury 1961:39). The development of irrigation techniques at this time is not surprising, given an environmental shift, lowered water tables, and the probable resultant decline in floodwater farming.

This evidence, in conjunction with the pollen and tree-ring evidence, suggests that primarily a lack of effective moisture during the spring and summer created the agricultural difficulties; this lack of moisture probably also promoted vegetational changes that may have caused the larger game animals to vacate large areas. Under these conditions (and perhaps a scarcity of arable land) there would have been little choice but to move into areas in which the supply of soil moisture was more adequate and perhaps more predictable-assuming that the people did not wish to revert completely to a collecting economy.

The apparent increase in the scope of social integration through time cannot be quite so neatly explained, but there is a fairly obvious logical argument. It is possible that as agricultural conditions became more difficult, more and more cooperation was needed in order to achieve successful crops. Such cooperation might then have led to the establishment of a wider network of integrative institutions (for example: clans and religious societies), which would have been important in the maintenance of solidarity in all aspects of life.

The probability that agricultural difficulties underlie many of these responses is indicated by the fact that agriculture (floodwater farming) today is extremely unproductive in many formerly occupied areas, including most of the upper Little Colorado River drainage area. Since it seems likely that the prehistoric Pueblos relied more heavily on floodwater farming than on any other method, it would appear that there was a shift from a situation in which this 
type of farming was possible to a situation in which it was almost impossible.

We know, for example, that the people occupying Broken K Pueblo and Carter Ranch Site were practicing agriculture, and the absence of irrigation works suggests that they were employing floodwater farming. If these people were still living in the area today, they would probably have had to shift to a different pattern of subsistence.

The recent (1960s) climatic records for the area (Snowflake) suggest this. Although the growing season, mean annual temperature, and mean annual precipitation appear to be sufficient for marginal agriculture, the mean night temperature (in summer) and the mean July rainfall argue against it. Corn agriculture generally requires a mean summer night temperature of at least $55^{\circ} \mathrm{F}$. (Finch and Baker 1917:29, in Yarnell 1964:131), and a mean July rainfall of about 2.5 inches-judging from the Hopi situation (Beaglehole 1937:33). The Snowflake area, however, has a mean summer night temperature of only $51^{\circ} \mathrm{F}$. and a mean July rainfall of 2.39 inches. And furthermore, there are sometimes periods of three or more consecutive years in which the July rainfall is less than 0.9 inches (R. J. Martin 1933:13, 17). In addition, Carter (1945:90) shows that this area suffers from "spring drought." That is, the months of April, May, and June combined generally have less than two inches of rainfall.

These statistics are not greatly different from those found in the Hopi country, where agriculture is extremely tenuous (R. J. Martin 1933). The Hopi are fortunate in having springs and water seeps, as well as sand dunes, which tend to retain soil moisture. Without these advantages the area would be inad- equate for agriculture (Forde 1931:360-61; Thompson 1945:16; Carter 1945:85-86). Whiting (1939:4) believes that, "The scant and irregular rainfall would not permit an agricultural subsistence for even a short period of time, were it not augmented by these springs ...."

Since such springs (and sand dunes) are not found in the Snowflake area, it is not remarkable that floodwater farming is not carried on there by present-day peoples. Apparently no corn will grow unless it is irrigated, and even then the crops frequently are not successful (Mrs. James Carter, rancher, Snowflake, Arizona, personal communication). Referring to the Little Colorado River valley itself, R. J. Martin (1933:2) states that the July and August peak of precipitation is received "too late during the season of crop growth and development to assure any success in agriculture without resorting to irrigation in the early stages of germination and growth. ..."

It is interesting to note that, given the prehistoric Puebloan technology, it is doubtful that irrigation could have been employed if the environment had been similar to that of today. The streams and arroyos of today are so deeply dissected that irrigation ditches leading from them probably would have had to be much deeper than the technology could have permitted. Thus, agriculture might have been virtually impossible.

In any event, the Snowflake area probably could not support an agriculturally based economy today. Since we know that it did so prior to roughly A.D. 1400 , the existence of an environmental shift is strongly supported. 


\section{ALTERNATIVES TO A SHIFTING ENVIRONMENT}

Although the interpretations set forth thus far seem to be consistent with the facts, some alternative possibilities must be considered. In short, there is the possibility that the responses discussed here resulted from other factors besides environmental shift. The following possible causal factors among others, have been suggested, and their pertinence is generally considered to be in the realm of explaining decreasing population, abandonments, and aggregation: (1) flood (Stubbs 1950:10), (2) fire (Stubbs 1950:10), (3) inner cultural tendency (Kroeber 1953:153), (4) internal dissension (Titiev 1944:96-99), (5) disease (Titiev 1944:98), and (6) enemy attack (Kidder, in Guthe 1925:9-10; Jett 1964). (The citations do not reflect the viewpoints of the authors concerned in all cases.) Most of these possibilities are no longer very seriously considered, and they need not be discussed in great detail.

Both flood and fire should probably be discounted as causal factors, not only because there is little evidence for either of them but also because it is inconceivable that large areas of the Southwest were suddenly subjected to them between A.D. 1050 and 1300. Furthermore, they certainly cannot be used to explain the fact that aggregation centered around the major drainages.

Inner cultural tendency must also be discarded as a causal factor. It is not a testable hypothesis, and even if it were, we would want to know the causal factors underlying the tendency.

Internal dissension is in a similar category, but there are some very specific reasons for rejecting it. Internal dissension would presumably involve competition between at least two factions within a village. One faction might eventually be forced to move away, as was the case at Old Oraibi in 1906 (Titiev 1944), but it is doubtful that both factions would find it necessary to leave. It is therefore not reasonable to believe that this factor could have been responsible for the abandonments of villages and subsequent aggregation. Furthermore, it does not seem likely that when a faction had been forced to leave a village it would immediately become a part of a much larger aggregation of peoples (where internal dissension ought to have been worse rather than better).
A second reason for rejecting this possibility is that it does not seem probable that it could have occurred almost simultaneously over large areas of the Southwest-and the widespread abandonments did begin almost simultaneously, or at least within a fairly narrow range of time.

The idea that disease may have caused the abandonments and subsequent aggregations is somewhat more probable than any of the factors yet discussed, but it also seems unlikely. Hill (1963:107, 130) has shown that in neither animal nor human populations does disease frequently promote abandonment or population movement-even on a local level. It thus seems highly improbable that it could explain large-scale abandonments in the South. west. Even in the case of a newly introduced disease, most populations sooner or later strike a balance with it (Wolf 1959:196). Furthermore, there is no evidence for widespread epidemic disease in the prehistoric Southwest, and it does not appear that modern Pueblo peoples have frequently been forced to move as a result of disease (Crane 1926:150; Titiev 1944:97-98).

The possibility of enemy attack cannot be dismissed so easily. Hopi tradition frequently mentions the fact that warfare existed in prehistoric times, and it is possible that raids by nomadic Athabascans forced population aggregation (Mindeleff 1900:640-42; Stubbs 1950:10; Woodbury 1959:124-33; Jett 1964; and others).

It is doubtful, though, that the Athabascans arrived in the Southwest as early as A.D. 1100, when the population disturbances began; in any case, there is little concrete evidence of warfare (Bluhm 1957:121; Ellis 1964b:213-14). Certainly little evidence exists in the Little Colorado River drainage area (Longacre 1970:14).

If enemy attack had been involved, it is likely that we would find that many of the sites of this period had been burned and that many portable possessions of the inhabitants had not been removed (given the absence of orderly evacuation). An examination of a small sample of historic cases of warfare in the Southwest clearly suggests this.

The destruction of Awatobi in the late sixteenth century is a good example. The "West Mound" of this 
early Hopi town was occupied in Pueblo III times (about A.D. 1100-1300), and there is no evidence of enemy attack. The rooms were not burned, and few portable objects were found on the floors of the villages (Burgh 1959:189). The village grew larger, however, and sometime around A.D. 1700 it was attacked by a group of Hopi warriors from other nearby villages. The story of this attack is part of Hopi tradition, and it is also documented in the archaeological evidence for that period at the site. The specific evidence is as follows (Fewkes 1893:365-73; Hargrave 1935:20; Brew 1937:126, 135-37):

1. Large stacks of charred and half-burned corn ears were found in many of the rooms, indicating the presence of widespread fire.

2. A human skeleton was found on the floor of a kiva.

3. Large quantities of ceramic vessels and other artifacts remained in situ on the floors.

4. There were "defensive" walls in various locations at the site.

It is thus likely that an attack did take place.

There are other examples, many of which involve historically recorded attacks on Pueblo villages by the Apaches, Navajos, and Spanish (Stevenson 1904:285; Hodge 1937:98, 101; Miller 1941:17-19). In the several cases examined by the author, the villages were burned by the attackers. In several cases the record clearly indicates that large quantities of portable objects were left in the abandoned villages (Miller 1941:17-19). The fact that this kind of evidence is rarely found in sites occupied prior to A.D. 1500 or 1600 suggests that warfare was not a significant cause of abandonment and aggregation.
At Broken K Site itself, there is even some positive evidence arguing against enemy attack. Aside from the fact that the site was not located in a defensible position, and that there were relatively few portable artifacts in situ on the floors, it was discovered that almost all of the rooms that had been burned were habitation rooms or kivas. In fact, of 26 habitation rooms, 10 showed evidence of burning. Of a total of six excavated kivas, four had burned. But only one of 24 storage rooms exhibited such evidence. It will be recalled that the habitation rooms and kivas generally contained firepits, while the storage rooms did not. This suggests that the fires had been set by sparks from these firepits, and not by enemies.

It is known, of course, that enemy attack can promote aggregation and possibly other responses. This actually happened to some extent at the time of the famous Pueblo revolt against the Spanish in 1680 . It is notable, however, that the Spanish attacks promoted the relocation of villages into defensive locations on mesa-tops (Fewkes 1907:561; Forde 1931:366), in distinct contrast to the kind of movement noted for the earlier periods (Bluhm 1957:121). It seems likely that the events of Spanish times have unduly influenced our thinking with regard to Pueblo abandonments and aggregation in the twelfth, thirteenth, and fourteenth centuries.

This is not to imply that warfare did not exist in the Southwest in pre-Spanish times, for there are a few isolated sites in which its presence has been identified. The suggestion here is simply that it does not seem to have been as widespread or as significant a phenomenon as was the environmental shift. Still, the importance of warfare in prehistoric times has not yet been accurately evaluated, and it is not possible to state with certainty that it was as unimportant as the present writing suggests. 


\section{AFTER BROKEN $\mathrm{K}$}

Chapter 14 presented a discussion of a number of possible responses to an environmental shift. It was suggested that this shift promoted trends in the pattern of economic and social development in the Southwest and that these trends were characterized primarily by increasing aggregation and integration. The impression should not be left, however, that these trends terminated at about the time Broken $\mathrm{K}$ was abandoned (about A.D. 1300). Fairly clear evidence suggests that they continued up into historic times.

The purpose of this chapter is to examine the development of these trends between A.D. 1300 and the ethnohistoric present. The reason for doing this is that the trends seem to be important to our understanding of the development of western Pueblo social organization. In any event, certain aspects of Pueblo social organization can most easily be explained in terms of an orderly development of adaptive responses to a shifting physical environment.

\section{Aggregation}

As has been suggested, the process of aggregation continued well beyond A.D. 1300 in many areas of the Southwest. During the period known as Pueblo IV (about A.D. 1300-1600), a tremendous decrease occurred in the number of occupied villages and a concomitant increase in the sizes of these villages (Kroeber 1928:385; Steward 1937:97; Eggan 1950:124-25; Wendorf 1956:24-25; Bluhm 1957).

The drainage area of the Little Colorado River was no exception. Shortly after A.D. 1300 only a few pueblos remained, located only on the main waterways, such as the Little Colorado River and Silver Creek. These pueblos were over three times as large as Broken K.

In the Jeddito area (Hopi country), a few miles to the north, a similar development occurred, but it seems to have been somewhat later than most other areas in the Southwest. In fact, while other regions were being abandoned during the thirteenth and fourteenth centuries, the Jeddito area seems to have been increasing rapidly in population. It has been suggested, primarily on the basis of stylistic similarities in ceramics, that some of these people might have come from the Little Colorado River area itself
(Hargrave 1935:23-24; Brew 1940:45-46; Hack 1942:78-80; Eggan 1950:129-30; Wendorf 1956:21; Bluhm 1957:152).

A summary of the demographic changes occurring in the Southwest between A.D. 1300 and 1540 has been given by Wendorf (1956:21) as follows:

... the years between 1300 and 1540 saw a general reduction in the area occupied by Puebloan peoples and important population changes throughout the Southwest. During this interval many large communities were built along the Rio Puerco, the Little Colorado, and the White Mountain areas, which were abandoned within a few years. By 1540 the Pueblo population, including the Chaco Anasazi, had concentrated into a few large communities-at Hopi, Zuni, Acoma, and along the Rio Grande.

Since that time, the situation has remained generally stable (except during the period of the Pueblo Rebellion of 1680). It would thus appear that the modern Pueblos constitute the most advanced stage in the trend of population aggregation.

\section{Integration}

The hypothesized trend toward a widening scope of social integration, concomitant with aggregation, also seems to have continued between A.D. 1300 and 1600 , and there is strong evidence suggesting that modern Pueblo villages are much more highly integrated (village-wide) than any before them. Hawley (1937:518) characterized the Pueblos in general as follows:

In each pueblo the kinship system is tied up with the clan, fraternity, and kiva groups, although the range and nature of kinship extensions varies from pueblo to pueblo. Each form of organization overlaps the others in membership and functions, and hence, with the kinship system, forms a strongly integrated social structure.

Similar observations have been made by Kroeber (1917:183), Parsons (1925:112), Bunzel (1932b:476), Brainard (1935:320), Goldman (1937:320-21), Eggan (1950:116), Dozier (1964:90), and others.

One indication of the broadening scope of integration through time was found in a comparison of the western Pueblos with Broken K Pueblo and Carter 
Ranch Site, with respect to the localization of social units. It was discovered that the breakdown of strict localization has apparently reached a somewhat more advanced stage among the Hopi and Zuni than in either of the archaeological examples.

Among the Hopi, for example, localization is so weak that Kroeber (1917:103) was able to say that, "there is no localization to speak of at Oraibi and little anywhere at Hopi, the clans being distributed nearly as if they had been randomly strewn over the pueblo." Although not all authorities agree completely with this statement, it is generally agreed that the traces of localization are slight (Mindeleff 1900:650-53; Forde 1931:373-74; Brainard 1935:192). Even families within lineages are not localized to a very great extent (Brainard 1935:202), and there is a modern tendency toward neolocal residence (Titiev 1944:15-16).

A similar lack of localization has been observed at Zuni, and here the breakdown is apparently even greater than among the Hopi. The Zuni seldom even think of the clan as an independent organization. "In daily life it is common residence, and known blood common to individuals, and even friendship and neighborliness, that count" (Kroeber 1917:48). There is no central clan house, no recognized head, and no clan meetings. In fact, the clan never acts as a unified body. It is true, however, that there is a tendency for each clan to be proportionately most heavily represented in a particular portion of the village (Kroeber 1917:91, 118-19).

Further evidence of the lack of localization is found in the fact that when Zunis move out of the pueblo into the surrounding area, they often reside in clusters of blood-related people-but these people are often not of the same clan. This is an indication that even lineages are not highly localized.

The reader will recall that at Carter Ranch Site and Broken $\mathrm{K}$, the evidence suggests quite clear-cut localization (whether of clans or not), even though it may already have begun to break down. Thus, if decreasing localization reflects an increasing scope of social integration, then there is evidence of continued increasing integration between A.D. 1300 and the 1960s.

Further evidence of the high degree of integration in present-day Pueblo communities is found in an examination of their kinship systems. Among the Hopi the primary kinship extension is to the clan; but, one way or another, every individual can consider himself related to everybody in his village. Kinship may even be extended to other villages and even tribes (Eggan 1950:26-29). The sibling relationship is a particularly strong integrative force, and it is extended to all members of one's clan and phratry who are roughly equivalent in age, as well as to the children of the father's clan and to the clans and phratries of ceremonial fathers and "doctor" fathers (Titiev 1944:12-13; Eggan 1950:44).

Among the Zuni, kinship extensions are also extremely wide. In fact, there is little awareness of kinship-distance, and there are no special terms for people of different clans (Kroeber 1917:76-78). There is so little distinction between a person's mother's and father's kinsmen that Forde (1931:384) viewed the Zuni as essentially bilateral. Eggan (1950:195-96) mentions that Kroeber also once espoused this idea.

It is not possible, of course, to compare the details of the Hopi and Zuni kinship systems with the reflections of such systems at Broken $\mathrm{K}$ and Carter Ranch Site. However, the possibility of discrete breaks in degrees of social distance between the identified residence units at these sites suggests that kinship-distance may have followed similar lines. If so, there is further evidence of an increased scope of social integration since A.D. 1300.

Integration in the religious or ritual aspects of life also seems to have increased in scope since that time. It will be recalled that in the two archaeological sites there seems to have been a tendency for each major residence unit to have its own kiva. Among the Hopi and Zuni, this is clearly not the case. Ceremonial rooms are of ten owned or built by a particular clan or lineage, and the same group may supply the ceremonial paraphernalia and some of the ritual leaders; but in general, membership is open to anyone (Stevenson 1904:413-21; Kroeber 1917:151-54, 161; Hawley 1937:515; Titiev 1944:89-92, 103, 106-107; Eggan $1950: 52,117,203 ; 1964: 181-82)$. Men often spend their leisure time in the kivas nearest their own homes (Parsons 1936:XLIII).

Among both the Hopi and Zuni, ceremonies are collective in the sense that they are directed toward the concerns that are important to the community as a whole (Goldman 1937:336-37; Eggan 1950:117). Furthermore, it sometimes happens that two or more societies unite for joint ritual performances (Titiev 
1944:151, 168). In short, Hopi and Zuni rituals and ceremonial societies constitute strong pan-village integrative mechanisms.

Comparing this situation with the apparent localization of ritual within individual residence units at Carter Ranch Site and Broken K, it would seem that there is some evidence in support of a suggestion presented by Brainard (1935:57) and later stated by Titiev (1944:103), as follows:

There is a possibility that at one stage of Hopi cultural development the entire membership of a religious society was drawn from the proprietary clan, but in modern times it has been customary for ordinary participants, as well as minor officials, to be selected from any clan in a village.

The evidence for this is no more than suggestive, of course, since it is not at all certain that we can determine recruitment of membership by using the stylistic elements of potsherds.

In the realm of political integration, the Hopi and Zuni are only loosely integrated. The Hopi generally have a village chief and certain other chiefs and priests who serve as a community council (Brainard 1935:76, 78-80). They are in no sense legislative, and they depend on the cooperation and agreement of the people. Authority is usually phrased in terms of kinship or ritual rather than in secular terms (Eggan $1950: 106-107,116)$. Nonetheless, there is a weakly centralized political authority-in a very general sense.

Among the Zuni, political authority is much more overt and centralized. The emphasis is more on tribal organization than on clan organization, and the ultimate political authority consists of a hierarchy of priesthoods. The Bow priesthood serves as an executive body in matters related to the spiritual welfare of the community. A governor and his assistants manage secular matters, but subject to appointment and direction of the hierarchy of priests. "That this control is relatively efficient is evidenced by the degree of social and ceremonial integration maintained in the face of all the modern influences toward disintegration and dismemberment" (Eggan 1950:218). (See also Bunzel 1932b:478 and Goldman 1937:313.)

It does not seem likely that Hopi and Zuni political integration can be compared adequately with political integration in the two archaeological examples. It can be said, however, that neither site had a highly centralized political authority. If they had had such an authority, we would expect to find material evidence of it-that is, such things as centralized storage facilities reflecting a redistributive economy, and specialized rooms or houses that might have served as centralized meeting places. At Carter Ranch Site, Longacre (1964b; 1970:43) found evidence of differential treatment of high-status burials, which seems to indicate the existence of a hierarchy of some kind. The single adult male burial at Broken $\mathrm{K}$ might be indicative of a similar kind of organization.

With respect to the scope of economic integration, the Hopi and Zuni must be placed fairly high on any scale. Among the Hopi, the basic economic unit is the household or localized lineage segment, but economic cooperation and reciprocity are extended far beyond this unit-to clan, between clans, between phratries, between societies, etc. There is even sometimes cooperation between villages (Beaglehole 1936; 1937). Apparently, economic cooperation is narrowly or widely defined, depending on the nature of the particular activity considered.

The clan is a particularly close-knit economic unit. It owns the land, and its member lineages often cooperate in agricultural labor and in the distribution of the produce (Forde 1931:373). Beaglehole (1937:9) says:

The social, ceremonial and juridical unit which is the Hopi clan is also an institution of economic functions. ... it is evident that the productive capacity of the small household group is increased many times by its ability to draw on the services of all members of the clan group.... it is perhaps not incorrect to define the Hopi clan as a body of men, women and children ... united for the cooperative production of food supplies and other major forms of wealth.

The clan is particularly important in times of stress, for it comes to the assistance of its needy members (Beaglehole 1937:9).

Cooperation between clans is also quite extensiveespecially the clans representing bilateral kin. There are many mutual obligations, including gift exchange (Beaglehole 1937:6-7). One of the most important kinds of cooperation involves cooperation of a man with his brother-in-law at harvesting and herding (Titiev 1944:29). Furthermore, clans sometimes share land with one another in return for services (Beaglehole 1937:16). 
There is also extensive economic cooperation between members of kiva groups which, as will be recalled, cross-cut kinship ties. This is especially true in the working of the land (Forde 1931:375-76, 396). There are even cases in which two or more societies cooperate with one another in a specific economic activity (Parsons 1936:998, 1001).

On certain occasions an entire village may cooperate. A few such occasions are listed as follows:

1. Planting and harvesting, in some cases (Parsons 1936:940-41, 953-54).

2. Transportation of crops from fields to village (Beaglehole 1937:43).

3. Hunting. Most Hopi hunting is and was communal, and everyone gets a share of the meat (Beaglehole 1936:8; Parsons 1936:277-78).

4. Collection of wild plants, especially food-plants (Parsons 1936:1035-36).

5. Cleaning of the village springs (Titiev 1944:187).

6. Piki stone quarrying expeditions, and metate stone expeditions (Titiev 1944:197-98).

7. Salt gathering expeditions (Titiev 1944:199).

In addition, a tremendous amount of gift exchange takes place on the occasions of marriage, birth, naming ceremonies, initiation, death, rituals, games, visiting, grinding parties, water-carrying, cooking, and borrowing (Brainard 1935:253-54; Beaglehole 1937:72-78, 80-81; Titiev 1944:37; Eggan 1950:60, 1964:180). In the past there have even been formalized markets where trade was carried out by the women (Parsons 1936:158). Of course, many other examples of intra-village economic integration are found among the Hopi.

Zuni economic integration is apparently much like that at Hopi-so much so, in fact, that detailed discussion here would involve repetition. One notable difference, though, is the fact that clans do not own the agricultural fields at Zuni. A man may cultivate any plot of land he chooses, provided that it has not already been appropriated. Thus, with respect to land-ownership, the Zunis appear to be even more integrated than the Hopi. For more complete discussions of Zuni economic integration, see Stevenson (1904:350), Cushing (1920:195), and Goldman (1937:314-30).

There is no way at present to compare Broken $\mathrm{K}$ and Carter Ranch Site with the Hopi or Zuni with respect to scope of economic integration. Nonetheless, the evidence presented in Chapter 10 does suggest that this integration was less developed in prehistoric times. If the social units isolated at Broken $\mathrm{K}$, for example, were cooperating economically, the nonrandom distribution of sherds and artifacts do not indicate that this cooperation extended beyond the largest of the units. In other words, each major unit (I and II) seems to have maintained a great deal of stylistic integrity, and this might indicate the presence of economic integrity as well.

Still, it is not reasonable to believe that the occupants of the site lived in a large community for no reason at all. There must have been a number of integrative ties. Presumably, economic ties were fundamental in both promoting and maintaining pan-village integration.

\section{Discussion}

It would appear, on the basis of the evidence presented here, that both aggregation and integration continued to increase between A.D. 1300 and the ethnohistoric present. The general increase in the sizes (and decrease in numbers) of villages clearly suggests aggregation, and the increased scope of integration is indicated by several lines of evidence.

A fundamental assumption underlying the discussion of integration is the idea that an increasing scope of social integration is accompanied by decreasing localization and by the development of pan-village integrative institutions-economic, social, and religious institutions. Although it has not been possible to get at a detailed description of either localization or pan-village institutions in the prehistoric cases, it is interesting that all of the evidence seems to point in the same direction.

The trend toward decreasing localization has been particularly well documented. If it is true that localized clusters of stylistic elements reflect the loci of social groups, there can be little doubt that Broken $\mathrm{K}$ and Carter Ranch Site exhibit a much higher degree of localization than do the Hopi or Zuni. It would be extremely interesting, as a check on this inference, to examine the distribution of female-associated stylistic elements in a western Pueblo village. Presumably, such a study would delineate similar loci of social groups to those which ethnologists have derived from modern data.

Although the trend toward the decreasing localization of social units is most convincing, it has also been shown that a decrease in ritual localization (development of pan-village ritual) is likely. It is assumed, of course, that we can determine which groups were using which kivas by examining the 
stylistic elements on their floors. This also could be more clearly demonstrated by studying the distributions of stylistic elements in modern Pueblo villages.

The proposed increases in the scope of economic, political, and kinship integration cannot yet be documented as clearly as can the other trends. The evidence with respect to these is no more than suggestive. It may be possible in the future to find ways of testing the validity of these proposed trends.

In any event, it seems likely that increased aggregation and integration were important in the development of western Pueblo social organization and that they were related to a basic need for economic cooperation. This idea is given some support by the fact that the Hopi and Zuni are each highly integrated economically, on a village-wide basis. Their highly developed networks of economic cooperation would seem to be efficient, and perhaps necessary, to survival in a marginal environment. It is doubtful that individual families or lineages could have existed in historic times as independent unitsthey are simply too dependent on one another. If families or lineages were capable of maintaining independent existence, there would seem to have been no reason for them to have aggregated in the first place. People could have continued to live in small, isolated villages, just as they did prior to A.D. 1100 .

An examination of the Hopi and Zuni hunting pattern is particularly instructive in this light. As has already been noted, hunting is a community concern, and nearly all the men in a village participate in any given hunting expedition (Beaglehole 1936:8). This is especially true in the hunting of large game animals (Parsons 1936:277-78). It does not seem likely that individual families or lineages would have much success in hunting by themselves; deer, antelope, and jackrabbit drives would not even be possible. For these things, aggregation was clearly an advantage. It may also have been an advantage in the collection of wild plant-foods, and in agriculture itself-since these concerns involve widespread cooperation today.

In short, it seems likely that an environmental shift promoted conditions which made increased economic cooperation necessary. This in turn, led to aggregation, and to the development of broadened social and religious integrative institutions which were necessary to the maintenance of larger and larger aggregates of people. Although this hypothesis cannot yet be considered fully tested, it is an explanation consistent with the facts of western Pueblo social organization. 


\section{SUMMARY AND CONCLUSIONS}

It was suggested at the beginning of this paper, that archaeology has not yet reached its potential with respect to making contributions to the general field of anthropology. This study represents an application of a particular body of theory and method to the analysis of a particular archaeological site, and it is hoped that it has pointed out some of the kinds of contributions that archaeologists might make.

Archaeologists are faced with two primary problem areas. These are, (1) the description of past cultural and social systems in time and space, and (2) the explanation of stability and change in these systems. In order to explain stability and change, it is first necessary to describe the systems. Although archaeologists have always been concerned with description, it is fair to say that they have not generally been concerned with describing systems. Instead, there has been a tendency to describe traits and make trait-lists. This is somewhat analogous to describing a baseball game as a baseball, a bat, eighteen men, and an umpire, without describing the complicated systemic articulations of these things. The traits themselves do not describe the game, just as culture-traits do not describe cultural or social systems.

The description of whole systems (insofar as is possible) becomes extremely important when one is concerned with explaining stability and change. As Sears (1961:224) has stated, "Regularities in the processes of cultural development cannot be determined until the cultures are reconstructed in some degree." One reason for this is that the forces promoting stability and change are operative on complete, on-going systems rather than on aggregates of individual traits. If we wish to adequately understand the processes of sociocultural change, we must study whole systems and their relationships to the causal forces involved. Eventually, it should be possible to discover regularities in sociocultural change, and these should constitute significant contributions to anthropology and social science in general.

The present study has attempted to deal with both descriptive and explanatory aspects of archaeology, from a systemic point of view. The theoretical model used may be restated here, as follows:

Postulate I: Human behavior is patterned or structured, and was so in prehistoric times. Archaeologists can excavate the structured remains of this behavior and can make inferences concerning prehistoric systems of behavior.

Postulate II: The elements of human behavior change in form and relative frequency through time, and the material items associated with these kinds of behavior also change in form and relative frequency. This change is a result of selective pressures, as well as "drift."

The first of these postulates is fundamental to the description of prehistoric social systems. The fact that present-day human behavior is patterned is well known, but the fact that this was the case in prehistoric times as well has not received the attention it deserves. It has been almost as though we were implicitly assuming that prehistoric men lived unpatterned or haphazard lives, or that it was simply impossible to discover such patterns archaeologically. Perhaps the most significant contribution this study can make lies in its support of the idea that patterned behavior existed in prehistoric times and that the fossilized remains of this behavior can be excavated and interpreted. Since this has been found to be true with respect to two Southwestern Pueblo sites (see also Longacre $1963,1964 \mathrm{~b}, 1970$ ), it ought to be true of all of them-and other prehistoric sites in the world as well. It seems unlikely that there will be any exceptions.

The purposes of the present study were basically threefold: (I) to describe as much of the structure and social organization of a prehistoric site as was possible to discover, (2) to examine adaptive changes in this organization in the light of the evolution of the social organization of the western Pueblos, and (3) to contribute to the growing corpus of anthropological theory, method, and knowledge.

The focus of the analysis was on Broken K Pueblo, located eleven miles east of Snowflake, Arizona. The site is a 95-room, single-storied, surface masonry pueblo, dating from about A.D 1150 to 1280 . It is 
the largest and latest site in the Hay Hollow Valley, and it is located in a savanna-woodland vegetation zone. The climate is semiarid today, and the landscape has been heavily dissected by a pattern of torrential summer thunderstorms.

The site could not be completely excavated, and a system of random-sampling was employed. Fifty percent of the rooms were selected for excavation (46 rooms), but eight additional rooms as well as other selected locations were also excavated. Excavation was by natural levels, and cultural levels were screened in an effort to ensure comparability of samples. All possibly relevant materials were saved, and charcoal and pollen samples were taken from most rooms. Formal artifact-types were occasionally discovered, with the aid of statistics.

The numerous nonrandom (patterned) distributions presented and interpreted in this study were discovered by means of various quantitative methods, both simple and sophisticated, and many of these distributions were tested by means of chi-square and other common statistical techniques. This quantitative approach permitted a clear understanding of the relationships among variables, and there is no reason to believe that the approach significantly governed interpretation. In several cases, in fact, statistical manipulations merely served to quantify and verify relationships that probably would have been determined without them. However, in many cases where the relationships among data were not at all obvious, the use of quantitative description was of tremendous value. This was particularly true of the factor-analysis studies of the distribution (and mutual covariation) of pottery-types and ceramic design-elements.

Regardless of the techniques actually used in defining the nonrandom distributions of patterned remains, it was quite clear that the interpretation of these distributions would be extremely difficult unless the temporal variable could be controlled within the site. Various lines of evidence, primarily architectural and stratigraphic, were used in this pursuit, and all rooms, including ceremonial rooms (kivas) were roughly dated relative to one another. The major temporal breakdown was between early and late. The south half of the village was, in general, early, and the north half was generally late.

The most interesting aspect of the intra-site dating effort was the fact that pollen data was found useful in this respect. It was found that the early rooms contained significantly more arboreal (tree) pollen than did the late rooms, while the latter had relatively more nonarboreal pollen (especially Cheno-ams and Gramineae). This shift in relative abundance of pollen-types was not totally unexpected, since the general pollen chronology for the area exhibits exactly the same changes at this time period (Schoenwetter 1962; Hevly 1964). It does seem remarkable that it was possible to observe the changes within an individual site. This suggests that pollen data may be useful as an independent means of intra-site dating in the future-particularly as pollen chronologies become more refined (Hill and Hevly 1968).

The next step in the analysis was the establishment of statistically valid room-types. Two discrete modes of room-size were found. The small rooms ( 2.5 to 6.5 sq. $m$. in floor area) generally contained no features and few artifacts, but they did contain large amounts of the pollen of economic plants (especially corn and squash). The large rooms (6.6 to $33.5 \mathrm{sq}$. $\mathrm{m}$. of floor area) were significantly associated with firepits, mealing-bins, ventilators, artifacts (including sherds), lithic waste, animal bone, and seeds; but they contained little economic pollen. These rooms were called habitation rooms, while the small ones were called storage rooms. A third class of rooms was considered ceremonial (kivas), since these rooms contained features common to Hopi and Zuni ceremonial rooms. Twenty-six habitation rooms, twentyfour storage rooms, and four kivas were fully excavated.

This determination of statistically valid roomtypes serves as a clear demonstration of patterned human behavior in prehistoric times-although the fact that the occupants of Broken $\mathrm{K}$ must have consciously constructed and recognized these types is not surprising. It is interesting to note that it was possible to make use of lithic waste, animal bone, seeds, and pollen in the systematic definition of such types. It would not be surprising to find a number of other attributes of pueblo rooms that could be used in a similar study.

The reason for determining formal room-types in the first place. was more than simply the desire to describe the structure of the site or to create taxonomic categories as an end in itself. It was hoped that once such types were established it would be possible to determine their functional characteristics. Several functions were determined by examining the spatial clustering of both artifact and non-artifact materials, including pollen-types. The functional 
meanings of these materials were derived from direct ethnographic or worldwide comparative evidence in most cases. Some of the probable functions and some possible functions of the room-types are listed in Table 16. The plaza contained several large roasting pits, which were probably used in a specialized form of cooking. It also contained evidence of chert (hunting) tool manufacture and ceremonial dancing.

Thus, it has been shown that a number of activities were not carried out in a random manner throughout the village but rather were carried out in well-defined and differentiated locations-although the locations probably overlapped somewhat in function. Our knowledge of these activities and their locations permits at least a rudimentary understanding of the basic structure of some of the activity systems at the site. What is perhaps most important, however, is the fact that this structure can be compared with equivalent activity structures discovered in other pueblo and non-pueblo sites; and it is possible that causal explanations of similarities and differences can be arrived at (perhaps on a cross-cultural basis).

Certain sociological inferences can be made about Broken $\mathrm{K}$ on the basis of the room-function study, and these, too, are subject to comparison with other prehistoric communities. One such inference is that there was very little functional specialization at the site. Each household apparently carried on all of the kinds of activities necessary to existence, and certain others as well (even though there was probably much cooperation between households). Also, each household apparently stored its own food, and there was probably no centralized redistributive authority. This is suggested by the fact that the ratio of habitation to storage rooms was about $1: 1$, and they were distributed (for the most part) in pairs throughout the site. Given the likelihood that there was no centralized economic authority, it is also likely that no centralized political authority existed either. These inferences are not new or surprising, since they have been suggested by ethnographic data. The important point

TABLE 16

Functional Characteristics of Room-types

\begin{tabular}{lll}
\hline Habitation Rooms & \multicolumn{1}{c}{ Storage Rooms } & Ceremonial Rooms \\
\hline $\begin{array}{l}\text { Food preparation } \\
\text { (incl. cooking) }\end{array}$ & Probable Functions & Storage of plant foods \\
Water storage and use & $\begin{array}{l}\text { Storage of non-food items } \\
\text { "Work" }\end{array}$ & $\begin{array}{l}\text { Weaving } \\
\text { Manufacture of } \\
\text { hunting tools }\end{array}$ \\
$\begin{array}{l}\text { Manufacture of } \\
\text { hunting tools }\end{array}$ & Possible Functions & \\
\hline & & Eating \\
\hline $\begin{array}{l}\text { Manufacture of pottery } \\
\text { Manufacture of ground } \\
\text { and pecked stone tools }\end{array}$ & Sleeping \\
$\begin{array}{l}\text { Manufacture of ornamental } \\
\text { ceremonial items }\end{array}$ & Lounging \\
\begin{tabular}{l} 
Sleeping \\
\hline
\end{tabular} & & \\
\hline
\end{tabular}


is that they can be made in the absence of such data, and similar kinds of inferences can readily be made for prehistoric communities throughout the world.

One particularly interesting observation about the room-functions at Broken $\mathrm{K}$ is that it is possible to make some limited inferences about the sexual division of labor in a spatial context. Most of the activities found to have been performed in habitation rooms, for example, were probably female activitiesbased on ethnographic evidence; and the same may be true with respect to storage rooms. Ceremonial rooms, on the other hand, contained evidence of male activities primarily-ceremonies, weaving, and the manufacture of hunting tools. The plaza, as might be expected, contained evidence of both male and female activities. It seems likely that the sexual division of labor was very similar to that existing among the modern western Pueblos, and this was precisely Longacre's inference with respect to Carter Ranch Site (1970:48-50).

Five uxorilocal residence units apparently existed at Broken $\mathrm{K}$, and these can be grouped into two larger (more inclusive) residence units. The existence of these units was demonstrated as follows:

1. Nonrandom distributions of ceramic designelements, pottery-types, firepit-types, storage pits, chopper-types, and animal bone indicated discrete localizations within the pueblo (which could not be explained in terms of functionally specific areas).

2. Through the use of ethnographic evidence, it was found that these items and stylistic elements were probably associated with female activities (except perhaps choppers and animal bone, for which there is no clear evidence).

3. All of the female-associated items were found to have been usable in the day-to-day maintenance of a residence unit.

4. Each unit was found to have had temporal continuity-at least 65 years.

This evidence is probably sufficient for the establishment of the existence of uxorilocal residence units, especially when it is considered in the light of the fact that such units are characteristic of the modern western Pueblos. Of all residence systems known, only uxorilocal and duolocal systems should be characterized by highly nonrandom distributions of female-associated items or stylistic elements, and it seems unlikely that duolocal residence was present in this area.
The two large residence units (I and II) at Broken $\mathrm{K}$ may be considered residence groups (rather than simple aggregates of women), because there is evidence that they were integrated internally. This was suggested by the fact that the subunits within each large unit were much more similar to one another with regard to the above-mentioned stylistic elements than any of them were to the other large unit. This sharing of stylistic elements suggests that there was less social distance within each unit than between units, and it may also be an indirect measure of economic cooperation. It was also found that each large unit probably controlled or used its own kiva. This is believed to have been the case because, in general, each kiva had stylistic affinities with only one of the two large units.

The residence groups were probably corporate groups also. This was suggested by the evidence of cooperation within the groups, as well as the evidence concerning the sharing of ritual matters. It also seems likely, however, that nonmovable property (that is, rooms) was inherited within each group. Most rooms were apparently inhabited for at least 65 years, or roughly three generations, by the same group. This suggests that they were inherited.

Thus, in all likelihood, Broken $\mathrm{K}$ Pueblo contained two major uxorilocal residence groups (each with at least two subgroups), and they may have practiced matrilineal inheritance. It was not possible to be sure that matrilineal descent was also involved, but it is frequently the case that this form of descent is found associated with uxorilocal residence and matrilineal inheritance (Murdock 1949). The fact that the western Pueblos have matrilineal descent strengthens the probability that such was the case at Broken K.*

Carter Ranch Site was found to have probably contained two uxorilocal residence units (Longacre 1964b, 1970). In terms of numbers of rooms, these units were the same size as the subunits of Units I and II at Broken K (about 20 rooms per unit), and they may have been "equivalent" in terms of social organization. This suggests that Carter Ranch Site as a whole was equivalent to only one of the major groups at Broken $\mathrm{K}$. It may be that as villages increased in

*It seems very unlikely, however, that descent systems (as distinct from residence patterns) can really be identified archaeologically. Descent systems are abstractions that exist in the minds of people (anthropologists included), and as such they of ten have no material correlates (Hill, n.d.). 
size through time (probably through aggregation), there was an increasing number of large units per village. There may also have been an increase in numbers of subunits per large unit.

The modern Hopi and Zuni also have a hierarchy of social organizational units-lineages, clans, and so forth; in this general respect there seems to have been continuity since at least A.D. 1100. It may be that the largest units at Broken $\mathrm{K}$ were equivalent to clans (or phratries), while the subunits were equivalent to lineages (or clans), but this cannot be demonstrated. It may in the future be possible to compare prehistoric pueblos with one another with respect to equivalent social units. Furthermore, it seems certain that this kind of study can be extended to other areas of the world besides the Southwest.

It will be interesting to consider, for a moment, the kinds of stylistic elements that were used in defining the loci of social units at Broken K. As has been said, these elements were probably associated with female manufacture and use. It seems likely that there might have been a number of other classes of artifacts at the site that would have yielded femaleassociated stylistic differences. These would have been useful in delineating the loci of uxorilocal groups, if their intra-class stylistic differences had been discovered. In fact, it seems probable that all or most female-associated items would exhibit such differences. This would include such items as mealingbins, metates, manos, mortars, pestles, plastering stones, pot-polishing pebbles, and probably a number of other things. It is even possible that varieties of corn would differ among residence groups, since it is known that this is the case among the modem Hopi (Whiting 1939:12). Presumably, in societies having groups of related co-resident males (virilocal, patrilocal, avunculocal primarily), it should be found that male-associated stylistic elements are much more tightly clustered than are female-associated elements. Studies of the distributions of male and femaleassociated stylistic elements among present-day aboriginal peoples would almost certainly shed invaluable light on this problem.

The size of the prehistoric population at Broken $\mathrm{K}$ was estimated with the aid of ethnographic and cross-cultural comparative evidence. Probably between 120 and 190 people at one time were in the village (about 2.5 people per inhabited room). Each major residence unit had about 55 people, and each subunit had about 24 people. Some slight correspondence exists in population size between the subunits and the Hopi clan (or Zuni subclan) and between the major units and the Hopi phratry (or Zuni clan). Although this correspondence is not clear-cut, it may be that this kind of study will improve in accuracy as more prehistoric pueblo sites are subjected to the kind of treatment presented here.

Two burials were found at the site-an infant and an adult male. There was no cemetery within fifty meters of the site. The infant burial was found in a pit beneath the floor of a room, and this is consistent with ethnographic data concerning infant burial. There were no accompanying mortuary offerings, but the large quantities of Sphaeralcea pollen recovered suggest graveside ritual (Sphaeralcea is used ceremonially and medicinally only among the Hopi and Zuni).

The adult male had been interred prior to the construction of the northern (late) portion of the village, so he was probably a member of one of the social units located in the southern half. There are several reasons for believing that he was a high-status individual and that he represented some kind of pan-village integrative institution.

A number of sociological changes occurring at this time (about A.D. 1050-1300) in the Southwest seem to have been promoted by a minor environmental shift. This shift is documented by the nearly simultaneous occurrence of at least the following events:

1. A shift from a relative abundance of aboreal pollen to a relative abundance of nonarboreal pollen.

2. A shift in the widths of tree-rings, from wide to narrow (probably reflecting a shortage of effective soil moisture).

3. A widespread cycle of erosion.

Evidence suggests that these events were related to one another, and that they may reflect conditions inimical to agriculture.

There were several apparent responses to this environmental shift throughout the Southwest. Of major importance was a general decrease in population, which was in full force by about A.D. 1250. At the same time, many villages were abandoned, and people aggregated into fewer but larger villages along major drainage-ways. There also appears to have been an increase in the scope of inter-village integration, as indicated by the fact that Great Kivas become more common with the beginning of the environmental 
shift (about A.D. 1050). These kivas were probably associated with inter-village ritual institutions. There is also evidence of a broadened scope of intra-village integration, as evidenced by the fact that the ratio of ceremonial rooms (kivas) to other types of rooms became continuously smaller through time.

The same trends were noted in the vicinity of Broken $\mathrm{K}$ and Carter Ranch Site (Hay Hollow Valley). Furthermore, these two sites were compared with respect to their relative degrees of pan-village integration, and it was found that Broken $\mathrm{K}$ was more broadly integrated internally than was Carter Ranch Site. The evidence for this was as follows:

1. At Carter Ranch Site, both small residence units apparently owned or controlled their own kivas; at Broken K, kivas were shared by the subunits within each major residence unit.

2. The residence units were less strictly localized at Broken $\mathrm{K}$ than at Carter Ranch Site.

3. The architecture and room-features at Broken $\mathrm{K}$ were much more homogeneous stylistically than was the case at Carter Ranch Site. (This suggests increased sharing of ideas, and thus an increased scope of integration.)

In addition to the evidence for increasing scope of integration and aggregation through time, there is direct evidence that the people were responding to a shifting environment. The idea that agriculture was becoming difficult is indicated by the significant replacement of domesticates (corn and squash) with wild food-crops through time. It is even probable that domesticates were never important parts of the diet at Broken $\mathrm{K}$. An increase in the proportion of food-grinding tools through time may reflect the increase in the amount and variety of wild plants being collected and processed. Furthermore, a 20 percent increase in storage space between the early and late portions of the site suggests a need to store increased quantities of seed for planting in the event of crop failure.

There is also evidence that hunting may have become difficult. The hunting of deer, mountain sheep, and jackrabbit was replaced through time by the hunting of cottontail; and the relative proportion of hunting tools to other kinds of artifacts declined at the same time.

Several alternatives to the hypothesis of environmental shift have been examined, in an effort to determine whether or not any of them might have promoted the above discussed responses. The possibilities of flood, fire, inner cultural tendency, internal dissension, and disease were shown to be highly unlikely. The possibility of enemy attack cannot be lightly dismissed, but it also is somewhat unlikely. There is little evidence for it in the Southwest at this time period.

After Broken $\mathrm{K}$ was abandoned, the processes of aggregation and integration continued. By 1540 there were only a few remaining large pueblos-at Hopi, Zuni, and along the Rio Grande. An examination of the ethnographic evidence indicates that the Hopi and Zuni have a much wider scope of intra-village integrative mechanisms than did either Carter Ranch Site or Broken K. It is particularly notable that today there is little descent group localization, and ceremonial society members are recruited from the entire village.

Hopi and Zuni economic integration is extremely significant on a village-wide scope (even though there is no centralized economic authority), and it is doubtful that individual families or lineages could exist as independent units. It seems likely that beginning about A.D. 1050, the environmental shift made subsistence so difficult that previously separate family or lineage groups were forced to aggregate for mutual support (as well as moisture). This aggregation, in turn, led to the development of broadened integrative mechanisms to bind the larger groups together. In short, much of western Pueblo social organization can probably be explained in terms of adaptation to a shifting physical environment.

This paper is not regarded as an end in itself, nor does it provide any ultimate answers. It is hoped, however, that it represents a step in a productive direction. The basic theoretical orientation employed has been shown to be fruitful in terms of describing, and to some extent explaining, prehistoric social systems; it may be useful in increasing the usefulness of archaeology to anthropology and social science in general. While we cannot excavate prehistoric social systems or cultures, we can excavate the patterned material remnants of them. Having described at least the outlines of these systems, we can begin to compare them in space and time-and we should eventually be able to arrive at some generalizations or regularities with respect to culture process. In other words, we hope to be able to explain similarities and differences among cultural systems. 
The comparison and explanation of cultural similarities and differences is not solely an archaeological concern. It is of fundamental importance in all of anthropology. It seems likely, in agreement with Eggan (1950:7, 1954), Lehman (1964:384-92), and Service (1964:364), that comparisons will be most useful if they are in terms of both structuralfunctional and evolutionary studies. Only in this way can we really begin to explain the similarities and differences. If archaeology can make such explanatory contributions, then it certainly merits a place in the behavioral sciences.

Archaeology can, of course, study regularities in human behavior over a much longer time span than can the ethnologist or social anthropologist. Even the "revisits" to present-day primitive societies can probably not achieve the time depth necessary for a thorough understanding of many evolutionary and historical questions-especially those involving relatively slow evolutionary change. Furthermore, the number of societies to which archaeology has access is vastly greater than the number available to the ethnologist. As the ethnographic sample decreases in size, due to modern culture-contact and assimilation, it may become increasingly necessary to turn to archaeology for the study of primitive societies.

In short, anthropology has a number of questions to ask about human behavior, and all of the answers will not be found in any single subfield of that science. In fact, many of the answers will probably be supplied, at least in part, by other sciences. Within anthropology itself, there seems to be an increasing awareness of this situation. The present study clearly exemplifies the need on the part of archaeologists to look to ethnographic, social anthropological, zoological, botanical, geological, and other evidence in answering behavioral questions. Linguistic and physical anthropological information could have been fruitfully employed here had there been time to do so.

One of the crucial concerns for archaeology in the future would seem to lie in the development of research designs and techniques which can be used in recovering and analyzing data that will be useful in making more complete descriptions of prehistoric social systems, and more complete explanations of their changes in time and space. This paper has illustrated several such techniques. It must always be remembered, however, that techniques, as such, are without value except in the light of finding solutions to problems. If one is interested in studying the spatial and temporal distributions of pottery-types and other culture-traits, then presumably the techniques we already possess are suitable for the job. If, on the other hand, one is interested in studying the cultural contexts (that is, functions or uses) of such traits, then it is important that other techniques suitable to that purpose be employed. 
APPENDIX 1

ANIMAL BONE COUNTS FROM BROKEN K PUEBLO

\begin{tabular}{|c|c|c|c|c|c|c|c|c|c|c|c|c|}
\hline \multicolumn{13}{|c|}{ Counts From Fills } \\
\hline $\begin{array}{c}\text { Room } \\
\text { Numbers }\end{array}$ & 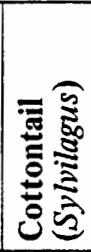 & 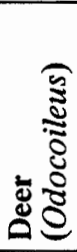 & 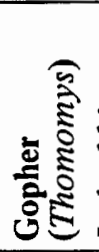 & 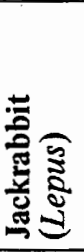 & 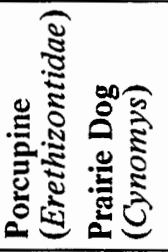 & \multicolumn{3}{|c|}{ 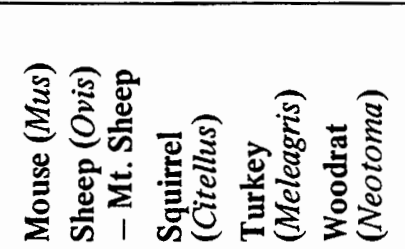 } & : & 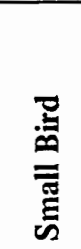 & 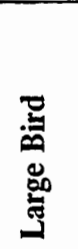 & $\stackrel{\stackrel{0}{\rightleftarrows}}{\stackrel{5}{\rightleftarrows}}$ \\
\hline 1 & 10 & 3 & & 22 & 3 & & & & & & & 38 \\
\hline $4-5$ & 104 & 14 & 1 & 56 & 5 & & & 2 & & 1 & & 183 \\
\hline 6-kiva & 5 & & & & 1 & 3 & & & & & & 9 \\
\hline 7 & 48 & 7 & 1 & 35 & 1 & & & & & & & 92 \\
\hline 9 & & & & 5 & 1 & & & & & & & 6 \\
\hline 11 & 31 & 9 & & 35 & 1 & & & & & & & 76 \\
\hline 22 & & 10 & & & & & & & & 1 & & 11 \\
\hline 30 & 6 & & & 1 & & & & & & & & 7 \\
\hline $31-33$ & 14 & 6 & 2 & 113 & & & & & & & & 135 \\
\hline 39 & 12 & 14 & 2 & 30 & 1 & & & & & & & 59 \\
\hline 41-kiva & 71 & 21 & 1 & 136 & & & & & & 10 & & 239 \\
\hline 48 & 3 & & & 4 & 2 & & & & & & & 9 \\
\hline 51 & 26 & 2 & 3 & 44 & & & & & & 2 & & 77 \\
\hline 61 & 2 & & & 1 & & & & & & & & 3 \\
\hline 62 & 35 & 47 & 2 & 62 & 1 & & & 4 & & & & 151 \\
\hline 64 & 1 & 2 & & & & & & & & & & 3 \\
\hline 69 & 53 & 4 & & 11 & & & & & & 1 & & 69 \\
\hline 73 & 7 & 12 & & & & & & & & & & 19 \\
\hline Plaza-kiva & 17 & 81 & & 52 & 3 & & & & & & & 153 \\
\hline Totals & 445 & 232 & 12 & 607 & $0 \quad 19$ & 3 & 0 & 4 & 0 & 15 & & 1339 \\
\hline \multicolumn{13}{|c|}{$\begin{array}{l}\text { ThOTE: counts represent numbers of identifiable bones found in room fills. Rooms and areas not listed contained } \\
\text { no bone. Several genera were not represented (above), probably because the fill levels were not consistently } \\
\text { sifted. }\end{array}$} \\
\hline \multicolumn{13}{|c|}{ Counts From Floors } \\
\hline $\begin{array}{c}\text { Room } \\
\text { Numbers }\end{array}$ & 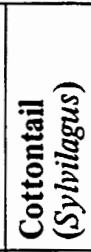 & 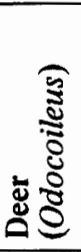 & 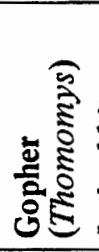 & 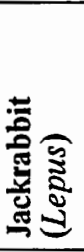 & 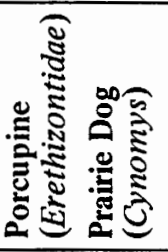 & 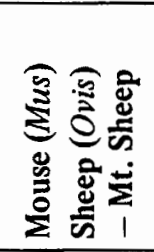 & 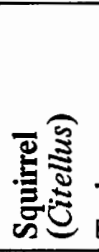 & 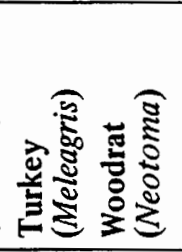 & 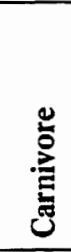 & $\begin{array}{l}\text { 总 } \\
\overline{\bar{E}} \\
\text { 竎 }\end{array}$ &  & 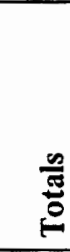 \\
\hline 1 & 103 & 5 & 3 & 3 & & & 1 & & & 2 & & 117 \\
\hline 2 & 12 & 1 & & & 1 & & & & & & & 15 \\
\hline $4-5$ & 77 & 44 & 24 & 8 & 3 & & 2 & 111 & & 1 & 6 & 276 \\
\hline 6-kiva & 7 & & 1 & 2 & & & & & & & & 10 \\
\hline 7 & 131 & 6 & 8 & 23 & 2 & 7 & & & & 1 & & 179 \\
\hline 8 & 6 & 1 & & & & & & & & & & 7 \\
\hline 9 & 16 & 2 & & 1 & & & & & & & & 19 \\
\hline 11 & 427 & 16 & 15 & 59 & 4 & 16 & & & & & & 537 \\
\hline 20 & 18 & & & & & & & & & & & 18 \\
\hline
\end{tabular}


Animal Bone Counts (continued)

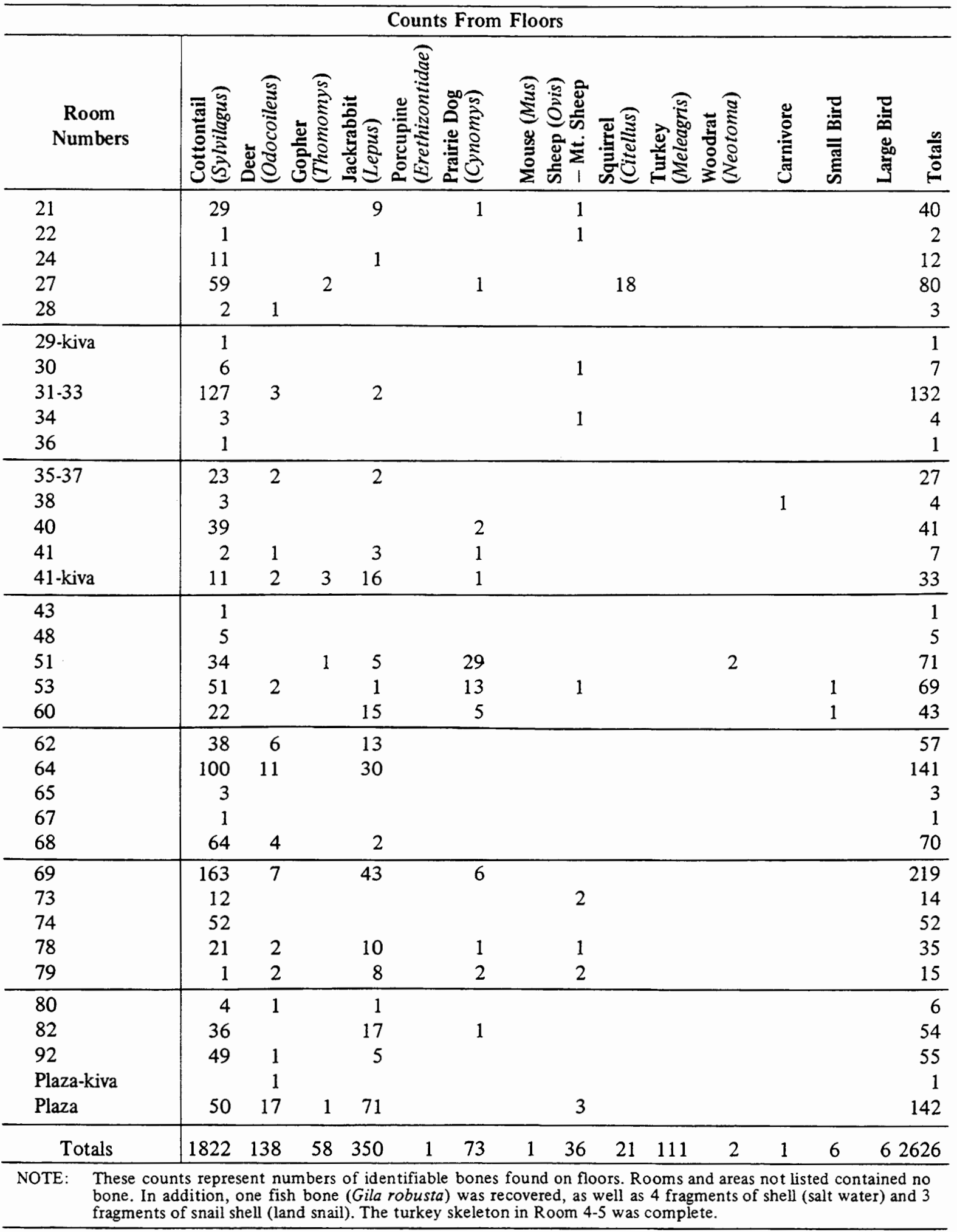




\section{APPENDIX 2}

\section{PLANT REMAINS FOUND AT BROKEN K, AND THEIR USES AMONG MODERN HOPI AND ZUNI}

References for ethnobotanical information: Stevenson 1909; Whiting 1939; Schoenwetter 1962; Richard H. Hevly, University of Arizona, personal communication.

Alnus (alder): Shrub or low tree common on flood plains of permanent streams in upper parkland and forest zones. No ethnographic use reported.

Amaranthus (pigweeds): Found in disturbed sediment conditions, as in arroyos, along roadsides, and along the dissected flood plains in the grassland zone. Hopi eat $A$. blitoides as greens. Zuni eat seed of same, and use $A$. hybridus (pigweed) as red color for a wafer bread of corn meal. Also used by Zuni in certain dances, and sometimes rubbed on cheeks as rouge.

Artemisia (sagebrush and wormwood types, a composite): Desert shrub, having wide range of environmental conditions. Hopi eat $A$. dracunculoides (baked). Also used for digestive disorders and prayer sticks. Zuni eat seeds of $A$. wrightii. They use $A$. frigida in dance of "The Coming of the Corn Maidens." They also use it as a "tea" for remedy of severe colds.

Berberis (barberry or algreta): A shrub of the pinyon-juniper woodland or juniper-savanna grassland. Found at considerable distance from Hopi villages. Hopi use for tools, especially arrows, spindle-shafts and battens. Also used medicinally to heal gums. Zuni use to color skin and ceremonial objects (purple).

Betula (birch): A streamside tree of high mountain areas in Southwest. Hopi get it south of San Francisco Mountains. Used as buckskin dye. No use discovered for Zuni.

Caryophyllaceae (pink family): All southwestern species are herbs. No ethnographic use reported.

Celtis (hackberry): A streamside tree. No ethnographic use reported.

Chenopodium (goosefoot family): Found in disturbed sediments, arroyos, and so on. Commonly lamb's-quarters, saltbush, and greasewood types. Hopi eat Beta vulgaris as greens; it is sometimes cultivated in small gardens. Also used as a "tea" for medicinal purposes, and to color blue piki bread. Important as main kiva fuel (greasewood). Zuni eat seeds of Atriplex powellii, Chenopodium leptophyllum and Cycloloma atriplicifolium. Atriplex canescens (saltbush) used for prayer plume twigs for use in prayers for abundance of cottontail rabbit; also used for cure of ant bites. Chenopodium cornutum used for relief of headache. Eurotia lanata used as remedy for burns.

Cleome (Rocky Mountain beeweed, Cleome serrulata): Found in parkland and grassland zones. Hopi allow it to mature and seed in cornfields, insuring supply for succeeding spring. Young plants boiled for food. Also used for prayer sticks and ceramic paint (black). Zuni cook and eat the leaves, as well as use it for prayer sticks and ceramic paint.

Compositae (sunflower family): Found in extremely wide environmental conditions. Primary palynological divisions are high-spine and low-spine composites. High-spine contains sunflower, aster, goldenrod, snakeweed, and burroweed types. Lowspine includes ragweed or cocklebur types. Hopi use many varieties as tea for medicinal purposes, and some varieties are eaten. Zuni grind Helianthus annuus ceremonially, and use in curing rattlesnake bite.

Cornus (dogwood): A streamside tree or large shrub. No use found for Hopi. Zuni use delicate stems to make plume offerings.

Cruciferae (mustard family): Includes cauliflower, cabbage, turnip, blistercress, spectacle pod, bladderpod, radish, tansy mustard, and others. Several species occasionally cultivated. Some are eaten by Hopi; others used medicinally and ceremonially. No use found for Zuni.

Cryptanthe (borge family): Hopi use medicinally for boils, swelling, and pain. Zuni use to relieve extreme fatigue. 
Cucurbita (squash): A cultigen among both Hopi and Zuni (C. mixta and $C$. moschata).

Cycloloma (from the goosefoot family, Chenopodiaceae): Typical of disturbed sediments, arroyos, and dissected floodplains. No use found for Hopi. Zuni eat seeds of $C$. atriplicifolium (winged pigweed).

Cyperaceae (sedge family): Typically found in hygric environment, such as the margins of ponds and marshes. Hopi occasionally use ceremonially because of its association with water. No use found for Zuni.

Ephedra ("Mormon tea"): A desert shrub, occasionally found in parkland and grassland zones. Hopi use in cure of syphilis, and it has wide reputation for this (both $E$. torreyana and $E$. viridis). Zuni use it in same way, and also as a beverage.

Eriogonum (buckwheat family): Herbaceous or small shrub, an onion. Hopi use medicinally and perhaps eat it. Zuni grind blossom to powder and use in ceremonial dances. Also for relief of "general miserable feeling," and sore tongue.

Euphorbiaceae (spurge family): Common in disturbed areas, especially roadsides. Hopi use the berries of Reverchonia arenaria A. Gray for rubbing on piki stone to oil it. Three species used medicinally. Zuni use two species to increase the flow of a mother's milk.

Fraxinus (ash, includes ironwood): A streamside tree or shrub. Hopi use ironwood (Forestiera) for digging-sticks. No use found for Zuni.

Gramineae (grass family): Wide range of environmental conditions. Hopi eat seeds of Sporobolus airoides; they eat Oryzopsis hymenoides in time of famine. Grasses also used in basketry, hair brushes, brooms, roofing, reed pipes, weaving rods, flutes, prayer sticks. Zuni eat seeds of two species; also use in prayer sticks, basketry, hair brushes, and brooms.

Juglans (walnut): Found in floodplains of permanent streams. No use found for Hopi or Zuni.

Juniperus (juniper, probably J. utahensis): Found in parkland and lower forest zones, and may extend into grasslands. Hopi use for firewood, general construction, rake for cleaning brush from fields, childbirth ritual (leaves), burial purification, medicine; also, berries are eaten with piki bread. Zuni use it for ceremonial torches, tinder to ignite New Year fire, a tea for muscular relaxation in childbirth.

Kallstroemia: A herb, a single species of which is found in northern Arizona; occasionally locally abundant. No use found for Hopi or Zuni.

Leguminosae (bean family, referring here to uncultivated varieties only): Peanuts occasionally cultivated by Hopi. Hopi children eat sweet roots. Also used as an emetic and medicinally, as well as in baskets and brooms. No use found for Zuni.

Liguliflorae (a composite-lettuce, dandelion, and salsify types): Found in extremely wide environmental conditions. No reference for Hopi or Zuni (see Compositae).

Nyctaginaceae (four o'clock family): Tuberous roots contain narcotics. Hopi "medicine men" use Quamoclidion multiflorum to induce visions while making a diagnosis. Zuni use Tripterocalyx wootonii to relieve effects of poisonous fluid from snakes.

Oenothera (evening primrose): Large herbs and conspicuous white flower; common around Hopi mesas. Important among Hopi as the "White Flower" associated with the northeast direction. Maidens wear them in hair on holidays. No use found for Zuni.

Opuntia (cactus family, Cactaceae): Includes both prickly pear (Platyopuntia) and cholla (Cylindropuntia). The latter recovered at Broken $\mathrm{K}$ Pueblo primarily. Found in arid and semiarid microenvironments. Hopi eat several genera and species; often boiled. Zuni eat fruit of Opuntia whipplei (and they store it). Also used in Cactus Fraternity ritual.

Pinus Edulis (pinyon pine): Primarily found in parkland and forest, but occasionally in grasslands. Hopi eat nuts, and use gum in repairing ceramic vessels. There are various other economic and ceremonial uses for the gum. Also used as firewood. Zuni toast and eat the nuts; also store them. Buds and shoots eaten by members of the Sword Swallowers Fraternity when they desire female children. Needles used in cure of syphilis (often chewed or in form of a "tea"). 
Pinus ponderosa (western yellow pine): Found primarily in forests. Hopi obtain it eighty miles away, in the San Francisco Mountains. Used for large roof timbers, prayer sticks; the needles are smoked ceremonially. No use found for Zuni, but certainly used in similar ways.

Polemoniaceae (phlox family; pollen-types at Broken $\mathrm{K}$ mostly referable to the genus Gilia): Hopi grind Gilia aggregata flowers with meal for hunters' petition before antelope hunt; the animals like to eat this plant. Gilia longiflora leaves are boiled for stomachache. Zuni use Gilia multiflora for relief of headache, dressing of wounds. Gilia $s p$. used for headache, swelling of throat, fevers, bowel and kidney disorders, and to induce vomiting.

Polygonum (buckwheat family, Polygonaceae; pollentypes of aquatic species recovered from Broken $\mathrm{K}$ only): Not recognized by Hopi. Zuni grind the root and sprinkle it in bowl of water used in physical purification. Also used as emetic or purgative. Rumex mexicanus used to sooth throat after sword swallowing.

Portulacaceae (purslane): An occasional weed. Hopi cook it in gravy, as at Hano (Portulaca oleracea L.). No use found for Zuni.

Potamogeton: No use found for Hopi or Zuni.

Quercus (oak): Typically found under forest and upper parkland conditions in this area. Hopi use it for rabbit sticks, arrows, bows, digging sticks, clubs, weft battens, axe handles, and other utensils. No use found for Zuni, but probably used.

Rhus (sumac, poison ivy, or skunkbush): Rhus trilobata is one of the four Hopi "kiva fuels." Berries are made into a "lemonade." Also used as a mordant in dying wool, and as body paint. Twigs used in basketry and for cradles. Roots and buds used medicinally "for a consumptive." Buds are used as a deodorant or perfume. Also used for prayer sticks and ceremonial equipment. Zuni Sword Swallowers use it for plume offerings (most sacred fetish of that fraternity). Also used in basketry.

Salix (willow): Typically found along shallowly dissected floodplains in lower parkland and grassland zones. Hopi use Salix $s p$. in roof construction and prayer sticks (pahos). Sometimes transplanted to convenient places. Zuni use Salix irrorata for tool used in stirring corn and other foods. Also used in basketry.

Sphaeralcea (mallow family, Malvaceae): Globe mallow grows under a variety of conditions. Hopi use it medicinally for broken bones and when defecation is difficult or accompanied by blood. Zuni use root of Sphaeralcea lobata (niggerweed) for a "tea" which is drunk each evening during the ceremony of the Sword Swallowers Fraternity.

Typha (cattail): Found in hygric conditions. Ceremonially important to Hopi as a plant associated with water. Also, mature heads are chewed with tallow as gum; children chew stems as children elsewhere chew sugar cane. No use found for Zuni.

Yucca (from the lily family, Liliaceae): No use found for Hopi. Zuni eat fruit of Yucca baccata and the seedpods of Yucca glauca. Yucca baccata stalk used in whipping people at initiation into a particular fraternity. Also used in purification whipping. Used in weaving yucca "cloth" prior to introduction of sheep. Used in basketry. Yucca glauca used in making rope and mats. Used for paint brushes, and to make suds for washing head and cleaning woolen garments and blankets.

Zannichellia: No use found for Hopi or Zuni.

Zea (corn, Gramineae): Cultivated and eaten by historic and prehistoric Pueblo Indians. 


\section{APPENDIX 3 \\ SEEDS FROM BROKEN K PUEBLO}

\begin{tabular}{|c|c|c|c|c|c|c|c|c|c|c|c|}
\hline \multirow[b]{2}{*}{$\begin{array}{l}\text { Room } \\
\text { Numbers }\end{array}$} & \multicolumn{11}{|c|}{ Seeds From Broken K Pueblo } \\
\hline & 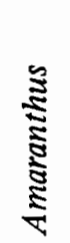 & 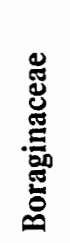 & 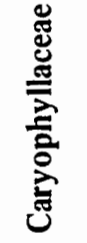 & 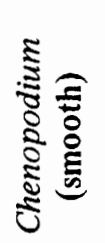 &  & 䒕 & 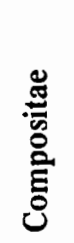 & 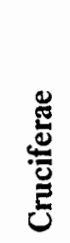 & 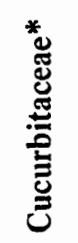 & $\begin{array}{l}\text { : } \\
\text { s } \\
\frac{0}{0} \\
0\end{array}$ & 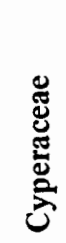 \\
\hline $\begin{array}{ll}1 & \\
1 & \text { (Pit C) } \\
2 & \\
4 & \\
5 & \text { (Fill) }\end{array}$ & & 1 & & 1 & & & 1 & & & 4 & \\
\hline $\begin{array}{ll}6 & \text { (Firepit) } \\
7 & \\
7 & \text { (Mealing bin) } \\
7 & \text { (Fill) } \\
8 & \\
\end{array}$ & 4 & 4 & & 6 & & 1 & & & 19 & 1 & \\
\hline $\begin{array}{ll}21 & \\
21 & \text { (Pit C) } \\
21 & \text { (Fill) } \\
22 & \text { (Pit X fill) } \\
24 & \text { (Mealing bin) } \\
\end{array}$ & & 3 & & $\begin{array}{r}18 \\
18 \\
16 \\
\end{array}$ & 2 & & & & & $\begin{array}{l}1 \\
1 \\
1\end{array}$ & \\
\hline $\begin{array}{ll}25 & \\
27 & \\
31 \text { (Mealing bin) } \\
33 \text { (Mealing bin) } \\
33 \text { (Feces) } \\
\end{array}$ & & 1 & & $\begin{array}{r}5 \\
45 \\
\end{array}$ & 50 & & & & 21 & $\begin{array}{r}3 \\
15 \\
\end{array}$ & \\
\hline $\begin{array}{l}36 \\
41 \text { (Firepit) } \\
41 \text {-kiva } \\
41-\text {-kiva (fill) } \\
49\end{array}$ & 1 & & & $\begin{array}{c}40 \\
14 \\
1\end{array}$ & $\begin{array}{c}40 \\
1\end{array}$ & & & & & 1 & \\
\hline $\begin{array}{l}53 \\
61 \\
62 \text { (Fill) } \\
64 \text { (Fill) } \\
67 \text { (Mealing bin) } \\
\end{array}$ & 2 & & 3 & $\begin{array}{l}3 \\
1 \\
7 \\
\end{array}$ & & & & & & & \\
\hline $\begin{array}{l}69 \\
73 \\
73 \text { (Fill) } \\
78 \text { (Firepit) } \\
79 \text { (Mealing bin) }\end{array}$ & & & & $\begin{array}{l}1 \\
2 \\
1\end{array}$ & 1 & & & 1 & 2 & $\begin{array}{l}1 \\
1 \\
1 \\
2\end{array}$ & 5 \\
\hline $\begin{array}{l}82 \\
82 \text { (Mealing bin) } \\
92 \text { (Mealing bin } 1) \\
92 \text { (Mealing bin 2) } \\
92 \text { (Mealing bin } 3) \\
92 \text { (Mealing bin 4) }\end{array}$ & & & & $\begin{array}{r}24 \\
1\end{array}$ & & & & & 30 & $\begin{array}{l}4 \\
1 \\
1 \\
1 \\
\end{array}$ & \\
\hline $\begin{array}{l}\text { Plaza-kiva (floor) } \\
\text { Plaza-kiva (fill) }\end{array}$ & & & & & & & & & & & \\
\hline Totals & 7 & 9 & 3 & 197 & 94 & 1 & 1 & 1 & 72 & 39 & 5 \\
\hline
\end{tabular}

NOTE: These counts represent numbers of seeds found on floors and from pits in floors except as otherwise designated. The asterisk $\left(^{*}\right)$ signifies that both Cucurbita mixta and Cucurbita pepo were present. 


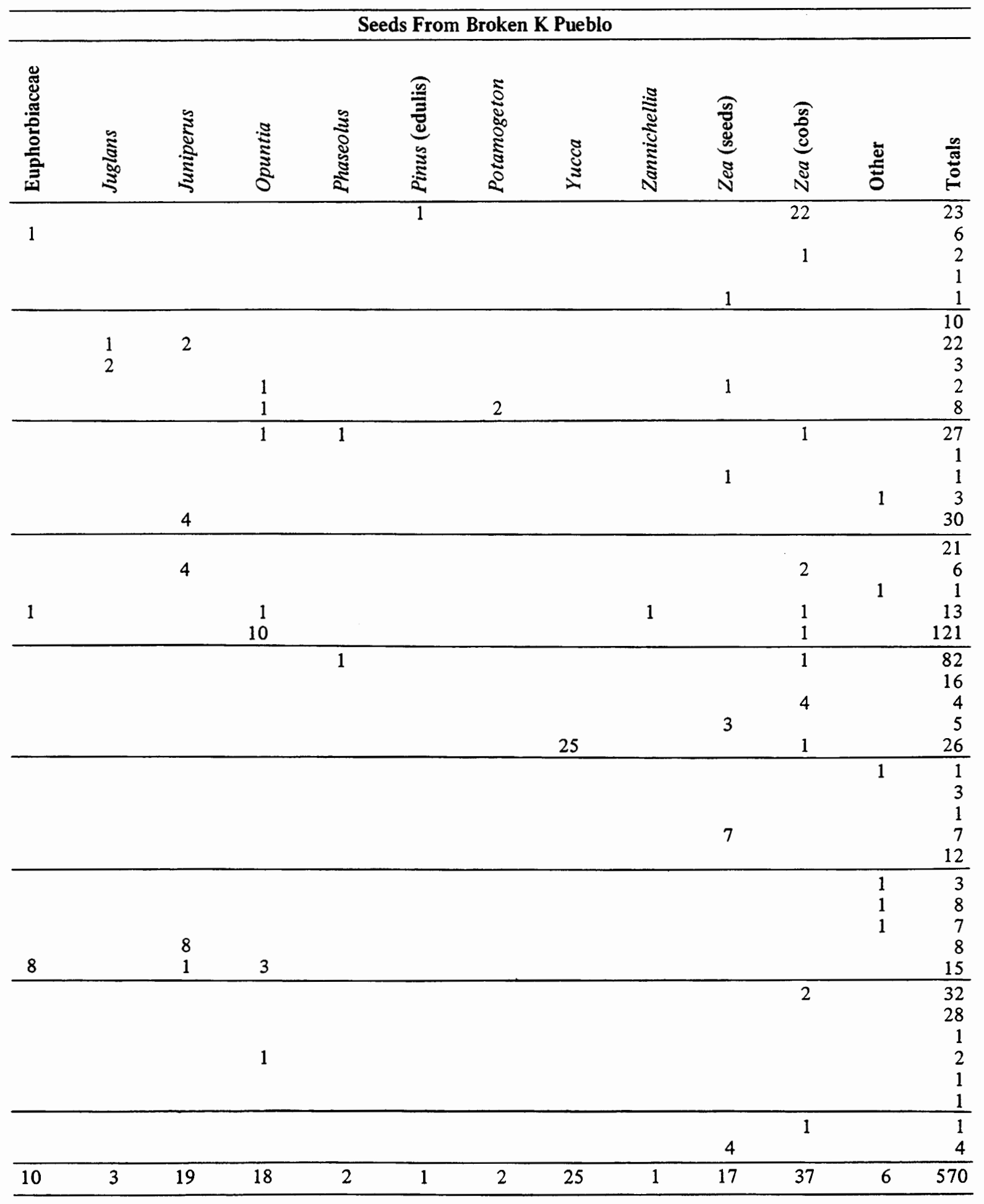




\section{APPENDIX 4 \\ POLLEN COUNTS, IN NUMBERS OF GRAINS, FROM FLOORS AND FEATURES AT BROKEN K PUEBLO}

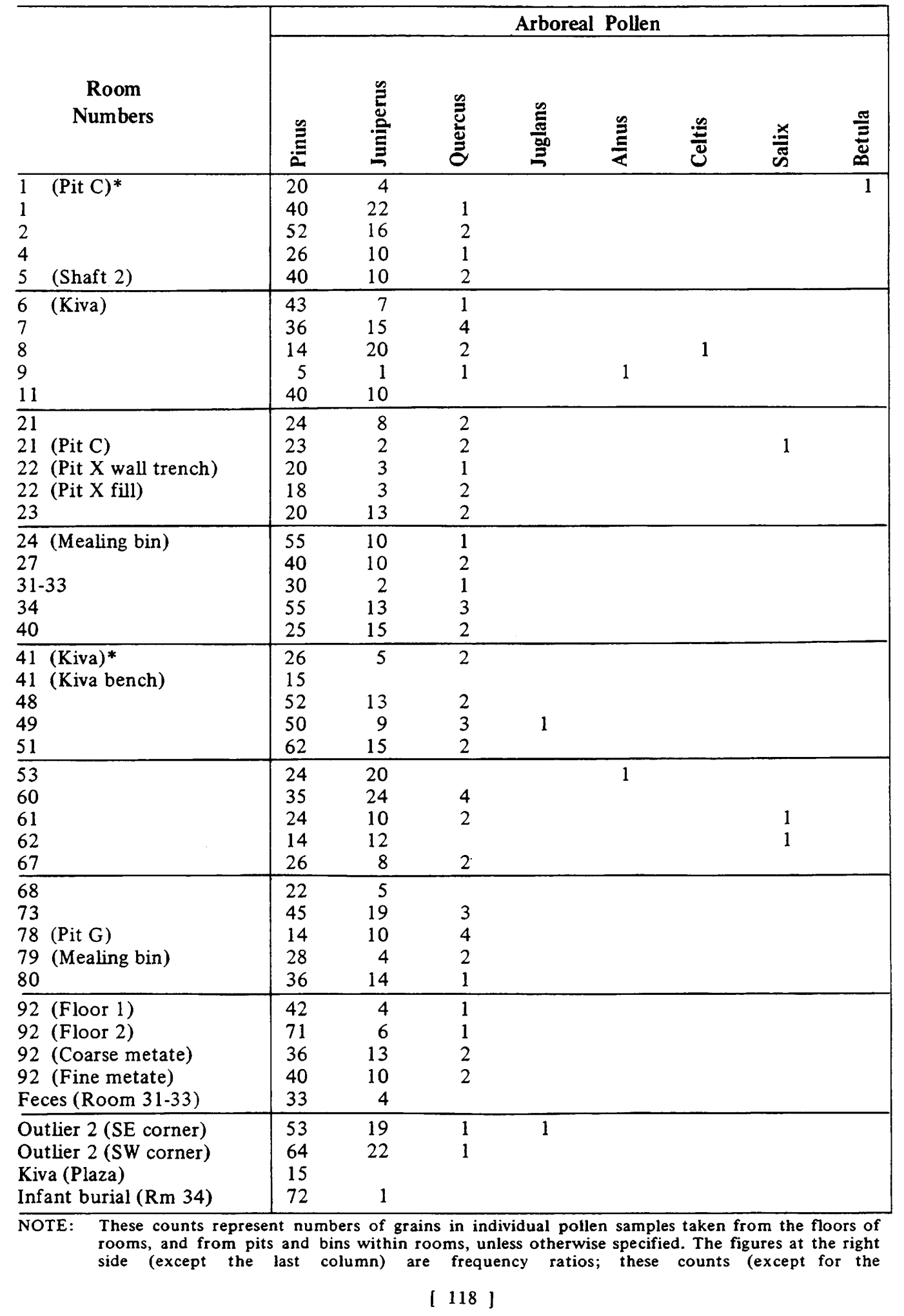




\begin{tabular}{|c|c|c|c|c|c|c|c|c|c|}
\hline \multirow[b]{2}{*}{$\stackrel{\mathscr{2}}{\underline{\Xi}}$} & \multirow[b]{2}{*}{ 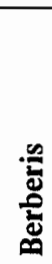 } & \multirow[b]{2}{*}{ 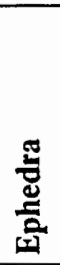 } & \multicolumn{3}{|c|}{ Compositae } & \multirow[b]{2}{*}{ 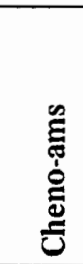 } & \multirow[b]{2}{*}{ 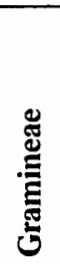 } & \multirow[b]{2}{*}{ 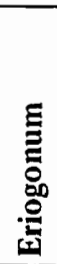 } & \multirow{2}{*}{ 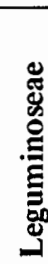 } \\
\hline & & & 号 & 音 & 亭 & & & & \\
\hline & & $\begin{array}{l}8 \\
5 \\
1 \\
6 \\
\end{array}$ & $\begin{array}{l}16 \\
14 \\
15 \\
41 \\
21 \\
\end{array}$ & $\begin{array}{l}16 \\
22 \\
37 \\
35 \\
21\end{array}$ & $\begin{array}{l}4 \\
1 \\
5 \\
7\end{array}$ & $\begin{array}{l}32 \\
43 \\
52 \\
44 \\
21\end{array}$ & $\begin{array}{r}5 \\
16 \\
14 \\
7 \\
3\end{array}$ & $\begin{array}{l}2 \\
6\end{array}$ & \\
\hline \multirow[t]{3}{*}{1} & & $\begin{array}{r}11 \\
2 \\
4 \\
1\end{array}$ & $\begin{array}{l}16 \\
24 \\
17 \\
11 \\
14\end{array}$ & $\begin{array}{l}36 \\
25 \\
18 \\
11 \\
26\end{array}$ & $\begin{array}{l}6 \\
6 \\
1 \\
1 \\
6\end{array}$ & $\begin{array}{l}44 \\
50 \\
50 \\
16 \\
46\end{array}$ & $\begin{array}{r}10 \\
10 \\
23 \\
3 \\
13\end{array}$ & $\begin{array}{l}6 \\
4 \\
1 \\
1\end{array}$ & 1 \\
\hline & & $\begin{array}{l}3 \\
3 \\
3 \\
1 \\
1\end{array}$ & $\begin{array}{l}34 \\
35 \\
33 \\
18 \\
36\end{array}$ & $\begin{array}{l}34 \\
38 \\
30 \\
18 \\
40\end{array}$ & $\begin{array}{r}4 \\
6 \\
10 \\
2\end{array}$ & $\begin{array}{l}35 \\
35 \\
10 \\
13 \\
22\end{array}$ & $\begin{array}{r}16 \\
10 \\
5 \\
9 \\
20\end{array}$ & $\begin{array}{l}3 \\
2 \\
3 \\
2\end{array}$ & \\
\hline & & $\begin{array}{l}7 \\
4 \\
1 \\
2 \\
3 \\
\end{array}$ & $\begin{array}{l}24 \\
18 \\
10 \\
13 \\
23\end{array}$ & $\begin{array}{l}22 \\
26 \\
10 \\
15 \\
45\end{array}$ & $\begin{array}{l}2 \\
8 \\
8 \\
6 \\
\end{array}$ & $\begin{array}{l}57 \\
10 \\
20 \\
24 \\
55 \\
\end{array}$ & $\begin{array}{r}12 \\
11 \\
5 \\
8 \\
18 \\
\end{array}$ & $\begin{array}{l}3 \\
1 \\
2 \\
1 \\
2\end{array}$ & \\
\hline \multirow[t]{2}{*}{1} & & $\begin{array}{l}3 \\
1 \\
2 \\
2 \\
3 \\
\end{array}$ & $\begin{array}{r}28 \\
3 \\
23 \\
25 \\
13 \\
\end{array}$ & $\begin{array}{r}34 \\
4 \\
23 \\
25 \\
24 \\
\end{array}$ & $\begin{array}{r}6 \\
2 \\
10 \\
2 \\
4 \\
\end{array}$ & $\begin{array}{l}44 \\
46 \\
41 \\
28 \\
43 \\
\end{array}$ & $\begin{array}{l}16 \\
18 \\
10 \\
11 \\
\end{array}$ & $\begin{array}{l}7 \\
1 \\
2 \\
1 \\
\end{array}$ & \\
\hline & 1 & $\begin{array}{l}4 \\
4 \\
2 \\
2 \\
1\end{array}$ & $\begin{array}{l}24 \\
15 \\
25 \\
24 \\
22\end{array}$ & $\begin{array}{l}46 \\
25 \\
22 \\
32 \\
20\end{array}$ & $\begin{array}{r}4 \\
12 \\
6 \\
4 \\
5\end{array}$ & $\begin{array}{l}44 \\
38 \\
24 \\
56 \\
21\end{array}$ & $\begin{array}{r}26 \\
20 \\
10 \\
20 \\
8\end{array}$ & $\begin{array}{l}1 \\
1\end{array}$ & \\
\hline & & $\begin{array}{l}2 \\
4 \\
5 \\
3\end{array}$ & $\begin{array}{l}37 \\
13 \\
19 \\
20 \\
20\end{array}$ & $\begin{array}{l}15 \\
32 \\
24 \\
22 \\
30\end{array}$ & $\begin{array}{r}1 \\
10 \\
2 \\
2 \\
12\end{array}$ & $\begin{array}{l}21 \\
31 \\
76 \\
70 \\
30\end{array}$ & $\begin{array}{r}9 \\
13 \\
18 \\
22 \\
17\end{array}$ & $\begin{array}{l}4 \\
2 \\
3\end{array}$ & \\
\hline & & $\begin{array}{l}2 \\
3 \\
2 \\
4\end{array}$ & $\begin{array}{r}18 \\
25 \\
20 \\
19 \\
5\end{array}$ & $\begin{array}{r}36 \\
32 \\
27 \\
22 \\
6\end{array}$ & $\begin{array}{l}4 \\
8 \\
9 \\
7\end{array}$ & $\begin{array}{l}45 \\
26 \\
64 \\
68 \\
31\end{array}$ & $\begin{array}{r}15 \\
5 \\
9 \\
7 \\
26\end{array}$ & $\begin{array}{l}2 \\
2 \\
1\end{array}$ & \\
\hline & & $\begin{array}{r}4 \\
2 \\
10 \\
3\end{array}$ & $\begin{array}{r}20 \\
18 \\
11 \\
9\end{array}$ & $\begin{array}{r}18 \\
33 \\
10 \\
9\end{array}$ & $\begin{array}{r}4 \\
10 \\
2\end{array}$ & $\begin{array}{r}58 \\
41 \\
130 \\
3\end{array}$ & $\begin{array}{r}19 \\
19 \\
10 \\
2\end{array}$ & $\begin{array}{l}1 \\
3\end{array}$ & \\
\hline
\end{tabular}

arboreal/nonarboreal column) are separate counts and are thus independent of the other entries. The asterisks (*) signify that there were so few grains in a sample that the standard 200-grain count could not be made; in these cases a 100 -grain count is used. 
Pollen Counts From Floors and Features (cont'd)

\begin{tabular}{|c|c|c|c|c|c|c|c|}
\hline \multirow[b]{2}{*}{$\begin{array}{c}\text { Room } \\
\text { Numbers }\end{array}$} & \multirow[b]{2}{*}{ 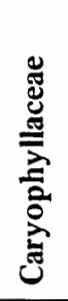 } & \multirow[b]{2}{*}{ 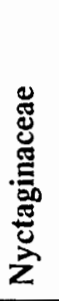 } & \multirow[b]{2}{*}{ 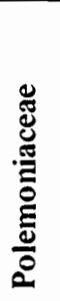 } & \multirow[b]{2}{*}{ 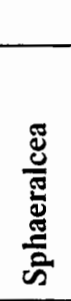 } & & \multicolumn{2}{|c|}{ Economic } \\
\hline & & & & &  & 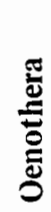 & $\stackrel{\mathscr{\Xi}}{\stackrel{\Xi}{U}}$ \\
\hline $\begin{array}{ll}1 & (\text { Pit C })^{*} \\
1 & \\
2 & \\
4 & \\
5 & \text { (Shaft 2) } \\
\end{array}$ & & & & $\begin{array}{l}1 \\
1 \\
2 \\
3 \\
\end{array}$ & $\begin{array}{r}4 \\
10 \\
1 \\
2 \\
6 \\
\end{array}$ & $\begin{array}{l}1 \\
4 \\
\end{array}$ & $\begin{array}{r}8 \\
1 \\
10 \\
6 \\
\end{array}$ \\
\hline $\begin{array}{ll}6 & \text { (Kiva) } \\
7 & \\
8 & \\
9 \\
11 \\
\end{array}$ & & 1 & & $\begin{array}{l}2 \\
3 \\
5 \\
1 \\
1 \\
\end{array}$ & $\begin{array}{r}4 \\
2 \\
10 \\
25 \\
20 \\
\end{array}$ & 1 & $\begin{array}{r}2 \\
6 \\
8 \\
50 \\
5 \\
\end{array}$ \\
\hline $\begin{array}{ll}21 & \\
21 & \text { (Pit C) } \\
22 & \text { (Pit X wall trench) } \\
22 & \text { (Pit X fill) } \\
23 & \\
\end{array}$ & & & $\begin{array}{l}1 \\
1\end{array}$ & $\begin{array}{r}6 \\
3 \\
11 \\
4 \\
4 \\
\end{array}$ & $\begin{array}{l}5 \\
5 \\
6 \\
4 \\
5 \\
\end{array}$ & $\begin{array}{l}2 \\
1\end{array}$ & $\begin{array}{r}6 \\
5 \\
5 \\
10 \\
\end{array}$ \\
\hline $\begin{array}{l}24 \text { (Mealing bin) } \\
27 \\
31-33 \\
34 \\
40\end{array}$ & & & & $\begin{array}{l}3 \\
5 \\
2 \\
1\end{array}$ & $\begin{array}{r}1 \\
6 \\
26 \\
18 \\
2 \\
\end{array}$ & $\begin{array}{l}1 \\
2 \\
1\end{array}$ & $\begin{array}{l}3 \\
5 \\
2 \\
1 \\
5 \\
\end{array}$ \\
\hline $\begin{array}{ll}41 & \text { (Kiva)* } \\
41 & \text { (Kiva bench) } \\
48 & \\
49 & \\
51 & \\
\end{array}$ & & & & $\begin{array}{l}4 \\
1 \\
4\end{array}$ & $\begin{array}{l}4 \\
5 \\
3 \\
4 \\
9 \\
\end{array}$ & $\begin{array}{l}1 \\
2\end{array}$ & $\begin{array}{l}4 \\
5 \\
1 \\
5 \\
\end{array}$ \\
\hline $\begin{array}{l}53 \\
60 \\
61 \\
62 \\
67 \\
\end{array}$ & & & 2 & $\begin{array}{l}3 \\
3 \\
2 \\
8\end{array}$ & $\begin{array}{l}4 \\
6 \\
6 \\
2 \\
7\end{array}$ & & $\begin{array}{r}4 \\
12 \\
22 \\
5 \\
5 \\
\end{array}$ \\
\hline $\begin{array}{l}68 \\
73 \\
78 \text { (Pit G) } \\
79 \text { (Mealing bin) } \\
80 \text {. } \\
\end{array}$ & 1 & & 6 & $\begin{array}{l}5 \\
1 \\
4 \\
2 \\
\end{array}$ & $\begin{array}{r}10 \\
8 \\
1 \\
5 \\
5\end{array}$ & $\begin{array}{l}1 \\
1\end{array}$ & $\begin{array}{r}7 \\
2 \\
11 \\
5 \\
8 \\
\end{array}$ \\
\hline $\begin{array}{l}92 \text { (Floor 1) } \\
92 \text { (Floor 2) } \\
92 \text { (Coarse metate) } \\
92 \text { (Fine metate) } \\
\text { Feces (Room 31-33) }\end{array}$ & & 1 & & $\begin{array}{l}2 \\
1 \\
1 \\
2 \\
\end{array}$ & $\begin{array}{r}6 \\
9 \\
8 \\
12 \\
\end{array}$ & $\begin{array}{r}3 \\
1 \\
12\end{array}$ & $\begin{array}{l}4 \\
2 \\
2 \\
2 \\
2\end{array}$ \\
\hline $\begin{array}{l}\text { Outlier } 2 \text { (SE corner) } \\
\text { Outlier } 2 \text { (SW corner) } \\
\text { Kiva (Plaza) } \\
\text { Infant burial ( } R \mathrm{~m} 34)\end{array}$ & & & & $\begin{array}{r}1 \\
91\end{array}$ & $\begin{array}{l}1 \\
1 \\
5\end{array}$ & & $\begin{array}{l}1 \\
5 \\
8\end{array}$ \\
\hline
\end{tabular}

NOTE: These counts represent numbers of grains in individual pollen samples taken from the floors of rooms, and from pits and bins within rooms, unless otherwise specified. The figures at the right side (except the last column) are frequency ratios; these counts 




(except for the arboreal/nonarboreal column) are separate counts and are thus independent of the other entries. The asterisks $\left(^{*}\right)$ signify that there were so few grains in a sample that the standard 200-grain count could not be made; in these cases a 100-grain count is used. 


\section{APPENDIX 5 \\ DISTRIBUTIONS OF POTTERY-TYPE AND CERAMIC DESIGN-ELEMENT FACTORS NOT ILLUSTRATED IN TEXT}

The distribution maps in this appendix show the percentages that each of the factors contributes to the total factor-composition of each provenience unit (see Chapter 6). The class-intervals used were determined by graphic means.

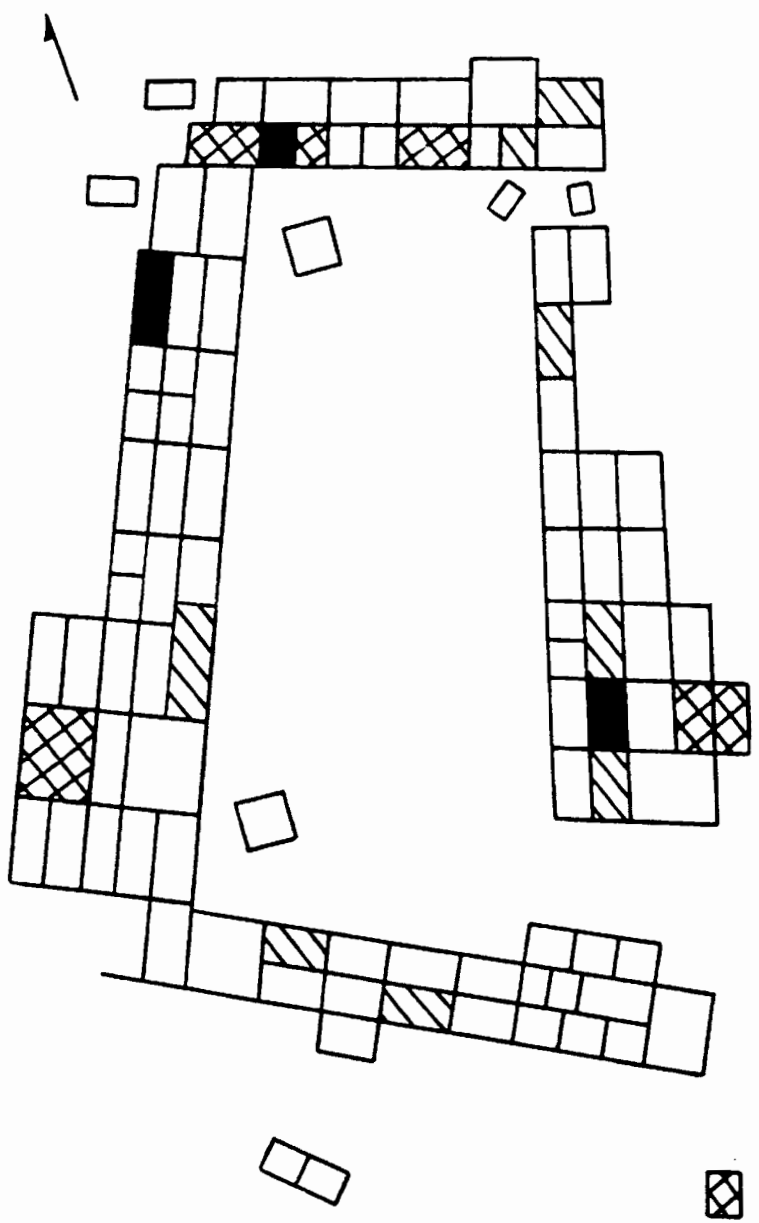

Figure A1. Factor 5, pottery-types, floors. Hatched areas indicate 1-23 percent of factor-composition; cross-hatched, 30-44 percent; shaded, 59-100 percent.
Several of these factors cannot presently be interpreted. Others have been referred to in the text but are not illustrated there.

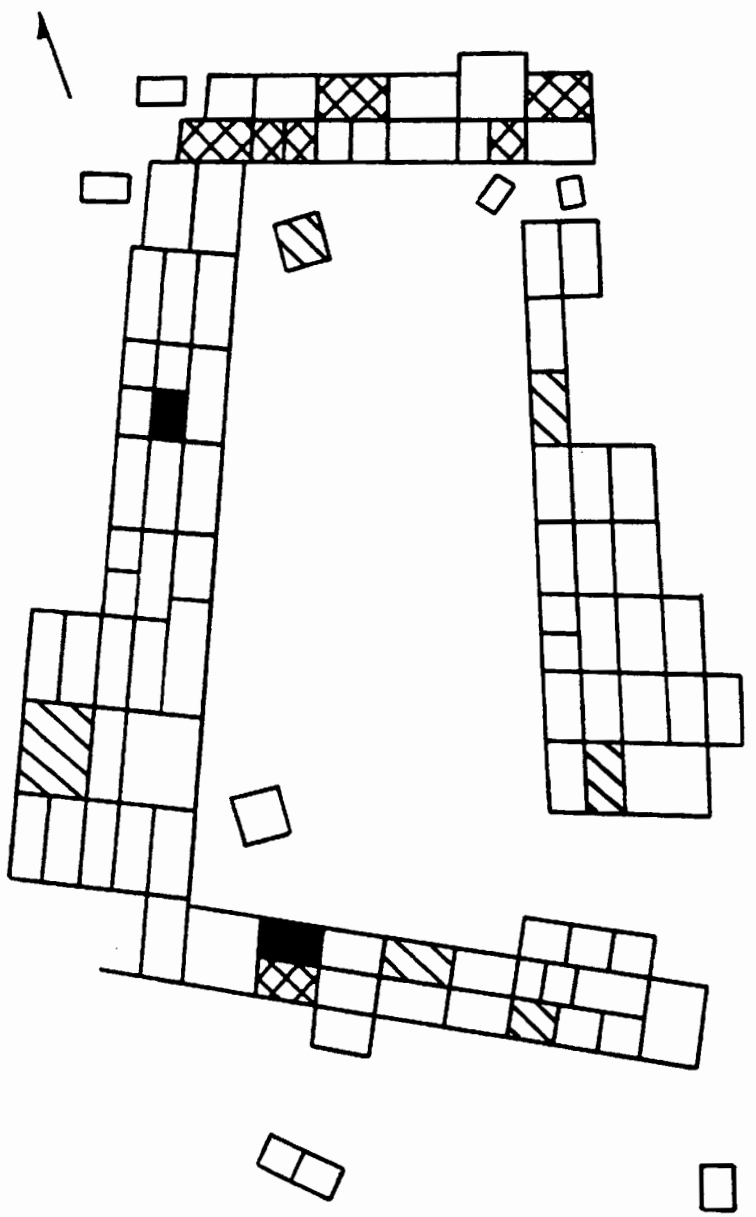

Figure A2. Factor 6, pottery-types, floors. Hatched areas indicate 1-10 percent of factor-composition; cross-hatched, 13-27 percent; shaded, 50-90 percent. 




Figure A3. Factor 7, pottery-types, floors. Hatched areas indicate 412 percent of factor-composition; cross-hatched, 18-22 percent; shaded, 37-65 percent.

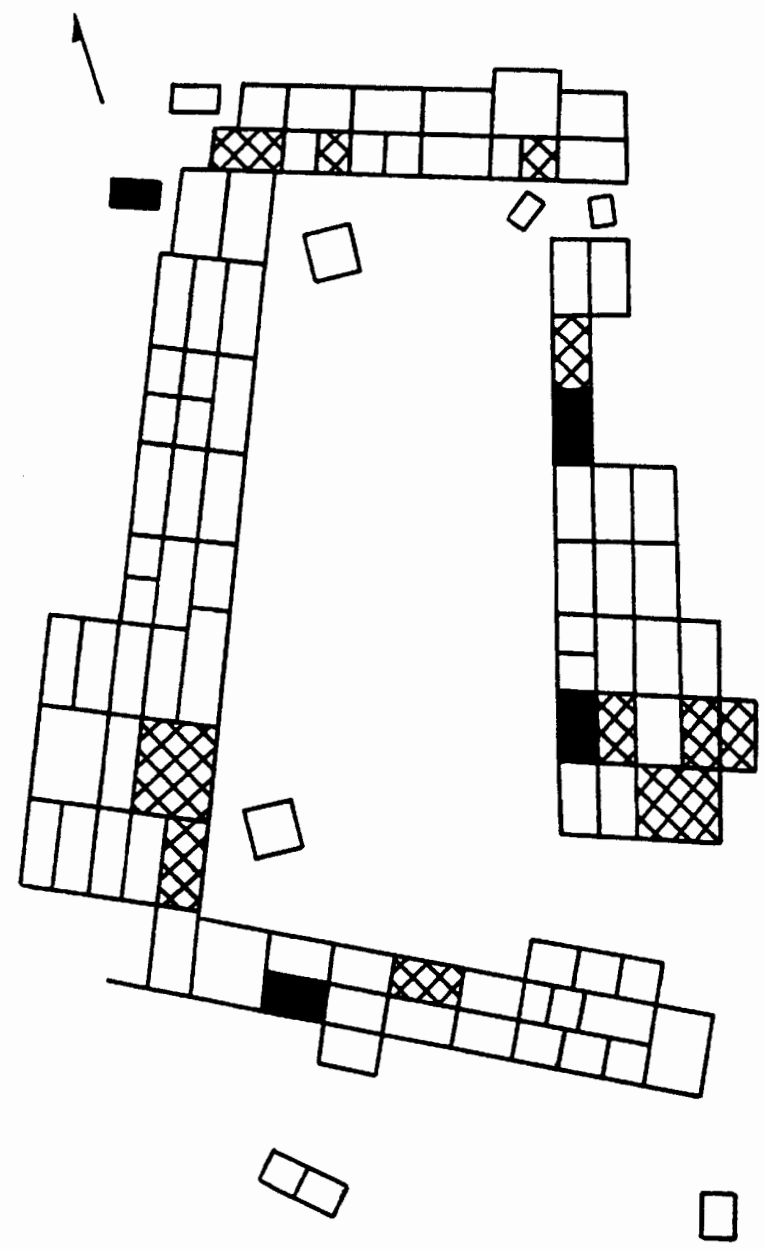

Figure A4. Factor 7, ceramic designs, floors. Crosshatched areas indicate 1-23 percent of factorcomposition; shaded, 45-70 percent. 


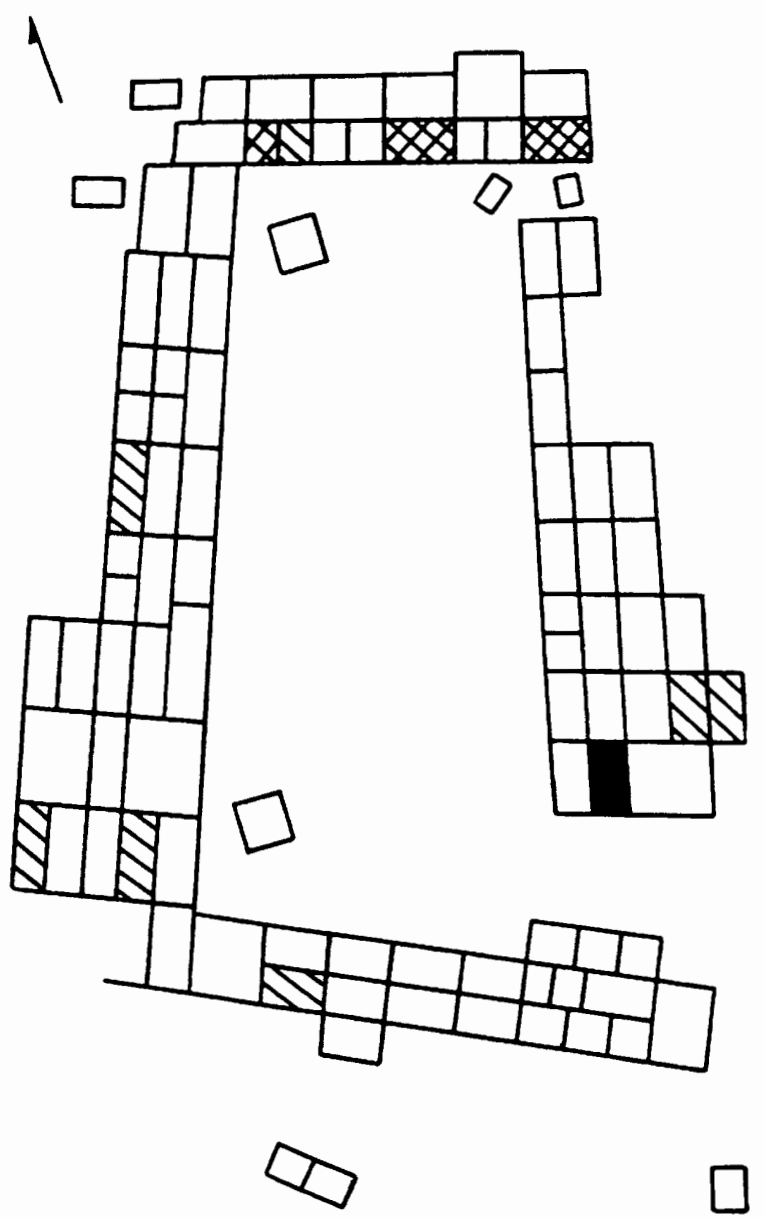

Figure A5. Factor 8, ceramic designs, floors. Blank areas indicate $\mathbf{0 . 7}$ percent of factor-composition; hatched, $12-31$ percent; cross-hatched, $40-56$ percent; shaded, 85 percent.



Figure A6. Factor 10, ceramic designs, floors. Hatched areas indicate 1-20 percent of factorcomposition; cross-hatched, $21-45$ percent; shaded, 46-60 percent. 


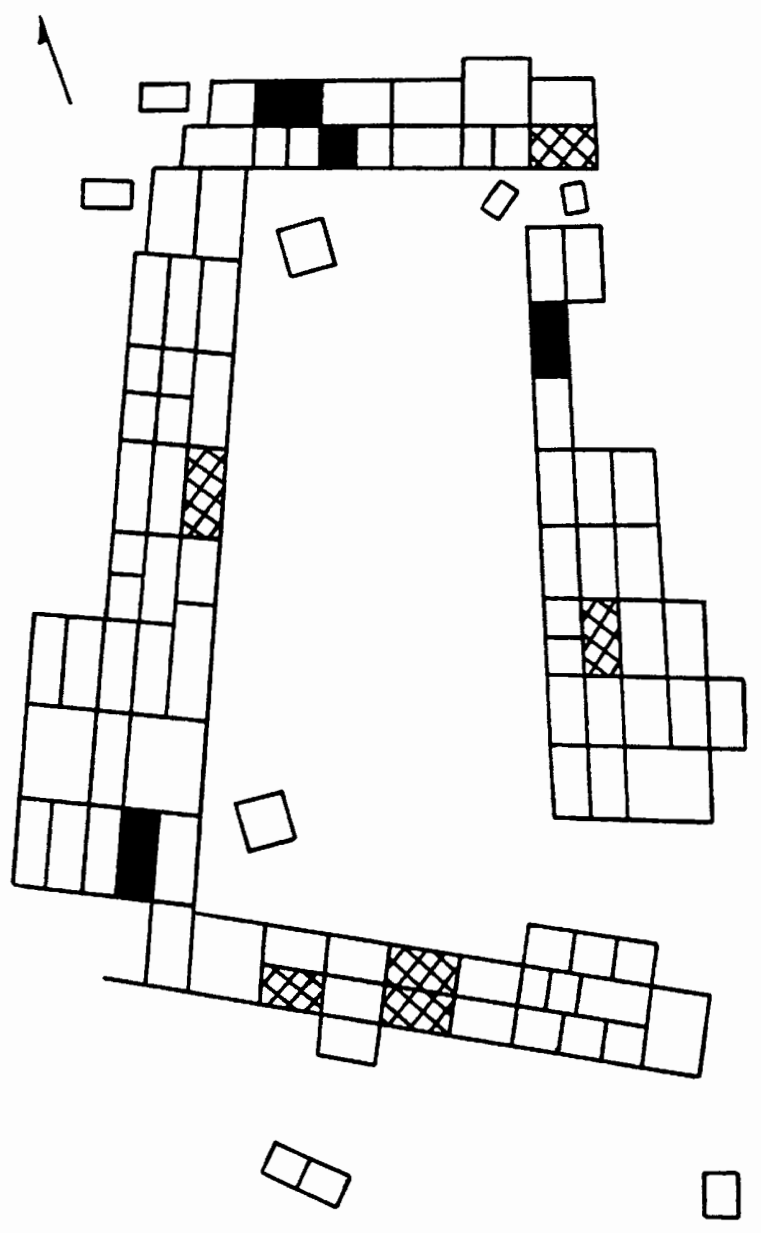

Figure A7. Factor 11, ceramic designs, floors. Blank areas indicate 0-8 percent of factor-composition; cross-hatched, 12-22 percent; shaded, 46-70 percent.

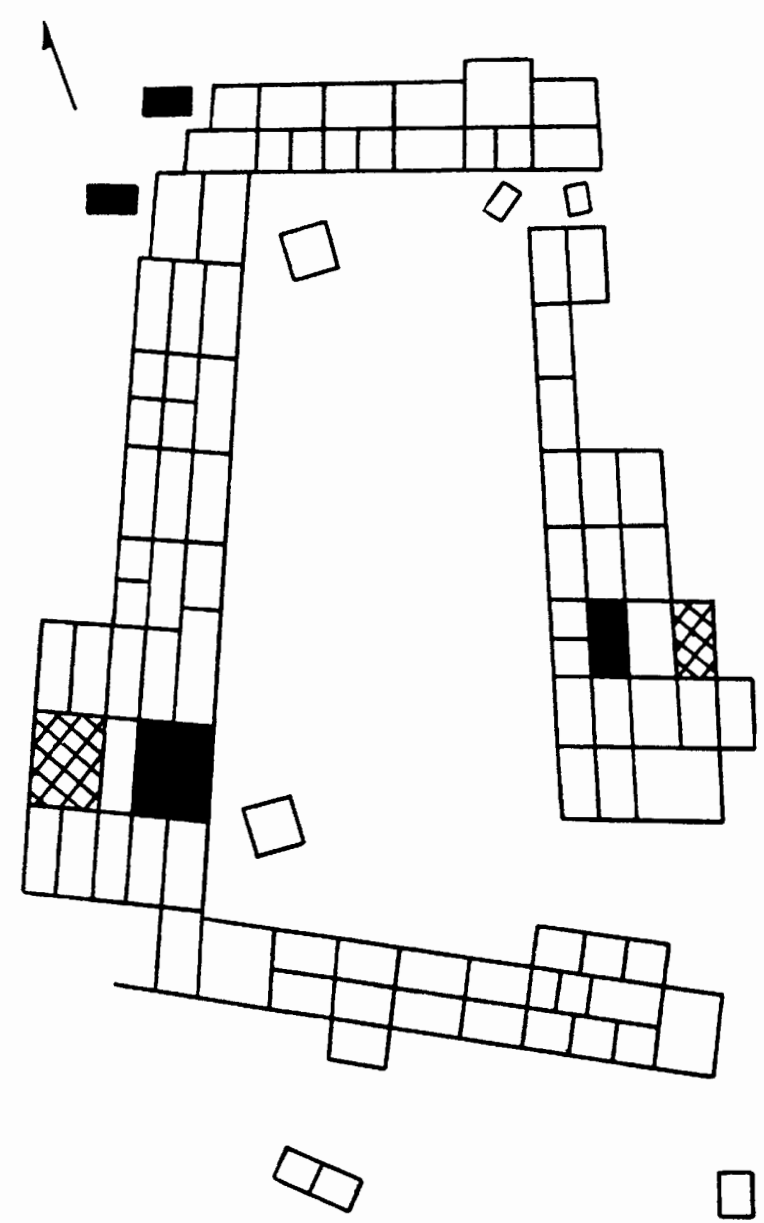

Figure A8. Factor 5, ceramic designs, fills. Blank areas indicate $0-10$ percent of factor-composition; cross-hatched, 18-23 percent; shaded, $48-83$ percent. 


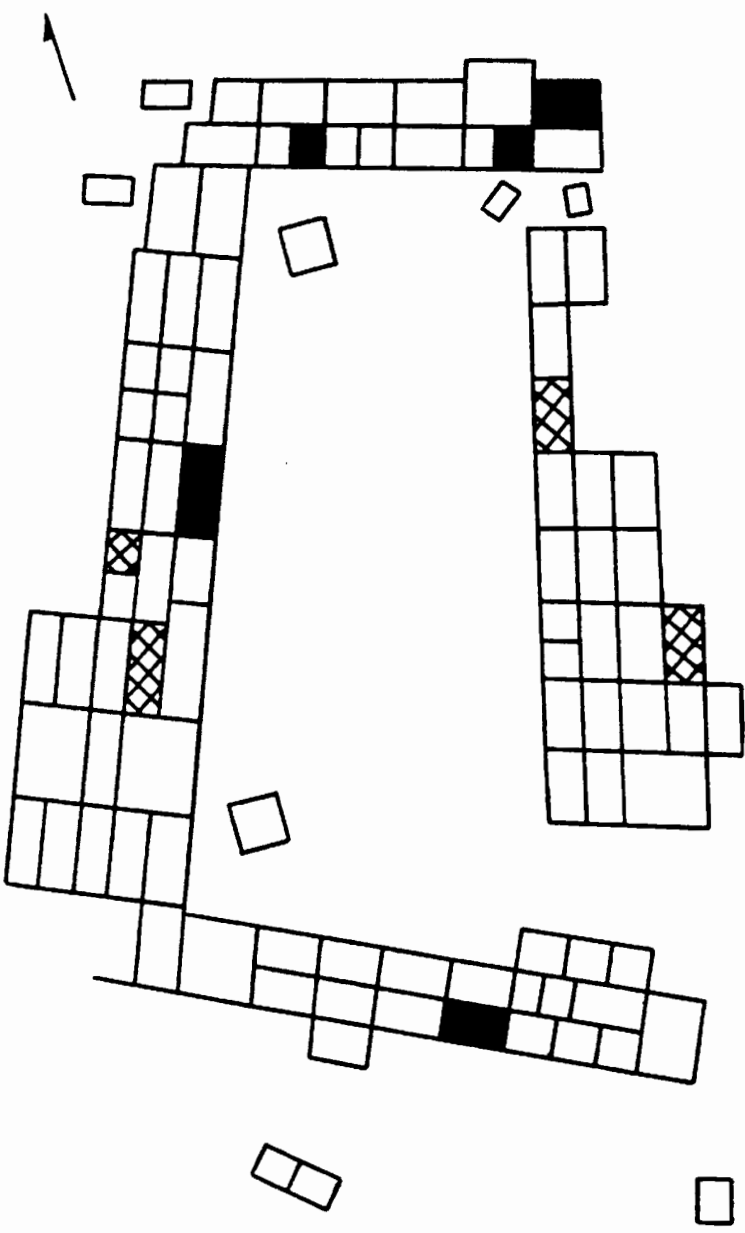

Figure A9. Factor 6, ceramic designs, fills. Blank areas indicate $0-18$ percent of factor-composition; cross-hatched, 24-56 percent; shaded, 93-100 percent.

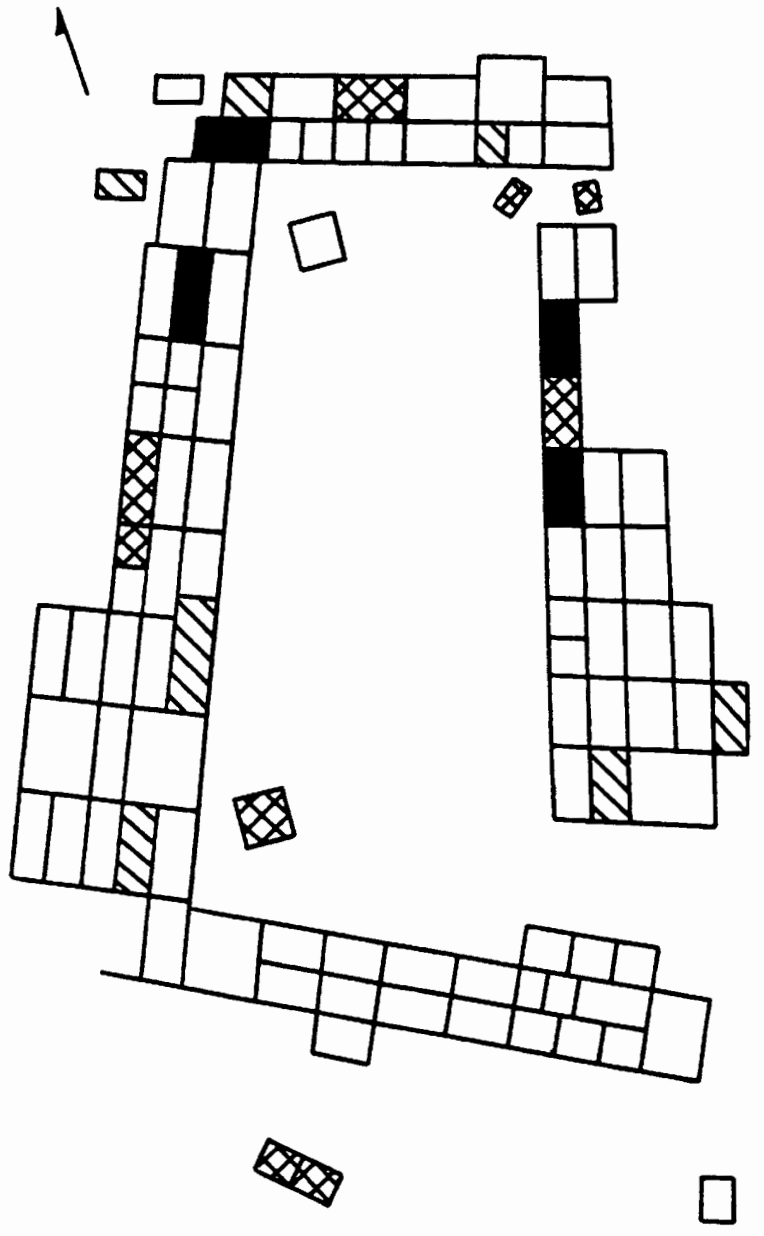

Figure A10. Factor 7, ceramic designs, fills. Blank areas indicate 0.8 percent of factor-composition; hatched, 14-29 percent; cross-hatched, 40-70 percent; shaded, 86-100 percent. 


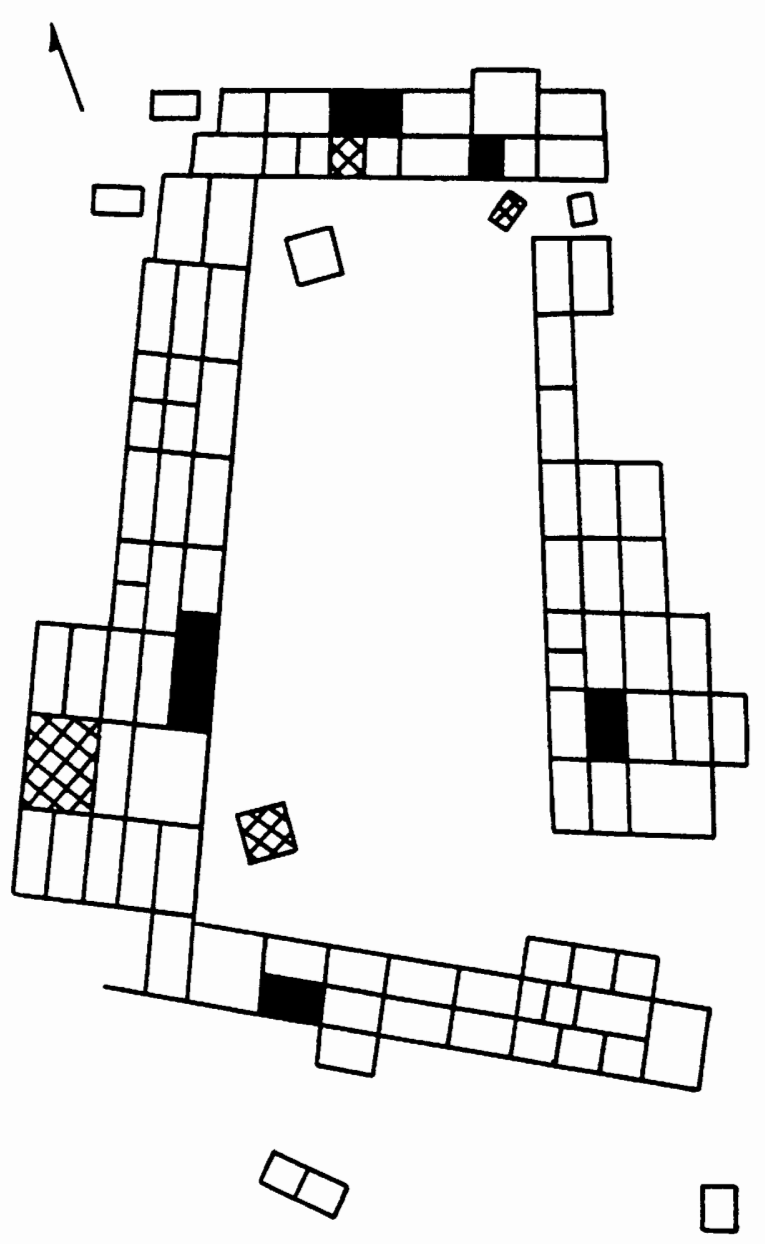

Figure A11. Factor 8, ceramic designs, fills. Blank areas indicate $0-20$ percent of factor-composition; cross-hatched, 29-43 percent; shaded, 58-87 percent. 


\section{APPENDIX 6 \\ DISTRIBUTION OF POTTERY TYPES (SHERD COUNTS) ON FLOORS}

\begin{tabular}{|c|c|c|c|c|c|c|c|c|}
\hline $\begin{array}{c}\text { Room } \\
\text { Numbers }\end{array}$ & 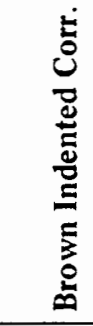 & 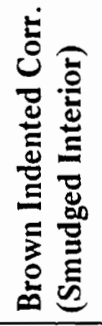 & 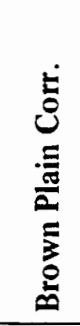 & 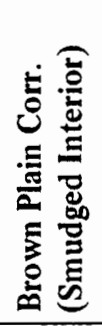 & 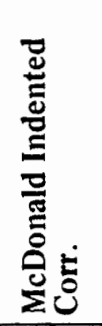 & 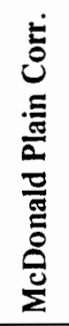 & 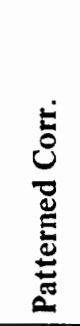 & $\stackrel{\frac{2}{0}}{\stackrel{0}{0}}$ \\
\hline $\begin{array}{l}1 \\
2 \\
4-5 \\
6 \quad \text { (kiva) } \\
7\end{array}$ & $\begin{array}{r}302 \\
52 \\
89 \\
24 \\
68\end{array}$ & $\begin{array}{r}27 \\
4 \\
16 \\
11\end{array}$ & $\begin{array}{r}21 \\
7 \\
7 \\
2 \\
1\end{array}$ & $\begin{array}{l}2 \\
6 \\
8 \\
1\end{array}$ & $\begin{array}{r}11 \\
16 \\
31 \\
3 \\
11\end{array}$ & 1 & $\begin{array}{l}8 \\
6\end{array}$ & $\begin{array}{l}1 \\
1\end{array}$ \\
\hline $\begin{array}{l}8 \\
9 \\
11 \\
20 \\
21\end{array}$ & $\begin{array}{r}9 \\
40 \\
58 \\
10 \\
33\end{array}$ & $\begin{array}{l}1 \\
1 \\
5\end{array}$ & $\begin{array}{l}1 \\
3 \\
1 \\
5\end{array}$ & $\begin{array}{l}1 \\
2\end{array}$ & $\begin{array}{r}14 \\
2 \\
5\end{array}$ & 1 & $\begin{array}{l}1 \\
1\end{array}$ & \\
\hline $\begin{array}{l}24 \\
27 \\
28 \\
29 \\
30\end{array}$ & $\begin{array}{r}64 \\
7 \\
\\
74 \\
3\end{array}$ & 4 & 1 & & $\begin{array}{r}11 \\
3 \\
\\
4\end{array}$ & 2 & $\begin{array}{l}6 \\
1\end{array}$ & $\overline{2}$ \\
\hline $\begin{array}{l}31-33 \\
34 \\
35-37 \\
36 \\
38\end{array}$ & $\begin{array}{l}38 \\
23 \\
12 \\
23 \\
19\end{array}$ & $\begin{array}{l}4 \\
1 \\
6 \\
5\end{array}$ & $\begin{array}{l}3 \\
2 \\
3 \\
3\end{array}$ & $\begin{array}{l}1 \\
1\end{array}$ & $\begin{array}{l}3 \\
4\end{array}$ & $\begin{array}{l}2 \\
1\end{array}$ & 2 & 4 \\
\hline $\begin{array}{l}40 \\
41 \\
41 \text { (kiva) } \\
43 \\
49\end{array}$ & $\begin{array}{r}10 \\
36 \\
40 \\
5 \\
19\end{array}$ & $\begin{array}{l}7 \\
1 \\
1 \\
1\end{array}$ & $\begin{array}{l}1 \\
9 \\
6\end{array}$ & $\begin{array}{l}2 \\
1\end{array}$ & $\begin{array}{l}1 \\
4 \\
1\end{array}$ & 3 & $\begin{array}{l}1 \\
2\end{array}$ & \\
\hline $\begin{array}{l}51 \\
53 \\
60 \\
62 \\
64 \\
\end{array}$ & $\begin{array}{r}1 \\
135 \\
115 \\
63 \\
142 \\
\end{array}$ & $\begin{array}{l}1 \\
1 \\
8 \\
6 \\
\end{array}$ & $\begin{array}{l}1 \\
5 \\
\end{array}$ & $\begin{array}{l}2 \\
2 \\
2\end{array}$ & $\begin{array}{l}3 \\
7 \\
8\end{array}$ & $\begin{array}{l}1 \\
3 \\
\end{array}$ & $\begin{array}{r}1 \\
3 \\
4 \\
26 \\
\end{array}$ & 1 \\
\hline $\begin{array}{l}65 \\
68 \\
69 \\
73 \\
74\end{array}$ & $\begin{array}{r}57 \\
18 \\
103 \\
5 \\
9 \\
\end{array}$ & $\begin{array}{l}4 \\
1 \\
4 \\
1 \\
1\end{array}$ & $\begin{array}{l}4 \\
1 \\
5 \\
1 \\
\end{array}$ & 1 & $\begin{array}{l}2 \\
1 \\
3\end{array}$ & 4 & 3 & 1 \\
\hline $\begin{array}{l}78 \\
79 \\
80 \\
82 \\
92\end{array}$ & $\begin{array}{r}11 \\
27 \\
77 \\
65 \\
198 \\
\end{array}$ & $\begin{array}{l}4 \\
9\end{array}$ & $\begin{array}{r}1 \\
1 \\
11 \\
1\end{array}$ & 1 & $\begin{array}{r}1 \\
1 \\
1 \\
3 \\
16\end{array}$ & & $\begin{array}{r}2 \\
6 \\
10\end{array}$ & $\begin{array}{l}3 \\
4\end{array}$ \\
\hline $\begin{array}{l}\text { Outlier } 2 \\
\text { Plaza-kiva } \\
\text { Plaza }\end{array}$ & $\begin{array}{r}31 \\
20 \\
743\end{array}$ & $\begin{array}{r}3 \\
54\end{array}$ & $\begin{array}{r}1 \\
1 \\
52\end{array}$ & $\begin{array}{l}1 \\
7\end{array}$ & $\begin{array}{r}4 \\
2 \\
43\end{array}$ & 7 & $\begin{array}{r}4 \\
18\end{array}$ & $\begin{array}{l}2 \\
3\end{array}$ \\
\hline Totals & 2878 & 202 & 162 & 40 & 219 & 25 & 111 & 26 \\
\hline
\end{tabular}




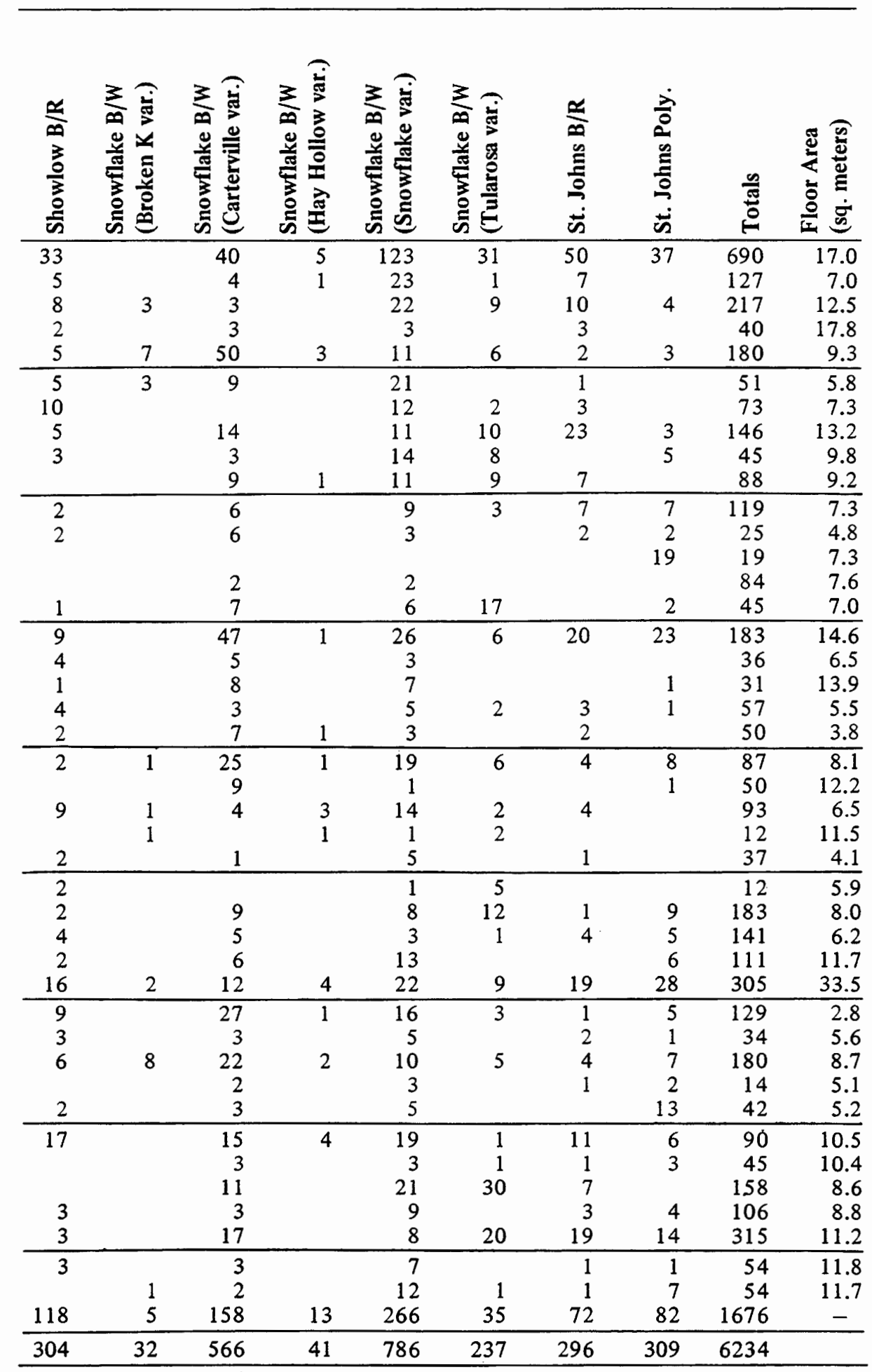

input matrix for the factor analysis of pottery-types (although it was transformed into proportions). Complete sherd counts (by room, pit, etc.) can be found in Martin, Hill, and Longacre (1966). 
APPENDIX 7

\section{DISTRIBUTION OF CERAMIC DESIGN ELEMENTS FROM FLOORS}

\begin{tabular}{|c|c|c|c|c|c|c|c|c|c|c|}
\hline \multirow[b]{2}{*}{ Room Numbers } & \multicolumn{10}{|c|}{ Design Element Numbers } \\
\hline & 6 & 19 & 20 & 29 & 31 & 39 & 45 & 46 & $\begin{array}{l}50- \\
51 \\
\end{array}$ & 65 \\
\hline $\begin{array}{l}1 \\
2 \\
4-5 \\
6 \\
7 \\
\end{array}$ & 2 & $\begin{array}{l}3 \\
1\end{array}$ & $\begin{array}{l}2 \\
1\end{array}$ & $\begin{array}{l}4 \\
1 \\
2 \\
1 \\
1\end{array}$ & & & 1 & 1 & 1 & $\begin{array}{l}1 \\
1 \\
2 \\
3\end{array}$ \\
\hline $\begin{array}{l}8 \\
9 \\
11 \\
20 \\
21 \\
\end{array}$ & $\begin{array}{l}1 \\
3\end{array}$ & & $\begin{array}{l}1 \\
1\end{array}$ & $\begin{array}{l}4 \\
1 \\
1 \\
\end{array}$ & & $\begin{array}{l}1 \\
3 \\
\end{array}$ & & & 4 & 1 \\
\hline $\begin{array}{l}24 \\
25 \\
27 \\
30 \\
33\end{array}$ & $\begin{array}{l}1 \\
1 \\
1 \\
1\end{array}$ & $\begin{array}{l}1 \\
1\end{array}$ & 1 & $\begin{array}{l}1 \\
1\end{array}$ & 1 & & $\begin{array}{l}1 \\
1 \\
5\end{array}$ & 4 & & 1 \\
\hline $\begin{array}{l}34 \\
36 \\
37 \\
38 \\
40 \\
\end{array}$ & 1 & 1 & 2 & $\begin{array}{l}1 \\
1 \\
3 \\
\end{array}$ & $\begin{array}{l}1 \\
6\end{array}$ & $\begin{array}{l}3 \\
1\end{array}$ & 1 & & 2 & \\
\hline $\begin{array}{l}51 \\
53 \\
62 \\
64 \\
65\end{array}$ & 1 & $\begin{array}{l}1 \\
1 \\
1 \\
1\end{array}$ & $\begin{array}{l}2 \\
2\end{array}$ & 2 & 1 & & $\begin{array}{l}1 \\
1\end{array}$ & $\begin{array}{l}1 \\
2 \\
1\end{array}$ & $\begin{array}{l}1 \\
1\end{array}$ & \\
\hline $\begin{array}{l}68 \\
69 \\
73 \\
74 \\
78\end{array}$ & 1 & & $\begin{array}{l}1 \\
3\end{array}$ & $\begin{array}{l}1 \\
2\end{array}$ & & $\begin{array}{l}1 \\
1\end{array}$ & & 1 & & 1 \\
\hline $\begin{array}{l}79 \\
80 \\
82 \\
92 \\
\text { Outlier } 2 \\
\end{array}$ & $\begin{array}{l}2 \\
1 \\
2 \\
1 \\
\end{array}$ & & $\begin{array}{l}2 \\
1 \\
1\end{array}$ & $\begin{array}{l}2 \\
1\end{array}$ & 2 & & & & & $\begin{array}{l}1 \\
1 \\
\end{array}$ \\
\hline $\begin{array}{l}\text { Burial (room 27) } \\
41 \text {-kiva } \\
\text { Plaza-kiva } \\
\end{array}$ & $\begin{array}{r}11 \\
1\end{array}$ & & 1 & $\begin{array}{l}2 \\
1 \\
\end{array}$ & & & $\begin{array}{l}5 \\
1\end{array}$ & 6 & 7 & 4 \\
\hline Totals & 33 & 11 & 21 & 33 & 11 & 10 & 17 & 16 & 16 & 16 \\
\hline
\end{tabular}

NOTE: These counts represent numbers of ceramic design elements on floors. This is the computer input matrix used in the design-element factor analysis (floors) presented in this volume. It includes only those design-elements having a total frequency of at least 10 at the site, and only those rooms having a frequency of at least 5 sherds. Several design-elements were 
$($ cont'd $\longrightarrow$ )

\begin{tabular}{|c|c|c|c|c|c|c|c|c|c|c|c|}
\hline & \multicolumn{11}{|c|}{ Design Element Numbers } \\
\hline \multirow[t]{6}{*}{67} & 82 & 84 & 89 & $\begin{array}{l}90- \\
94 \\
\end{array}$ & $\begin{array}{l}95- \\
99 \\
\end{array}$ & 110 & 115 & 127 & $127 \mathrm{R}$ & 130 & 131 \\
\hline & 1 & 1 & 3 & 1 & 1 & 1 & 1 & 6 & 4 & & \\
\hline & 5 & 2 & & & & & & & & & 2 \\
\hline & 2 & 2 & & 1 & & 1 & & & & & \\
\hline & & & & & & & & 1 & 2 & 1 & \\
\hline & & & & & 2 & & 3 & & 1 & 2 & 2 \\
\hline & 2 & 2 & & 2 & & & & & 2 & & \\
\hline 1 & & & 1 & 1 & & & 1 & 1 & & & \\
\hline 1 & 1 & & & & & & 1 & & & & \\
\hline & & & & & & 1 & 1 & & & & \\
\hline \multirow[t]{5}{*}{1} & 2 & 1 & & & & & & & & & \\
\hline & 2 & & & & 1 & & & & & & \\
\hline & 1 & 2 & & & & & & 3 & 2 & & \\
\hline & & & 1 & 1 & & & & 2 & & & \\
\hline & & & 1 & 1 & & & & 1 & & & \\
\hline \multirow[t]{3}{*}{1} & 3 & 2 & & 1 & 2 & 1 & 1 & 2 & 4 & 1 & 1 \\
\hline & & & & & & & & & & & 2 \\
\hline & 1 & & & 1 & 2 & 1 & & 1 & & & \\
\hline 2 & & 1 & & & 1 & & & 1 & & & \\
\hline \multirow[t]{3}{*}{7} & 5 & & & 1 & 2 & & & 3 & & & \\
\hline & & & & 2 & 3 & 1 & & 1 & & & \\
\hline & 1 & & 1 & 2 & & & 3 & 2 & 3 & & \\
\hline 1 & 1 & 1 & & & 3 & 6 & & & & & \\
\hline 1 & & 1 & 1 & 1 & & & & 3 & & 1 & \\
\hline & 2 & & & 1 & & & & & & & 1 \\
\hline \multirow[t]{3}{*}{3} & & & 1 & & & & 2 & & & & \\
\hline & & 1 & & 1 & & & & 2 & & & 1 \\
\hline & 1 & & 1 & 1 & 1 & & & 2 & 2 & & \\
\hline & 1 & & & & & & 1 & 1 & 2 & & \\
\hline 2 & 1 & & & 1 & & & 1 & & & 1 & 1 \\
\hline \multirow[t]{2}{*}{1} & & & & 1 & & & & & 1 & & \\
\hline & & & & & 2 & & 1 & 1 & & & \\
\hline \multirow{3}{*}{1} & 8 & & & & & & & & & 11 & \\
\hline & & & 3 & & & & & & & & \\
\hline & & & 1 & & 1 & 1 & & & & & - \\
\hline 22 & 40 & 16 & 14 & 19 & 21 & 13 & 16 & 33 & 23 & 17 & $\overline{10}$ \\
\hline
\end{tabular}

lumped as one, since they were very similar to one another (that is, 50-51, 90-94, 95-99). Design elements having the suffix " $R$ " are redwares. The distributions of design elements having fewer than 10 occurrences at the site may be found in the Archives, Department of Anthropology, Field Museum of Natural History. They were too numerous to warrant publication in this volume. 
Distribution of Ceramic Design Elements From Floors (cont'd)

\begin{tabular}{|c|c|c|c|c|c|c|c|c|c|c|}
\hline \multirow[b]{2}{*}{ Room Numbers } & \multicolumn{10}{|c|}{ Design Element Numbers } \\
\hline & 133 & $133 \mathrm{R}$ & 134 & $134 \mathrm{R}$ & 135 & 146 & 147R & 148 & 153 & 155 \\
\hline 1 & 2 & 1 & 1 & & 1 & & & & & \\
\hline 2 & 1 & & & & & & 1 & & & \\
\hline $4-5$ & 2 & 1 & & & & 2 & 1 & & & 1 \\
\hline $\begin{array}{l}6 \\
7\end{array}$ & 1 & & & & & & & 0 & 0 & \\
\hline 8 & 1 & & & & & & & & & \\
\hline 9 & & 1 & & & & & 1 & & 2 & \\
\hline 11 & 1 & & & & & & & & 6 & 2 \\
\hline 20 & & & & & & & & & & \\
\hline 21 & 2 & 1 & 2 & & 1 & & & & & \\
\hline 24 & & & & 1 & 1 & & 1 & & 1 & \\
\hline $\begin{array}{l}25 \\
27\end{array}$ & & & 1 & 1 & & & 1 & & & \\
\hline $\begin{array}{l}27 \\
30\end{array}$ & & & & 1 & & 5 & 1 & & & 1 \\
\hline $\begin{array}{l}30 \\
33\end{array}$ & 1 & 1 & 2 & 3 & 3 & 11 & 1 & 2 & 1 & 9 \\
\hline$\overline{34}$ & & & 1 & & & & & & 3 & \\
\hline 36 & 1 & & & & & & & & 1 & \\
\hline 37 & & & & & & & & & & \\
\hline 38 & & 1 & & & & & & & & \\
\hline 40 & & & & & 1 & & & & 3 & \\
\hline$\overline{51}$ & 1 & & & & & & & & & \\
\hline 53 & & & & & & & & & 1 & \\
\hline 62 & 2 & & & & & & & & & \\
\hline 64 & 2 & & & 1 & & 1 & 1 & & & 1 \\
\hline 65 & & & & & & & & & & \\
\hline$\overline{68}$ & 2 & & & 1 & & 3 & & & & \\
\hline 69 & 1 & 1 & & 1 & & & & & & \\
\hline 73 & 1 & & & 1 & 1 & 1 & & & & \\
\hline 74 & & & & & 1 & & & & & \\
\hline 78 & 2 & & & & & & & & & \\
\hline$\overline{79}$ & & 1 & & & & & & & & \\
\hline 80 & & & 2 & & 1 & & & 6 & & \\
\hline 82 & & 1 & & & & & & & & \\
\hline & & & & 2 & 1 & & & & 3 & \\
\hline Outlier 2 & & & & & & & & & 1 & \\
\hline Burial (room 27) & 6 & & & & & & 4 & & & \\
\hline 41-kiva & & & & & 2 & 1 & & & & \\
\hline Plaza-kiva & & 1 & & & 1 & & & & & \\
\hline Totals & 29 & 10 & 10 & 11 & 14 & 24 & 12 & 10 & 31 & 15 \\
\hline
\end{tabular}

NOTE: These counts represent numbers of ceramic design elements on floors. This is the computer input matrix used in the design-element factor analysis (floors) presented in this volume. It includes only those design-elements having a total frequency of at least 10 at the site, and only those rooms having a frequency of at least 5 sherds. Several design-elements were 


\begin{tabular}{|c|c|c|c|c|c|c|c|c|c|c|c|c|}
\hline \multicolumn{13}{|c|}{ Design Element Numbers } \\
\hline \multirow[t]{2}{*}{156} & 158 & $158 \mathrm{R}$ & 159 & 160 & $160 \mathrm{R}$ & 164 & 169 & 174 & 175 & 176 & 177 & Totals \\
\hline & 1 & & 1 & 2 & 2 & 3 & & 2 & $\begin{array}{l}4 \\
1\end{array}$ & 3 & 3 & $\begin{array}{l}56 \\
18\end{array}$ \\
\hline \multirow[t]{2}{*}{1} & & 1 & 2 & 1 & 1 & 2 & & & 1 & 1 & & $\begin{array}{r}25 \\
8\end{array}$ \\
\hline & & & & & & & 1 & 1 & 1 & & & 32 \\
\hline \multirow[t]{3}{*}{6} & 1 & & 1 & & & & & & & & & 26 \\
\hline & 1 & 1 & & 2 & 3 & & 1 & 1 & & 1 & 1 & 22 \\
\hline & & & & 3 & & & 1 & & & & & 21 \\
\hline 1 & & & 1 & & 1 & & & 3 & & & & 10 \\
\hline 4 & & & & & & & & 1 & & & & 19 \\
\hline \multirow[t]{4}{*}{1} & & & & & 2 & & & & & & & 11 \\
\hline & & & & & 1 & & & & & & & 13 \\
\hline & 1 & & & & & & & 2 & & 1 & & 15 \\
\hline & 1 & 4 & 1 & & 2 & 1 & 1 & 2 & 4 & & & $\begin{array}{l}14 \\
80\end{array}$ \\
\hline \multirow[t]{6}{*}{1} & & & & & 2 & & & & & & & $\begin{array}{l}6 \\
9\end{array}$ \\
\hline & & & & & & & & & & & & $\begin{array}{r}10 \\
8\end{array}$ \\
\hline & & & 1 & & & 1 & 7 & 2 & 3 & 2 & 2 & 53 \\
\hline & 2 & & & & & & 4 & & 1 & & & 10 \\
\hline & & & 1 & & & 1 & & & & & & 11 \\
\hline & & & & & 2 & & & & & & 1 & 24 \\
\hline \multirow[t]{6}{*}{1} & 1 & 1 & 3 & 2 & 1 & & 1 & & 3 & 1 & & 37 \\
\hline & 1 & & 2 & 2 & & & 1 & 1 & & & 1 & 21 \\
\hline & & & & & & & & & & & & 12 \\
\hline & 2 & 1 & & & & & & & 1 & & & 17 \\
\hline & & & & & & & & & & 1 & & 12 \\
\hline & & & & & 4 & & & & & & 1 & 7 \\
\hline 1 & & 1 & & & & 1 & & & & & 2 & 17 \\
\hline \multirow[t]{6}{*}{1} & & & & & & & & & & & 1 & $\overline{10}$ \\
\hline & & & & & 2 & & 1 & & & & 1 & 26 \\
\hline & & 2 & & 1 & & 1 & 2 & & & & & 14 \\
\hline & & 1 & & & 1 & & & & & & & 14 \\
\hline & 5 & & & & & & 6 & & 4 & & & 77 \\
\hline & & & & & $\begin{array}{l}1 \\
2\end{array}$ & & & & 1 & & & $\begin{array}{r}13 \\
8\end{array}$ \\
\hline 17 & 17 & 12 & 13 & 13 & 27 & 10 & 26 & 15 & 24 & 10 & 13 & 791 \\
\hline
\end{tabular}

lumped as one, since they were very similar to one another (that is, 50-51, 90-94, 95-99). Design elements having the suffix " $R$ " are redwares. The distributions of design elements having fewer than 10 occurrences at the site may be found in the Archives, Department of Anthropology, Field Museum of Natural History. They were too numerous to warrant publication in this volume. 


\section{APPENDIX 8 \\ DISTRIBUTION OF CERAMIC DESIGN ELEMENTS FROM FILLS}

\begin{tabular}{|c|c|c|c|c|c|c|c|c|c|c|c|c|}
\hline \multirow[b]{2}{*}{ Room Numbers } & \multicolumn{12}{|c|}{ Design Element Numbers } \\
\hline & 6 & 7 & 9 & 10 & 12 & 13 & 15 & 17 & 18 & 19 & 20 & 22 \\
\hline $\begin{array}{l}1 \\
2 \\
4-5 \\
6 \text { (kiva) } \\
7 \\
\end{array}$ & $\begin{array}{r}11 \\
1 \\
1 \\
1 \\
\end{array}$ & $\begin{array}{l}2 \\
4\end{array}$ & $\begin{array}{l}2 \\
3\end{array}$ & & 1 & $\begin{array}{l}1 \\
1\end{array}$ & 1 & 2 & 2 & 1 & $\begin{array}{r}3 \\
10 \\
1 \\
\end{array}$ & $\begin{array}{l}1 \\
1\end{array}$ \\
\hline $\begin{array}{l}9 \\
11 \\
19 \\
20 \\
21 \\
\end{array}$ & 1 & $\begin{array}{l}3 \\
1\end{array}$ & $\begin{array}{l}1 \\
1\end{array}$ & $\begin{array}{l}3 \\
4 \\
9 \\
\end{array}$ & $\begin{array}{l}1 \\
2\end{array}$ & & & 1 & & & 1 & 1 \\
\hline $\begin{array}{l}22 \text { (kiva) } \\
24 \\
27 \\
28 \\
29\end{array}$ & 1 & & & & 8 & 2 & 3 & 1 & & $\begin{array}{l}2 \\
1\end{array}$ & 4 & 1 \\
\hline $\begin{array}{l}30 \\
31-33 \\
34 \\
36 \\
39 \\
\end{array}$ & 1 & & 1 & & 1 & 5 & $\begin{array}{l}1 \\
1\end{array}$ & 1 & 2 & $\begin{array}{l}1 \\
1 \\
1\end{array}$ & $\begin{array}{l}1 \\
1 \\
1 \\
4\end{array}$ & 2 \\
\hline $\begin{array}{l}39 \text { (kiva) } \\
40 \\
41 \\
41 \text { (kiva) } \\
44 \text { (a,b) }\end{array}$ & $\begin{array}{l}2 \\
1 \\
5 \\
1 \\
\end{array}$ & & 1 & 2 & 1 & $\begin{array}{l}1 \\
1\end{array}$ & & & & & 2 & 1 \\
\hline $\begin{array}{l}51 \\
53 \\
54 \\
60 \\
61 \\
\end{array}$ & & $\begin{array}{l}1 \\
1\end{array}$ & & & 1 & & & & & & & \\
\hline $\begin{array}{l}62 \\
64 \\
65 \\
68\end{array}$ & $\begin{array}{l}2 \\
4\end{array}$ & $\begin{array}{l}1 \\
3 \\
2\end{array}$ & $\begin{array}{l}2 \\
2\end{array}$ & 1 & 3 & & $\begin{array}{l}1 \\
3\end{array}$ & & & 1 & & 3 \\
\hline 69 & 2 & 9 & 15 & & & & & 1 & & & & 1 \\
\hline $\begin{array}{l}73 \\
80 \\
92 \\
\text { Outlier no. } 1 \\
\text { Burial (room 27) }\end{array}$ & & 3 & & & & & & $\begin{array}{l}1 \\
1\end{array}$ & & & 1 & \\
\hline $\begin{array}{l}\text { Plaza-kiva } \\
\text { Unfinished kiva (S.W. plaza) }\end{array}$ & 8 & 1 & 2 & & & 1 & 2 & 2 & 1 & 3 & 1 & $\begin{array}{l}3 \\
1 \\
\end{array}$ \\
\hline Totals & 49 & 31 & 31 & 19 & 18 & 12 & 19 & 11 & 11 & 12 & 32 & 16 \\
\hline
\end{tabular}

NOTE: These counts represent numbers of ceramic design-elements in fill levels. This is the computer input matrix used in the design-element factor analysis (fills) presented in this volume. It includes only those design-elements having a total frequency of at least 10 at the site, and only those rooms having a frequency of at least 10 sherds. Several design-elements 
$($ cont'd $\longrightarrow)$

\section{Design Element Numbers}



\begin{tabular}{rrrrrrrrrr} 
& & & & 1 & 1 & & & 3 & \\
2 & 9 & 1 & 2 & & & & & 1 & 2 \\
\hline & & 4 & 1 & 1 & 1 & 4 & 4
\end{tabular}

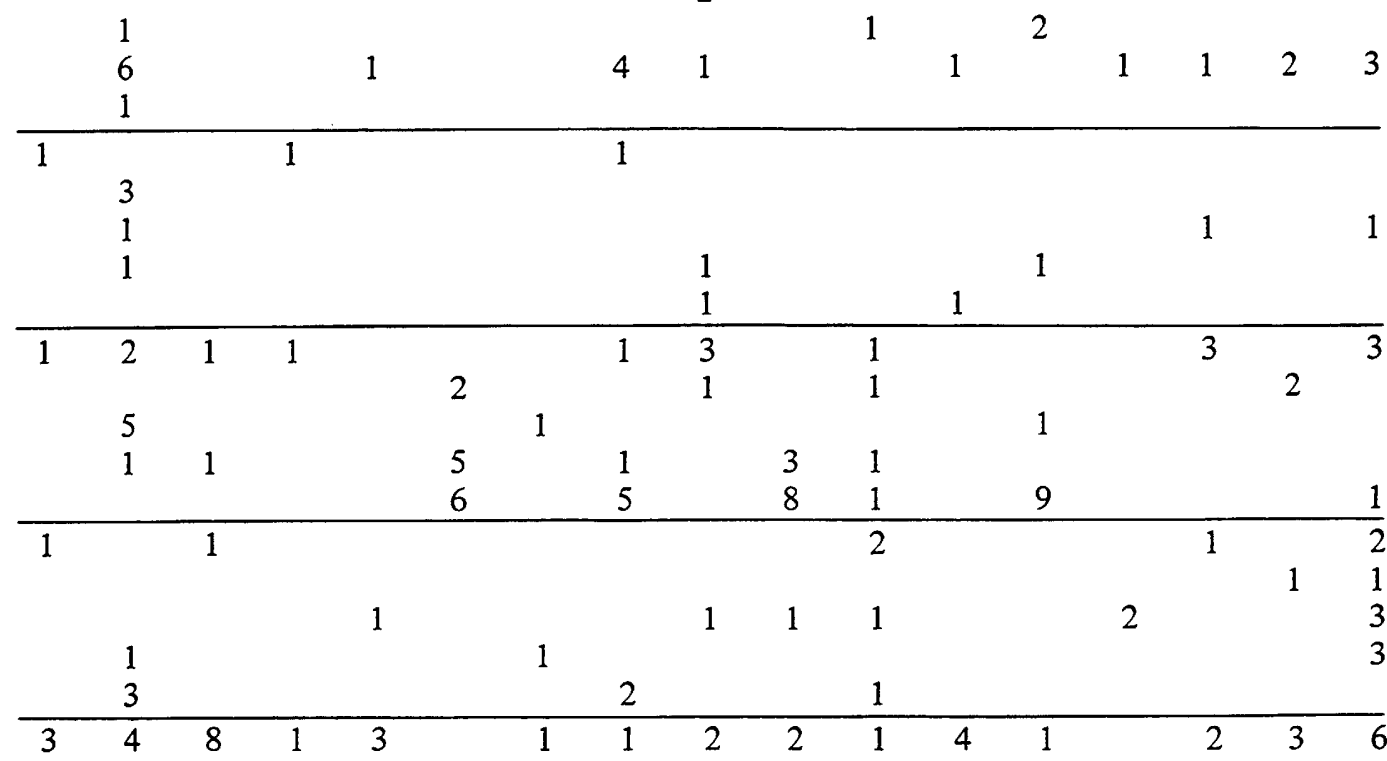

\begin{tabular}{rrrrrrrrrrrrrrrrrr}
13 & 77 & 21 & 22 & 14 & 47 & 10 & 18 & 29 & 20 & 16 & 10 & 22 & 11 & 16 & 20 & 63 \\
\hline
\end{tabular}

were lumped as one, since they were very similar to one another (i.e., 72-75, 77-81). Design elements having the suffix " $R$ " are redwares. The distributions of design-elements having fewer than 10 occurrences at the site may be found in the Archives, Department of Anthropology, Field Museum of Natural History. They were too numerous to warrant inclusion in this volume. 


\section{Distribution of Ceramic Design Elements From Fills (cont'd)}

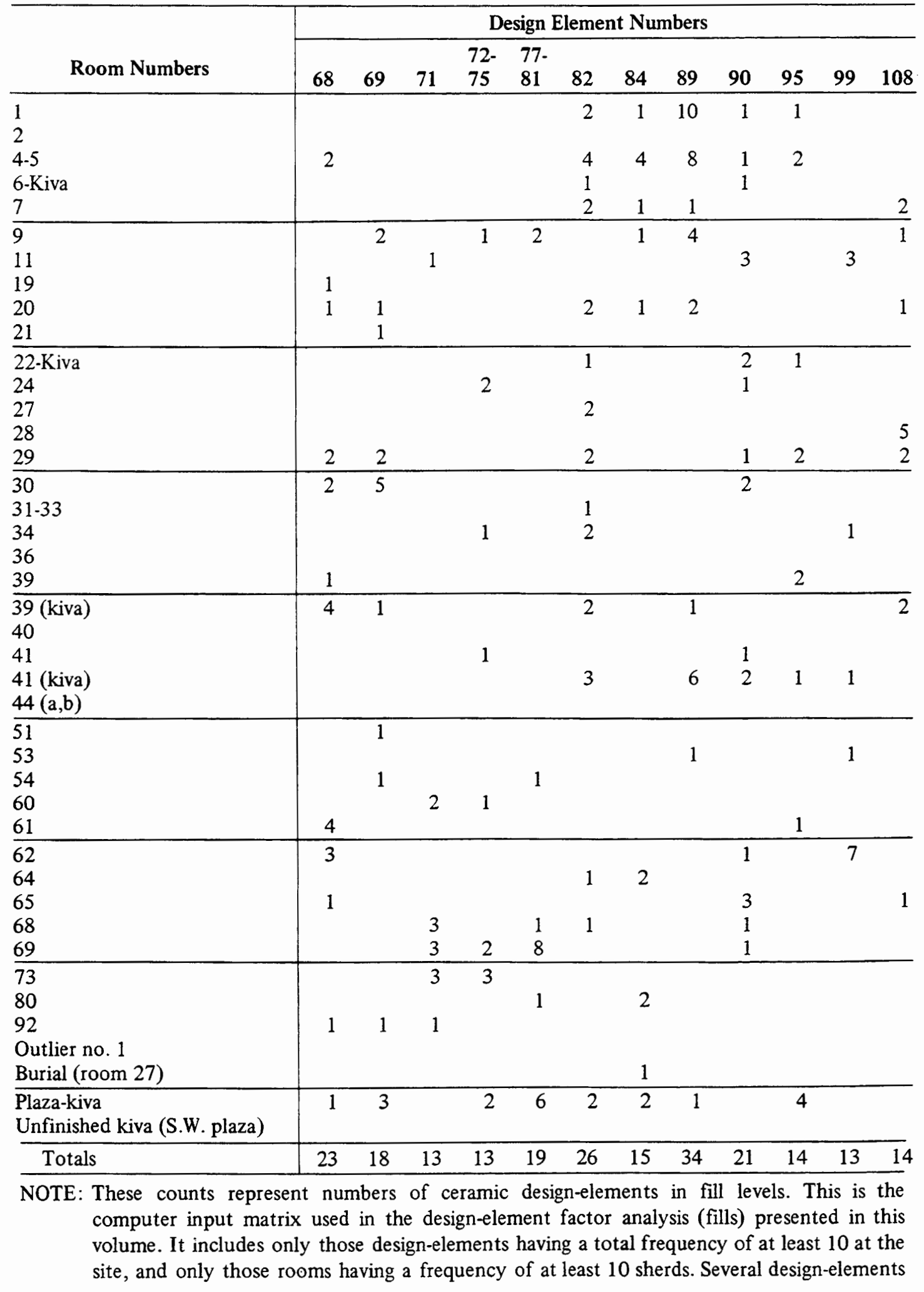


(cont'd $\longrightarrow$ )

\begin{tabular}{|c|c|c|c|c|c|c|c|c|c|c|c|c|c|c|c|c|}
\hline & & & & & & & $\operatorname{sign} \mathrm{E}$ & lement & Num & bers & & & & & & \\
\hline 110 & 115 & 127 & $127 \mathrm{R}$ & $128 \mathrm{R}$ & 130 & 131 & 133 & 133R & 134 & 135 & 136 & 137 & 139 & 140 & 141 & 146 \\
\hline 1 & 3 & 14 & 6 & 2 & 3 & & 2 & 1 & 2 & & & 1 & 1 & & & \\
\hline & 2 & 3 & $\begin{array}{l}8 \\
4\end{array}$ & & & & 5 & 2 & 6 & 1 & 1 & 2 & $\begin{array}{l}2 \\
1\end{array}$ & & & 4 \\
\hline & 1 & & 6 & & & & 1 & & 2 & & & & & & & \\
\hline 1 & 5 & 4 & & & 1 & & & & & & & & & & & \\
\hline & & 1 & & & & & & 1 & & & & & 2 & & & 1 \\
\hline & 4 & 1 & 1 & & & & & 1 & 1 & 1 & & & & & & \\
\hline 2 & 1 & 1 & 1 & & & & & & & & & & & & & \\
\hline & & & & & & & 5 & & & 3 & & & & & 11 & \\
\hline & & & 3 & & & & 2 & & 1 & & & & & & & \\
\hline & & & 3 & & & & 1 & 1 & & 1 & & 2 & & & & \\
\hline 1 & 1 & 3 & 2 & & & 1 & 1 & & 4 & & & & & & & \\
\hline & 4 & 2 & 2 & & & & & & & & & & & & & \\
\hline 1 & & & & & & & & & 3 & & 1 & 1 & & & & \\
\hline & & & & & & & 1 & & 3 & & & 3 & & & & \\
\hline & & & & & 1 & & 3 & & & & & & & & & \\
\hline & & 3 & 3 & 5 & & 2 & 1 & 4 & 5 & & & & & & & 1 \\
\hline & 2 & 1 & & & & & & & & & & & & & & \\
\hline 2 & & 6 & 3 & 3 & & 2 & 1 & 2 & & & & & & & & \\
\hline & & 1 & & & & & & & & & & & 1 & & & \\
\hline & & 1 & 2 & & & & & 1 & & & & & & 8 & & 1 \\
\hline & & 3 & & & & & 1 & & & & & & & 1 & & \\
\hline 1 & & & 2 & & 1 & & & & 1 & & & 1 & & 2 & & \\
\hline & & & & & & & 1 & & & & & & & & & \\
\hline & & & 3 & & 1 & & 1 & & 1 & & & & & & & \\
\hline 1 & 1 & 5 & 4 & & 1 & 2 & 5 & 1 & 2 & & & & 1 & & & 1 \\
\hline 1 & & & 1 & & 2 & & 3 & 3 & 1 & & 2 & & 5 & & & \\
\hline & 1 & & 2 & & & & & & 1 & & & & 2 & & & \\
\hline & 3 & 13 & 1 & & & & 3 & & & 3 & 14 & & & & & \\
\hline 1 & & & 5 & & & 7 & 1 & & & & & & & & & \\
\hline & 5 & 1 & & & & & 1 & & & & & & & & 8 & \\
\hline & & & & & & & 1 & & & & & & & & & \\
\hline & 2 & & & & & 1 & & & 1 & & & & & & & \\
\hline & & & 4 & 3 & & & 1 & & & & & & & & & \\
\hline 6 & 3 & 1 & & & & 1 & 2 & 3 & 3 & 3 & & 2 & 2 & 1 & & 3 \\
\hline & & & 1 & & & & & 1 & & & & & & & & \\
\hline 18 & 38 & 64 & 67 & 13 & 10 & 16 & 43 & 21 & 37 & 12 & 18 & 12 & 17 & 12 & 19 & 11 \\
\hline
\end{tabular}

were lumped as one, since they were very similar to one another (i.e., 72-75, 77-81). Design elements having the suffix " $R$ " are redwares. The distributions of design-elements having fewer than 10 occurrences at the site may be found in the Archives, Department of Anthropology, Field Museum of Natural History. They were too numerous to warrant inclusion in this volume. 
Distribution of Ceramic Design Elements From Fills (cont'd)

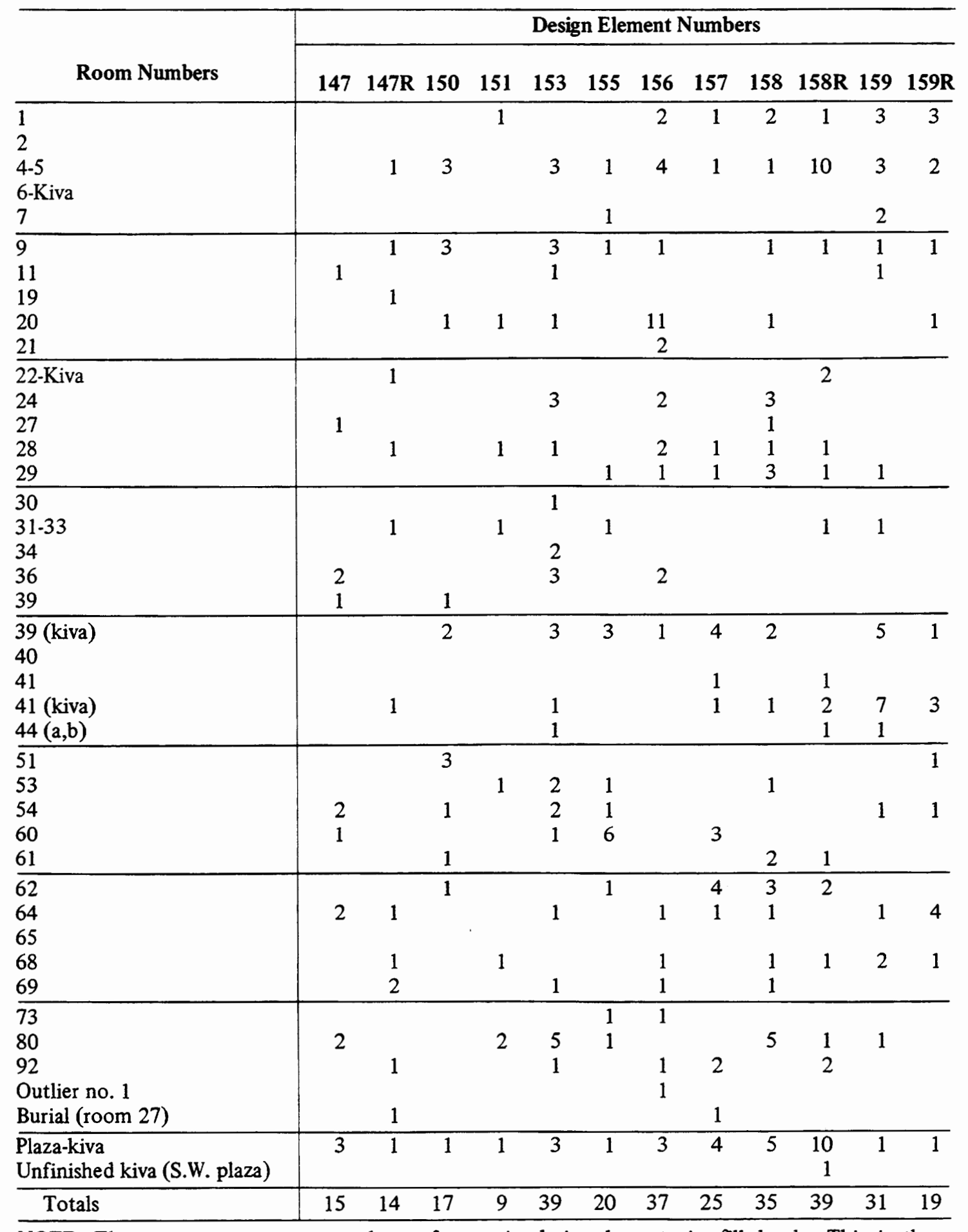

NOTE: These counts represent numbers of ceramic design-elements in fill levels. This is the computer input matrix used in the design-element factor analysis (fills) presented in this volume. It includes only those design-elements having a total frequency of at least 10 at the site, and only those rooms having a frequency of at least 10 sherds. Several design-elements 


\begin{tabular}{|c|c|c|c|c|c|c|c|c|c|c|c|c|c|c|c|}
\hline \multicolumn{16}{|c|}{ Design Element Numbers } \\
\hline 160 & 160R & 161 & 162 & 164 & 165 & 169 & 172 & 173 & 174 & 175 & 176 & 177 & 178 & 179 & Totals \\
\hline 2 & $\begin{array}{l}1 \\
1\end{array}$ & 1 & $\begin{array}{l}1 \\
1\end{array}$ & 3 & & 1 & 4 & 8 & $\begin{array}{l}9 \\
2\end{array}$ & 22 & $\begin{array}{r}12 \\
1\end{array}$ & $\begin{array}{l}5 \\
2\end{array}$ & 11 & 2 & $\begin{array}{r}196 \\
14\end{array}$ \\
\hline 7 & 1 & 6 & 1 & $\begin{array}{l}2 \\
1\end{array}$ & & 1 & $\begin{array}{l}3 \\
1\end{array}$ & 9 & 7 & 12 & 7 & 2 & 2 & 2 & $\begin{array}{r}237 \\
18\end{array}$ \\
\hline 3 & & 3 & 1 & & & & & & & 1 & & 2 & & & 49 \\
\hline $\begin{array}{l}1 \\
1 \\
1\end{array}$ & $\begin{array}{l}2 \\
1\end{array}$ & 1 & 1 & 1 & $\begin{array}{l}1 \\
2 \\
2\end{array}$ & $\begin{array}{l}1 \\
3\end{array}$ & & 2 & & 1 & 3 & & & 1 & $\begin{array}{l}58 \\
24 \\
10 \\
62 \\
18\end{array}$ \\
\hline 1 & 1 & 1 & 1 & $\begin{array}{l}6 \\
1\end{array}$ & & 1 & 1 & & 4 & 1 & 1 & & 4 & 1 & $\begin{array}{l}21 \\
34 \\
23 \\
41 \\
98\end{array}$ \\
\hline 1 & 1 & $\begin{array}{l}1 \\
3\end{array}$ & 1 & & & 1 & 1 & 1 & $\frac{4}{2}$ & $\begin{array}{l}1 \\
3 \\
3\end{array}$ & $\begin{array}{l}1 \\
1\end{array}$ & 2 & 4 & 1 & $\begin{array}{l}\frac{70}{29} \\
22 \\
19 \\
15 \\
51\end{array}$ \\
\hline 1 & 3 & 2 & 2 & & & 4 & 1 & $\begin{array}{l}1 \\
1\end{array}$ & $\begin{array}{l}1 \\
3\end{array}$ & $\begin{array}{l}2 \\
3\end{array}$ & $\begin{array}{l}1 \\
4\end{array}$ & $\begin{array}{l}1 \\
3 \\
3\end{array}$ & 2 & & $\begin{array}{r}80 \\
11 \\
17 \\
104\end{array}$ \\
\hline 1 & & & & & & & & & 1 & & & & & 1 & 10 \\
\hline $\begin{array}{l}1 \\
2 \\
\end{array}$ & & $\begin{array}{l}1 \\
2\end{array}$ & & $\begin{array}{l}9 \\
2\end{array}$ & & & 1 & & 1 & & & & & & $\begin{array}{l}24 \\
25 \\
27 \\
20 \\
20 \\
\end{array}$ \\
\hline 4 & 3 & & & 1 & & 2 & 1 & 2 & 2 & 1 & & 1 & & & 89 \\
\hline 1 & 3 & & & 2 & & 2 & 1 & 1 & 3 & 4 & & & 1 & & $\begin{array}{l}69 \\
14\end{array}$ \\
\hline $\begin{array}{l}1 \\
4\end{array}$ & $\begin{array}{l}1 \\
5\end{array}$ & $\begin{array}{l}1 \\
1\end{array}$ & & & & 1 & 3 & 1 & 1 & 2 & & 1 & 1 & & $\begin{array}{r}41 \\
132\end{array}$ \\
\hline 1 & & 1 & & & 9 & & & 1 & $\begin{array}{l}1 \\
3\end{array}$ & 2 & 1 & & 1 & & $\begin{array}{l}35 \\
51 \\
23 \\
11 \\
28\end{array}$ \\
\hline 5 & 7 & 3 & 1 & 2 & & 1 & & & 2 & 1 & & 2 & 2 & 4 & $\begin{array}{r}178 \\
10\end{array}$ \\
\hline 40 & 32 & 29 & 10 & 30 & 12 & 21 & 17 & 28 & 43 & 63 & 32 & 24 & 24 & 12 & 2058 \\
\hline
\end{tabular}

were lumped as one, since they were very similar to one another (i.e., 72-75, 77-81). Design elements having the suffix " $R$ " are redwares. The distributions of design-elements having fewer than 10 occurrences at the site may be found in the Archives, Department of Anthropology, Field Museum of Natural History. They were too numerous to warrant inclusion in this volume. 



\section{REFERENCES}

Aberle, David F.

1961 Matrilineal Descent in Cross-cultural Perspective. In Matrilineal Kinship, edited by David M. Schneider and Kathleen Gough, pp. 655-727. University of California Press, Berkeley.

Aiken, Howard H. (Director)

1955 Tables of the Cumulative Binomial Probability Distribution. The Annals of the Computation Laboratory of Harvard University, Vol. 35. Harvard University Press, Cambridge.

AKERS, J. P.

1962 Geology and Ground Water in the Central Part of Apache County, Arizona. U.S. Geological Survey, Openfile Report.

Arkin, Herbert, and Raymond R. Colton 1961 Tables for Statisticians. Barnes and Noble, Inc., New York.

BeAglehole, ERNEST

1936 Hopi Hunting and Hunting Ritual. Yale University Publications in Anthropology, No. 4. New Haven.

1937 Notes on Hopi Economic Life. Yale University Publications in Anthropology, No. 15. New Haven.

Beaglehole, Ernest, and Pearl Beaglehole 1935 Hopi of the Second Mesa. Memoirs of the American Anthropological Association, No. 44. Menasha.

Beaglehole, Pearl

1935 Census Data From Two Hopi Villages. American Anthropologist, Vol. 37, No. 1 (Part 1), pp. 41-54. Menasha.

BINFORD, LEWIS R.

1962 Archaeology as Anthropology. American Antiquity, Vol. 28, No. 2, pp. 217-25. Salt Lake City.

1964 A Consideration of Archaeological Research Design. American Antiquity, Vol. 29, No. 4, pp. 42541. Salt Lake City.
1965 Archaeological Systematics and the Study of Culture Process. American Antiquity, Vol. 31, No. 2, pp. 203-10. Salt Lake City.

1967 Smudge Pits and Hide Smoking: The Use of Analogy in Archaeological Reasoning. American Antiquity, Vol. 32, No. 1, pp. 1-12. Salt Lake City.

1968 Archeological Perspectives. In New Perspectives in Archeology, edited by S. R. Binford and Lewis R. Binford. pp. 5-32. Aldine Publishing Company, Chicago.

BINFORD, LEWIS R., AND S. R. BINFORD

1966 A Preliminary Analysis of Functional Variability in the Mousterian of Levallois Facies. In "Recent Studies in Paleoanthropology," edited by J. Desmond Clark and F. Clark Howell. American Anthropologist, Vol. 68, No. 2 (Part 2), pp. 238-95. Menasha.

Bluhm, Elaine ANN

1957 Patterns of Settlement in the Southwestern United States, A.D. 500-1250. Doctoral dissertation, unpublished. University of Chicago.

BRAINARD, MARGARET

1935 The Hopi Family: A Study of the Changes Represented in Its Present Structure and Functions. Doctoral dissertation, unpublished. University of Chicago.

BRETERNITZ, DAVID

1963 Archaeological Interpretations of Tree Ring Specimens for Dating Southwestem Ceramic Styles. Doctoral dissertation, unpublished. University of Arizona, Tucson.

BREW, J. 0 .

1937 The First Two Seasons at Awatovi. American Antiquity, Vol. 3, No. 2, pp. 122-37. Menasha. 
1940

Preliminary Report of the Awatovi Expedition of 1939. Plateau, Vol. 13, No. 3, pp. 37-48. Flagstaff.

BRYAN, K.

1925 Date of Channel Trenching (Arroyo Cutting) in the Arid Southwest. Science, Vol. 62, No. 1607, pp. 338-44. Washington.

1945 The Geology of Chaco Canyon New Mexico in Relation to the Life and Remains of the Prehistoric Peoples of Pueblo Bonito. Smithsonian Miscellaneous Collections, Vol. 122, No. 7, Pub. 4141. Washington.

Bunzel, Ruth L.

1929 The Pueblo Potter, A Study of Creative Imagination in Primitive Art. Columbia University Press, New York.

1932a Zuni Katcinas. Forty-seventh Annual Report of the Bureau of American Ethnology, pp. 837-1086. Washington.

1932b Introduction to Zuni Ceremonialism. Forty-seventh Annual Report of the Bureau of American Ethnology, pp. 467-544. Washington.

BURGH, ROBERT F.

1959 Ceramic Profiles in the Western Mound at Awatovi, Northeastern Arizona. American Antiquity, Vol. 25, No. 2, pp. 184-202. Salt Lake City.

CARter, George F.

1945 Plant Geography and Culture History in the American Southwest. Viking Fund Publications in Anthropology, No. 5. Wenner-Gren Foundation for Anthropological Research, Inc.

CHAMPe, John L.

1961 Four Statements for Archaeology. Report of the Committee on Ethics and Standards. American Antiquity, Vol. 27, No. 2, pp. 137-8. Salt Lake City.

\section{Chang, KWang-ChIH}

1958 Study of Neolithic Social Grouping: Examples From the New World. American Anthropologist, Vol. 60, No. 2, pp. 298-334. Menasha.
Clark, J. G. D.

1960 Discussion. In "The Application of Quantitative Methods in Archaeology," edited by Robert F. Heizer and Sherburne F. Cook. Viking Fund Publications in Anthropology, No. 28, pp. 125-8. Wenner-Gren Foundation for Anthropological Research, Inc.

Cochran, William G.

1952 The $\chi^{2}$ Test of Goodness of Fit. The Annals of Mathematical Statistics, Vol. 23, pp. 315-45. Baltimore.

COCKRUM, E. L.

1960 The Recent Mammals of Arizona. University of Arizona Press, Tucson.

COOK, S. F., AND Robert F. Heizer

1965 The Quantitative Approach to the Relation Between Population and Settlement Size. Reports of the University of California Archaeological Survey, No. 64. University of California Archaeological Research Facility, Berkeley.

Cooley, M. E., ANd R. H. Hevly

1964 Geological and Depositional Environment of Laguna Salada, Arizona. In "Chapters in the Prehistory of Eastern Arizona, II." Fieldiana: Anthropology, Vol. 55, pp. 188-200. Chicago Natural History Museum, Chicago.

Crane, L.

1926 Indians of the Enchanted Desert. Little, Brown, and Company, Boston.

Cronin, Constance

1962 An Analysis of Pottery Design Elements, Indicating Possible Relationships Between Three Decorated Types. In "Chapters in the Prehistory of Eastern Arizona, I." Fieldiana: Anthropology, Vol. 53, pp. 105-14. Chicago Natural History Museum, Chicago.

\section{Cummings, Byron}

1940 Kinishba, A Prehistoric Pueblo of the Great Pueblo Period. University of Arizona Press, Tucson. 
CUShing, F. H.

1920 Zuni Breadstuff. Indian Notes and Monographs, Vol. 8. Museum of the American Indian, New York.

Cushing, F. H., J. W. Fewkes, AND E. C. Parsons 1922 Contributions to Hopi History. American Anthropologist, Vol. 24, No. 3, pp. 253-98. Menasha.

DANSEREau, P.

1957 Biogeography-An Ecological Perspective. Ronald Press, New York

DeEtz, JAmes D. F.

1960 An Archaeological Approach to Kinship Change in Eighteenth Century Arikara Culture. Doctoral dissertation, unpublished. Harvard University.

1965 The Dynamics of Stylistic Change in Arikara Ceramics. Illinois Studies in Anthropology, No. 4. University of Illinois Press, Urbana.

Deming, William Edwards

1950 Some Theory of Sampling. John Wiley and Sons, Inc., New York.

Donaldson, ThOMas

1893 Moqui Pueblo Indians of Arizona and New Mexico. Eleventh Census of the United States, Extra Census Bulletin. Washington.

Douglass, A. E.

1929 The Secret of the Southwest Solved by Talkative Tree Rings. National Geographic, Vol. 56, No. 6, pp. 736-70. Washington.

Dozier, EdWARD P.

1964 The Pueblo Indians of the Southwest: A Survey of the Anthropological Literature and a Review of Theory, Method, and Results. Current Anthropology, Vol. 5, No. 2, pp. 79-97. Utrecht.

Duncan, Otis D., Ray P. Cuzzort, and BeVerly DUNCAN

1961 Statistical Geography: Problems in Analyzing Areal Data. Free Press of Glencoe, Illinois.
EGgAN, FREDERICK RUSSELl

1950 Social Organization of the Western Pueblos. University of Chicago Press, Chicago.

1952 The Ethnological Cultures and Their Archaeological Backgrounds. In Archeology of Eastern United States, edited by James B. Griffin. University of Chicago Press, Chicago.

1964 Alliance and Descent in Western Pueblo Society. In Process and Pattern in Culture, edited by Robert A. Manners. Aldine Publishing Company, Chicago.

Ellis, Florence Hawley

1951 Pueblo Social Organization and Southwestern Archaeology. American Antiquity, Vol. 17, No. 2, pp. 148-51. Salt Lake City.

1964a Archaeological History of Nambe Pueblo, Fourteenth Century to the Present. American Antiquity, Vol. 30, No. 1, pp. 34-42. Salt Lake City.

1964b Comments on Jett's Pueblo Indian Migrations. American Antiquity, Vol. 30, No. 2, pp. 213-15. Salt Lake City.

FEWKES, WALTER J.

1893 A-wa-to-bi: An Archaeological Verification of a Tusayan Legend. American Anthropologist, Vol. 6, pp. 363-75. Menasha.

1900 Tusayan Migration Traditions. Nineteenth Annual Report of the Bureau of American Ethnology, Part II, pp. 577-633. Washington.

1907 Hopi. In "Handbook of the American Indians North of Mexico, Part I," pp. 560-68. Bureau of American Ethnology Bulletin, No. 30. Washington.

FINCH, V. C., AND O. E. BAKER

1917 Geography of the World's Agriculture. U.S. Department of Agriculture, Office of Farm Management. Washington.

FISHER, R. A. (Sc.D., F.R.S.)

1938 Statistical Methods for Research Workers. Oliver and Boyd, Edinburgh and London. 
FORDE, C. DARYELL

1931 Hopi Agriculture and Land Ownership. Journal of the Royal Anthropological Institute of Great Britain and Ireland, Vol. 61, pp. 357-405. London.

Freeman, Leslie G., JR, and James A. Brown 1964 Statistical Analysis of Carter Ranch Pottery. In "Chapters in the Prehistory of Eastern Arizona, II." Fieldiana: Anthropology, Vol. 55, pp. 126-54. Chicago Natural History Museum, Chicago.

FRUCHTER, BENJAMIN

1954 Introduction to Factor Analysis. D. Van Nostrand Company, Inc., Princeton, New Jersey.

GLADWIN, H. S.

1947 Tree Rings and Droughts. Medallion Papers, No. 37, pp. 1-36. Gila Pueblo, Globe, Arizona.

GOLDMAN, IRVING

1937 The Zuni Indians of New Mexico. In Cooperation and Competition Among Primitive Peoples, edited by Margaret Mead, pp. 313-53. McGraw-Hill Book Company, New York.

Gough, KathleEN

1961 Descent Groups of Settled and Mobile Cultivators. In Matrilineal Kinship, edited by David M. Schneider and Kathleen Gough, pp. 45-56. University of California Press, Berkeley.

Guthe, C. E.

1925 Pueblo Pottery Making. Yale University Press, New Haven.

HACK, JOHN T.

1942 The Changing Physical Environment of the Hopi Indians of Arizona. Papers of the Peabody Museum of American Archaeology and Ethnology, Vol. 35, No. 1. The Museum, Cambridge.

HARGRAVE, LYNDON L.

1932 Oraibi: A Brief History of the Oldest Inhabited Town in the United States. Museum Notes, Vol. 4. Museum of Northern Arizona, Flagstaff.
1935 The Jeddito Valley and the First Pueblo Towns in Arizona to be Visited by Europeans. Museum Notes and Plateau, Vol. 8, No. 4, pp. 19-25. Museum of Northern Arizona, Flagstaff.

HARMAN, HaRry $\mathrm{H}$.

1960 Modern Factor Analysis. University of Chicago Press, Chicago.

HAURY, EMIL W.

1956 Speculations on Prehistoric Settlement Patterns in the Southwest. In "Prehistoric Settlement Patterns in the New World," edited by G. R. Willey. Viking Fund Publications in Anthropology, No. 23, pp. 3-10. Wenner-Gren Foundation for Anthropological Research, Inc.

Haury, Emil W., and L. L. HaRgrave

1931 Recently Dated Pueblo Ruins in Arizona. Smithsonian Miscellaneous Collections, Vol. 82, No. 11. Washington.

HAWLEY, FloRENCE M.

1937 Pueblo Social Organization as a Lead to Pueblo History. American Anthropologist, Vol. 39, No. 3 (Part 1), pp. 504-22. Menasha.

HEIZER, ROBERT F.

1960 Physical Analysis of Habitation Residues. In "The Application of Quantitative Methods in Archaeology," edited by Robert F. Heizer and Sherburne F. Cook. Viking Fund Publications in Anthropology, No. 28, pp. 93-157. Wenner-Gren Foundation for Anthropological Research, Inc.

Hevly, Richard Holmes

1964 Pollen Analysis of Quaternary Archaeological and Lacustrine Sediments From the Colorado Plateau. Doctoral dissertation, unpublished. University of Arizona, Tucson.

HiLl, JAMES N.

1963 A Processual Analysis of Non-seasonal Population Movement in Man and Other Terrestrial Mammals. Masters thesis, unpublished. University of Chicago, Chicago. 
1965 Broken K: A Prehistoric Society in Eastern Arizona. Doctoral dissertation, unpublished. University of Chicago, Chicago.

1966 A Prehistoric Community in Eastern Arizona. Southwestern Journal of Anthropology, Vol. 22, No. 1, pp. 9-30. Albuquerque.

1968 Broken K Pueblo: Patterns of Form and Function. In New Perspectives in Archeology, edited by S. R. Binford and Lewis R. Binford. pp. 103-142. Aldine Publishing Company, Chicago.

1970 Prehistoric Social Organization in the American Southwest: Theory and Method. In Reconstructing Prehistoric Pueblo Societies, edited by William A. Longacre. University of New Mexico Press, Albuquerque. (Printed for The School of American Research, Santa $\mathrm{Fe}$, New Mexico).

Hill, James N., AND RichaRd H. Hevly

1968 Pollen at Broken K Pueblo: Some New Interpretations. American Antiquity, Vol. 33, No. 2, pp. 200-210. Salt Lake City.

HODGE, F. W.

1937 History of Hawikuh, New Mexico. The Southwest Museum, Los Angeles.

HUMPHREY, R. R.

1955 Forage Production on Arizona Ranges, IV. Coconino, Navajo, Apache Counties-A Study in Range Conditions. Arizona Agricultural Experiment Station Bulletin, No. 266, pp. 1-84.

JENNINGS, JESSE D. AND OTHERS

1956 The American Southwest: A Problem in Cultural Isolation. In "Seminars in Archaeology: 1955," edited by Robert Wauchope. American Antiquity, Vol. 22, No. 2 (Part 2), pp. 60-127. Salt Lake City.

JetT, STEPHEN C.

1964 Pueblo Indian Migrations: An Evaluation of the Possible Physical and Cultural Determinants. American Antiquity, Vol. 29, No. 3, pp. 281-300. Salt Lake City.
JOHNSON, FREDERICK

1961 A Quarter Century of Growth in American Archaeology. American Antiquity, Vol. 27, No. 1, pp. 1-6. Salt Lake City.

JUDD, NEIL M.

1954 The Material Culture of Pueblo Bonito. Smithsonian Institution Miscellaneous Collections, Vol. 124. Washington.

KenNard, E. A.

1937 Hopi Reactions to Death. American Anthropologist, Vol. 39, No. 3, pp. 491-6. Menasha.

Kidder, Alfred V.

1927 Southwestern Archaeological Conference. Science, Vol. 66, No. 1716, pp. 489-91. Lancaster.

KROEBER, A. L.

1917 Zuni Kin and Clan. Anthropological Papers of the American Museum of Natural History, Vol. 28 (Part II). The American Museum of Natural History, New York.

1928 Native Culture in the Southwest. University of Califormia Publications in American Archaeology and Ethnology, Vol. 23, No. 9, pp. 375-98. University of California Press, Berkeley.

1953 Cultural and Natural Areas of Native North America. University of California Press, Berkeley.

LEHMAN, F. K.

1964 Typology and the Classification of Sociocultural Systems. In Process and Pattern in Culture, edited by Robert Manners. pp. 376-96. Aldine Publishing Company, Chicago.

LEOPOLD, L. B., E. B. LEOPOLD, AND F. WENDORF 1963 Some Climatic Indicators in the Period A.D. 1200-1400, New Mexico. In "UNESCO and World Meteorological Organization Symposium on Changes of Climate with Special Reference to the Arid Zone." Arid Zone Research Series, No. 20, pp. 265-70. UNESCO, Paris. 
LI AN-CHE

1937 Zuni: Some Observations and Queries. American Anthropologist, Vol. 39, No. 1, pp. 62-76. Menasha.

LISTER, ROBERT H.

1961 Twenty-five Years of Archaeology in the Greater Southwest. American Antiquity, Vol. 27, No. 1, pp. 39-45. Salt Lake City.

LONGACRE, WILLIAM A.

1963 Archaeology as Anthropology: A Case Study. Doctoral dissertation, unpublished. University of Chicago.

1964a A Synthesis of Upper Little Colorado Prehistory, Eastern Arizona. In "Chapters in the Prehistory of Eastern Arizona, II." Fieldiana: Anthropology, Vol. 55, pp. 201-15. The Chicago Natural History Museum, Chicago.

1964b Archaeology as Anthropology: A Case Study. Science, Vol. 144, No. 3625, pp. 1454-55. Washington.

1964c The Ceramic Analysis. In "Chapters in the Prehistory of Eastern Arizona, II." Fieldiana: Anthropology, Vol. 55, pp. 110-25. The Chicago Natural History Museum, Chicago.

1966 Changing Patterns of Social Integration: A Prehistoric Example From the American Southwest. American Anthropologist, Vol. 68, No. 1, pp. 94-102. Menasha.

1970 Archaeology as Anthropology: A Case Study. Anthropological Papers of the University of Arizona, No. 17. University of Arizona Press, Tucson.

MANNERS, ROBERT A. (EDITOR)

1964 Process and Pattern in Culture. Aldine Publishing Company, Chicago.

Martin, Paul S., and John B. Rinaldo 1950 Sites of the Reserve Phase, Pine Lawn Valley, Western New Mexico. Fieldiana: Anthropology, Vol. 38, No. 3. The Chicago Natural History Museum, Chicago.

Martin, Paul S., John B. Rinaldo, W. A. LongACRE, AND OTHERS

1962 Chapters in the Prehistory of Eastern Arizona, I. Fieldiana: Anthropology,
Vol. 53. The Chicago Natural History Museum, Chicago.

Martin, Paul S., John B. Rinaldo, W. A. LongACRE, AND OTHERS

1964 Chapters in the Prehistory of Eastern Arizona, II. Fieldiana: Anthropology, Vol. 55. The Chicago Natural History Museum, Chicago.

Martin, Paul S., James N. Hill, and William A. LONGACRE

1966 Documentation for Chapters in the Prehistory of Eastern Arizona, III. Archives of Archaeology, No. 27. Society for American Archaeology and the University of Wisconsin Press, Madison.

Martin, Paul S., William A. Longacre, and JAMES N. HILL

1967 Chapters in the Prehistory of Eastern Arizona, III. Fieldiana: Anthropology, Vol. 57. Field Museum of Natural History, Chicago.

Martin, Paul Stanley

1963 The Last 10,000 Years: A Fossil Pollen Record of the American Southwest. The University of Arizona Press, Tucson.

Martin, Paul Stanley, and William B. Byers 1965 Pollen and Archaeology at Wetherill Mesa. Memoirs of the Society for American Archaeology, No. 19, pp. 122-35. Salt Lake City.

MARTIN, R. J. (EDITOR)

1933 Climatic Summary of the United States, Section 25, Northern Arizona, From Establishment of Stations to 1930. U.S. Department of Agriculture, Weather Bureau.

MCGREGOR, JOHN C.

1965 Southwestern Archaeology. University of Illinois Press, Urbana.

MEgGaRs, BetTy J., AND OTHERS

1956 Function and Evolutionary Implications of Community Patterning. In "Seminars in Archaeology: 1955," edited by Robert Wauchope. American Antiquity, Vol. 22, No. 2 (Part 2), pp. 130-57. Salt Lake City. 
Miller, Mamie Ruth Tanquist

1941 Pueblo Indian Culture as Seen by the Early Spanish Explorers. University of California Press, Los Angeles.

MindeLEFF, Cosmos

1900 Localization of Tusayan Clans. Nineteenth Annual Report of the Bureau of American Ethnology, pp. 635-53. Washington.

MiNDELEFF, Victor

1891 A Study of Pueblo Architecture, Tusayan and Cibola. Eighth Annual Report of the Bureau of American Ethnology, 1886-1887, pp. 13-228. Washington.

Murdock, George Peter

1949 Social Structure. The Macmillan Company, New York.

Naroll, RaOUL

1962 Floor Area and Settlement Population. American Antiquity, Vol. 27, No. 4, pp. 587-89. Salt Lake City.

NichOL, A. A.

1952 The Natural Vegetation of Arizona. Arizona Agricultural Experiment Station Bulletin, No. 127, pp. 188-230.

O'Kane, Walter Collins

1953 The Hopis: Portrait of a Desert People. University of Oklahoma Press, Norman.

PARSONS, E. C.

1925 A Pueblo Indian Journal, 1920-1921. Memoirs of the American Anthropological Association, No. 32. Menasha.

1929 The Social Organization of the Tewa of New Mexico. Memoirs of the American Anthropological Association, No. 36. Menasha.

1932 Isleta, New Mexico. Forty-seventh Annual Report of the Bureau of American Ethnology, pp. 193466. Washington.

1936 Hopi Journal of Alexander M. Stephen. Columbia University Contributions to Anthropology, Vols. 23 and 24. Columbia University Press, New York.
1939 Pueblo Indian Religion. University of Chicago Publications in Anthropology and Ethnology (2 vols.). Chicago.

RAGIR, SONIA

1967 A Review of Techniques for Archaeological Sampling. In A Guide to Field Methods in Archaeology, edited by Robert F. Heizer and John A. Graham, pp. 181-197. The National Press, Palo Alto.

REED, ERIK K.

1956 Types of Village-plan Layout in the Southwest. In "Prehistoric Settlement Patterns in the New World," edited by G. R. Willey. Viking Fund Publications in Anthropology, No. 23, pp. 11-17. Wenner-Gren Foundation for Anthropological Research.

RINALDO, JOHN B.

1959 Foote Canyon Pueblo, Eastern Arizona. Fieldiana: Anthropology, Vol. 49 , No. 2. The Chicago Natural History Museum, Chicago.

1964a Architectural Details, Carter Ranch Pueblo. In "Chapters in the Prehistory of Eastern Arizona, II." Fieldiana: Anthropology, Vol. 55, pp. 15-58. The Chicago Natural History Museum, Chicago.

1964b Artifacts. In "Chapters in the Prehistory of Eastern Arizona, II." Fieldiana: Anthropology, Vol. 55, pp. 63-109. The Chicago Natural History Museum, Chicago.

1964c Burials and Mortuary Customs. In "Chapters in the Prehistory of Eastern Arizona, II." Fieldiana: Anthropology, Vol. 55, pp. 59-62. The Chicago Natural History Museum, Chicago.

ROBERTS, JOHN M.

1956 Zuni Daily Life. Monograph No. 2, Note Book No. 3, Laboratory of Anthropology, University of Nebras$\mathrm{ka}$, Lincoln.

ROOTENBERG, S.

1964 Archaeological Field Sampling. American Antiquity, Vol. 30, No. 2 (Part 1), pp. 181-88. Salt Lake City. 
SACKETT, JAMES R.

1966 Quantitative Analysis of Upper Paleolithic Stone Tools. In "Recent Studies in Paleoanthropology," edited by J. Desmond Clark and F. Clark Howell. American Anthropologist, Vol. 68, No. 2 (Part 2), pp. 356-394. Menasha.

\section{SCHOENWETTER, JAMES}

1962 The Pollen Analysis of Eighteen Archaeological Sites in Arizona and New Mexico. In "Chapters in the Prehistory of Eastern Arizona, I." Fieldiana: Anthropology, Vol. 53, pp. 168-209. The Chicago Natural History Museum, Chicago.

SCHOENWETter, James, AND Frank W. EdDy

1964 Alluvial and Palynological Reconstruction of Environments, Navajo Reservoir District. Museum of New Mexico Papers in Anthropology, No. 13. Museum of New Mexico Press, Santa $\mathrm{Fe}$.

SCHNEIDER, David M.

1961 The Distinctive Features of Matrilineal Descent Groups. In Matrilineal Kinship, edited by David M. Schneider and Kathleen Gough, pp. 1-29. University of California Press, Berkeley.

SeArs, William $\mathrm{H}$.

1961 The Study of Social and Religious Systems in North American Archaeology. Current Anthropology, Vol. 2, No. 3, pp. 223-46. Utrecht.

SELlers, W. D.

1960 Arizona Climate. University of Arizona Press, Tucson.

SERVice, Elman R.

1962 Primitive Social Organization, An Evolutionary Perspective. Random House, New York.

1964 Archaeological Theory and Ethnological Fact. In Process and Pattern in Culture, edited by Robert A. Manners, pp. 364-375. Aldine Publishing Company, Chicago.
SIEGEL, SIDNEY

1956 Nonparametric Statistics for the Behavioral Sciences. McGraw-Hill Book Company, New York.

SMITH, WATSON

1952 Excavations in Big Hawk Valley, Wupatki National Monument, Arizona. Museum of Northern Arizona Bulletin, No. 24. Flagstaff.

Southwestern Ceramic Seminars

1958 - The Southwestern Ceramic Seminars.

1968 Research Center, Museum of Northern Arizona, Flagstaff. Unpublished.

Spaulding, Albert C.

1953 Statistical Techniques for the Discovery of Artifact Types. American Antiquity, Vol. 18, No. 4, pp. 305-13. Salt Lake City.

1960 Statistical Description and Comparison of Artifact Assemblages. In "The Application of Quantitative Methods in Archaeology," edited by R. F. Heizer and S. F. Cook, pp. 60-83. Viking Fund Publications in Anthropology, No. 28. Wenner-Gren Foundation for Anthropological Research, Inc.

Stevenson, Matilda Coxe

1904 The Zuni Indians: Their Mythology, Esoteric Fraternities, and Ceremonies. Twenty-third Annual Report of the Bureau of American Ethnology, 1901-1902. Washington.

1909 Ethnobotany of the Zuni Indians. Thirtieth Annual Report of the Bureau of American Ethnology, pp. 31-102. Washington.

Steward, JULIAN HAYNes

1937 Ecological Aspects of Southwestern Society. Anthropos, Vol. 32, pp. 87-104.

STRONG, W. D.

1936 Anthropological Theory and Archaeological Fact. In Essays in Anthropology, edited by Robert H. Lowie, pp. 359-370. University of California Press, Berkeley. 
Stubbs, Stanley A.

1950 Bird's Eye View of the Pueblos. University of Oklahoma Press, Norman.

TAYLOR, WALTER W.

1948 A Study of Archeology. Memoirs of the American Anthropological Association, No. 69. Menasha.

1954 Southwestern Archaeology: Its History and Theory. American Anthropologist, Vol. 56, No. 4 (Part 1), pp. 561-75. Menasha.

Thompson, Laura, and Alice Joseph

1945 The Hopi Way. University of Chicago Press, Chicago.

Titiev, Mrscha

1944 Old Oraibi: A Study of the Hopi Indians of Third Mesa. Papers of the Peabody Museum of American Archaeology and Ethnology, Vol. 22, No. 1. The Museum, Cambridge.

Vescelius, G. S.

1960 Archaeological Sampling: A Problem of Statistical Inference. In Essays in the Science of Culture in Honor of Leslie A. White, edited by Gertrude Dole and Robert L. Carneiro, pp. 457-68. Thomas Y. Crowell Company, New York.

WATSON, James B.

1945 The Historical Development of Hopi Economy and Its Relations to Other Aspects of Culture. Masters dissertation, unpublished. University of Chicago.

WAUCHOPE, ROBERT (EDITOR)

1956 Seminars in Archaeology: 1955. Memoirs of the Society for American Archaeology, No. 11. Salt Lake City.

WENDORF, FRED

1956 Some Distributions of Settlement Patterns in the Pueblo Southwest. In "Prehistoric Settiement Patterns in the New World," edited by G. R.
Willey, Viking Fund Publications in Anthropology, No. 23, pp. 18-25. Wenner-Gren Foundation for Anthropological Research, Inc.

WHITING, AlFRED F.

1939 Ethnobotany of the Hopi. Museum of Northern Arizona Bulletin, No. 15. Flagstaff.

WILLEY, GORDON R. (EDITOR)

1956 Prehistoric Settlement Patterns in the New World. Viking Fund Publications in Anthropology, No. 23. WennerGren Foundation for Anthropological Research, Inc.

Willey, Gordon R., AND Philip Phillips

1958 Method and Theory in American Archaeology. University of Chicago Press, Chicago.

WOLF, ERIC R.

1959 Sons of the Shaking Earth. University of Chicago Press, Chicago.

WOODBURY, RICHARD B.

1954 Prehistoric Stone Implements of Northeastern Arizona. Papers of the Peabody Museum of Archaeology and Ethnology, Vol. 34. The Museum, Cambridge.

1959 A Reconsideration of Pueblo Warfare in the Southwestern United States. Actas del XXXIII Congreso Internacional de Americanistas, Vol. 2, pp. 124-33. San Jose.

1961 Prehistoric Agriculture at Point of Pines, Arizona. Memoirs of the Society for American Archaeology, No. 17. Salt Lake City.

\section{YARNELL, RICHARD ASA}

1964 Aboriginal Relationships Between Culture and Plant Life in the Upper Great Lakes Region. Anthropological Papers of the Museum of Anthropology, University of Michigan, No. 23. Ann Arbor. 